\title{
Preparation of SiCNFs Composite Anode by Electrophoretic Deposition (EPD)
}

\author{
Meng Yao
}

Follow this and additional works at: https://researchrepository.wvu.edu/etd

\section{Recommended Citation}

Yao, Meng, "Preparation of SiCNFs Composite Anode by Electrophoretic Deposition (EPD)" (2017). Graduate Theses, Dissertations, and Problem Reports. 7000.

https://researchrepository.wvu.edu/etd/7000

This Dissertation is protected by copyright and/or related rights. It has been brought to you by the The Research Repository @ WVU with permission from the rights-holder(s). You are free to use this Dissertation in any way that is permitted by the copyright and related rights legislation that applies to your use. For other uses you must obtain permission from the rights-holder(s) directly, unless additional rights are indicated by a Creative Commons license in the record and/ or on the work itself. This Dissertation has been accepted for inclusion in WVU Graduate Theses, Dissertations, and Problem Reports collection by an authorized administrator of The Research Repository @ WVU.

For more information, please contact researchrepository@mail.wvu.edu. 


\title{
Preparation of Si/CNFs Composite Anode by Electrophoretic Deposition (EPD)
}

\author{
Meng Yao \\ Dissertation submitted to \\ Benjamin M. Statler College of Engineering and Mineral Resources \\ at West Virginia University \\ in partial fulfillment of the requirements \\ for the degree of \\ Doctor of Philosophy \\ In \\ Mechanical Engineering
}
Xingbo Liu, Ph.D., Committee Chairperson
Xueyan Song, Ph.D.
Xiaodong Shi, Ph.D.
Hui Zhang, Ph.D.
Ismail Celik, Ph.D.
Department of Mechanical and Aerospace Engineering Morgantown, West Virginia

2017

Keywords: silicon anode, composite film, surface modification, EPD, suspension stability 


\title{
ABSTRACT
}

\section{Preparation of Si/CNFs Composite Anode by Electrophoretic Deposition (EPD)}

\author{
Meng Yao
}

Recently, lithium ion batteries (LIBs) have been widely used in the field of portable electronic devices and electric vehicles due to high adaptability, high working voltage and low toxicity. However, traditional electrode materials have greatly limited the future of LIBs because of their low theoretical specific capacities; meanwhile, new electrode materials always need to be prepared by complicated and expensive methods, indicating the small probability of large-scale promotion. In this study, the Si/CNFs composite film anode without any binder by a simple and effective method - electrophoretic deposition (EPD) - is developed, which exhibits improved electrochemical properties.

This thesis is firstly focused on building a metastable/stable system for the multicomponent (Si/CNFs) EPD. It's observed that in the basic condition $(\mathrm{pH} 9-10)$ or acidic condition ( $\mathrm{pH} 0.5$ ), a suspension in ethanol consisting of surface-modified $\mathrm{Si}$ and CNFs can approximately keep stable for at least $0.5 \mathrm{~h}$, which can meet the minimum requirements for a successful deposition. Based on the dynamics analysis, a new "three-step growth theory" on the deposition process is proposed.

Then, this thesis is focused on preparing different composite films by EPD and improving their electrochemical performance via optimizing the component and microstructures. Three kinds of $\mathrm{Si}$ nanoparticles are used: $\mathrm{Si}, \mathrm{Si}$ with hydroxyl groups $(\mathrm{Si}-\mathrm{OH})$ and $\mathrm{Si}$ with amino groups $\left(\mathrm{Si}-\mathrm{NH}_{2}\right)$, while only one carbonaceous material is investigated: $\mathrm{CNFs}$ with carboxyl groups (CNFs-COOH). The possible factors on the film density, thickness and the microstructure have been studied, including the applied voltage, concentration, additives and after-treatment procedures. The results show that each dense composite film exhibits better performance than the tradition graphite anode. To be specific, the Si/CNFs-COOH film is obtained in ethanol by EPD at $\mathrm{pH} 10$, which has the specific capacity of $610 \mathrm{mAh} / \mathrm{g}$ after 100 cycles at $400 \mathrm{~mA} / \mathrm{g}$. The Si$\mathrm{OH} / \mathrm{CNFs}-\mathrm{COOH}$ film with honeycomb structure is obtained in ethanol by EPD at $\mathrm{pH} 10$, which has the specific capacity of $510 \mathrm{mAh} / \mathrm{g}$ at $400 \mathrm{~mA} / \mathrm{g}$ after 300 cycles. The $\mathrm{Si}-\mathrm{NH}_{2} / \mathrm{CNFs}-\mathrm{COOH}$ film is obtained by EPD at $\mathrm{pH} 0.5$, which has the specific capacity of $1020 \mathrm{mAh} / \mathrm{g}$ at $400 \mathrm{~mA} / \mathrm{g}$ after 100 cycles. 


\section{ACKNOWLEDGEMENTS}

First of all, I would like to thank my supervisor Dr. Xingbo Liu for the strong support of my Ph.D. research, for his patience, motivation, and immense knowledge.

Besides my supervisor, I would like to thank the rest of committee members: Dr. Xueyan Song, Dr. Xiaodong Shi, Dr. Hui Zhang, and Dr. Ismail Celik, for their insightful comments on my research. I would like to especially thank Dr. Hui Zhang for her selfless help at the beginning of my academic career. She taught me how to do real research.

Next, I would like to thank my teammates for the stimulating discussions and for the funs we have had in the past six years. In particular, I am grateful to Dr. Greg Collins, Dr. Wenyan Li and Dr. Jianhua Yan for helping me so much on building up a LIBs lab, experimental test and data analysis.

Last and the most importantly, I would like to thank my parents and my dear sister for their continuous support spiritually, especially when I made mistakes or was in troubles in my work. Their support is a huge source of my motivation. 


\section{TABLE OF CONTENTS}

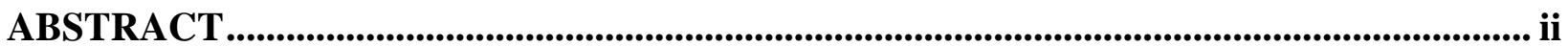

ACKNOWLEDGEMENTS ............................................................................................................ iii

List of Figures................................................................................................................................................ vi

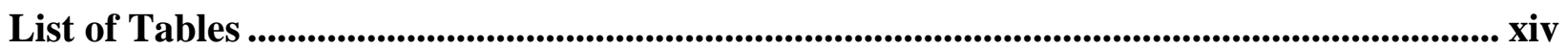

List of Symbols and Notations ........................................................................................................................

1. INTRODUCTION

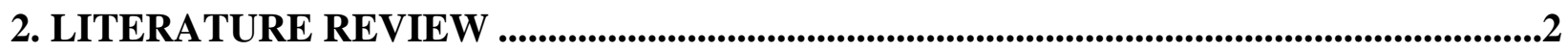

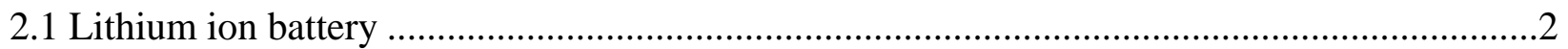

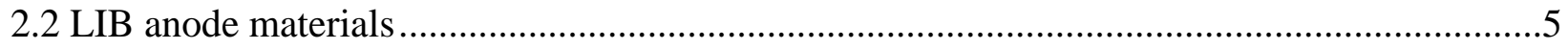

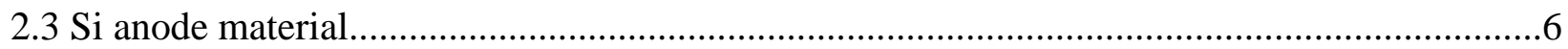

2.3.1 Mechanism of (de)lithiation of $\mathrm{Si}$...................................................................................

2.3.2 Development of Si-based anode materials ............................................................................ 10

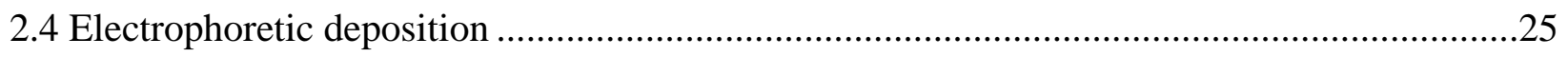

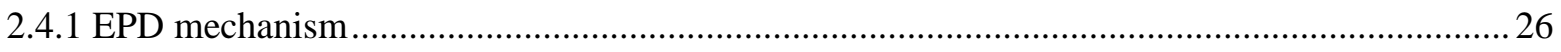

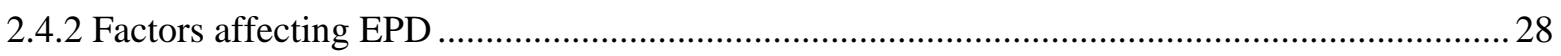

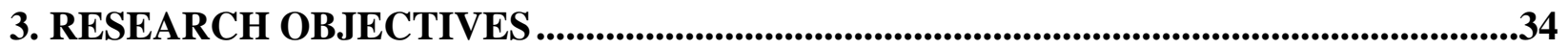

4. EXPERIMENTAL METHODS ..........................................................................................................36

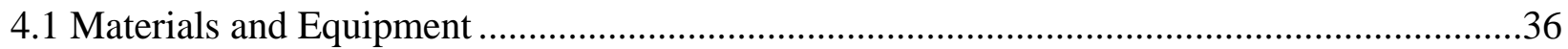

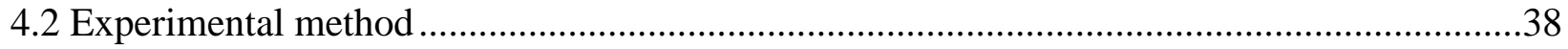

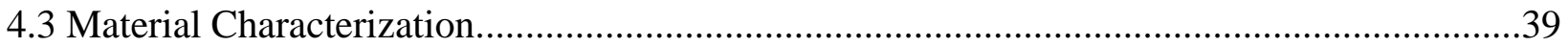

5. MULTI-COMPONENT EPD OF Si/CNFs COMPOSITION ANODE FOR LIB .............40

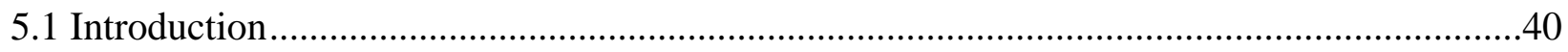

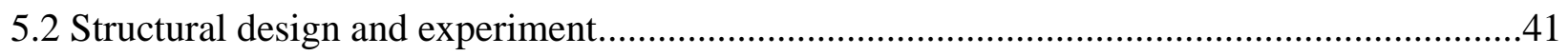

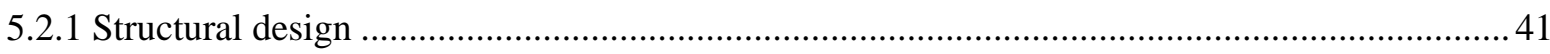

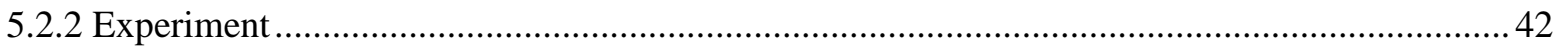




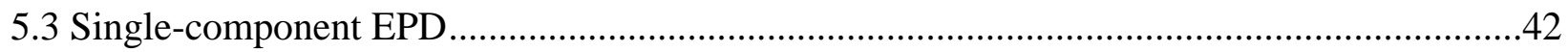

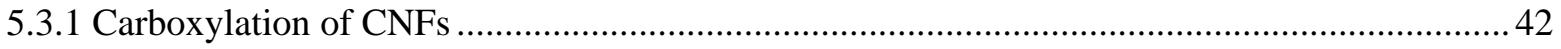

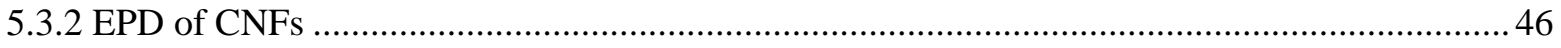

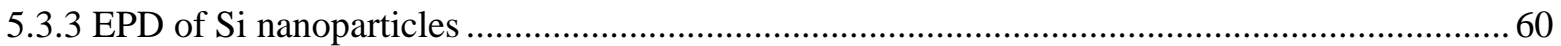

5.4 Multi-component EPD for simple Si/CNFs-COOH system ..........................................64

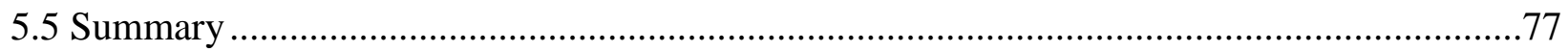

6. MULTI-COMPONENT EPD OF MODIFIED-Si/CNFs COMPOSITION

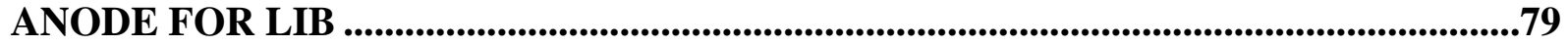

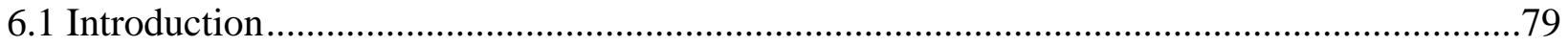

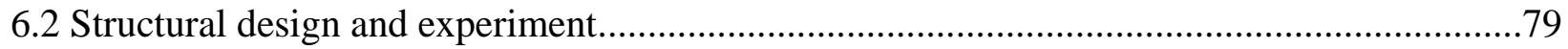

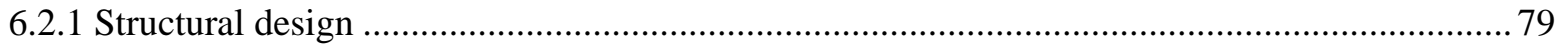

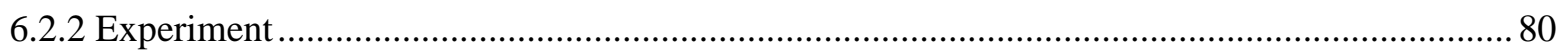

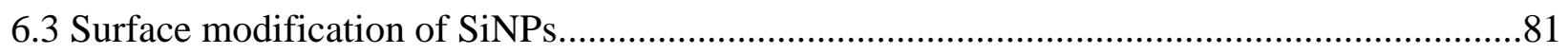

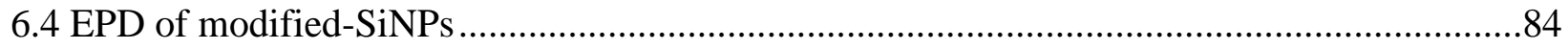

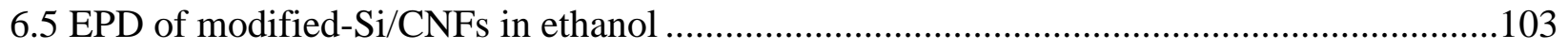

6.6 Preparation of Si/CNFs composite film with honeycomb structure ................................114

6.7 Preparation of Si/CNFs with necklace structure ......................................................134

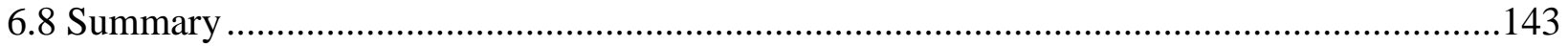

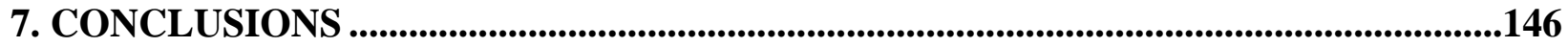

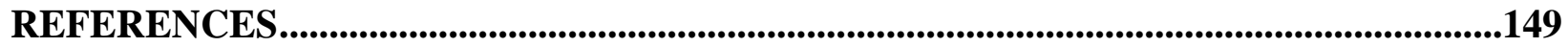




\section{List of Figures}

2.1 Schematic illustration of the Discharging/Charging mechanism of a LIB........................3

2.2 Total capacity of $18650 \mathrm{Li}$-ion cell as a function of anode capacity.................................4

2.3 A schematic representation of the different reaction mechanisms observed in electrode materials for lithium batteries ...................................................................

2.4 Si electrochemical lithiation and delithiation curve at room temperature and high temperature

2.5 Galvanostatic curve recorded on arrays of crystalline $\mathrm{Si}$ NWs grown by $\mathrm{Cu}-$ catalyzed VLS and mounted in half-cell geometry with a Li counter electrode .8

2.6 In situ TEM images of the electrochemical lithiation of a Si nanoparticle with an initial diameter of about $160 \mathrm{~nm}$ and SEM images of Si nanopillars with three different axial orientations $(<100>,<110>$, and $<111>$ ) after partial lithiation and subsequent removal of the lithiated phase to expose the crystalline cores

2.7 SEM images of typical morphology by a) ball milling or b) pyrolysis in the early years.

2.8 a) SEM and b) TEM images of $\mathrm{Si} / \mathrm{C}$ composites after $2 \mathrm{~h}$ pyrolysis ..............................15

2.9 The preparation process from a) PS and b) $\mathrm{SiO}_{2}$ template to the $\mathrm{Si}-\mathrm{C}$ composite .............17

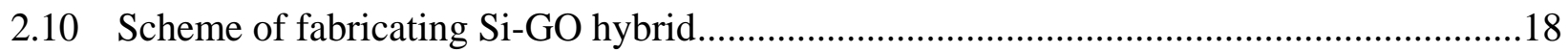

2.11 Schematics of a) fabrication process and b) hierarchical structural design for Si/porous C@C composite

2.12 Schematics of lithiation process of Yolk-Shell C/Si structure.....................................20

2.13 Schematic of fabrication processes and structure of the CNT-Silicon anode...................21

2.14 Schematic illustration of a core-shell structured $\mathrm{Si} @ \mathrm{TiO} 2-\mathrm{x} / \mathrm{C}$ mesoporous microfiber composite.

2.15 a) Schematic of fabrication process for the LBL Si-C/G electrode; b) Schematic of the structure changes of the electrode during lithiation/delithiation process .....................23

2.16 Schematic of microstructure of Si-Ni electrode......................................................24

2.17 Schematic of fabrication process for $\mathrm{Si} / \mathrm{SiO}_{\mathrm{x}}$ core-shell nanocoils anode electrode ..........25

2.18 Schematic illustration of electrophoretic deposition process. a) cathodic EPD; b) anodic EPD. 
2.19 Total potential energy versus interparticle distance curve between two particles.

2.20 Schematic of the stabilization of $\mathrm{Bi}_{2} \mathrm{O}_{3}$ nanoparticles in the ethanol and EPD process.

2.21 Diagram shows the ionic concentration and potential difference as a function of distance from the charged surface of a particle suspended in a dispersion medium

2.22 Variation of deposition weight with time during EPD of $\mathrm{Al} / \mathrm{NiO}$ in the mixture of ethanol-acetylacetone (1:1 in volume)

2.23 a) Experimental set-up for the aqueous EPD process; b) deposition rate as function of the electric field strength for different materials (time: $3 \mathrm{~min}$ ).

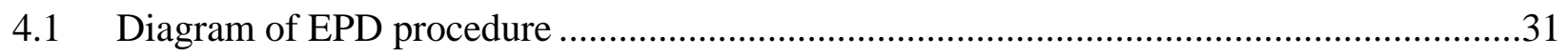

4.2 Diagram of the inner structure of a LIB coin cell ........................................................39

5.1 Structure diagram of CNFs/Si anode by multi-component EPD .................................42

5.2 Surface modification of CNFs in the acid solution ...............................................43

5.3 SEM images of a) p-CNFs and b) pretreated CNFs in the mixed acid ..........................43

5.4 Thermogravimetric curves of a) p-CNFs, b) CNFs treated by mixed acid refluxing $(0.5 \mathrm{~h}), \mathrm{c}) \mathrm{CNFs}$ treated by mixed acid refluxing $(2 \mathrm{~h})$.

5.5 FTIR spectra of CNFs with or without surface modification.... .45

5.6 a) diagram of the EDL according to the Stern model; b) diagram of the electric potential profile. The diffuse double layer starts from the Stern plane.....

5.7 Behavior of zeta potential of different $\mathrm{CNFs}-\mathrm{COOH}$ at $\mathrm{pH}$ value of $0.5 \sim 11 \ldots \ldots \ldots \ldots \ldots . . . .48$

5.8 Zeta potential profiles of CNFs-COOH (7\%) in different solvents ...............................49

5.9 Zeta potential profiles of CNFs-COOH (7\%) with different concentrations ....................50

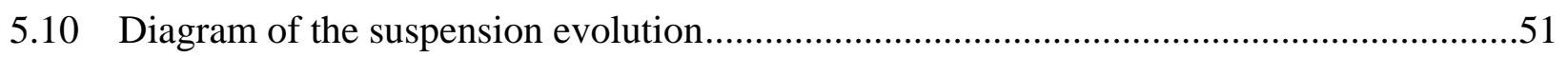

5.11 Profiles of RSH value versus standing time for CNFs-COOH (7\%) in different suspensions. CNFs concentration: $0.5 \mathrm{mg} / \mathrm{mL}$

5.12 Profiles of the deposited mass (versus applied voltage) for CNFs-COOH suspension at different $\mathrm{pH}$ values. CNFs concentration: $0.5 \mathrm{mg} / \mathrm{mL}$ .55

5.13 Photographs of deposited films on $\mathrm{Cu}$ foil after $10 \mathrm{~min}$ EPD in ethanol with different $\mathrm{pH}$ values: a) $\mathrm{pH} 1.5$, b) $\mathrm{pH} 0.5$, c) $\mathrm{pH} 10$. The applied voltage: $45 \mathrm{~V} / \mathrm{cm}$

5.14 Photographs of deposited films on $\mathrm{Cu}$ foil after $10 \mathrm{~min}$ EPD in ethanol at pH10 with the applied voltage of a) $30 \mathrm{~V} / \mathrm{cm}$ and b) $75 \mathrm{~V} / \mathrm{cm}$ .56 
5.15 Profiles of current changing in different CNFs-COOH (7\%) suspensions with different applied voltages. CNFs concentration: $0.5 \mathrm{mg} / \mathrm{mL}$.

5.16 Profiles of deposited mass changing with time in different $\mathrm{CNFs}-\mathrm{COOH}$ suspensions. CNFs concentration: $0.5 \mathrm{mg} / \mathrm{mL}$ .58

5.17 a) photograph of CNFs film (in ethanol, $\mathrm{pH} 10$, applied voltage: $45 \mathrm{~V} / \mathrm{cm}$ ); b) SEM image of CNFs film prepared by EPD in ethanol suspension with the concentration of $1 \mathrm{mg} / \mathrm{mL}$ .58

5.18 a) Galvanostatic discharge-charge curves for CNFs-COOH film; b) Cycling performance of CNFs-COOH film at the current rate of $400 \mathrm{~mA} / \mathrm{g}$

5.19 Profile of zeta potential of c-SiNPs in ethanol at different $\mathrm{pH}$ values ( $\mathrm{Si}$ concentration: $0.2 \mathrm{mg} / \mathrm{mL}$ )

5.20 Profiles of zeta potential values for c-SiNPs in different suspensions ( $\mathrm{Si}$ concentration: $0.2 \mathrm{mg} / \mathrm{mL}$ )

5.21 Profiles of zeta potential of c-SiNPs in ethanol with different concentrations.....

5.22 Photographs of c-SiNPs suspension in ethanol $(0.2 \mathrm{mg} / \mathrm{mL})$ a) without standing, b) with 15 min standing. $\mathrm{pH}$ value: 10

5.23 Profiles of zeta potential in different suspensions ( $\mathrm{pH}$ range: $0.5-11, \mathrm{CNFs}$ concentration: $0.5 \mathrm{mg} / \mathrm{mL}$, Si concentration: $0.2 \mathrm{mg} / \mathrm{mL}$ ).

5.24 Profiles of zeta potential in c-Si/CNFs-COOH suspensions with different $\mathrm{Si}$ contents (CNFs concentration: $0.5 \mathrm{mg} / \mathrm{mL}$ )

5.25 Profiles of zeta potential in c-Si/CNFs-COOH suspension with different total concentrations (weight ratio of CNFs to $\mathrm{Si}=5 / 2$ )

5.26 Profiles of RSH value versus standing time for c-Si/CNFs-COOH suspensions at different $\mathrm{pH}$ values

5.27 Photograph of c-Si/CNFs-COOH suspension at $\mathrm{pH} 1$ after $1 \mathrm{~h}$ standing.....

5.28 Profiles of the deposited mass (versus applied voltage) for $\mathrm{CNFs}-\mathrm{COOH}$ suspension at different $\mathrm{pH}$ values. CNFs concentration: $0.5 \mathrm{mg} / \mathrm{mL}$

5.29 Profiles of current changing in c-Si/CNFs-COOH suspensions with different applied voltages. Total concentration: $0.5 \mathrm{mg} / \mathrm{mL} \mathrm{CNFs}+0.2 \mathrm{mg} / \mathrm{mL} \mathrm{Si}$

5.30 Diagram of the growth of the film on $\mathrm{Cu}$ foil with different voltages in $\mathrm{c}-\mathrm{Si} / \mathrm{CNFs}-$ $\mathrm{COOH}$ suspension 
5.31 Profiles of deposited mass changing with time in c-Si/CNFs-COOH suspensions. Total concentration: $0.2 \mathrm{mg} / \mathrm{mL}(\mathrm{Si})+0.5 \mathrm{mg} / \mathrm{mL}(\mathrm{C})$ .71

5.32 a) photograph of a composite film on $\mathrm{Cu}$ foil $\left(4 \times 3.5 \mathrm{~cm}^{2}\right)$. EPD conditions: suspension concentration: $0.5 \mathrm{mg} / \mathrm{mL}$ CNFs-COOH + $0.2 \mathrm{mg} / \mathrm{mL} \mathrm{c-Si} ; \mathrm{pH}=10$; applied voltage: $45 \mathrm{~V} / \mathrm{cm}$; Deposition time: $10 \mathrm{~min}$. b) SEM image of the composite film

5.33 a) photograph of a composite film on $\mathrm{Cu}$ foil $\left(4 \times 3.5 \mathrm{~cm}^{2}\right)$. EPD conditions: suspension concentration: $0.5 \mathrm{mg} / \mathrm{mL} \mathrm{CNFs-COOH}+0.2 \mathrm{mg} / \mathrm{mL} \mathrm{c-Si} ; \mathrm{pH}=10$; applied voltage: $60 \mathrm{~V} / \mathrm{cm}$; Deposition time: $10 \mathrm{~min}$. b) SEM image of the composite film

5.34 Galvanostatic discharge-charge curves for the CNFs/Si composite film; b) cycling performance of the $\mathrm{Si} / \mathrm{CNF}$ composite film.

5.35 SEM image of the film after 50 cycles ........................................................... 75

5.36 Cycling performance of the composite film prepared under high electric filed (75 $\mathrm{V} / \mathrm{cm}$ ) at the current rate of $400 \mathrm{~mA} / \mathrm{g}$ .76

5.37 a) SEM image of the Si/CNFs film with high Si content; b) the corresponding

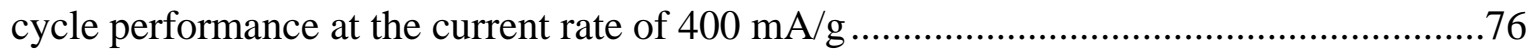

6.1 SEM images of a) c-SiNPs, b) Si-OH particles and c) $\mathrm{Si}_{-} \mathrm{NH}_{2}$ particles ........................81

6.2 FTIR spectra of SiNPs before and after surface modification .....................................81

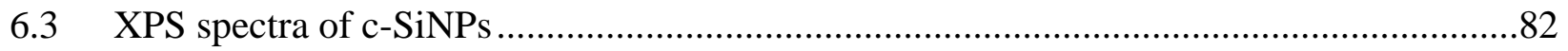

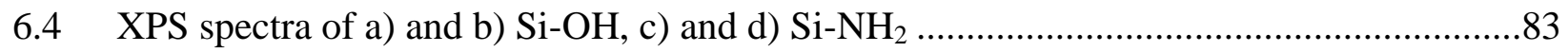

6.5 Zeta potential profiles of different Si particles in ethanol ..........................................84

6.6 Zeta potential profiles of different Si particles in water............................................85

6.7 Zeta potential profiles of $\mathrm{Si}-\mathrm{OH}$ suspension in different organic solvents ......................86

6.8 Zeta potential profiles of $\mathrm{Si}-\mathrm{NH}_{2}$ suspension in different organic solvents .....................86

6.9 Zeta potential profiles of Si suspension in ethanol with different concentrations .............87

6.10 Profiles of $\mathrm{RSH}$ value versus standing time for $\mathrm{Si}-\mathrm{OH}$ suspensions at different $\mathrm{pH}$ values in ethanol 
6.11 Profiles of $\mathrm{RSH}$ value versus standing time for $\mathrm{Si}^{-\mathrm{NH}_{2}}$ suspensions at different $\mathrm{pH}$ values in ethanol

6.12 Profiles of RSH value versus standing time for $\mathrm{Si}-\mathrm{OH}$ suspensions in water 91

6.13 Profiles of $\mathrm{RSH}$ value versus standing time for $\mathrm{Si}_{-} \mathrm{NH}_{2}$ suspensions in water..................92

6.14 Profiles of deposited mass versus applied voltage for Si-OH EPD in ethanol ...................93

6.15 Profiles of the deposited mass versus applied voltage in ethanol for $\mathrm{Si}-\mathrm{NH}_{2} \mathrm{EPD}$ (standing time for the suspension: $2 \mathrm{~h}$ )

6.16 a) Current-time profiles and b) electrical conductivity - time profiles in $\mathrm{Si}-\mathrm{OH}$ suspension (ethanol) with different applied voltages; c) diagram of the movement and deposition of $\mathrm{Si}-\mathrm{OH}$ in ethanol

6.17 a) Current-time profiles and b) electrical conductivity - time profiles in $\mathrm{Si}_{-} \mathrm{NH}_{2}$ suspension (ethanol) with different applied voltages .96

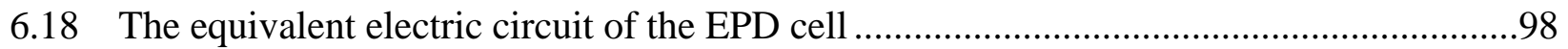

6.19 Profile of a) current versus time and deposited mass versus time in $\mathrm{Si}-\mathrm{OH}$ suspension

6.20 Profile of a) current versus time and deposited mass versus time in $\mathrm{Si}-\mathrm{NH}_{2}$ suspension

6.21 Profiles of zeta potential values in different $\mathrm{CNFs} / \mathrm{Si}$ suspension (ethanol) 103

6.22 Profiles of zeta potential values in different $\mathrm{CNFs} / \mathrm{Si}$ suspension (water) 104

6.23 Profiles of zeta potential versus $\mathrm{pH}$ value in $\mathrm{Si}-\mathrm{OH} / \mathrm{CNF}$ - $\mathrm{COOH}$ suspension with different concentration

6.24 Profiles of zeta potential versus $\mathrm{pH}$ value in $\mathrm{Si}-\mathrm{NH}_{2} / \mathrm{CNF}$ - $\mathrm{COOH}$ suspension with different concentration

6.25 Profiles of zeta potential versus $\mathrm{pH}$ values in modified-Si/CNFs-COOH suspension with different ratio of $\mathrm{Si}$ to $\mathrm{C}$

6.26 Profiles of RSH value versus standing time for different suspensions in ethanol .108 
6.27 Photograph of Si-OH/CNFs-COOH suspension in ethanol at $\mathrm{pH} 0.5$ after $1 \mathrm{~h}$ standing

6.28 Profiles of the deposited mass versus applied voltage in modified-Si/CNFs suspensions

6.29 Photographs of Si-OH/CNFs deposition film after 10min EPD in ethanol at pH10 with different applied voltages. a) $45 \mathrm{~V} / \mathrm{cm}$, b) $75 \mathrm{~V} / \mathrm{cm}$.

6.30 Photograph of $\mathrm{Si}-\mathrm{NH}_{2} / \mathrm{CNFs}-\mathrm{COOH}$ deposition films (a: $60 \mathrm{~V} / \mathrm{cm}, \mathrm{b}: 75 \mathrm{~V} / \mathrm{cm}$ ) after 10 s fast-jitter test

6.31 Profile of current versus time in $\mathrm{Si}-\mathrm{OH} / \mathrm{CNF}-\mathrm{COOH}$ suspension

6.32 Profile of current versus time in $\mathrm{Si}-\mathrm{NH}_{2} / \mathrm{CNFs}-\mathrm{COOH}$ suspension

6.33 Profiles of deposited mass versus time in different suspensions

6.34 SEM image of Si-OH film on $\mathrm{Cu}$ foil.....

6.35 a) cycle performance of $\mathrm{Si}-\mathrm{OH}$ film; b) galvanostatic discharge-charge curves for the $\mathrm{Si} / \mathrm{CNF}$ film.

6.36 a) low-magnification and b) high-magnification SEM images of the CNFs/Si film;

c) lower-magnification and d) high-magnification SEM images of the cross section of the composite film

6.37 TGA profile of Si/CNFs composite 118

6.38 SEM images of Si/CNFs composite film with different deposition time. a) $1 \mathrm{~min}$, b) $3 \mathrm{~min}, \mathrm{c}) 10 \mathrm{~min}, \mathrm{~d}) 15 \mathrm{~min}$

6.39 SEM images of the Si/CNFs composite film after (a, b) $1 \mathrm{~min}$ and (c, d) 3 min EPD......120

6.40 SEM images of the Si/CNFs composite film without the assistance of lithium borate after a) $1 \mathrm{~min}, \mathrm{~b}$, c) $10 \mathrm{~min}$ EPD, d) the cross-section image of the film after $10 \min \mathrm{EPD}$

6.41 SEM images of Si-OH/CNFs composite at a) high-magnification and b) low magnification with $\mathrm{LiClO}_{4}$ additives; SEM images of Si/CNFs composite at c) high-magnification and d) low-magnification with $\mathrm{Li}_{2} \mathrm{CO}_{3}$ additives 122 
6.42 SEM and EDX images of Si-OH/CNFs-COOH composite films with the applied voltages of a, d) $30 \mathrm{~V} / \mathrm{cm}, \mathrm{b}, \mathrm{e}) 45 \mathrm{~V} / \mathrm{cm}$ and c, f) $60 \mathrm{~V} / \mathrm{cm}$

6.43 SEM images of a) CNFs film, b, c, d) Si/CNFs films at different magnification with TX-100 additive

6.44 SEM images of Si/CNFs composite $a, b)$ with the additive of SDS and c, d) with the additive of quaternary ammonium compound at different magnifications

6.45 a) Galvanostatic discharge-charge curves for the CNFs/Si composite film; b) cyclic voltammetry profiles of the Si/CNFs composite film

6.46 a) Galvanostatic discharge-charge curves for the CNFs/Si composite film after washing; b) cyclic voltammetry profiles of the Si/CNFs composite film after washing

6.47 a) cycling performance and b) rating performance of the Si/CNFs film after washing

6.48 SEM images of CNFs/Si composite after 60 cycles. a, b) top view, c, d) cross section

6.49 Cycling performance of the composite film prepared with different applied voltages

6.50 SEM images of Si/CNFs films with different initial ratios of Si to CNFs. a, b) 1:5; c, d) $4: 5$.....

6.51 a) cycling performance of Si/CNFs films with different initial ratios of Si to CNFs; b) profiles of Coulombic efficiency of different Si/CNFs films

6.52 Cycle performance of Si/CNFs composite films with different salt additives

6.53 Profiles of cycle performance of Si/CNFs film a) with TX-100 additive, b) with ionic additives

6.54 a) photograph of Si/CNFs film in ethanol at pH0.5, b) SEM image of Si/CNFs film in ethanol at $\mathrm{pH} 0.5$. The insert of $\mathrm{b}$ is the cross-section SEM

6.55 Scheme of the deposition process in $\mathrm{Si} / \mathrm{CNFs}$ suspension. 
6.56 SEM images of Si/CNFs composite film without Si surface treatment. a) low magnification, b) high magnification

6.57 SEM images of a) Si/CNFs composite after 1 min EPD, b) Si/CNFs composite after 2 min EPD

6.58 SEM images of a) Si/CNFs composite after $10 \mathrm{~min}$ EPD. Weight ratio of Si to CNFs: a) $1: 5$, b) $4: 5$

6.59 SEM images of the $\mathrm{Si} / \mathrm{CNF}$ composite film under the magnetic stirring conditions.

a) low magnification; b) high magnification

6.60 SEM images of the film by step-by-step EPD in ethanol at pH0.5. a) CNFs film after 5 min EPD. b) the composite film consisting of 5min-EPD CNFs and $1 \mathrm{~min}$ EPD SiNPs

6.61 a) Galvanostatic discharge-charge curves for the necklaced-like CNFs/Si composite film; b) cycling performance of the Si/CNFs composite film

6.62 Cyclic voltammetry profiles of the necklaced-like Si/CNFs composite film..... 140

6.63 Rating performance of the necklaced-like Si/CNFs film. 141

6.64 SEM images of necklaced-like CNFs/Si composite after 100 cycles. 142

6.65 Cycle performance of necklaced-like Si/CNFs film with high Si weight ratio 142

6.66 Cycle performance of necklaced-like Si/CNFs film under stirring condition 143 


\section{List of Tables}

2.1 Physical property parameters of some anode materials.....................................................6

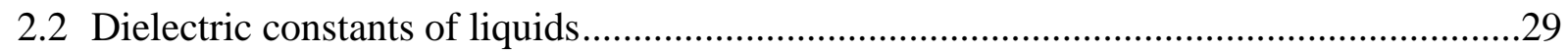

4.1 Experimental materials and chemical reagents...............................................................36

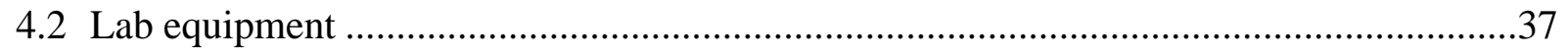

5.1 Losing mass of CNFs with different acid treatment time …………………………........4

5.2 Assignment of infrared absorptions for pure and acid-treated CNFs ...............................45

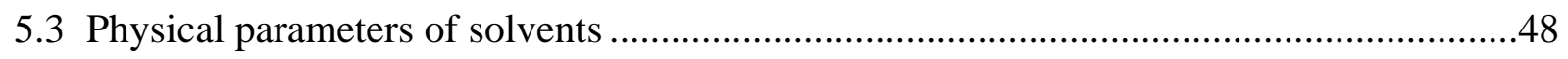

5.4 Zeta potential values for $\mathrm{CNFs}-\mathrm{COOH}(7 \%)$ in different suspensions.............................52

$5.5 \mathrm{C}_{\mathrm{rd}}$ values for CNFs-COOH (7\%) in different suspensions ............................................54

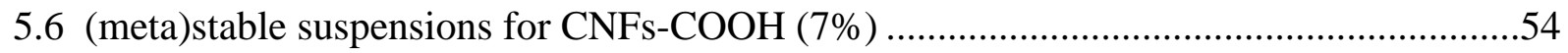

5.7 Zeta potential values for $\mathrm{c}-\mathrm{Si} / \mathrm{CNFs}-\mathrm{COOH}$ in ethanol at different $\mathrm{pH}$ values..................66

$5.8 \mathrm{C}_{\mathrm{rd}}$ values for c-Si/CNFs-COOH suspensions at different $\mathrm{pH}$ values................................67

6.1 Assignment of infrared absorptions for SiNPs and modified-Si.......................................82

6.2 Zeta potential values for $\mathrm{Si}-\mathrm{OH}$ and $\mathrm{Si}-\mathrm{NH}_{2}$ in different suspensions ...............................87

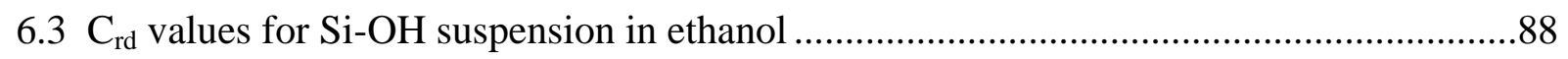

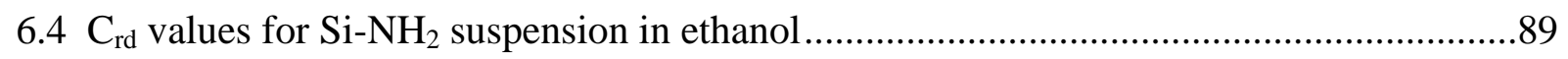

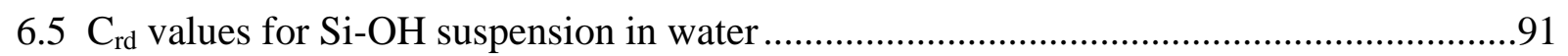

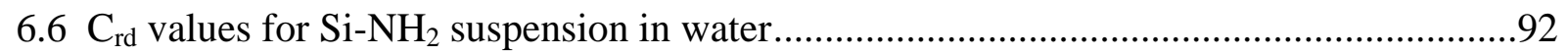

$6.7 \mathrm{pH}$ range for single-component EPD process ………......................................................92

6.8 Zeta potential values for modified-Si/CNFs in different suspensions (ethanol)..............108

$6.9 \mathrm{C}_{\mathrm{rd}}$ values for different composite suspensions in ethanol ...............................................109 


\section{List of Symbols and Notations}

\begin{tabular}{|c|c|}
\hline LIB & Lithium ion battery \\
\hline PE & Polyethylene \\
\hline PP & Polypropylene \\
\hline $\mathrm{LiPF}_{6}$ & Lithium hexafluorophosphate \\
\hline DMC & Dimethyl carbonate \\
\hline $\mathrm{EC}$ & Ethylene carbonate \\
\hline PVDF & Polyvinylidene Fluoride \\
\hline NMP & N-Methyl-2-pyrrolidinone \\
\hline SDS & Sodium Dodecyl Sulfonate \\
\hline TX-100 & Triton $\mathrm{X}-100$ \\
\hline CNFs & Carbon nanofibers \\
\hline SiNPs & Silicon nanoparticles \\
\hline EPD & Electrophoretic deposition \\
\hline$\zeta$ & Zeta potential \\
\hline$\mu$ & Electrophoretic mobility \\
\hline $\mathrm{E}$ & Electric field strength \\
\hline $\mathrm{C}$ & Concentration \\
\hline $\mathrm{S}$ & Surface area \\
\hline$\varepsilon$ & Dielectric permittivity of the solvent; \\
\hline $\mathrm{k}_{\mathrm{B}}$ & The Boltzmann constant \\
\hline $\mathrm{n}_{\infty}$ & The bulk concentration of the ions \\
\hline$\psi_{\mathrm{d}}$ & Stern plane potential \\
\hline$\kappa^{-1}$ & Debye length \\
\hline $\mathrm{V}_{\mathrm{s}}$ & The settling rate \\
\hline$\Delta \rho$ & $\begin{array}{l}\text { The difference of density between the settled layer and the } \\
\text { homogenous suspension }\end{array}$ \\
\hline $\mathrm{R}$ & Particle diameter \\
\hline$\eta$ & Viscosity of the solvent \\
\hline$f(\kappa \cdot a)$ & Henry's function \\
\hline RSH & The relative sediment height \\
\hline $\mathrm{C}_{\mathrm{rd}}$ & The relative dynamic concentration of the homogeneous zon \\
\hline
\end{tabular}


$\Lambda$

A
Deposition time

The Yield

Current

Conductivity

Correction coefficient on the electric field 


\section{Chapter 1}

\section{INTRODUCTION}

With the fast development of modern society, demand for energy is increased even more quickly than we can imagine. A large amount of non-renewable energy source such as petroleum, natural gas, and coal are consumed every day, accompanied by serious environmental problems, therefore, it has great value to develop new clean and renewable energy ${ }^{[1]}$.

In the past, chemical power sources, like lead acid battery, cadmium nickel battery, and nickel metal hydride battery, were widely used because of its high conversion efficiency, high adaptability and long lifetime. As an uprising star, lithium ion battery (LIB) ${ }^{[2]}$ has attracted more and more attention due to its high working voltage, high energy density, low self-discharge, no memory effect and low toxicity, which has broader prospects in the field of portable electronics and electric vehicles.

Recently, the major countries of the world have introduced a series of policies to support LIB research, even rising the development of new energy vehicles to central strategic level. Therefore, the requirements for LIB performance become higher and higher, especially in terms of energy density/specific capacity and cycle life. As an important part, the anode of LIB has become one of the hot topics in the world. 


\section{Chapter 2}

\section{LITERATURE REVIEW}

\subsection{Lithium ion battery}

LIB research originates from lithium battery ${ }^{[3]}$. Due to the most negative potential $(-3.05$ V vs. a standard hydrogen electrode) and the lowest density among metals $\left(\rho=0.53 \mathrm{~g} \cdot \mathrm{cm}^{-3}\right)$, lithium ( $\mathrm{Li}$ ) has been considered as a potential alternative energy source since non-aqueous electrolytes such as $\mathrm{LiClO}_{4}$ in propylene carbonate was found in $1950 \mathrm{~s}{ }^{[4]}$. The first commercial lithium battery was made in the late 1960s, and different systems were subsequently exploited, such as $\mathrm{Li} / \mathrm{MoS}_{2}{ }^{[5]}$ and $\mathrm{Li} / \mathrm{Li}_{\mathrm{x}} \mathrm{MnO}_{2}{ }^{[6,7]}$. Some lithium batteries like $\mathrm{Li} / \mathrm{MnO}_{2}{ }^{[7,8]}$ cell are still being used for medical implants and military applications today. However, there are two serious problems for Li anode: 1) highly branched Li structures, called dendrites, can be formed constantly on the anode surface during cycling. They finally can penetrate the separator and cause short circuit; 2) high reactivity between Li and electrolyte results in security risks of battery storage and transportation. For example, the first manufacturer of commercial secondary lithium batteries in the world - Moli Energy, went bankrupt in the late 1980s because of a slew of negative news involving fire accidents during cells assembly.

Lithium battery has experienced the arduous process of development, but is still far from people's expectation. Luckily, some Li-containing compounds $\left(\mathrm{Li}_{\mathrm{y}} \mathrm{M}_{\mathrm{n}} \mathrm{Y}_{\mathrm{m}}\right)^{[9]}$ that allow $\mathrm{Li}^{+}$to free insert into or extract from interstitial sites were found in the late 1970s and early 1980s, combining with carbonaceous anode material to fabricate the secondary LIB. The first successful commercial LIB consisting of $\mathrm{LiCoO}_{2}$ cathode and soft carbon anode was made by Sony Corporation in 1991.

Generally, LIBs are made of four parts: cathode, anode, separator, and electrolyte.

LIB cathode materials ${ }^{[10]}$ mainly have four kinds of structure: $\mathrm{LiMO}_{2}$ (a layered structure, $\mathrm{M}=\mathrm{Ni}, \mathrm{Co}, \mathrm{Mn} \ldots$..), $\mathrm{LiMPO}_{4}$ (Olivine structure, $\left.\mathrm{M}=\mathrm{Ni}, \mathrm{Co}, \mathrm{Mn}, \mathrm{Fe} . ..\right), \mathrm{LiMn}_{2} \mathrm{O}_{4}$ (spinel structure) and $\mathrm{Li}_{3} \mathrm{M}_{2}\left(\mathrm{PO}_{4}\right)_{3}(\mathrm{NASCION}$ structure, $\mathrm{M}=\mathrm{V}, \mathrm{Fe} \ldots)$. In the current, the most common cathode materials are $\mathrm{LiCoO}_{2}, \mathrm{LiNiO}_{2}, \mathrm{LiMn}_{2} \mathrm{O}_{4}, \mathrm{LiNi}_{1-\mathrm{x}-\mathrm{y}} \mathrm{Co}_{\mathrm{x}} \mathrm{Mn}_{\mathrm{y}} \mathrm{O}_{2}$ and $\mathrm{LiFePO}_{4}$. Most of them have relatively low specific capacities $(<200 \mathrm{mAh} / \mathrm{g}$ ) and high working voltage of $3.3 \sim 4.0 \mathrm{~V}$ (vs. $\left.\mathrm{Li}^{+} / \mathrm{Li}\right)$. 
LIB anode materials ${ }^{[10-12]}$ mainly include carbonaceous materials (graphite, hard carbon, mesophase carbon micro beads...), $\mathrm{TiO}_{2}, \mathrm{Sn}, \mathrm{Si}$, transition metal oxides and transition metal sulfides. Among them, graphite is the most widely used anode with the specific capacity of 372 $\mathrm{mAh} / \mathrm{g}$ due to its high stability and low cost.

LIB separator ${ }^{[13]}$ mainly has two types: polyethylene (PE) and polypropylene (PP) porous membranes, which are ionic conductive but electron insulated. It is placed between anode and cathode to prevent internal short circuit.

LIB electrolyte ${ }^{[10,14]}$ provides a pathway for $\mathrm{Li}^{+}$transport between cathode and anode, which should have high $\mathrm{Li}^{+}$conductivity, low electron conductivity, wide electrochemical window, and high thermostability. Organic electrolyte is the first selection for current LIB that comprised of lithium salt $\left(\mathrm{LiPF}_{6}, \mathrm{LiClO}_{4}, \mathrm{LiBOB}, \mathrm{LiCF}_{3} \mathrm{SO}_{3} \ldots\right)$ and organic solution (DMC, DEC, EC, EMC...). The most common combination is $\mathrm{LiPF}_{6}$ dissolved in the mixture of EC and DMC (1:1 v\%). Besides, aqueous electrolyte, solid electrolyte and additives like ionic liquid have also attracted much attention.

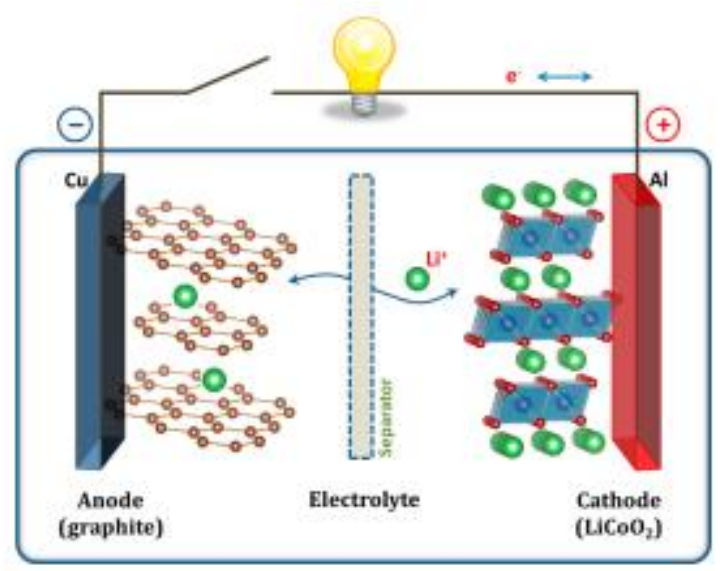

Fig. $2.1^{[10]}$ : Schematic illustration of the Discharging/Charging mechanism of a LIB Taking a typical LIB (Graphite/LiPF 6 -EC-DEC/LiCoO $\left.{ }_{2}\right)$ as an example, the working principle is showed in Fig.2.1. Before electrochemical cycling, $\mathrm{Li}^{+}$are located in the interstitial sites of $\mathrm{LiCoO}_{2}$. During the charging process, $\mathrm{Li}^{+}$are released and move to the graphite. At the same time, graphite can get enough electrons from the external circuit to form $\mathrm{Li}_{\mathrm{x}} \mathrm{C}_{\mathrm{n}}$ compound. During the discharging process, $\mathrm{Li}^{+}$and electron transport are reversed. Intercalation mechanism can be described that Li ions "rock" from one side to the other. Hence, LIBs are also called "rocking-chair batteries". Under ideal conditions, $\mathrm{Li}^{+}$insertion/extraction leads to the change of 
interlayer spacing but remaining layer structure stable. The equations of this reversible process are listed as followed.

$$
\begin{aligned}
& \text { Cathode: } \mathrm{LiCoO}_{2} \longleftrightarrow \mathrm{Li}_{1-x} \mathrm{CoO}_{2}+\mathrm{xLi}^{+}+\mathrm{xe}^{-} \quad 2.1 \\
& \text { Anode: } \mathrm{nC}+\mathrm{xLi}^{+}+\mathrm{xe}^{*} \longleftrightarrow \mathrm{Li}_{\mathrm{x}} \mathrm{C}_{\mathrm{n}} \\
& \text { Overall: } \mathrm{LiCoO}_{2}+\mathrm{nC} \longleftrightarrow \mathrm{Li}_{\mathrm{x}} \mathrm{C}_{\mathrm{n}}+\mathrm{Li}_{\mathrm{l} \cdot \mathrm{C}} \mathrm{CoO}_{2}
\end{aligned}
$$

The capacity of LIB is determined by both cathode and anode materials. For example ${ }^{[15]}$, if cathode material is fixed, the relationship between total capacity $\left(\mathrm{C}_{\mathrm{T}}\right)$ and anode capacity $\left(\mathrm{C}_{\mathrm{A}}\right)$ is shown in Fig.2.2. The equation 2.4 is also listed. $C_{T}$ is greatly improved as the increase of $C_{A}$ from $100-1200 \mathrm{mAh} / \mathrm{g}$. If $\mathrm{C}_{\mathrm{A}}$ is over $1200 \mathrm{mAh} / \mathrm{g}$, the improvement of $\mathrm{C}_{\mathrm{T}}$ becomes negligible.

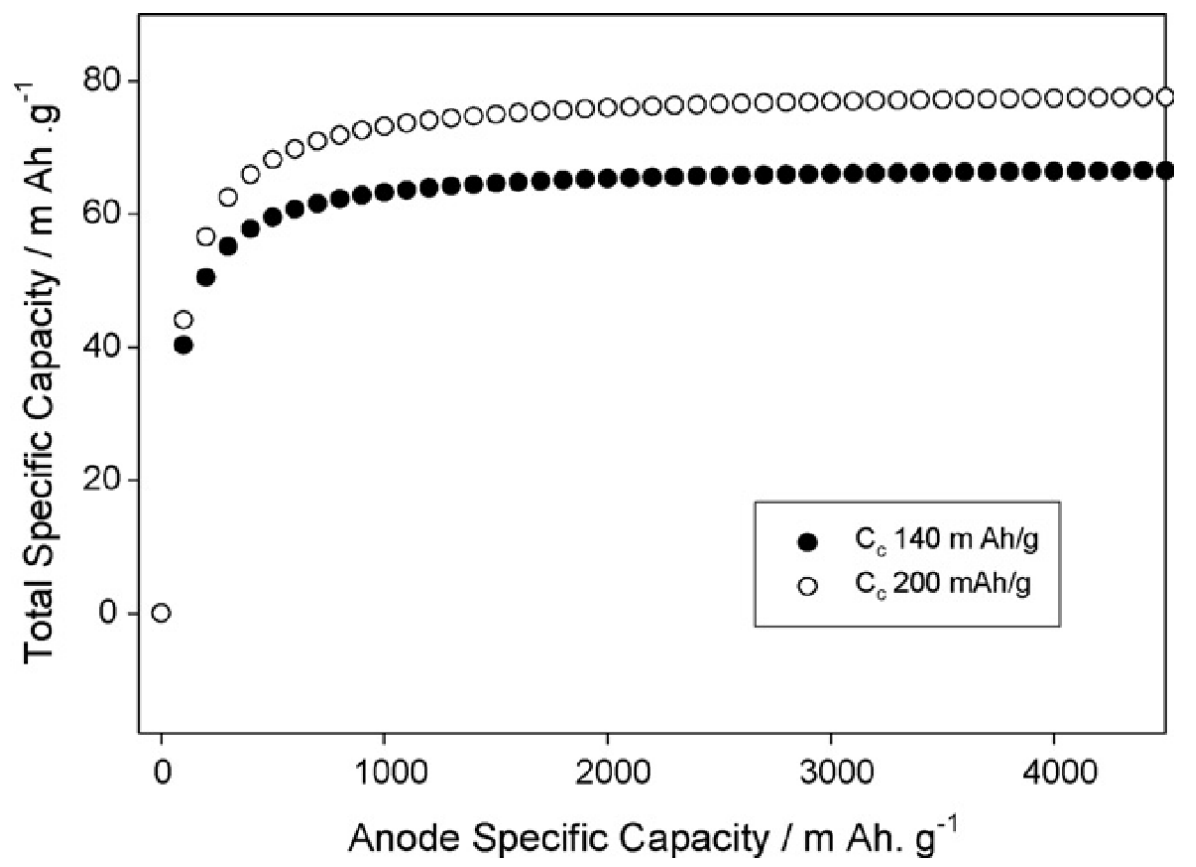

Fig.2.2 ${ }^{[15]}$ : Total capacity of $18650 \mathrm{Li}$-ion cell as a function of anode capacity (CA), including masses of other required internal components and case. Capacities of cathodes considered were 140 and $200 \mathrm{mAh} / \mathrm{g}$.

Total cell $(\mathrm{mAh} / \mathrm{g})=\frac{1}{\left(1 / \mathrm{C}_{\mathrm{A}}\right)+\left(1 / \mathrm{C}_{\mathrm{C}}\right)+\left(1 / \mathrm{Q}_{\mathrm{M}}\right)}$

where:

$$
\begin{aligned}
& \mathrm{C}_{\mathrm{A}}=\text { the theoretical specific capacity of the cathode material; } \\
& \mathrm{C}_{\mathrm{C}}=\text { the theoretical specific capacity of the anode material; }
\end{aligned}
$$


$\mathrm{Q}_{\mathrm{M}}=$ the specific capacity of other cell components (electrolyte, separator, current collector, case, etc.).

\subsection{LIB anode materials}

Anode material plays a very important role in a LIB. An ideal anode should satisfy the following requirements:

1) Low voltage platform of $\mathrm{Li}$ insertion/extraction to achieve high output voltage of battery;

2) A large number of $\mathrm{Li}^{+}$per unit mass that can be reversibly taken off or embedded to achieve high specific capacity;

3) High structural stability and thermostability to achieve long cycle life;

4) High ionic and electron conductivity to achieve good rate performance;

5) No chemical reaction with electrolyte occurs to achieve high-level safety;

6) Low cost and low toxicity.

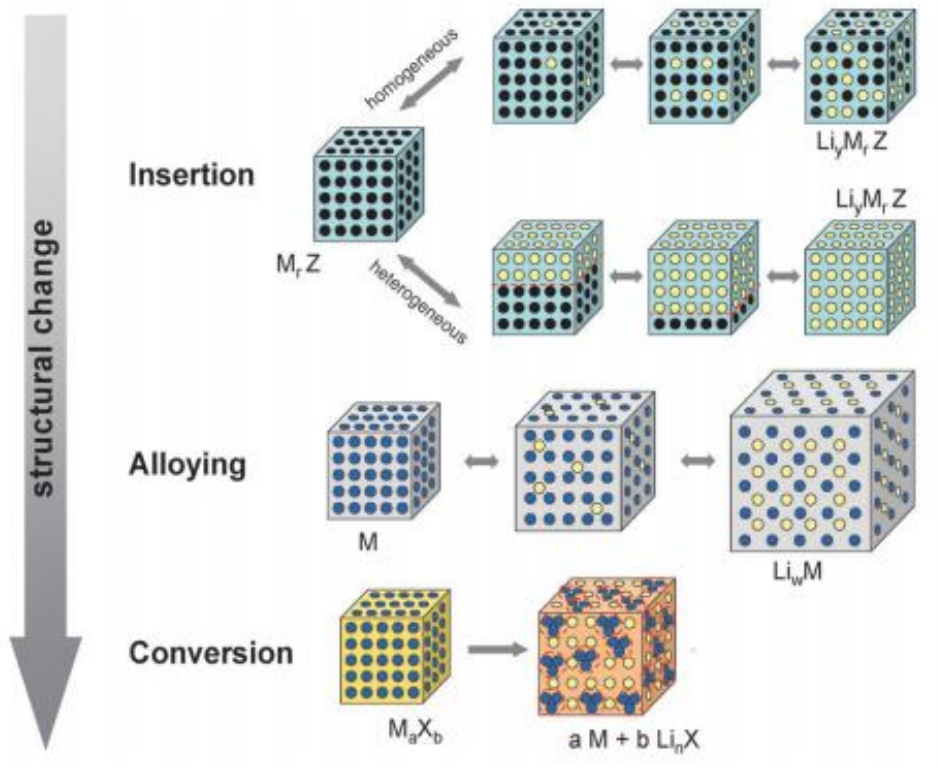

Fig.2.3 ${ }^{[16]}$ : A schematic representation of the different reaction mechanisms observed in electrode materials for lithium batteries. Black circles: voids in the crystal structure, blue circles: metal, yellow circles: lithium.

Anode materials can be divided into three groups on basis of $\mathrm{Li}$ insertion/extraction mechanism ${ }^{[16]}$, as shown in Fig.2.3.

Embedded type mainly includes carbonaceous materials, $\mathrm{TiO}_{2}$ and $\mathrm{Li}_{4} \mathrm{Ti}_{5} \mathrm{O}_{12}$, which obeys intercalation mechanism (Eq.2.3). Some materials such as $\mathrm{Si}, \mathrm{Ge}, \mathrm{Sn}$ and $\mathrm{Sb}$, called 
alloying anode, obeying the alloying mechanism. During electrochemical cycles, Li-alloys can be formed reversibly (Eq.2.5). Because the lithiation/delithiation process is not restricted by interlayer spacing of layer structure, much higher specific capacities can be obtained, especially for Si. The third type, conversion anode, mainly includes transition metal oxides, sulfides, nitrides, and phosphide. Li insertion/extraction is achieved by the conversion reaction, as shown in Eq.2.6.

$$
\begin{aligned}
& \mathrm{xLi}^{+}+\mathrm{xe}^{*}+\mathrm{M}=\mathrm{Li}_{\mathrm{x}} \mathrm{M} \\
& M_{\mathrm{a}} Y_{\mathrm{b}}+\mathrm{bnLi}=\mathrm{aM}+\mathrm{bLi}_{\mathrm{n}} \mathrm{Y}
\end{aligned}
$$

\subsection{Si anode material}

As the second most abundant element on earth, Si has the highest specific capacity (4200 $\mathrm{mAh} / \mathrm{g}$ for $\mathrm{Li}_{4.4} \mathrm{Si}$, as shown in Table2.1), which is considered as the most promising anode in the future.

Table2.1 ${ }^{[17]}$ : physical property parameters of some anode materials.

\begin{tabular}{|l|c|c|c|c|c|}
\hline Anode & $\mathrm{Li}$ & $\mathrm{C}$ & $\mathbf{S i}$ & $\mathrm{Li}_{4} \mathrm{Ti}_{5} \mathrm{O}_{12}$ & $\mathrm{Sn}$ \\
\hline $\begin{array}{l}\text { Density } \\
(\mathrm{g} / \mathrm{cm})\end{array}$ & 0.53 & 2.25 & $\mathbf{2 . 3 3}$ & 3.5 & 7.29 \\
\hline Lithiated phase & $\mathrm{Li}$ & $\mathrm{LiC}_{6}$ & $\mathbf{L i}_{4.4} \mathbf{S i}$ & $\mathrm{Li}_{4} \mathrm{Ti}_{5} \mathrm{O}_{12}$ & $\mathrm{Li}_{4.4} \mathrm{Sn}$ \\
\hline $\begin{array}{l}\text { Theoretical specific } \\
\text { capacity (mAh/g) }\end{array}$ & 3862 & 372 & $\mathbf{4 2 0 0}$ & 175 & 994 \\
\hline Volume change (\%) & 100 & 12 & $\mathbf{3 0 0}$ & -- & 260 \\
\hline Potential vs $\mathrm{Li}(\sim \mathrm{V})$ & 0 & 0.05 & $\mathbf{0 . 4}$ & 1.6 & 0.6 \\
\hline
\end{tabular}

However, there are three major disadvantages for $\mathrm{Si}$ anode.

1) Poor conductivity $\left(6.7 \times 10^{-4} \mathrm{~S} / \mathrm{cm}\right)$, indicating poor rate performance;

2) Huge volume change (up to 320\%) during lithiation/delithiation, which causes the fracture of Si particles and weakens the contact between anode and current collector. Finally, electrode structure will be totally damaged, accompanied by rapidly decreased capacity and bad cycle life;

3) Poor compatibility between $\mathrm{Si}$ and $\mathrm{LiPF}_{6}$. Si can react with $\mathrm{HF}$ (one of the decomposition products of $\mathrm{LiPF}_{6}$ ) to form solid electrolyte interface film (SEI). More 
Si will be exposed to the surface because of huge volume change during cycling, making this reaction further aggravated. Therefore, SEI will become unstable, indicating low coulombic efficiency and worse cycling performance.

These disadvantages have severely limited the application of $\mathrm{Si}$ in the field of high energy-density and high power-density LIBs.

\subsubsection{Mechanism of (de)lithiation of Si}

As described in Part2.2, Si anode is one of alloying anode materials. Its (de)lithiation mechanism, especially during the first two cycles, has been investigated for a long time.

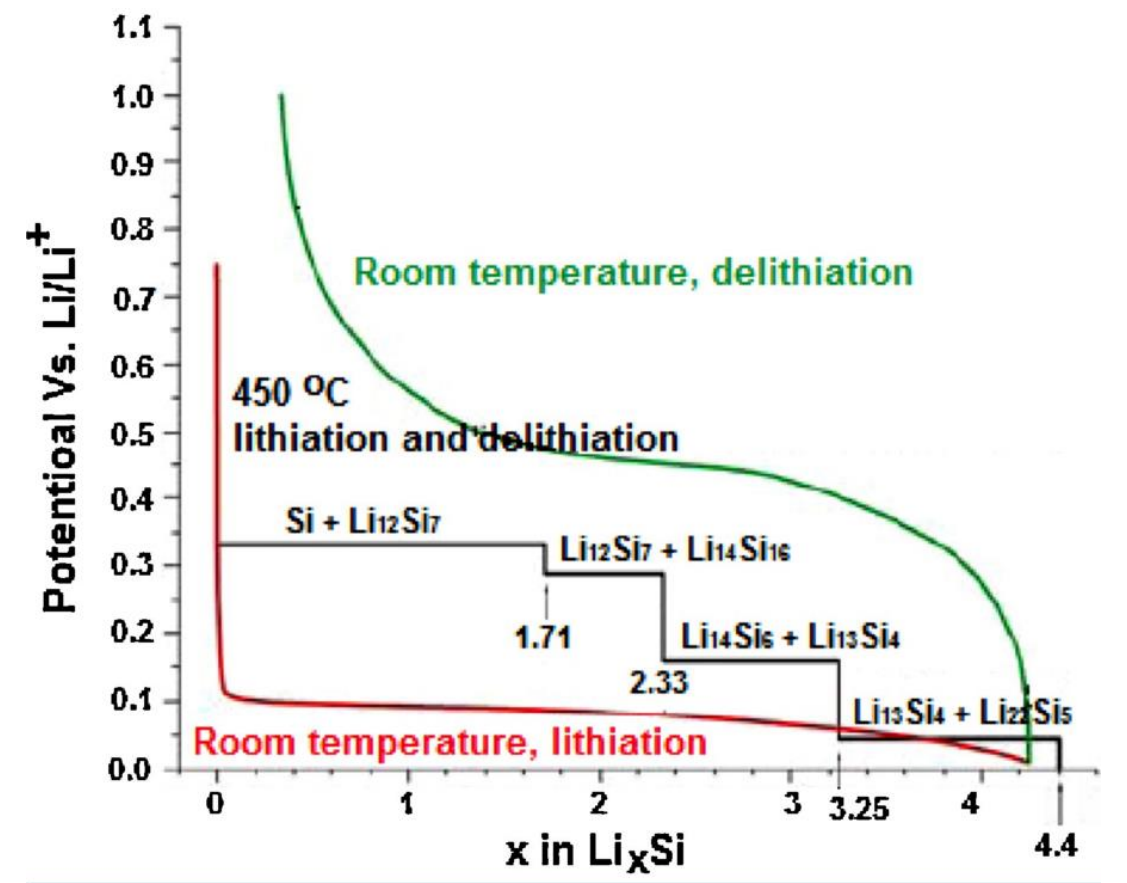

Fig.2.4 ${ }^{[17]}$ : Si electrochemical lithiation and delithiation curve at room temperature and high temperature. Black line: theoretical voltage curve at $450{ }^{\circ} \mathrm{C}$. Red and green line: lithiation and delithiation of crystalline $\mathrm{Si}$ at room temperature, respectively.

At high temperature, Si has the highest theoretical specific capacity of $4200 \mathrm{mAh} / \mathrm{g}$. Four phases ${ }^{[17]}$ can be formed during the alloying of $\mathrm{Li}-\mathrm{Si}: \mathrm{Li}_{1.71} \mathrm{Si}(332 \mathrm{mV}), \mathrm{Li}_{2.33} \mathrm{Si}(288 \mathrm{mV})$, $\mathrm{Li}_{3.75} \mathrm{Si}(158 \mathrm{mV})$ and $\mathrm{Li}_{4.4} \mathrm{Si}(44 \mathrm{mV})$, and alloying/de-alloying process is reversible, as shown in Fig.2.4. However, at room temperature, each $\mathrm{Si}$ atom can react with some $\mathrm{Li}$ atoms, usually no more than 3.75 . The corresponding theoretical capacity decreases to $3579 \mathrm{mAh} / \mathrm{g}$.

Fig.2.5 is the typical voltage profiles of $\mathrm{Si}$ anodes for the first two cycles at room temperature. 

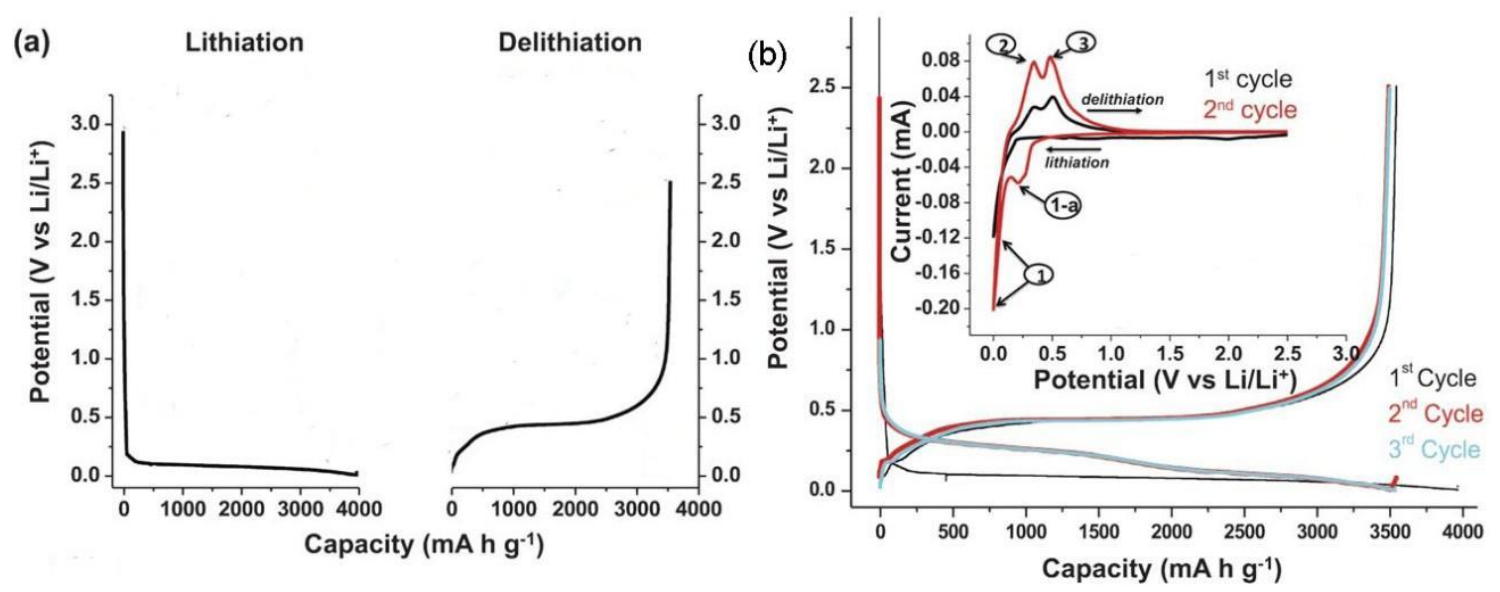

Fig. $2.5^{[18]}$ : Galvanostatic curve recorded on arrays of crystalline Si NWs grown by Cu-catalyzed VLS and mounted in half-cell geometry with a Li counter electrode.

During the first lithiation process (discharging), crystalline $\mathrm{Si}$ (c-Si) is gradually transformed into amorphous phase, forming amorphous intermetallic compounds (a-Li $\mathrm{x}_{\mathrm{x}} \mathrm{Si}$ ) such as $\mathrm{Li}_{12} \mathrm{Si}_{7}, \mathrm{Li}_{7} \mathrm{Si}_{3}$, and $\mathrm{Li}_{13} \mathrm{Si}_{4}{ }^{[19]}$. A long and even plateau of the lithiation curve (Fig.2.5a) represents a two-phase equilibrium between $\mathrm{c}-\mathrm{Si}$ and $\mathrm{a}-\mathrm{Li}_{\mathrm{x}} \mathrm{Si}^{[18]}$. The lithiation voltage plateau has been influenced by the ingredient of $\mathrm{Si}$. For n-doped $\mathrm{Si}^{[20]}$, lithiation starts around $90 \mathrm{mV}$, while it starts at $680 \mathrm{mV}$ for p-doped Si. At the end of this plateau, all the c-Si has disappeared and the voltage has dropped to around $60 \mathrm{mV}$. There are some controversies about the final state of a- $\mathrm{Li}_{\mathrm{X}} \mathrm{Si}$ when the voltage is further decreased $(<60 \mathrm{mV})$. Li et al. ${ }^{[21]}$ thought $\mathrm{Li}_{15 \pm \delta} \mathrm{Si}_{4}$ would be formed with a maximum capacity of $3800 \mathrm{mAh} / \mathrm{g}$, still less than $4200 \mathrm{mAh} / \mathrm{g}$.

During the first delithiation process (charging), $\mathrm{Li}_{15 \pm \delta} \mathrm{Si}_{4}$ is gradually replaced by an amorphous phase, $\mathrm{a}-\mathrm{Li}_{\mathrm{y}} \mathrm{Si}$ (y is commonly equal to $2^{[21]}$ ), which corresponds to a voltage plateau of $345 \mathrm{mV}$. When all the $\mathrm{Li}_{15 \pm \delta} \mathrm{Si}_{4}$ disappears, $\mathrm{Li}$ will be extracted from a- $\mathrm{Li}_{\mathrm{y}} \mathrm{Si}$ at a voltage plateau of $485 \mathrm{mV}$. In the end, amorphous $\mathrm{Si}$ is re-formed $\left(\mathrm{a}-\mathrm{Si}_{\mathrm{r}}\right)$. It's noticed that a-Sir different from commercial amorphous $\mathrm{Si}\left(\mathrm{a}-\mathrm{Si}_{\mathrm{c}}\right)$ without cycling. A single $\mathrm{Si}$ atom in $\mathrm{a}-\mathrm{Si}_{\mathrm{c}}$ has tetrahedral structure with some small distortions, while the structure of a-Si $\mathrm{i}_{\mathrm{r}}$ becomes more unordered and has wider distribution of lattice sizes.

Starting the $2^{\text {nd }}$ cycle, (de)lithiation mechanisms become similar. The $2^{\text {nd }}$ lithiation process can be divided into two stages. The first stage is the breakage of $\mathrm{Si}-\mathrm{Si}$ bond in a-Si $\mathrm{r}_{\mathrm{r}}$, accompanied by the formation of $\mathrm{a}-\mathrm{Li}_{2.3} \mathrm{Si}$ at a plateau of $200 \mathrm{mV}$. The second stage is the transformation from $\mathrm{Li}_{2.3} \mathrm{Si}_{\text {to }} \mathrm{Li}_{15 \pm \delta} \mathrm{Si}_{4}$ after all the a-Sir is gone. In theory, a- $\mathrm{Si}_{\mathrm{r}}$ should not be 
existed at the end of lithiation process, but Baris Key et al. ${ }^{[22]}$ still found some Si-Si bonds even if the voltage drops to $0 \mathrm{mV}$, possibly caused by volume effect. Huge volume change during cycling leads to bad connection between a-Si and current collector. Therefore, less Si atoms are involved into alloying reaction with the increase of cycles. There is no obvious difference between the first delithiation process and the following ones. But similarly, not all the Li can be extracted from $\mathrm{Li}_{15 \pm \delta} \mathrm{Si}_{4}$, finally leading to the decrease of the specific capacity of anode.

The reaction equations on (de)lithiation mechanism during the first two cycles are listed as follows.

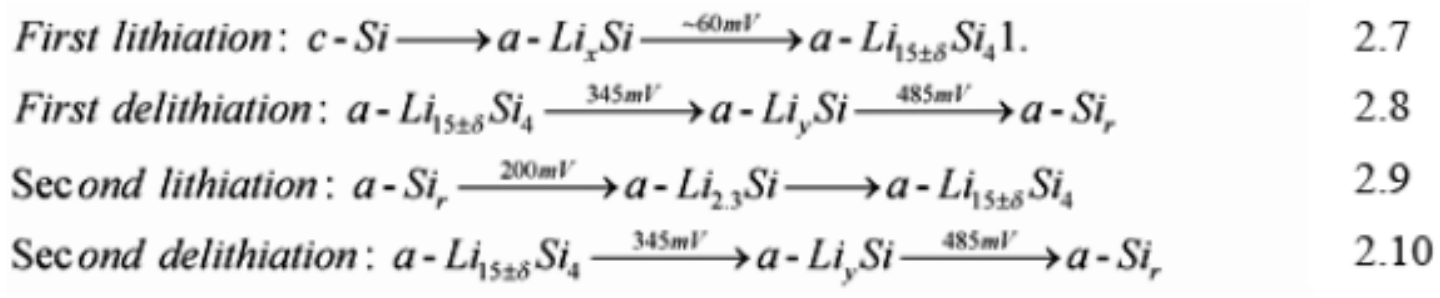

In most cases, $\mathrm{a}-\mathrm{Li}_{\mathrm{x}} \mathrm{Si}$ has been analyzed by using X-ray Diffraction (XRD), Nuclear Magnetic Resonance (NMR) and Transmission Electron Microscopy (TEM). It's still a challenge of monitoring the elements and structural changes in real-time in the process of Si phase transition because of the extreme sensitivity of a- $\mathrm{Li}_{\mathrm{x}} \mathrm{Si}$ to the environment. Recently, some insitu measurement techniques have been developed, which can provide more accurate information. For example, Etienne Radvanyi et al. ${ }^{[23]}$ used in-situ Auger Electron Spectroscopy (AES) to confirm the formation of a $\mathrm{Li}_{3.1} \mathrm{Si}$ shell surrounding $\mathrm{Si}$ core as lithiation process starts. Liu et al. ${ }^{[24]}$ studied the breakage of $\mathrm{Si}-\mathrm{Si}$ and recombination of $\mathrm{Li}-\mathrm{Si}$ at the a- $\mathrm{Li}_{3.5} \mathrm{Si}-\mathrm{c}-\mathrm{Si}$ interface by using in-situ TEM and proposed lithiation process is controlled by $\mathrm{Li}^{+}$migration of the interface.

Many people have been interested in the orientation of lithiation during the first cycle because most volume expansion happens during the initial crystalline-to-amorphous transformation than during the following cycles, helping better understand volume effect. For example, Lee et al. ${ }^{[25]}$ fabricated c-Si nanopillars with three different axial orientations $(<100>$, $<110\rangle$, and $<111>$ ). After the $1^{\text {st }}$ lithiation, the average volume expansion ratios of pillars with $\langle 100\rangle,\langle 110\rangle$, and $\langle 111\rangle$ axial orientations were $242.7 \%, 270.8 \%$, and $263.8 \%$, respectively, as shown in Fig.1.6, meaning the expansion prefers to take place at the (110) top surface planes. Beaulieu et al. ${ }^{[26]}$ studied the volume change of thin a-Si films by in situ Atomic Force 
Microscopy (AFM). The maximum volume change is about 300\%, little from the lateral direction due to physical constraint of the substrate.
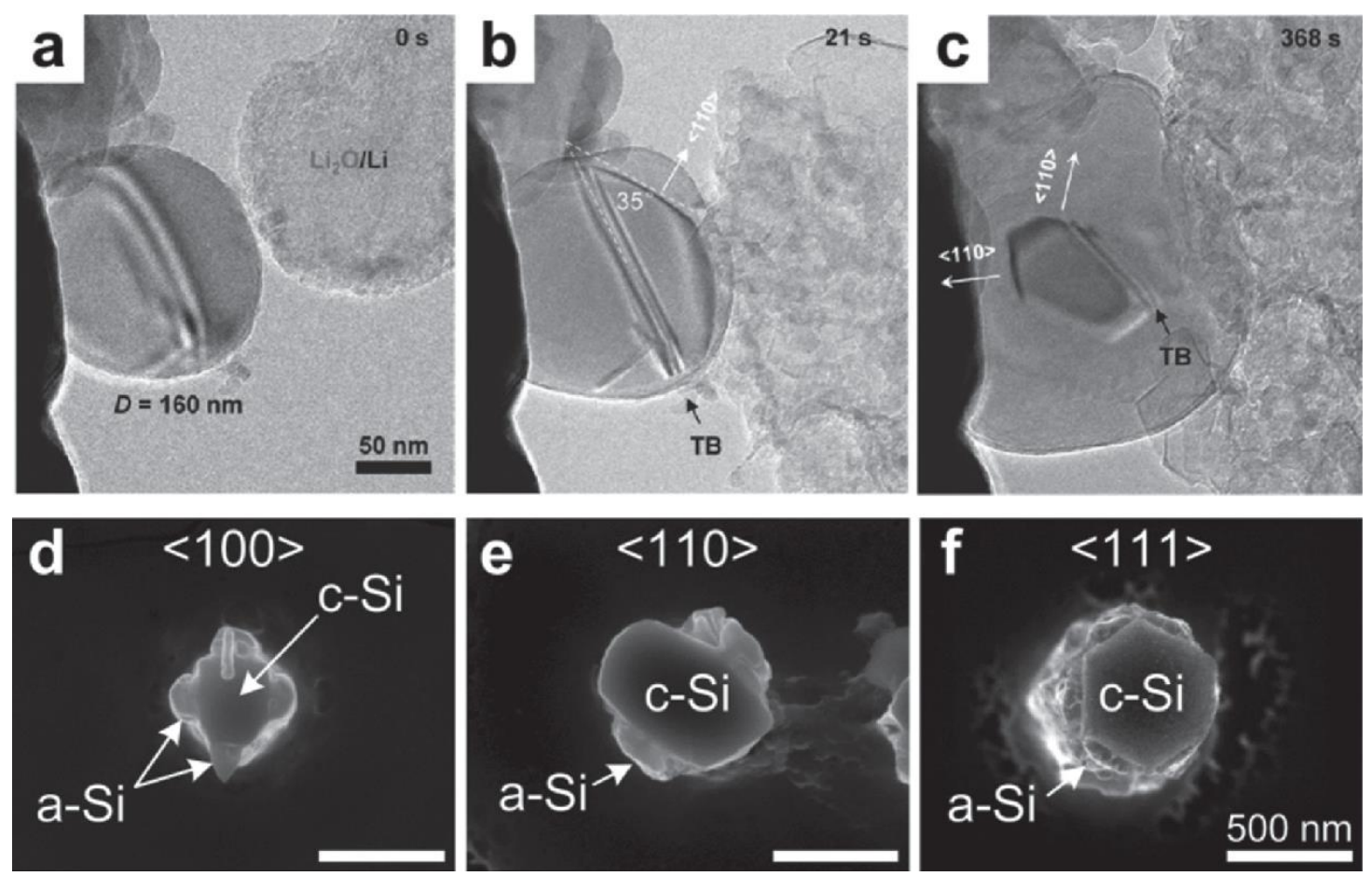

Fig.2.6 ${ }^{[25]}$ : a-c) In situ TEM images of the electrochemical lithiation of a Si nanoparticle with an initial diameter of about $160 \mathrm{~nm}$. a) Pristine nanoparticle; b) The same particle after 21 cycles of

lithiation; c) Further lithiation; d-f) SEM images of Si nanopillars with three different axial orientations $(<100>,<110>$, and $<111>$ ) after partial lithiation and subsequent removal of the lithiated phase to expose the crystalline cores.

\subsubsection{Development of Si-based anode materials}

Silicon has been considered as one of the most promising substitutes for tradition graphite anode due to its highest specific capacity in the nature. However, poor conductivity, huge volume change during lithiation/delithiation and unstable SEI have greatly limited its development. For example ${ }^{[27]}$, capacity loss of a commercial Si anode can be up to $50 \%$ after the $1^{\text {st }}$ cycle and the cycle life is no more than 10, making the industrialization impossible.

To solve these problems and improve electrochemical performance of Si anode, the key is increasing anode conductivity and prohibiting Si volume effect to maintain structural stability and good contact between anode and current collect during cycles. Nowadays, various approaches have been proposed, such as fabricating Si nanostructures, introducing carbonaceous 
framework, synthesizing Si alloy composite and so on. They can be mainly divided into two groups: 1) improvement of pure Si system; 2) formation of composite system. Besides, electrolyte also plays a very important role in the battery performance. For example, some additives like fluoroethylene carbonate (FEC) ${ }^{[28]}$ can effectively improve the stability of Si microstructure and prolong battery life. It makes no sense to compare different anode materials if using different electrolytes. Therefore, all the electrolytes used in the literatures here except specific mention are same: $\mathrm{LiPF}_{6}(1.0 \mathrm{M})$ dissolved in ethylene carbonate and diethyl carbonate (EC/DEC, 1:1 v\%).

\section{Pure Si anode material}

\section{1) Amorphous $\mathrm{Si}$}

Compared with crystalline $\mathrm{Si}$, amorphous $\mathrm{Si}(\mathrm{a}-\mathrm{Si})$ has lower activation energy barrier that can reduce strain force of the structure to relieve the volume change during cycling. For example, Farmakis F. et al. ${ }^{[29]}$ prepared the a-Si anode with the micro-grain structure by DC sputtering on $\mathrm{Cu}$ foil. This anode exhibits very stable specific capacity up to $2000 \mathrm{mAh} / \mathrm{g}$ after 50 cycles at $1 \mathrm{~A} / \mathrm{g}$.

Generally, most a-Si anodes only exhibit good cycle performance with not much high specific capacity at low current rate because of its limited inhibition of volume effect. What's worse, it's difficult to improve the cycle life further via adjusting the microstructure or lithiation orientation. Therefore, amorphous $\mathrm{Si}$ is not a research hotspot today.

\section{2) Nano-Si}

Nano-Si has higher specific surface area and more grain boundaries than bulk $\mathrm{Si}$, which is beneficial for $\mathrm{Li}^{+}$transport at the interface, leading to better rate performance. Besides, $\mathrm{Si}$ nanoparticles can use space resources more effectively than bulk ones, meaning apparent volume change during lithiation/delithiation will be decreased. For example, Liang J.W. et al. ${ }^{[30]}$ hydrothermally prepared porous Si nanospheres without any carbon coating in an autoclave at $180^{\circ} \mathrm{C}$, which delivers a great cycling stability of $950 \mathrm{mAh} / \mathrm{g}$ at $3.6 \mathrm{~A} / \mathrm{g}$ during 500 cycles.

At present, the research of nano-Si anode mainly focused on the design of microstructure and morphology, such as Si nanowires ${ }^{[31]}$, Si nanotubes ${ }^{[32]}$, Si nanospheres ${ }^{[30]}$ and other porous Si structures ${ }^{[33]}$.

As a typical 1D nanomaterial, Si nanowires and nanotubes exhibit improved electrochemical performance due to quick $\mathrm{Li}^{+}$transport along with $1 \mathrm{D}$ direction without interface 
barriers. For example, Cho J.H. et al ${ }^{[31]}$ used a special template (anodized aluminum oxide) to obtain the Si nanowire anode on the $\mathrm{Cu}$ foil, which can effectively avoid the formation of the parasitic Si islands along with Si nanowires and exhibit high specific capacity of $1000 \mathrm{mAh} / \mathrm{g}$ over 1100 cycles at $1 \mathrm{~A} / \mathrm{g}$.

Although some nano-Si anode materials have relatively high capacity and long life, the expensive and complex preparation methods have limited their large-scale production.

3) Si film

A few Si film anodes also showed good cycling stability, especially those consisting of amorphous Si and nano-Si. For example, Demirkan M.T. et al. ${ }^{[34]}$ prepared Si films with the controllable thickness by magnetron sputtering at different Ar pressures. The good cycle performance can be only obtained when the film density is low $\left(1.64 \mathrm{~g} / \mathrm{cm}^{3}\right.$, similar to $30 \%$ porosity). After 100 cycles, the specific capacity can be up to $650 \mathrm{mAh} / \mathrm{g}$ at $500 \mathrm{mAh} / \mathrm{g}$.

The main problem of Si film anode is low unit loading. Because of the serious volume effect during cycles, it's impossible to obtain a thick $(>10 \mu \mathrm{m})$ and dense film on the traditional $\mathrm{Cu}$ foil with long cycle life.

\section{Si/C composites}

Fabricating Si/C composites is a popular way to reduce irreversible capacity and prolong battery life. Carbonaceous materials such as porous carbon microsphere, graphite, carbon nanotubes/nanofiber (CNTs/CNFs), and graphene have been very attractive because of their softness and compliance, relatively low mass, good electronic conductivity, reasonable $\mathrm{Li}^{+}$ insertion ability, and small volume expansion. They cannot only improve the electrode's conductivity, but also provide a flexible skeleton to buffer the huge volume change stress of $\mathrm{Si}$ and maintain the anode structure. Carbonaceous materials have much smaller specific capacities than $\mathrm{Si}$ that will decrease the total capacity of composite anode, but considering the limit of specific capacities of the current cathode materials, as mentioned in Part2.1 (Fig.2.2), it's acceptable to sacrifice a portion of Si capacity to improve integral stability.

Recently, people have prepared various $\mathrm{Si} / \mathrm{C}$ composite anodes with specific morphologies by different methods such as high energy ball milling (HEBM), chemical vapor deposition (CVD), pyrolysis, chemical/physical etching, electrodeposition, electrospinning or multi-methods. Active material's performance primarily depends on its microstructure, therefore, based on the structural features, $\mathrm{Si} / \mathrm{C}$ composite anodes can be divided into four groups: $\mathrm{Si} / \mathrm{C}$ 
particles, including various hierarchical structures; $\mathrm{Si} / \mathrm{C}$ co-axial structures; $\mathrm{Si} / \mathrm{C}$ film; other structures.

1) $\mathrm{Si} / \mathrm{C}$ particles

Simple mixing type People started the research on introducing carbonaceous materials with simple mixing or coating method in the early days. Much attention was paid to the uniformity of mixture and continuity of carbon coating, hardly fine structure design, as shown in Fig.2.7.

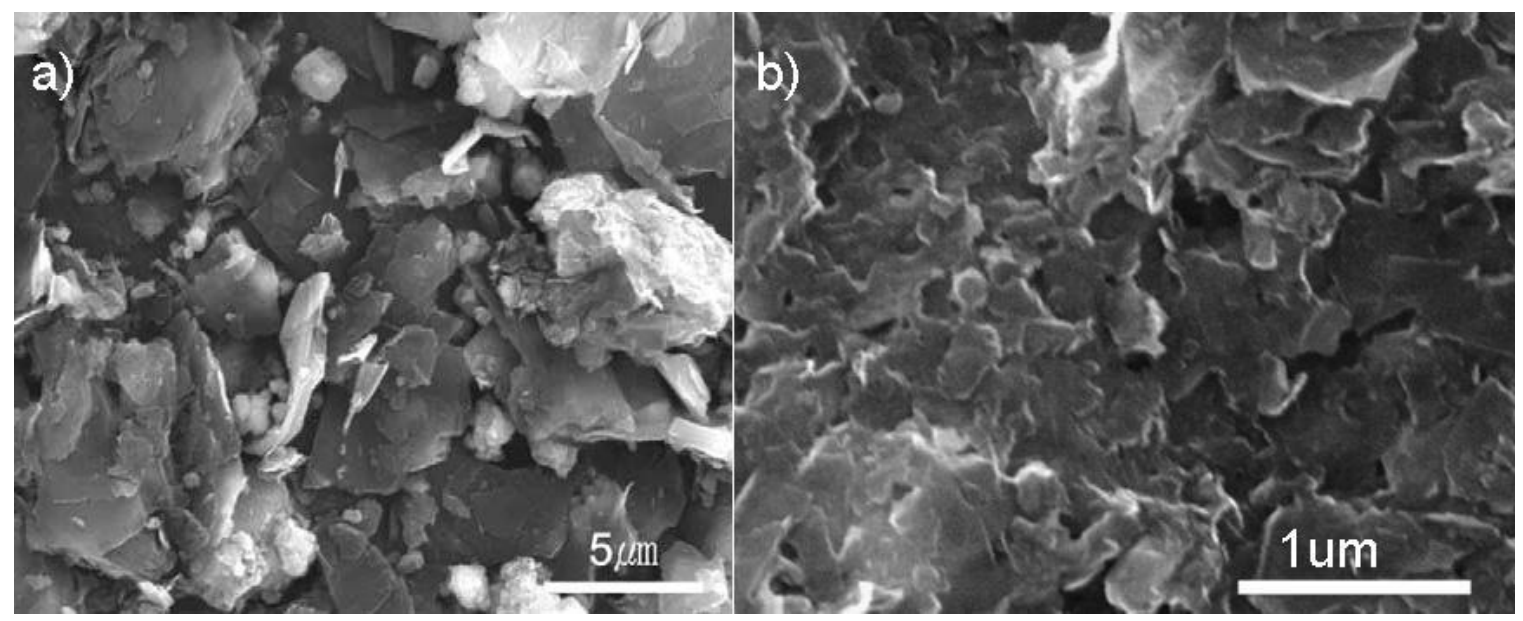

Fig.2.7: SEM of typical morphology by a) ball milling ${ }^{[35]}$ or b) pyrolysis ${ }^{[36]}$ in the early years

The typical synthesis methods are (HE)BM, thermal vapor deposition (TVD) and CVD.

Ball milling method has many advantages, such as uniform distribution of Si, controllable unit particle size, and accurate $\mathrm{Si} / \mathrm{C}$ ratio. Besides, it has great potential in industrialization because of low cost, simple operation and mild preparation conditions. Many people have synthesized $\mathrm{Si} / \mathrm{C}$ composites by using this method. The electrochemical performance can be improved via increasing the amount of $\mathrm{C}$ and prolonging the grinding time to reduce particle size. For example, Yoshio M. et al. ${ }^{[37]}$ prepared Si/graphite anode with different weight ratios. They found the composite still has the capacity of $500 \mathrm{mAh} / \mathrm{g}$ after 80 cycles when the ratio of Si to graphite is $7: 3$.

Composite performance can be also influenced by the anode components, such as carbon source and additives. Zuo P.J. et al. ${ }^{[38]}$ prepared Si/graphite anode (1:4 w\%) with the average size of $18 \mu \mathrm{m}$ by ball milling for $20 \mathrm{~h}$ under argon protection, which maintain a high capacity of $469 \mathrm{mAh} / \mathrm{g}$ after 40 cycles. They also used the same way to fabricate $\mathrm{Si} / \mathrm{Cu} / \mathrm{graphite}$ composite [39]. A new alloy phase $\left(\mathrm{Cu}_{3} \mathrm{Si}\right)$ could be formed to further improve the composite conductivity. 
Zhang Y. et al. ${ }^{[40]}$ introduced multi-walled carbon nanotubes (MWCNTs) into Si/graphite by using $12 \mathrm{~h}$ ball milling. Si particles were embedded into the "lamellar structures" of flaked graphite, and then tightly wrapped by MWCNTs network. A reversible capacity of $584 \mathrm{mAh} / \mathrm{g}$ after 20 cycles was maintained. Wang G.X. et al. ${ }^{[41]}$ mixed smaller crystalline Si particles (80 $\mathrm{nm})$ with $\mathrm{MCMB}(10 \mu \mathrm{m})$ and found MCMB framework remained spherical if grinding time is no more than 10h, which exhibit a capacity of $1066 \mathrm{mAh} / \mathrm{g}$ after 25 cycles.

However, the improvement of electrochemical performance of $\mathrm{Si} / \mathrm{C}$ composite made by ball milling is limited, especially on the cycle life side. The link between Si and C by means of physical mixing is not strong enough. Once the content of Si or cycle number is a little high, the continuous conductive network is hard to maintain the integrity.

Compared with ball milling, TVD/CVD method can provide more solid carbon coating around $\mathrm{Si}$ via pyrolysis of polymers or organics. There are two factors influencing composite cycling performance: carbon source (precursor) and deposition parameters.

Carbon sources mainly include benzene series and alkyl compounds. For example, Yoshio M. et al. ${ }^{[42]}$ utilized the decomposition of benzene vapor at $1000^{\circ} \mathrm{C}$ with $\mathrm{N}_{2}$ protection to deposit a carbon layer onto the surface of $\mathrm{Si}$, obtaining the composite anode with a reversible capacity of $800 \mathrm{mAh} / \mathrm{g}$. The carbon layer could suppress the decomposition of electrolyte on the surface of anode besides providing integral and continuous conductive networks. Some Sicontaining polymers, like polysiloxanes ${ }^{[43]}$, epoxy-silanes ${ }^{[44]}$, and pitch-polysiane composites ${ }^{[45]}$, are also good options of precursor because of better distribution of $\mathrm{Si}$ in the composite. However, these materials are toxic or hypertoxic. What's worse, some inactive chemical bonds, like $\mathrm{Si}-\mathrm{O}-\mathrm{C}, \mathrm{Si}-\mathrm{O}-\mathrm{Si}$ or silicates, can be formed in the composite at high pyrolysis temperature (generally around $1000^{\circ} \mathrm{C}$ ), leading to large irreversible capacity loss during the first cycle and the decrease of the specific capacity. Even using non-oxygen-containing Si precursors, like $\mathrm{SiCl}_{4}$ ${ }^{[46]}$, it is still hard to avoid the formation of inactive bonds. People have also attempted organic acid as carbon source with low toxicity and low pyrolysis temperature. For example, Guo L.P. et al. ${ }^{[47]}$ synthesized Si/C composites by pyrolyzing the mixture of Si nanoparticles and alginic acid dissolved in $\mathrm{Na}_{2} \mathrm{CO}_{3}$ solution. With the increase of the temperature (from $400^{\circ} \mathrm{C}$ to $700^{\circ} \mathrm{C}$ ), more amorphous $\mathrm{C}$ was produced and the composite exhibited better electrochemical performance. The reversible specific discharge capacity of Si/C at $700{ }^{\circ} \mathrm{C}$ was $560 \mathrm{mAh} / \mathrm{g}$ after 20 cycles. 
Deposition parameters, including temperature and reaction time, mainly affect the thickness and morphology of C layer. For example, Liu H.K. et al. ${ }^{[48]}$ mixed Si nanoparticles $(<100 \mathrm{~nm})$ in a citric acid/ethanol solution, then used spray-pyrolysis in air at low temperature (300 500 ${ }^{\circ} \mathrm{C}$ ) to prepare a homogeneous C layer on the surface of spheroidal Si nanoparticles. The results showed low temperature $\left(300{ }^{\circ} \mathrm{C}\right)$ results in large agglomerates of individual particles because of partially undecomposed citric acid, while high temperature $\left(500{ }^{\circ} \mathrm{C}\right)$ makes $\mathrm{C}$ layer too thin $(1 \mathrm{~nm})$. The best sample with $\mathrm{C}$ layer of $40 \mathrm{~nm}$ thick was obtained at $400^{\circ} \mathrm{C}$, retaining a specific capacity of $1120 \mathrm{mAh} / \mathrm{g}$ after 100 cycles. Yu J.L. et al. ${ }^{[49]}$ studied the effect of time on cycling performance. They used toluene as the precursor to make a uniform $\mathrm{C}$ layer on $\mathrm{Si}$ nanoparticles by dynamic CVD. The carbon thickness could easily be adjusted by changing reaction time. As shown in Fig.2.8, the composite actually has complex 3D skeleton with the subtle microstructure. After $2 \mathrm{~h}$ deposition, the sample with a $\mathrm{C}$ layer of $12 \mathrm{~nm}$ thick exhibited great cycle reversibility: a specific capacity of $1600 \mathrm{mAh} / \mathrm{g}$ at $0.3 \mathrm{~A} / \mathrm{g}$ after 70 cycles. As far as I know, this is the best result for those simple mixing composites prepared by CVD/TVD till now.

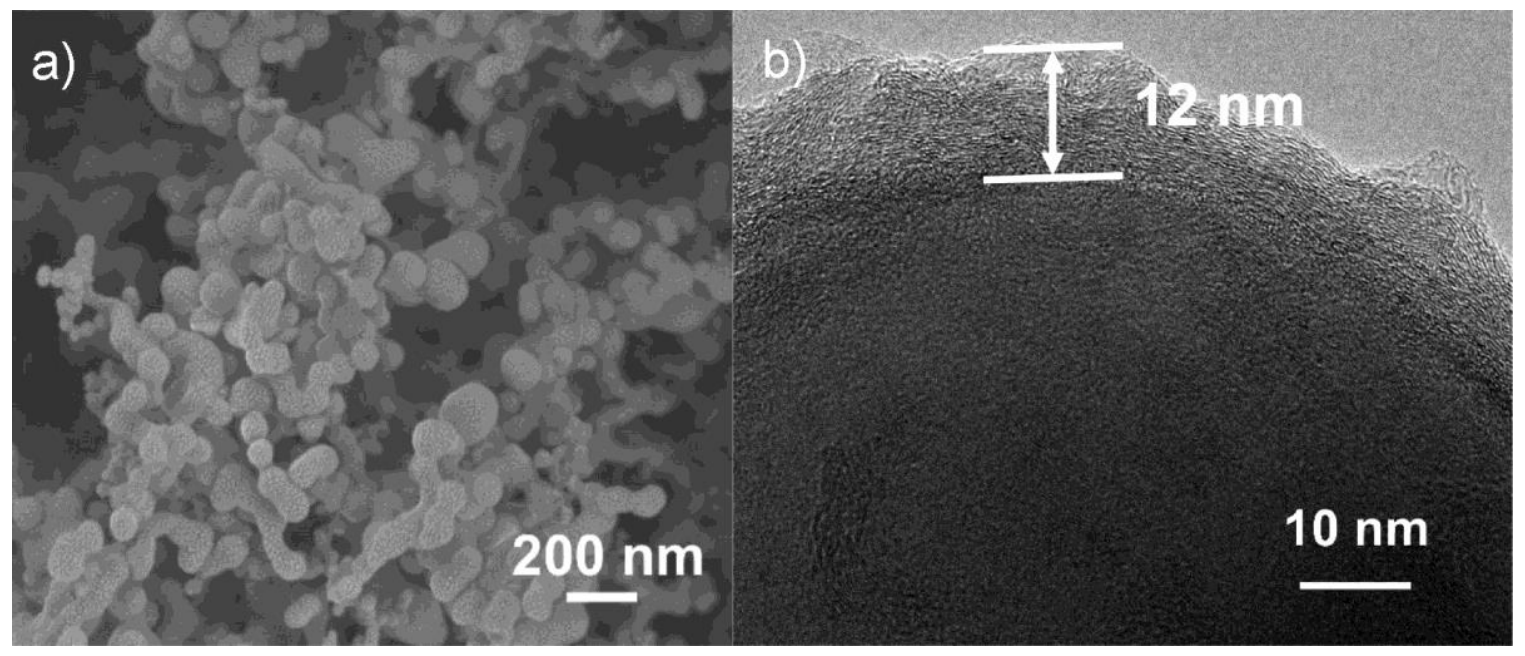

Fig.2.8 ${ }^{[49]}$ : a) SEM and b) TEM images of Si/C composites after $2 \mathrm{~h}$ pyrolysis.

The drawback of TVD/CVD is about Si dispersion, especially using small molecular precursors like organic acid or short-chain polymer, resulting in Si aggregation to some degree and non-uniform carbon coating after pyrolysis. To overcome the inherent defect of TVD/CVD, people have tried to combine it with ball milling. For example, Liu H.K. et al. ${ }^{[50]}$ mixed Si nanoparticles $(80 \mathrm{~nm})$ with PVA with weight ratio 1:9 by ball milling for $10 \mathrm{~h}$, and then used TVD at $600{ }^{\circ} \mathrm{C}$ under Ar flow to obtain Si particles with a disordered carbon layer, which exhibits high initial coulombic efficiency of $80.3 \%$. 
Hierarchical structure type As research continues, people found it was hard to further improve composite performance, especially cycle life, only with the aid of traditional mix or carbon coating, so they have paid more attention to the microstructure design, which in turn has greatly promoted the development of preparation methods. Most structures, aiming to optimize $\mathrm{Si}$ distribution, increase the strength of carbon layer, and reserve adequate space for $\mathrm{Si}$ volume change, belong to multidimensional hierarchical structures consisting of specific units. They can be divided into three groups.

The first one is hard template-assisted hierarchical structure. Two kinds of templates are commonly used: $\mathrm{C}$-containing materials and $\mathrm{SiO}_{\mathrm{x}}$. C-containing templates ${ }^{[51]}$ can be removed via calcination treatment and induce the formation of specific shape due to space effect. For example, Chen Y.J. et al. ${ }^{[52]}$ used a novel emulsion template to obtain Si/Carbon black (CB) composite with a specific capacity of $1300 \mathrm{mAh} / \mathrm{g}$ after 50 cycles. They modified CB with carboxyl group to improve the hydrophilic property and fabricated the stable oil-water interfaces via adjusting $\mathrm{pH}$ value. Si particles were surrounded by the interconnected $\mathrm{CB}$ network. After pyrolyzing, CB particles locating at the surfaces of emulsion droplets formed mesoporous cages that loosely encapsulate $\mathrm{Si}$ particles. Du Y.J. et al. ${ }^{[53]}$ prepared polystyrene (PS)@ $\mathrm{SiO}_{2}$ precursor through tetramethyl orthosilicate (TEOS) hydrolyzing, and removed PS template at $600^{\circ} \mathrm{C}$ for $6 \mathrm{~h}$. After magnesiothermic reduction and toluene pyrolysis, interconnected sandwich structure carbon/ $/ \mathrm{Si}_{-} \mathrm{SiO}_{2} /$ carbon nanospheres composite was formed (Fig.1.9a), which exhibits a high capacity of $1095 \mathrm{mAh} / \mathrm{g}$ after 200 cycles. $\mathrm{SiO}_{\mathrm{x}}$ templates can be removed by HF etching. Wang D.H. et al. ${ }^{[54]}$ firstly heated bulk $\mathrm{SiO}$ to form a composite composed of interconnected $\mathrm{Si}$ nanoparticles embedded in a $\mathrm{SiO}_{2}$ matrix. After removing $\mathrm{SiO}_{2}$ and filling $\mathrm{C}$ by thermal decomposition of acetylene gas at $620^{\circ} \mathrm{C}$, microsized Si-C composites with a capacity of 1459 $\mathrm{mAh} / \mathrm{g}$ after 200 cycles at 1A/g (Fig2.9 b) was obtained. Cui Y. et al. ${ }^{[55]}$ designed a non-filling C-coated porous $\mathrm{Si}$ microparticle by controllable chemical etching. $\mathrm{Si} / \mathrm{SiO}_{2}$ composites were firstly wrapped by $\mathrm{C}$ from the pyrolysis of resorcinol-formaldehyde resin and then etched by HF, leaving the interior pore structures unfilled for $\mathrm{Si}$ expansion. The anodes can be deeply cycled up to 1000 times with capacity remaining around $1500 \mathrm{mAh} / \mathrm{g}$ at $1 \mathrm{~A} / \mathrm{g}$. 
a)

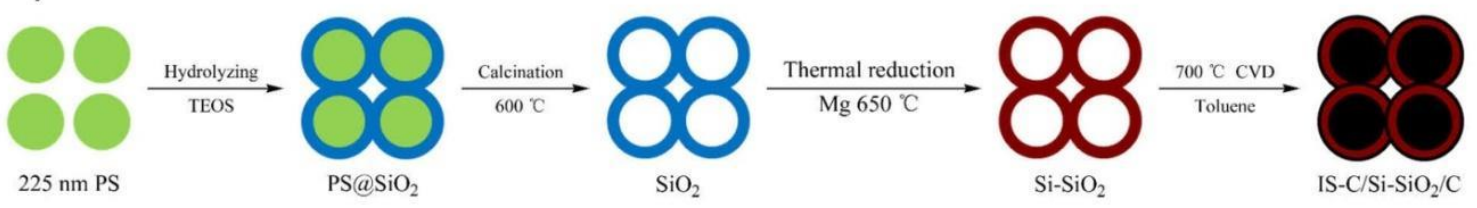

b)

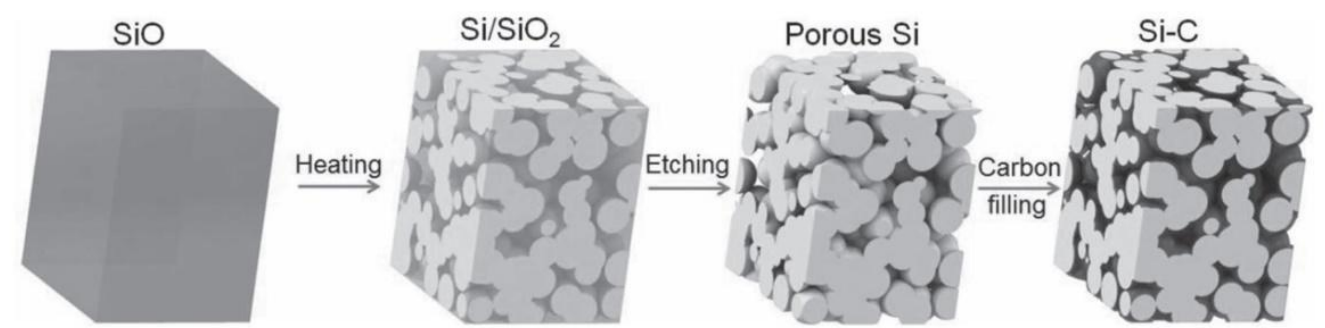

Fig. $2.9^{[54]}$ : the preparation process from a) PS and b) $\mathrm{SiO}_{2}$ template to the $\mathrm{Si}-\mathrm{C}$ composite

The second group is surface modification-assisted hierarchical structure. Through surface modification, some functional groups can be introduced on the surface of $\mathrm{Si}$ or $\mathrm{C}$, forming covalent bonds or electrostatic attraction among particles. The covalent/electrostatic linkage is beneficial to retaining the composite capacity and cycle life. For example, Brousse T. et al. ${ }^{[56]}$ functionalized graphite flakes with aminophenyl groups in aqueous acidic media and bridged $\mathrm{Si}$ nanoparticles via a phenyl group. Compared with a simple mixture, this composite shows higher capacity retention (from $38 \%$ to $52 \%$ ) after 50 cycles. Yu G.H. et al. ${ }^{[57]}$ fabricated a 3D ternary $\mathrm{Si} /$ conducting polymer/CNFs hybrid material which exhibits an excellent electrochemical performance $(1600 \mathrm{mAh} / \mathrm{g}$ over 1000 cycles at $3.3 \mathrm{~A} / \mathrm{g})$. The affinity between $\mathrm{Si}$ and in-situ polymer coating could be attributed to the synergism of electrostatic effect between the negatively charged-OH group and positively charged polypyrrole polymer backbone and hydrogen bonding between phosphoric acid groups in the phytic acid and native $\mathrm{SiO}_{2}$ at the $\mathrm{Si}$ surface. Since part of SiNPs may detach from the electronically conductive framework after some cycles, the 3D wrapping effect of SWCNTs can better confine SiNPs in the polymer framework to maintain the electrical connection within the entire electrode framework. 


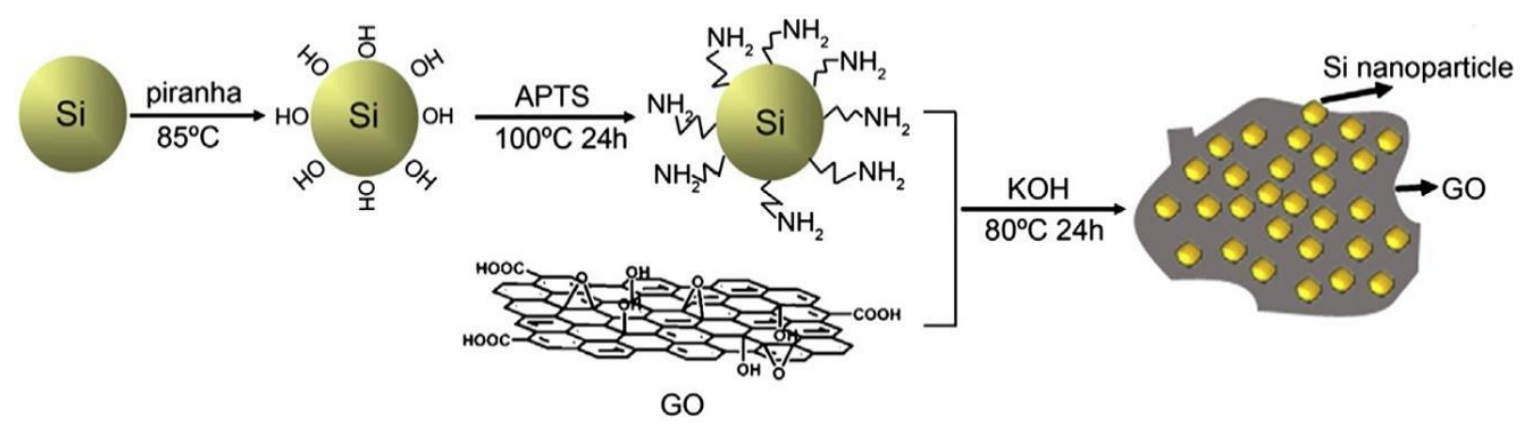

Fig.2.10 ${ }^{[59]}$ : Scheme of fabricating Si-GO hybrid.

Graphene, a 2-D sheet with a $\mathrm{sp}^{2}$ bond structure, should be emphasized because of its high electrical conductivity and thermal conductivity. More importantly, it also can be considered as a self-template due to its excellent physical behavior such as high mechanical strength, high elasticity and flexibility. Besides, graphene can be easily modified with some specific functional groups because of its large surface area with high reactive activity. Therefore, many $\mathrm{Si} /$ Graphene (or graphene oxide) composites have been studied. For example, Luo J.Y. et al. ${ }^{[58]}$ prepared crumpled graphene-encapsulated Si nanoparticles with a capacity of $940 \mathrm{mAh} / \mathrm{g}$ after 250cycles. A droplet generator produced a stream in which Si and graphene oxide particles were uniformly dispersed. After rapid evaporation, the crumpled graphene oxide sheets were formed due to isotropic capillary compression and Si particles were wrapped inside. Sun K.N. et al. ${ }^{[59]}$ studied the effect of surface charge on composite performance. They modified Si nanoparticles and graphene oxide (GO) with $-\mathrm{NH}_{2}$ and $-\mathrm{COOH}$ group, respectively. After mixing, Si was firmly anchored on GO by covalent immobilization, as shown in Fig.2.10. $\mathrm{Si} / \mathrm{Graphene}$ was formed via reductive anneal treatment. The homogeneous distribution of Si nanoparticles and the super high surface area of graphene supplied the hybrid enough internal space to accommodate the volume expansion during $\mathrm{Li}^{+}$insertion process, resulting in long cycle lift at the high current rate. There still have some problems for 3D graphene-wrapped composites. Firstly, the improvement of cycle performance can be only achieved when graphene is dispersed well without any agglomeration caused by van der Waals force, but actually, good dispersability of graphene can be damaged easily during cycles. Secondly, its large surface area results in a thick SEI layer, indicating low initial Coulombic efficiency. Thirdly, graphene is much expensive than other carbonaceous materials, especially for single graphene sheets. Therefore, the application of graphene in LIB is still in the experimental stage and further research is urgently needed. 


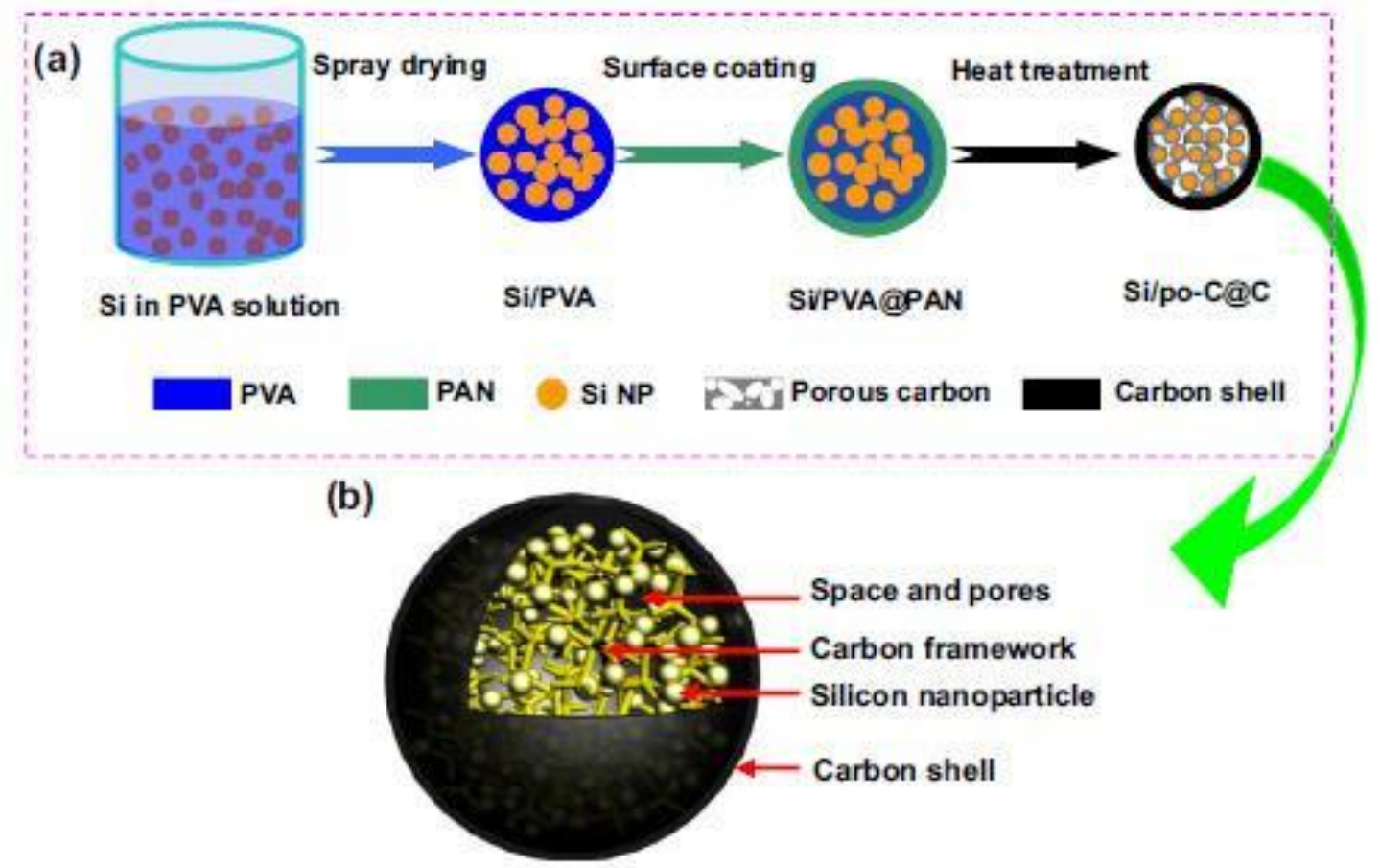

Fig.2.11 ${ }^{[62]}$ : Schematics of a) fabrication process and b) hierarchical structural design for Si/porous C@C composite.

The third group is core-shell structures, generally consisting of active core (mainly Si) coated with a stable protective shell (mainly C). This structure can not only construct the conductive network and improve the structural and thermal stability, but also can reduce the decomposition of active materials via reducing the contact area between electrode and electrolyte. Wang D.H. et al. ${ }^{[60]}$ studied the influence of buffer voids inside the shell on cycle performance of the composite. The $\mathrm{SiO}_{2}$ layer between $\mathrm{Si}$ (the core) and $\mathrm{C}$ (the shell) is used as a sacrificial template for generating void space. The void volume can be controlled by changing the thickness of $\mathrm{SiO}_{2}$. The results showed when the ratio of void to $\mathrm{Si}$ is around 3, the best performance of $\mathrm{Si} / \mathrm{C}$ core-shell composite is achieved, which is consistent with huge volume expansion of $300 \%$ during lithiation process. Neither less nor more void leads to severe capacity fading after several cycles. Recently, Li M. et al. ${ }^{[61]}$ fabricated a novel graphite/Si-porous carbon core-shell structure by spray drying/pyrolysis of slurry consisting of nano $\mathrm{Si}$, graphite, and citric acid. Natural graphite is the core, and $\mathrm{Si}$, which filled in the porous carbon matrix, is the shell. The capacity of this composite is about $600 \mathrm{mAh} / \mathrm{g}$ after 100 cycles. Li S. et al. ${ }^{[62]}$ used the similar method but different carbon sources to obtain a hierarchical core-shell structure, as shown in Fig.2.11. The inner $\mathrm{C}$ framework and surface $\mathrm{C}$ coating was from the pyrolysis of polyvinyl alcohol (PVA) and 
polyacrylonitrile (PAN), respectively. Besides, the pyrolysis of PVA also provided butter space for Si volume change. Compared with Li M.'s result, the composite exhibits higher capacity but worse cycling life, indicating too complex structure may not bring better performance because the structure is hardly maintained. In addition, Cui Y. et al. ${ }^{[63]}$ proposed a concept of "YolkShell" (Fig.2.12), which shows excellent capacity (2800 mAh/g at C/10) and cycle life (1000 cycles with $74 \%$ capacity retention) even with conventional PVDF binder.

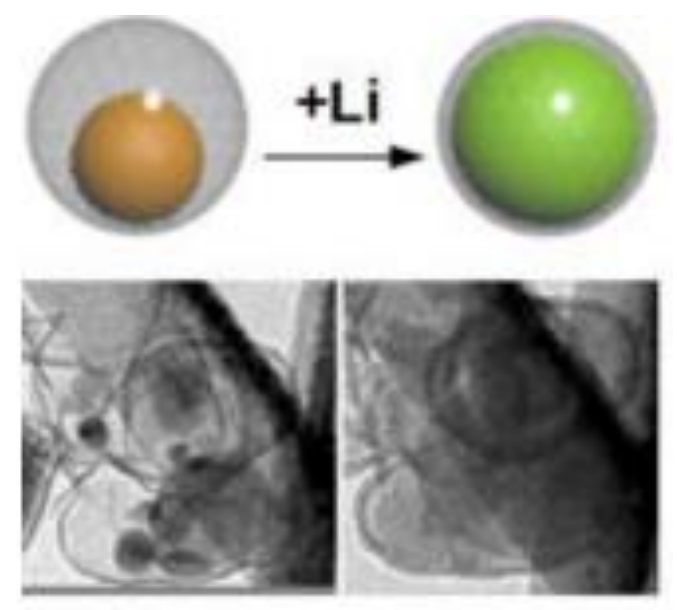

Fig.2.12 ${ }^{[63]}$ : Schematics of lithiation process of Yolk-Shell C/Si structure.

Core-shell structure still has some problems. One is about uniformity, especially for large scale production. It's hard to confirm all the active cores are coated with protective shell. Another problem is the complexity of preparation method, resulting in high cost and environmental issue.

2) $\mathrm{Si} / \mathrm{C}$ co-axial structure

$\mathrm{Si} / \mathrm{C}$ composite with coaxial tube/array is one of the most popular structures for LIB anode. $\mathrm{C}$ axis can provide firm connection with $\mathrm{Si}$, fluent $\mathrm{Li}^{+}$transport pathway, and inhibit $\mathrm{Si}$ volume effect during cycles. There have three groups based on the location of $\mathrm{Si}$.

The first group is $\mathrm{Si} / \mathrm{C}$ composite with $\mathrm{C}$ core and $\mathrm{Si}$ shell. As the most commonly used template, CNTs have excellent conductivity, large surface area, good mechanical flexibility and high chemical stability. Therefore, the combination of $\mathrm{Si}$ with CNFs can produce the anode with improved electrochemical performance. For example, Wang W. et al. ${ }^{[64]}$ used a simple two-step CVD method to deposit silicon nanoparticles on an aligned CNTs array substrate to obtain the composite with the capacity of $2000 \mathrm{mAh} / \mathrm{g}$ after 25 cycles. To improve the link between $\mathrm{Si}$ and CNTs, Martin C. et al. ${ }^{[65]}$ used diazonium chemistry to bind Si and CNTs closely with enhanced 
electron transport, which benefits the maintenance of $\mathrm{Si}$ axis during cycles. This composite exhibits high capacity of $1000 \mathrm{mAh} / \mathrm{g}$ after 35cycles, two times than the simple mixture of Si and CNFs. Zhang Q. et al. ${ }^{[66]}$ improved the core-shell structure further. They thought the traditional CVD only produced randomly aligned nanowire arrays without the effective control on size and array spacing. Highly non-uniform space distribution inevitably leads to insufficient space for strain relaxation at some certain locations. Therefore, they prepared a Si/CNTs core-shell nanowire array with controlled morphology. The vertically aligned CNTs core had large interwire spacing, and a cone shaped Si shell located along CNTs, as shown in Fig.2.13. This composite exhibits excellent capacity retention of more than $90 \%$ over 100 cycles at the current rate of $800 \mathrm{~mA} / \mathrm{g}$.

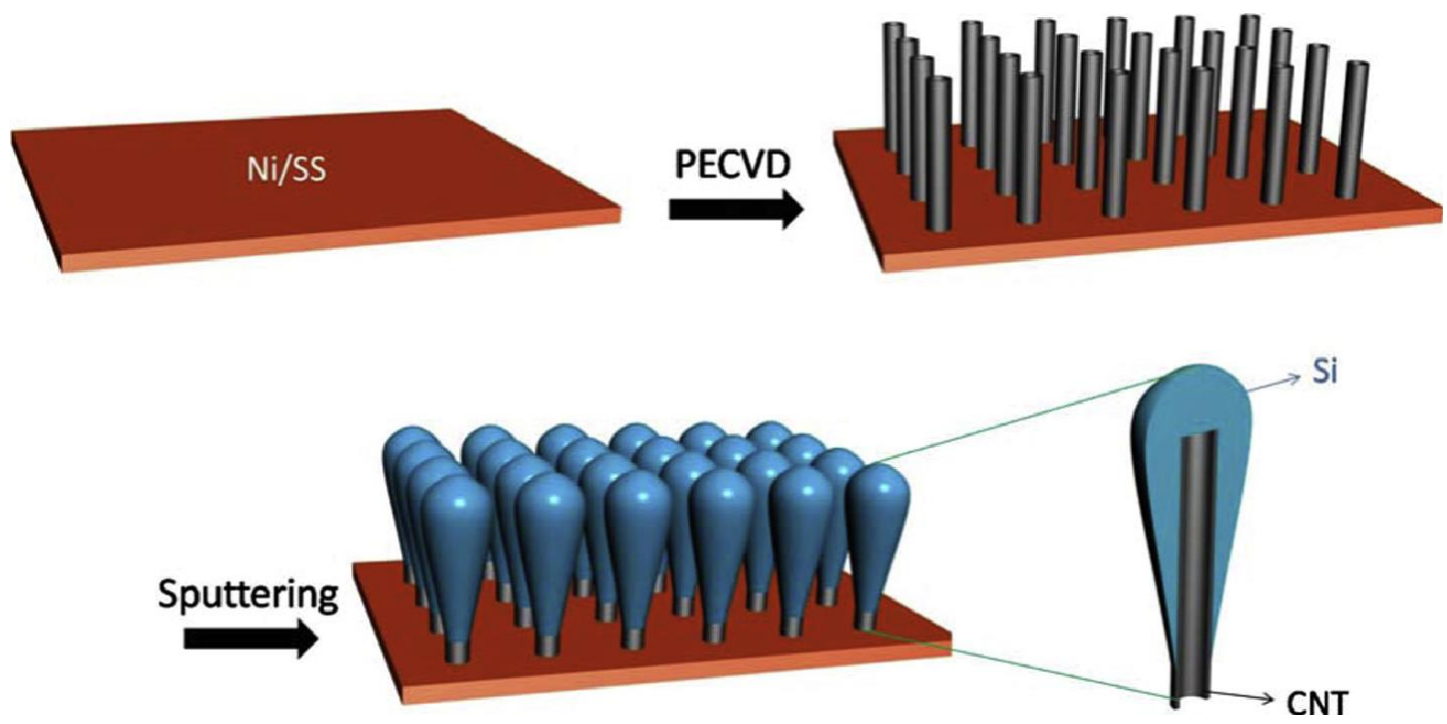

Fig.2.13 ${ }^{[66]}$ : Schematic of fabrication processes and structure of the CNT-Silicon anode

The second group is $\mathrm{Si} / \mathrm{C}$ composite with $\mathrm{Si}$ core and $\mathrm{C}$ shell. The corresponding capacity retention can often be improved by decreasing the diameter of Si axis or introducing enough space for volume effect. For example, Biswal S.L. et al. ${ }^{[67]}$ firstly produced freestanding porous Si nanoarrays by means of electrochemical stripping from bulk Si and then coated $\mathrm{C}$ layer by pyrolyzing polyacrylonitrile (PAN). Chundong Wang et al. ${ }^{[68]}$ deposited carbon nanoparticles on both internal and external surfaces of Si nanotubes (SiNTs) to obtain a core-shell structure, which delivers a high specific capacity of $2085 \mathrm{mAh} / \mathrm{g}$ at the current rate of $800 \mathrm{~mA} / \mathrm{g}$ after 200 cycles. Recently, C-coated Si nanowires have been used as self-standing paper-like anode without any binder or conductive additives ${ }^{[69]}$. Besides, some conductive polymer coatings such as PEDOT ${ }^{[70]}$ have also been studied to improve cycling performance of SiNWs core. 


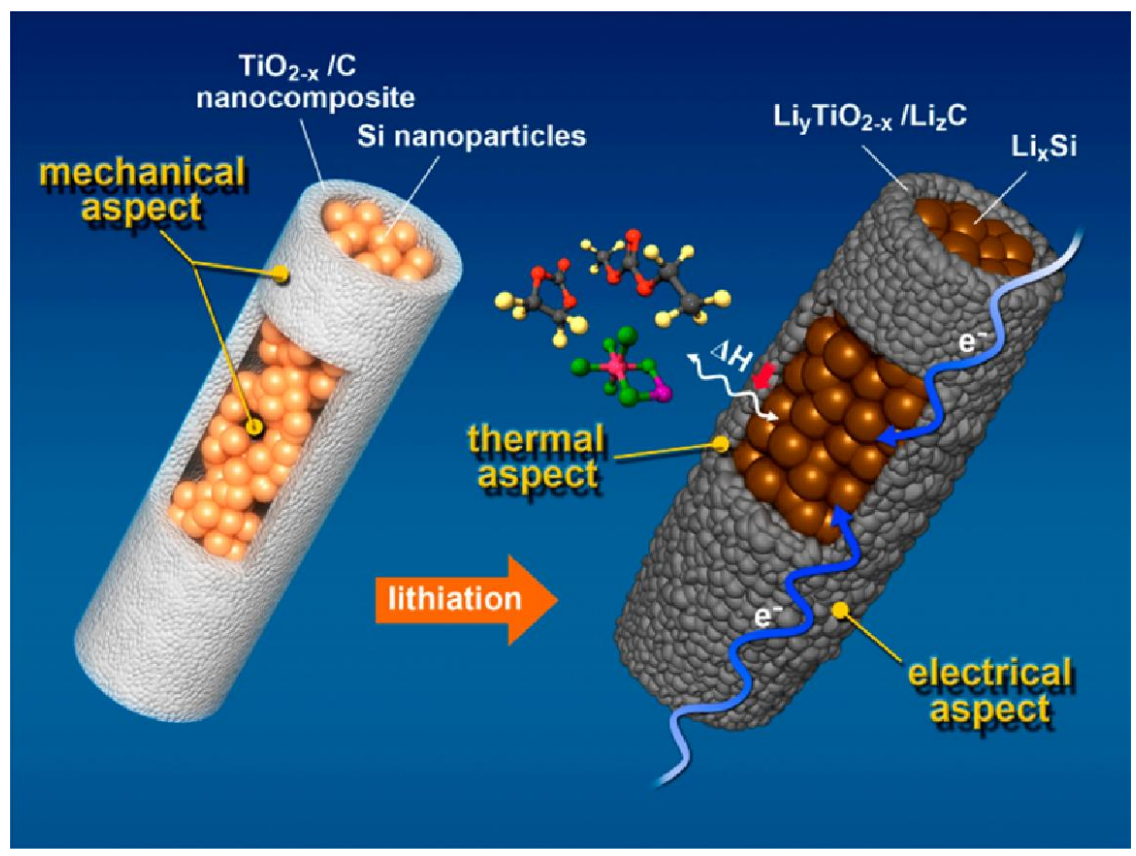

Fig.2.14 ${ }^{[71]}$ : Schematic illustration of a core-shell structured Si@TiO2-x/C mesoporous microfiber composite.

The third group is forming core-shell structure at the same time, commonly by using electrospinning technique. Electrospinning method has many advantages, such as simplicity, controlled diameter of the tube, and large-scale production. Generally, Si is the core. For example, Yoo J.K. et al. ${ }^{[71]}$ prepared highly porous continuous Si nanowires consisting of interconnected Si nanocrystals with a multi-level carbon coating, which shows a high reversible capacity of $1500 \mathrm{mAh} / \mathrm{g}$ after 50 cycles. Electrospinning method also helps introduce other active additives except for $\mathrm{C}$ via adjusting the initial reactive solution. Jeong G. et al. ${ }^{[71]}$ added $\mathrm{TiO}_{2}$ between $\mathrm{Si}$ core and $\mathrm{C}$ shell to act as a physical/chemical interfacial barrier, retarding exothermic reaction between highly lithiated Si phase and liquid electrolyte. Compared with other similar structures, SiNPs@Ti/C composite (Fig.2.14) exhibits very excellent rate capability of $939 \mathrm{mAh} / \mathrm{g}$ after 50 cycles at $12 \mathrm{~A} / \mathrm{g}$. The main problem of electrospinning method is relatively weak combination between $\mathrm{Si}$ and $\mathrm{C}$ in comparison with those made by CVD/TVD, leading to relatively short cycle life.

In brief, $\mathrm{Si} / \mathrm{C}$ coaxial structure is good candidate for LIB anodes, mainly because of the significantly enhanced conductivity and structural durability. The major problem is the complicated fabrication process, which greatly increases the cost and thus prevents the commercial application. 


\section{3) $\mathrm{Si} / \mathrm{C}$ film}

Generally, few people have reviewed $\mathrm{Si} @ \mathrm{C}$ composite films because this classification is slightly inaccurate. Most active Si@C composites on the current collector can be considered as $2 \mathrm{D}$ active films with various unit structures. But there is indeed one case that is a different from the previous structures, which is often prepared by CVD or electrodeposition. For example, Kim S.O. et al. ${ }^{[72]}$ deposited a diamond-like carbon with the thickness of $60 \mathrm{~nm}$ on the Si film. Wang J. et al. ${ }^{[73]}$ synthesized the amorphous Si/C multilayer film by RF magnetic sputtering (RFMS) method. The first deposit layer consists of carbon to get good conductivity and strong adhesion with current collector, and the outermost layer is still carbon to avoid Si oxidation and film collapse. Some people have found that doping element such as boron ${ }^{[74]}$ or aluminum ${ }^{[75]}$ into $\mathrm{C}$ or Si film can also improve the composite cycling performance. Wu J.X. et al. ${ }^{[76]}$ used a novel electrostatic spray deposition (ESB) to fabricate a Si embedded porous carbon/graphene hybrid film with layer-by-layer (LBL) structure, as shown in Fig2.15. Si nanoparticles cooperate with carbon framework and form sandwich-like morphology among graphene sheets, which demonstrates a high reversible capacity and good capacity retention without any binder.

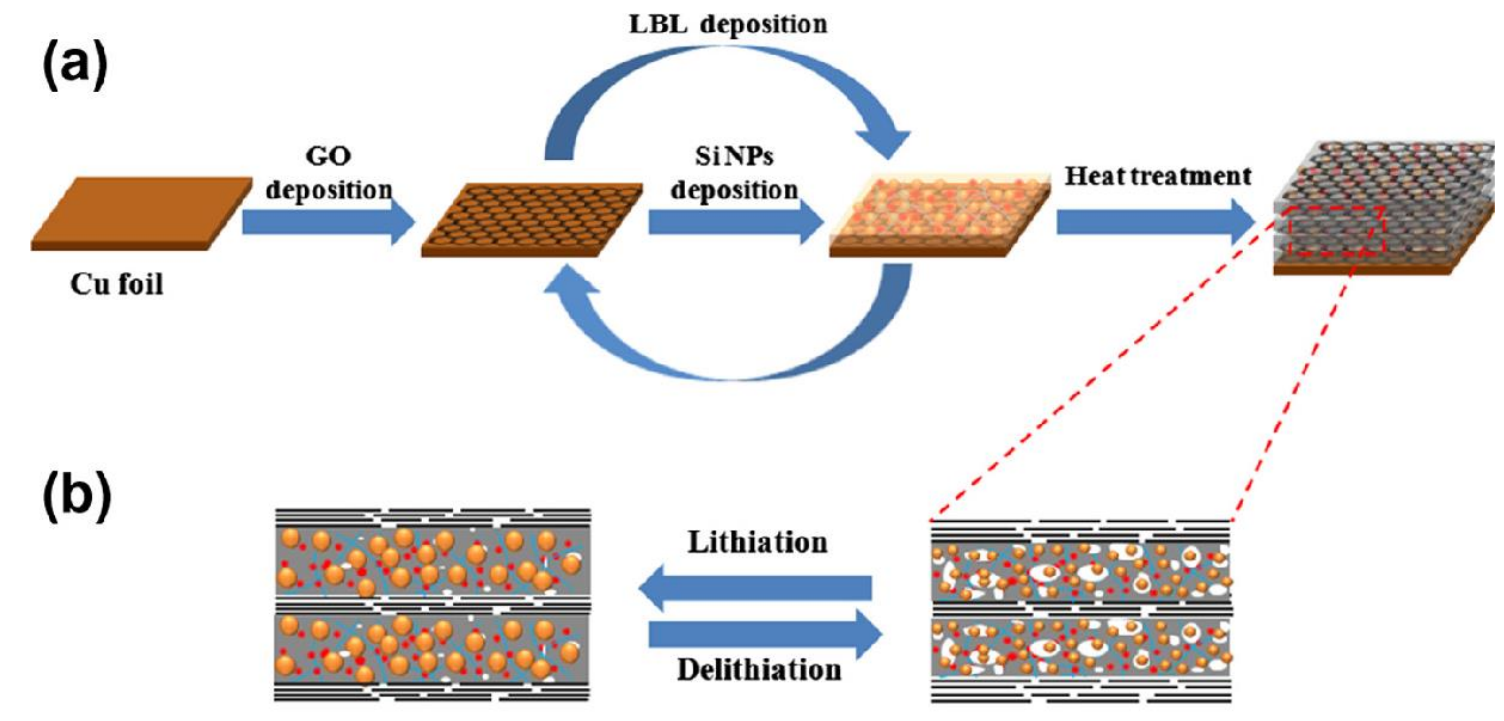

\section{Si NPs Graphene $\bigcirc \mathrm{CB}$ /}

\section{Porous carbon framework}

Fig2.15 ${ }^{[76]}$ : a) Schematic of fabrication process for the LBL Si-C/G electrode; b) Schematic of the structure changes of the electrode during lithiation/delithiation process. 
The problem of $\mathrm{Si} / \mathrm{C}$ film is low active loading and packing density. If the film is too thick, the top part often exhibits different cycling stability from the bottom part, which leads to the internal stress to tear the film. Therefore, building better top-down electron/ $\mathrm{Li}^{+}$transport path is the hotspot for $\mathrm{Si} / \mathrm{C}$ film preparation.

\section{$\mathrm{Si} / \mathrm{metal}$ (Si/M) composites}

Metals have good conductivities and mechanical strength, which cannot only increase the anode conductivity, but also effectively inhibit $\mathrm{Si}$ volume effect during (de)lithiation process. In the $\mathrm{Si} / \mathrm{M}$ composite, $\mathrm{Si}$ is generally dispersed into the metal substrate. The metals can be divided into two groups. One is Li-inert metal such as $\mathrm{Fe}, \mathrm{Cu}$, and Ni. For example, Zhang H.G. et al. ${ }^{[78]}$ prepared a 3D anode consisting of a Si film and a porous nickel metal scaffold, as shown in Fig.2.16. This metal framework cannot only improve the anode electrical conductivity, but also accommodate the volume change of Si during cycles, which exhibits high capacity of 2660 $\mathrm{mAh} / \mathrm{g}$ at $0.3 \mathrm{C}$ after 100 cycles. Although it's good for Si anode to improve the cycle life with the help of Li-inert metal, the energy density of composite must be decreased because the metals don't involve in lithiation reaction. Therefore, more people have chosen Li-active metals as the substrate to avoid unnecessary loss of capacity, such as $\mathrm{Mg}$ and Sn. For example, Choi N.S. et al ${ }^{[79]}$ fabricated 1D Si/Sn nanowires with the capacity of $1050 \mathrm{mAh} / \mathrm{g}$ after 45 cycles at $300 \mathrm{~mA} / \mathrm{g}$. However, Li-active metals also have volume effect during lithiation, bringing bad effect on long cycles.

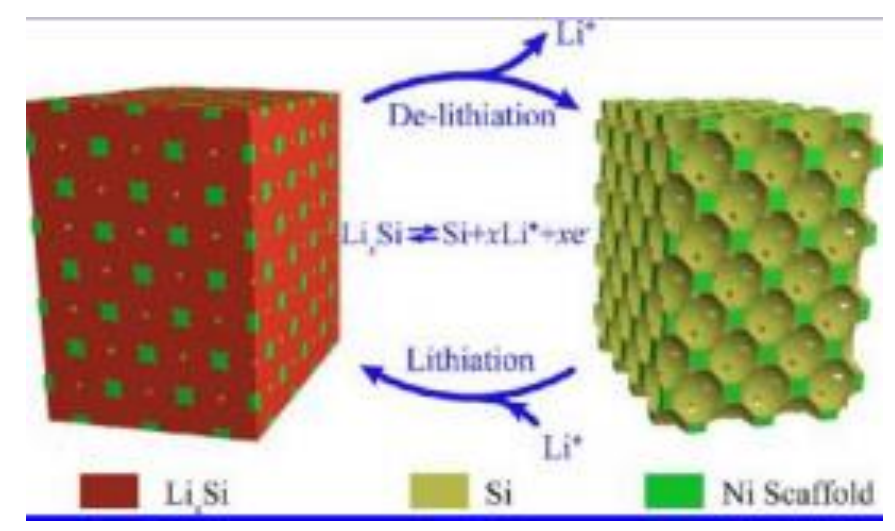

Fig.2.16 ${ }^{[78]}$ : Schematic of microstructure of Si-Ni electrode.

Actually, no matter what kind of metal is used, the whole competitiveness of Si/M composite on specific volumetric capacity is weaker than $\mathrm{Si} / \mathrm{C}$ composite as mentioned before. Therefore, focusing on the improvement of cycle life may be the future direction of Si/M composite. 


\section{Other composites}

Si can combine with the material with good $\mathrm{Li}^{+}$conductivity, such as metal oxides ${ }^{[80]}$, ceramic materials ${ }^{[81]}$ or $\mathrm{SiO}_{\mathrm{x}}{ }^{[82-84]}$, to form a composite anode.

Take $\mathrm{SiO}_{\mathrm{x}}$ as an example, it has smaller volume effect than that of Si during cycles because of less Si unit content. More importantly, a proper oxide layer can also suppress the volume expansion in some degree. Therefore, $\mathrm{SiO}_{\mathrm{x}}$ has attracted much attention as a candidate for Si substitute. For example, Yoo $\mathrm{H}$. et al ${ }^{[83]}$ prepared $\mathrm{Si} / \mathrm{SiO}_{\mathrm{x}}$ core-shell nanocoils anode by high-temperature annealing method with the help of Pt catalyst (Fig.2.17). Besides the buffer layer of $\mathrm{SiO}_{\mathrm{x}}$ during cycles, the empty space inside the structure improves the contact of $\mathrm{Si}$ with electrolyte, leading to better transport of $\mathrm{Li}^{+}$. Therefore, this composite anode exhibits a great improvement of electrochemical performance with a specific capacity of $1600 \mathrm{mAh} / \mathrm{g}$ at $0.2 \mathrm{C}$ after 70 cycles.

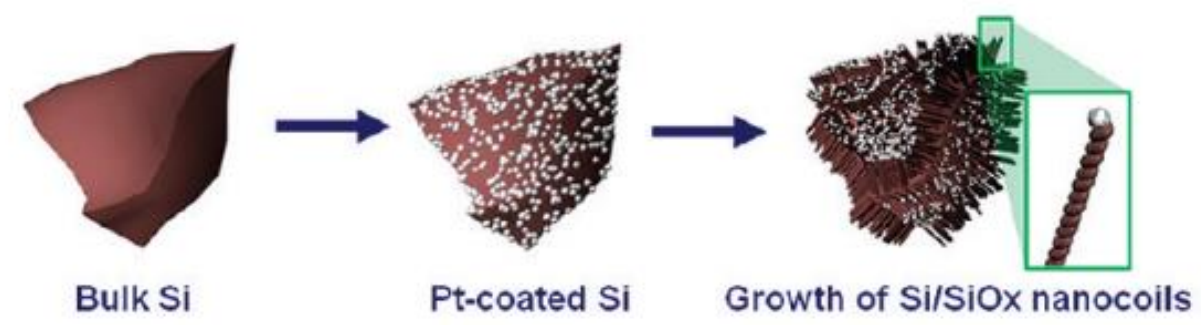

Fig.2.17 ${ }^{[83]}$ : Schematic of fabrication process for $\mathrm{Si} / \mathrm{SiO}_{\mathrm{x}}$ core-shell nanocoils anode electrode.

However, as the increase of oxygen content, cycle performance of the composite becomes worse because of the decrease of mechanical strength of oxide layer and excessive inactive Licontaining compounds formed by $\mathrm{Li}$ insertion.

\subsection{Electrophoretic deposition}

Electrophoretic deposition (EPD) is commonly employed in processing of a variety of coatings ${ }^{[85,86]}$ and free-standing objects ${ }^{[85]}$. EPD is achieved via the motion of charged particles, dispersed in a suitable suspension, towards an electrode under an applied electric field. Electrophoretic motion of charged particles during EPD results in the accumulation of particles and the formation of a homogeneous deposit at the relevant electrode. The deposition of positively charged particles on negative electrode is called cathodic electrophoretic deposition (c-EPD); while the deposition of negatively on positive electrode is called anodic electrophoretic deposition (a-EPD), as shown in Fig2.18. 
Generally, EPD can be applied to any solid with the small particle size ( $<30 \mathrm{um})$ and colloidal suspensions ${ }^{[85,86]}$, mainly including two steps. Firstly, particles suspended in a liquid are forced to move towards an electrode by applying an electric field (electrophoresis). Then, the particles gather at the electrode and form a coherent deposit layer (deposition). Compared with other deposition methods, EPD has many advantages, such as low cost, process simplicity, uniformity of deposits, controllable deposit morphology, and no limit of shape of substrate. Some people even have used EPD to obtain dense films on porous non-conductive substrates ${ }^{[87]}$. Besides, EPD only needs suspensions with relatively low solids loading and low viscosity, which implies convenient after-treatment procedures.

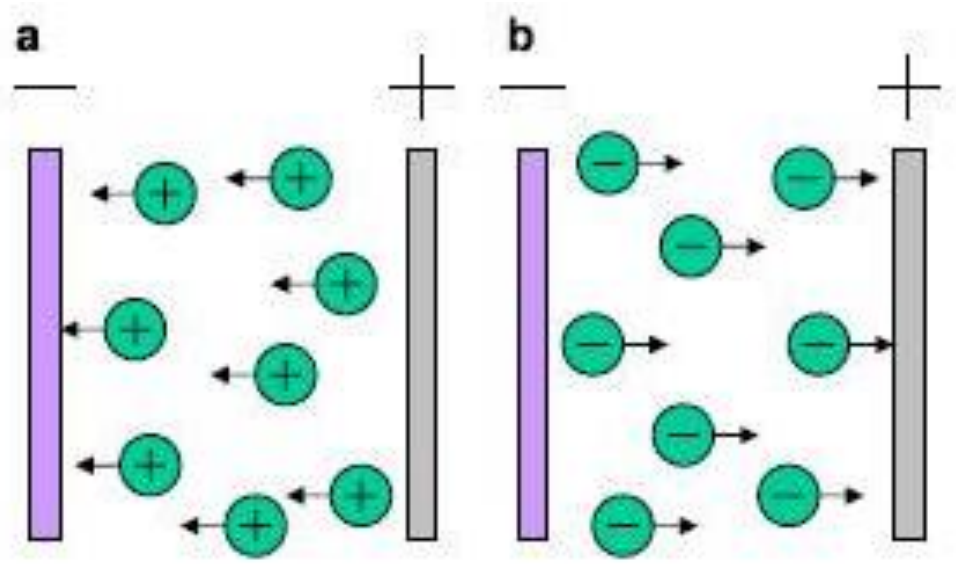

Fig. $2.18^{[91]}$ : Schematic illustration of electrophoretic deposition process. a) cathodic EPD; b) anodic EPD.

\subsubsection{EPD mechanism}

As mentioned in the previous part, EPD is a process where charged particles travel through a suspension under an external electric field. Charged particle is the precondition, therefore, the DLVO theory has been considered as the fundamental mechanism of EPD ${ }^{[88-90]}$. Based on this theory, some other theories ${ }^{[91]}$ have been also proposed to explain the particle behavior during EPD, mainly including flocculation by particle accumulation, particle charge neutralization, electrochemical particle coagulation, and electrical double layer distortion and thinning mechanism.

1) DLVO theory

DLVO (Derjaguin-Landau-Verwey-Overbeek) theory describes the force between charged particles consisting of the van der Waals attraction potential and repulsive electrostatic potential, given by Equation 2.11: 


$$
V_{T}=V_{A}+V_{R}
$$

where $V_{T}=$ total energy, $V_{A}=$ attractive energy, $V_{R}=$ repulsive energy.

And the potential energy curve for DLVO theory is shown in Fig.2.19.

When the distance between particles tends to be infinite, $V_{T}$ is 0 . As the decrease of the distance, $\mathrm{V}_{\mathrm{A}}$ becomes the dominant force and the absolute of $\mathrm{V}_{\mathrm{T}}$ is increased gradually to the maximum value. In this stage, although particles attract each other, the distance is too long to cause serious particle aggregation. If the distance continues to decrease, $V_{R}$ begins to dominate over $\mathrm{V}_{\mathrm{A}}$ leading to the change of the force between particles from attraction to repulsion. And the maximum repulsive force can be obtained when the distance is decreased to a specific value. At this moment, the particles in the suspension show the highest stability. If the particle distance is decreased further, $\mathrm{V}_{\mathrm{A}}$ becomes dominant again, so does the absolute of $\mathrm{V}_{\mathrm{T}}$, causing quick flocculation of particles.

Based on the DLVO theory, the stability of suspension depends on the total energy of interaction between particles, which can be greatly influenced by surface charge and particle concentration.

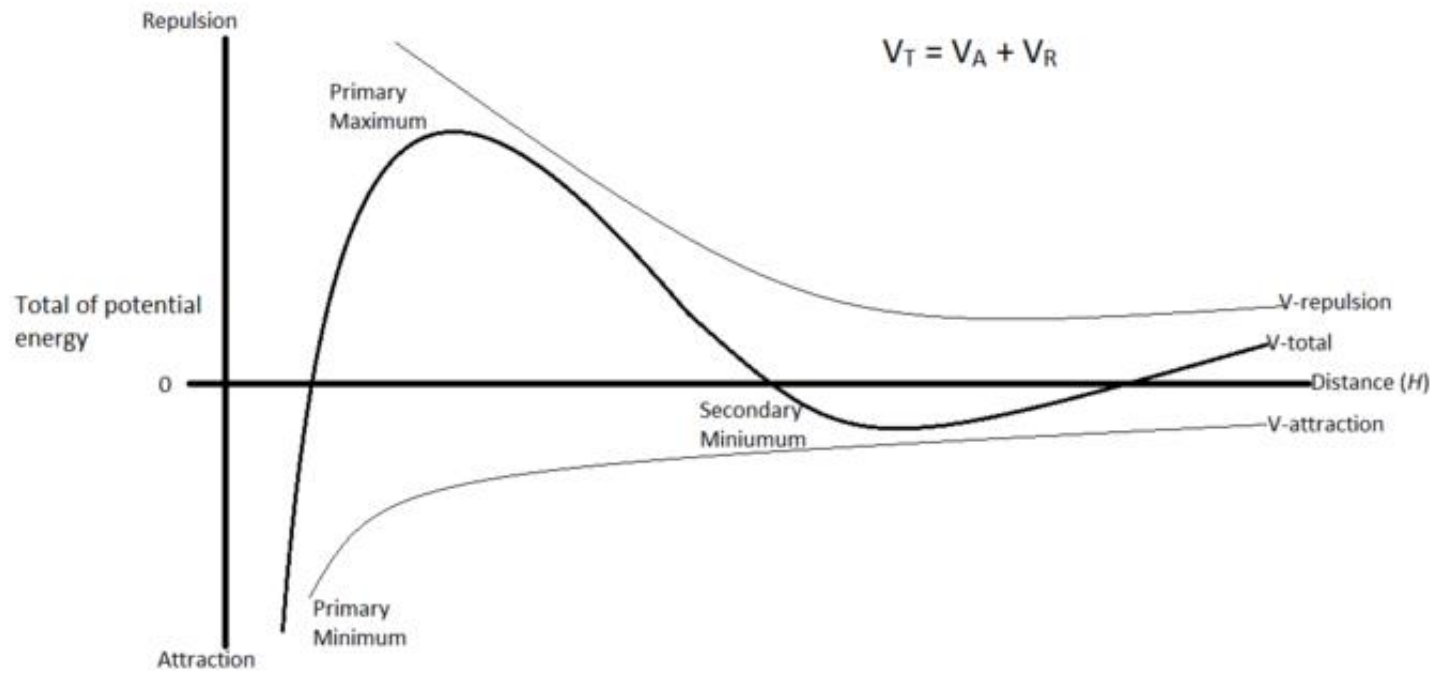

Fig.2.19: Total potential energy versus interparticle distance curve between two particles.

2) Flocculation by particle accumulation

This mechanism was firstly proposed by Hamaker and Verwey ${ }^{[92]}$, mainly appropriate for explaining the deposition of coatings on porous membranes ${ }^{[93]}$. They found the external 
applied electric field makes particles moving towards the electrode to accumulate during EPD. When the particles are close enough to each other, the pressure caused by arriving particles can overcome the repulsive force between particles, and the deposition happens by means of the gravitation.

3) Particle charge neutralization mechanism

This mechanism was proposed by Grillon et al. ${ }^{[94]}$, explaining the deposition of single particles and monolayers in very dilute suspensions. They though all the charged particles become neutral as contacting with the electrode. However, this mechanism is not suitable for long-time EPD, or the deposition on the substrate locating between electrodes.

4) Electrochemical particle coagulation mechanism

This mechanism was proposed by Koelmans et al ${ }^{[95]}$ to explain the deposition of particles with increased electrolyte concentration close to the electrode. Through calculating the ionic strength of particles next to the electrode under different electric fields, they found the similar value as that requires to coagulate in the suspension, indicating the decrease of the repulsive force between particles. They thought it should be caused by the increase of the electrolyte concentration close to electrode, leading to lower surface charge density. To be specific, this mechanism is suitable for the system that can generate $-\mathrm{OH}^{-}$during $\mathrm{EPD}{ }^{[91]}$.

5) Electrical double layer (EDL) distortion and thinning mechanism

This mechanism was proposed by Sarkar and Nicholson ${ }^{[96]}$ to explain the deposition of particles with a constant high electrolyte concentration near the electrode. They thought when a positive charged particle is moving towards to the cathode, the particle double layer is distorted with thinner ahead and wider behind due to the external electric field and fluid dynamics. Then, the negative ions in the tail of a particle prefer to attract cations locating the head of another one with a distorted double layer moving towards the cathode. Finally, the coagulation is achieved.

\subsubsection{Factors affecting EPD}

The factors affecting EPD can be divided into two groups: 1) suspension properties and 2) processing parameters.

\section{Suspension properties}

1) Particle size

A stable suspension is necessary for a successful EPD process, or else a nonuniform deposit layer will be obtained, such as consisting of a thinner top and a thicker bottom if the 
substrate is vertically placed. A suspension with large particles $(>20 \mu \mathrm{m})$ is usually unstable because the settlement easily occurs under gravity effect. Therefore, particles with the sizes of 1 $\sim 20 \mu \mathrm{m}$ has been suggested ${ }^{[91]}$. Recently, with the rapid development of nanotechnology, many coatings with nanoparticles have been prepared by EPD ${ }^{[97,98]}$. Well and stable dispersion of nanoparticles in the suspension is a precondition. For example, Zhu G.Z. et al ${ }^{[98]}$ prepared uniform $\mathrm{Bi}_{2} \mathrm{O}_{3}$ nano-films in the ethanol suspension with controlled thickness from $6 \mu \mathrm{m}$ to 18 $\mu \mathrm{m}$. Paper-manufacturing waste sodium lignin sulfonate (MZS) is used as the dispersant to avoid the aggregation of nanoparticles, as shown in Fig.2.20.

Particle size also plays an important role in improving the density of the deposited layer. For example, Das D. et al ${ }^{[99]}$ found narrow size distribution in the suspension is beneficial to obtain the uniform deposit with high packing density.

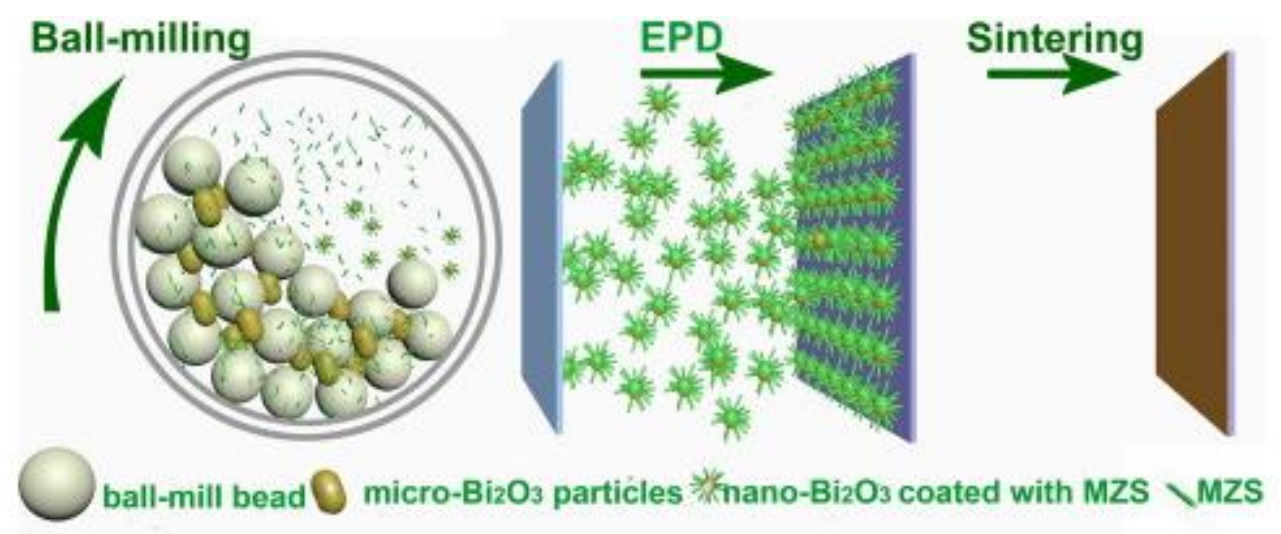

Fig.2.20 ${ }^{[98]}$ : Schematic of the stabilization of $\mathrm{Bi}_{2} \mathrm{O}_{3}$ nanoparticles in the ethanol and EPD process.

2) Dielectric constant

High dielectric constant leads to high ionic concentration in the suspension, which will reduce the thickness of double electric layer of particles and finally slow down the electrophoretic mobility. Low dielectric constant leads to failing deposition due to the decreased dissociative power. Therefore, the suitable range is about $12 \sim 25^{[91]}$. The dielectric constants of some common liquids are shown as Table2.2.

Table2.2: Dielectric constants of liquids

\begin{tabular}{|l|l|}
\hline Liquid & Dielectric constant \\
\hline Ethanol & 22.4 \\
\hline Acetone & 20.7 \\
\hline
\end{tabular}




\begin{tabular}{|l|l|}
\hline n-Propanol & 20.33 \\
\hline Iso-propanol & 19.92 \\
\hline n-Butanol & 17.51 \\
\hline
\end{tabular}

\section{3) Conductivity of suspension}

Like dielectric constant value, suspension conductivity also cannot be too low or too high. If it's too low, the particles will charge themselves under the external electric field and lose the stability. If it's too high, the double electric layer will be reduced seriously and the electrophoretic mobility will be decreased. The specific range of suspension conductivity for EPD depends on the temperature, dispersant concentration and the applied voltage ${ }^{[101]}$.

\section{4) Zeta potential}

A stable suspension must have a high zeta potential ( $\zeta$-potential) besides keeping the relatively low ionic conductivity. $\zeta$-potential ${ }^{[102]}$ is the electric potential in the interfacial electric double layer (EDL) at the location of the slipping plane relative to a point in the bulk fluid away from the interface, as shown in Fig.2.21, which indicates the stability of colloidal dispersions and determine the migration direction of particles.

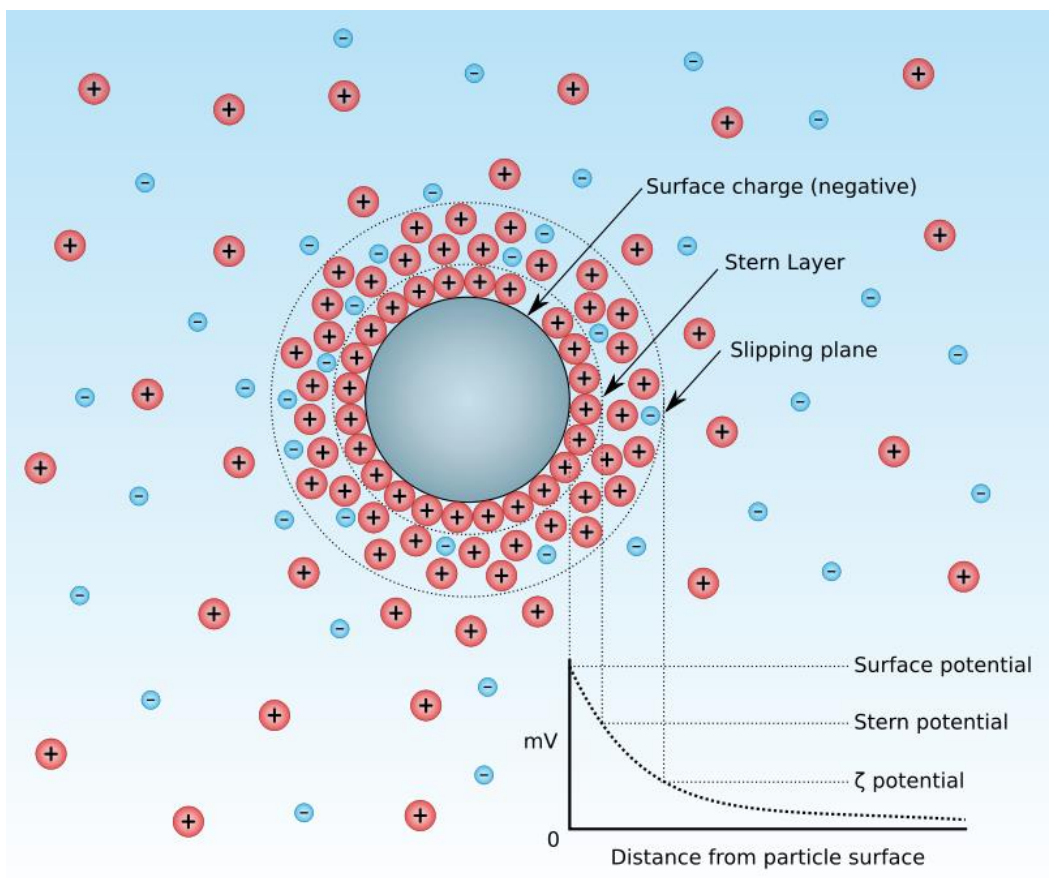

Fig.2.21 ${ }^{[102]}$ : Diagram shows the ionic concentration and potential difference as a function of distance from the charged surface of a particle suspended in a dispersion medium. 
The magnitude of the zeta potential shows the degree of electrostatic repulsion between adjacent, similarly charged particles in the suspension. When $\zeta$-potential is small, attractive forces may exceed the repulsion and particles agglomeration occurs. On the contrary, particles with high $\zeta$-potential (negative or positive) will repulse each other against coagulation or flocculation, which will lead to high particle packing density during deposition. Most people think the absolute value should be over $30 \mathrm{mV}$ to keep the suspension stable ${ }^{[91]}$, and it can be easily influenced by particle size, solvent, $\mathrm{pH}$ value, additives such as surfactant or conductive agent ${ }^{[103,104]}$.

\section{Processing parameters}

1) Deposition time

In most cases, the influence of deposition time on EPD can be divided into two stages. During the early time with a given constant voltage, the deposition yield has a linear relationship with the deposition time. The corresponding equation (Hamaker's Equation) is shown in Eq.2.12 [105].

$$
\frac{\mathrm{d} Y}{d t} \propto f \mu E C S
$$

where $\mathrm{Y}=$ yield, $\mathrm{t}=$ deposition time, $\mathrm{f}=$ deposition factor, $\mu=$ electrophoretic mobility, $\mathrm{E}=$ electric field strength, $\mathrm{C}=$ concentration, $\mathrm{S}=$ surface area.

As the increase of the deposition time, the deposition will gradually arrive at a saturation point with less increase. Fig.2.22 ${ }^{[106]}$ shows a typical example of $\mathrm{Al} / \mathrm{NiO}$ coating in the mixture of ethanol-acetylacetone (1:1 in volume) with the increasing deposition time. The linear relation between deposition mass with deposition time in short time and parabolic relation in prolonged time can be observed. Besides, the electric field in the suspension will decrease as the formation of a deposit layer on the electrode. 


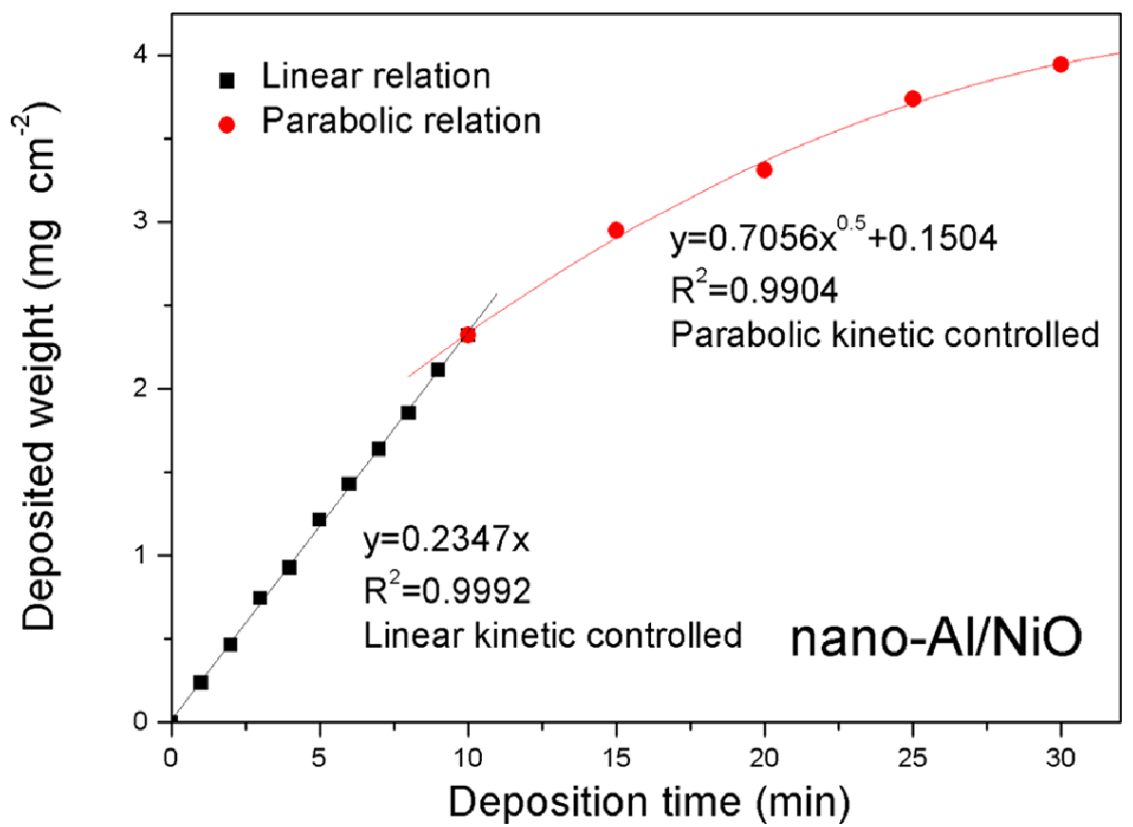

Fig.2.22 ${ }^{[106]}$ : Variation of deposition weight with time during EPD of Al/NiO in the mixture of ethanol-acetylacetone (1:1 in volume).

2) Applied voltage

Generally, for a given suspension system, both deposition rate and weight is proportional to the applied voltage ${ }^{[107]}$. And different suspension systems require different ranges of applied voltage.

a)

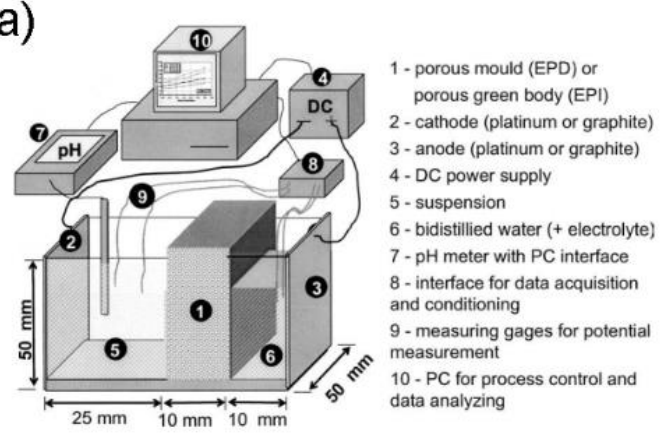

b)

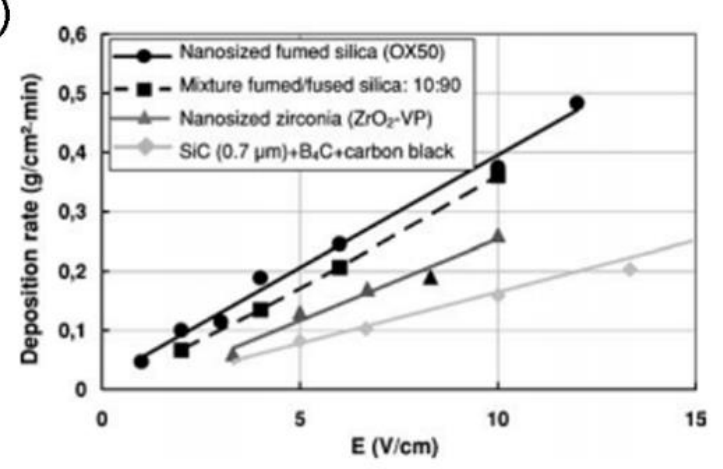

Fig. $2.23^{[108]}$ : a) Experimental set-up for the aqueous EPD process; b) deposition rate as function of the electric field strength for different materials (time: $3 \mathrm{~min}$ ).

In the aqueous suspension, the problem of water hydrolysis cannot be ignored. If the applied voltage is higher than hydrolysis voltage, oxygen and hydrogen gas will be generated around the electrode surface, leading to the formation of porous and inhomogeneous deposition layer. To solve this problem, some particular substrates or semi-permeable membranes have been 
introduced. For example, Tabellion J. et al ${ }^{[108]}$ deposited different particles (silica, $\mathrm{SiC}$, and zirconia) onto the 3D porous polymer moulds in the water (Fig.2.23a), and each particle shows the linear relationship between the deposition rate with the voltage (Fig.2.23b).

In the non-aqueous suspension, hydrolysis effect disappears and higher voltage can be used during EPD. For example ${ }^{[109]}$, in the isopropyl alcohol suspension, a dense carbon nanotubes film can be prepared onto the glass plates with ITO coating by EPD with the voltage range of $100-200 \mathrm{~V}$. However, too high voltage can bring bad effects on the quality of the deposit layer ${ }^{[91]}$. Firstly, too high voltage can cause the turbulence in the suspension to disturb the regular coating on the substrate; secondly, particles will move too fast towards the electrode to form a dense structure. 


\section{Chapter 3}

\section{RESEARCH OBJECTIVES}

Currently, carbonaceous materials, especially for the graphite, are dominant in LIB's anode market due to their stable charging/discharging platform, good cycle life and low costs. However, their capacity/energy density cannot meet the requirements of the next-generation LIB used in the electric vehicle and portable devices. The new anode materials with higher specific capacity are urgently needed.

Si has been considered as the most potential anode material because of the highest theoretical specific capacity and abundant reserves in the nature. Unluckily, huge volume effect and poor conductivity have mainly limited its practical application. To solve these problems, many methods have been developed, and various Si-containing anode materials with improved electrochemical properties have been prepared, as mentioned in Chapter2.3.

However, from the view of application, few Si-containing anode materials, which exhibit very high capacity $(>600 \mathrm{mAh} / \mathrm{g}$ ) and long cycle life (>100 cycles), can be promoted in industry because the (micro)-structure design is a priority in the lab work, not the cost of production or environmental issues. For example, most core-shell $\mathrm{Si} / \mathrm{C}$ structures and co-axial $\mathrm{Si} / \mathrm{C}$ structures have been prepared by CVD, which usually needs toxic $\mathrm{Si}$ source, the expensive equipment and complicated operation, meaning unreality in a short time in large-scale production. All the commercial composite anode materials consisting of $\mathrm{Si}$ and graphite have been prepared by ball milling method, which are greatly limited by the content of Si (no more than $10 \mathrm{wt} \%$ ) and hard to be improved further.

Based on the above, the choice of the preparation method is the first consideration in this thesis. Because of high-efficiency, simple operation and low cost, EPD is the only method to be used. Therefore, the objective of this thesis is preparing $\mathrm{Si} / \mathrm{C}$ composite anode materials with uniform morphology and improved electrochemical properties by multicomponent EPD.

This thesis mainly contains two parts as follow:

1) The first part demonstrates the feasibility of multicomponent EPD for Si/CNFs system. Based on the analysis of zeta potential and settling rate, the optimal $\mathrm{pH}$ value and concentration range for the (meta)stable Si/CNFs suspensions are obtained. Then, the 
composite films on the $\mathrm{Cu}$ foil with different ratio of $\mathrm{Si}$ to CNFs are prepared by EPD. The influences of applied voltage and deposition time on the film growth and the corresponding electrochemical properties are studied.

2) The second part describes the preparation of three kinds of Si/CNFs composite films with improved electrochemical properties by EPD. Some functional groups ( $\mathrm{Si}-\mathrm{OH}, \mathrm{Si}-\mathrm{NH}_{2}$ ) or carbon layer $(\mathrm{Si}-\mathrm{C})$ are introduced onto $\mathrm{Si}$ surface. Then, the suspension properties and EPD process for $\mathrm{Si}-\mathrm{OH} / \mathrm{CNFs}, \mathrm{Si}-\mathrm{NH}_{2} / \mathrm{CNFs}$ and $\mathrm{Si}-\mathrm{C} / \mathrm{CNFs}$ systems are investigated, respectively. The growth mechanisms and the reason for the improvement of electrochemical properties are discussed. 
Chapter 4

EXPERIMENTAL METHODS

\subsection{Materials and Equipment}

Table 4.1: Experimental materials and chemical reagents.

\begin{tabular}{|c|c|c|}
\hline Chemical reagents & $\begin{array}{c}\text { Reagent } \\
\text { specifications }\end{array}$ & Corporation \\
\hline Silicon nanoparticles (SiNPs) & $100 \mathrm{~nm}$ & Sigma - Aldrich \\
\hline Carbon nanofibers (CNFs) & $\begin{array}{c}\text { Graphitized, } \mathrm{D} \times \mathrm{L} \\
100 \mathrm{~nm} \times 20-200 \\
\mu \mathrm{m}\end{array}$ & Sigma - Aldrich \\
\hline Carbon black (CB) & Cell grade & MTI Corp. \\
\hline Hydrochloric acid $(\mathrm{HCl})$ & ACS reagent, $37 \%$ & Sigma - Aldrich \\
\hline Lithium hydroxide $(\mathrm{LiOH})$ & Anhydrous, $98 \%$ & Alfa Aesar \\
\hline Nitric acid $\left(\mathrm{HNO}_{3}\right)$ & ACS reagent, $70 \%$ & Sigma - Aldrich \\
\hline Sulfuric acid $\left(\mathrm{H}_{2} \mathrm{SO}_{4}\right)$ & $\begin{array}{l}\text { ACS reagent, } 95.0 \\
-98.0 \%\end{array}$ & Sigma - Aldrich \\
\hline Hydrogen peroxide $\left(\mathrm{H}_{2} \mathrm{O}_{2}\right)$ & $\begin{array}{c}\text { ACS reagent, } 30 \\
\text { wt. } \% \text { in } \mathrm{H}_{2} \mathrm{O}\end{array}$ & Sigma - Aldrich \\
\hline Hydrofluoric acid (HF) & 48 wt. $\%$ in $\mathrm{H}_{2} \mathrm{O}$ & Sigma - Aldrich \\
\hline Lithium (Li) & Cell grade & MTI Corp. \\
\hline Polyvinylidene Fluoride (PVDF) & Cell grade & MTI Corp. \\
\hline N-Methyl-2-pyrrolidinone (NMP) & ACS reagent & Sigma - Aldrich \\
\hline Sodium Dodecyl Sulfonate (SDS) & $\begin{array}{l}\text { ACS reagent, } \\
\geq 99.0 \%\end{array}$ & Sigma - Aldrich \\
\hline Triton X-100 (TX-100) & $\begin{array}{c}\text { For } \\
\text { electrophoresis }\end{array}$ & Sigma - Aldrich \\
\hline $\begin{array}{l}\text { Quaternary ammonium compound } \\
\qquad(\mathrm{QAC})\end{array}$ & ACS reagent & Sigma - Aldrich \\
\hline
\end{tabular}




\begin{tabular}{|c|c|c|}
\hline $\begin{array}{c}\text { LIB commercial electrolyte } \\
\left(\mathrm{LiPF}_{6} / \mathrm{EC}+\mathrm{DMC}\right)\end{array}$ & Cell grade & MTI Corp. \\
\hline $\begin{array}{c}\text { LIB separator } \\
(\text { Celgard } 2400)\end{array}$ & Cell grade & MTI Corp. \\
\hline Ethanol & $\begin{array}{c}\text { ACS reagent, } \\
\text { Anhydrous }\end{array}$ & Carolina Corp. \\
\hline Sucrose $\left(\mathrm{C}_{12} \mathrm{H}_{22} \mathrm{O}_{11}\right)$ & $\begin{array}{c}\text { ACS reagent, } \\
\geq 99.5 \%(\mathrm{GC})\end{array}$ & Sigma - Aldrich \\
\hline Lithium borate $\left(\mathrm{Li}_{2} \mathrm{~B}_{4} \mathrm{O}_{7}\right)$ & $99.997 \%$ & Alfa Aesar \\
\hline
\end{tabular}

Table2.2: Lab equipment

\begin{tabular}{|c|c|c|}
\hline Equipment & Model & Corporation \\
\hline Ultrasonic bath & $\begin{array}{c}\text { 3L Stainless Steel Cleaner, } \\
\text { Hot power: } 100 \mathrm{~W}, \\
\text { Ultrasonic power: } 120 \mathrm{~W}, \\
\text { Frequency: } 40 \mathrm{kHz}\end{array}$ & Spectralab Corp. \\
\hline Magnetic stirrer & PC-400D & Corning Corp. \\
\hline Ultra-precision balance & AXIS ALZ & CSG Corp. \\
& $\begin{array}{c}\text { Analytical balance } \\
200 \mathrm{~g} \times 0.01 \mathrm{mg}\end{array}$ & \\
\hline Arbin instrument & BT2143 32 channel & Arbin Corp. \\
\hline Electrochemical workstation & Autolab PGSTAT128N & Metrohm Corp. \\
\hline Glove box & $\mathrm{H}_{2} \mathrm{O}<0.5$ ppm & Self-made \\
& $\mathrm{O}_{2}<1$ ppm & TERPP Corp. \\
\hline Vacuum drying oven & Across International & MTI Corp. \\
\hline Tubular furnace & OTF-1200x-4-C4LVS & TDK-Lambda Corp. \\
\hline DC power supply & Genesys ${ }^{\mathrm{TM}} 600-1.3$ & \\
\hline
\end{tabular}




\subsection{Experimental method}

1) Anode materials and suspension preparation

See the following chapters for details.

Zeta potential is tested by Zetasizer Nano (Malvern Corp.).

2) EPD procedure

$\mathrm{Cu}$ foil $\left(1 \times 1,2 \times 2,4 \times 4 \mathrm{~cm}^{2}\right)$ and the stainless steel were used as the working electrode and the counter electrode, respectively. EPD was performed under potentiostatic conditions at applied voltage of up to $75 \mathrm{~V} / \mathrm{cm}$ and deposition times of up to $15 \mathrm{~min}$, as shown in Fig.4.1.

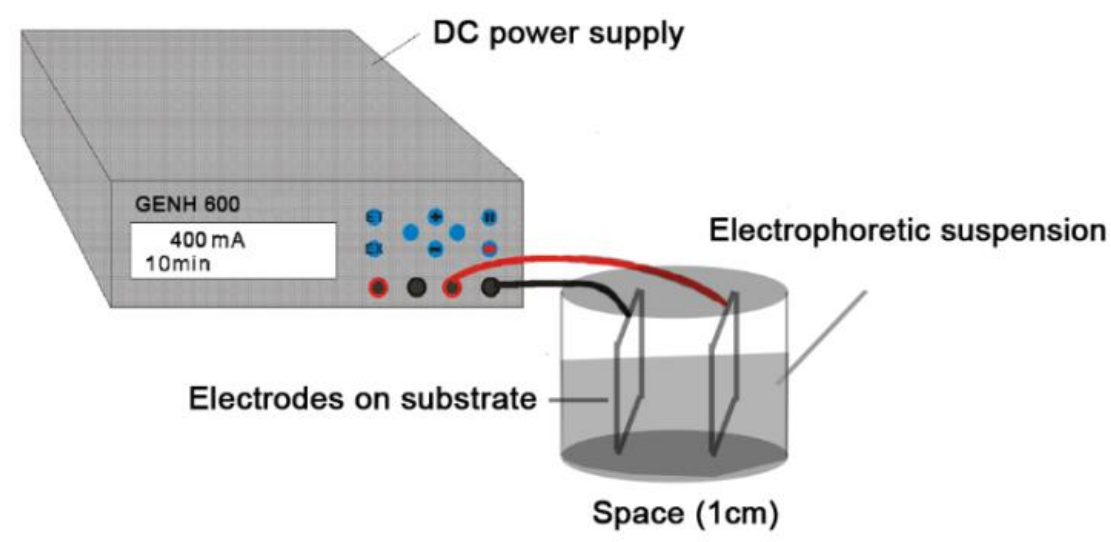

Fig.4.1: Diagram of EPD procedure

After the deposition, the $\mathrm{Cu}$ foil with the deposited layer was successively immersed into the diluted $\mathrm{HCl}$ and water several times to remove the impurities, and dried in Argon for $2 \mathrm{~h}$ at $150^{\circ} \mathrm{C}$.

3) Fabrication of coin cell batteries

Half cells were made using a small piece of as-prepared CNFs/Si film $\left(0.8 \times 0.8 \mathrm{~cm}^{2}\right)$ as the working electrode, lithium metal foil as the counter electrode, and Celgard 2400 as the separator. The liquid electrolyte was $1 \mathrm{M} \mathrm{LiPF}_{6}$ in ethylene carbonate / diethyl carbonate / dimethyl carbonate (1:1:1 volume ratio, 1\% VC). The cells (CR2032) were fabricated in an argon-filled glovebox (moisture and oxygen levels less than 1ppm), as shown in Fig.4.2.

4) Electrochemical measurement

Cell's cycling performance was tested with the voltage range of $3 \sim 0.05 \mathrm{~V}$ at different current rates of $400 \mathrm{~mA} / \mathrm{g}-1600 \mathrm{~mA} / \mathrm{g}$. The effective active materials consist of CNFs and $\mathrm{Si}$. 
During the test, $\mathrm{Li}+$ inserting into $\mathrm{Si} / \mathrm{CNF}$ s composite film is considered as the discharging process, and $\mathrm{Li}+$ extraction is charging process.

The cyclic voltammogram $(\mathrm{CV})$ were measured with the voltage range of $1.8 \sim 0.01 \mathrm{~V}$ at the scanning rate of $0.5 \mathrm{mV} / \mathrm{s}$.

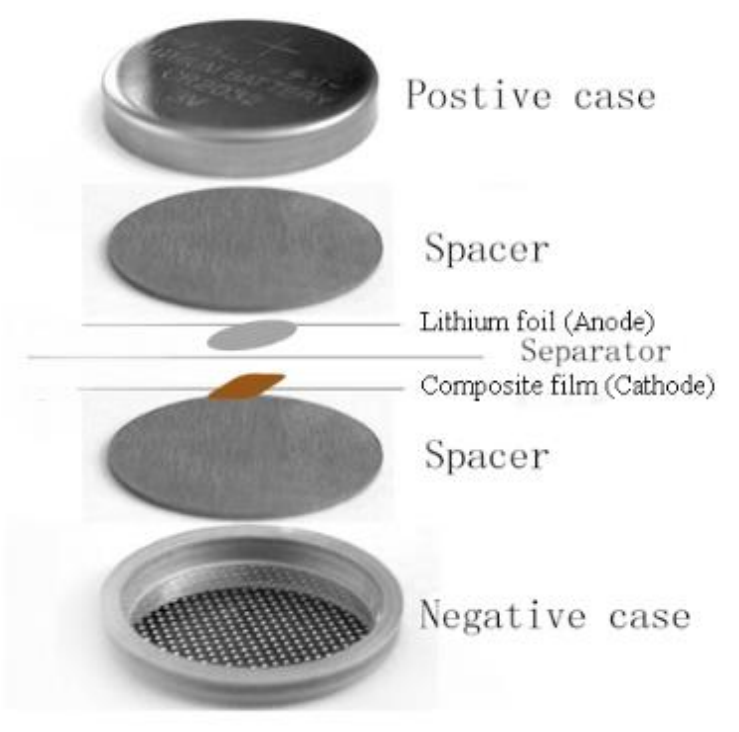

Fig.4.2: Diagram of the inner structure of a LIB coin cell.

\subsection{Material Characterization}

The film morphology was tested by scanning electron microscope (SEM, JSM-7600F, acceleration voltage: $5 \sim 10 \mathrm{~V}$ ) and transmission electron microscopy (TEM, JSM-2010).

The film component was tested by energy dispersive X-ray elemental analysis (EDX, JSM-7600F EDS system) and X-ray photoelectron spectroscopy (XPS, PHI VersaProbe 5000, Energy range: 0 - $1486.6 \mathrm{eV}$ Binding Energy with $\mathrm{Al} \mathrm{K} \alpha$ source).

The content of $\mathrm{Si}$ in the composite film was tested by thermogravimetric analysis (TGA, SDT Q600 v20.9 analyzer) in the air. The sample was scrapped off $\mathrm{Cu}$ foil by a knife, placed in an alumina pan, and heated from $20^{\circ} \mathrm{C}$ to $900^{\circ} \mathrm{C}$ with a heating rate of $10^{\circ} \mathrm{C} / \mathrm{min}$.

After cycling performance, some cells were disassembled in the glovebox and the working electrodes were washed by $\mathrm{N}$-methyl-pyrrolidone (NMP), diluted $\mathrm{HCl}$ and ethanol, and dried at $80^{\circ} \mathrm{C}$ in the vacuum oven before they were observed by SEM. 
Chapter 5

\section{MULTI-COMPONENT EPD OF Si/CNFs COMPOSITION ANODE FOR LIB}

\subsection{Introduction}

Currently, graphite is the most widely used anode material in the commercial LIBs. However, the low theoretical specific capacity $(372 \mathrm{mAh} / \mathrm{g})$ cannot meet the demands on higher energy density for future portable electronic devices and electric vehicles. As a potential replacement, silicon has been attracting more attention due to its large theoretical specific capacity (up to $4200 \mathrm{mAh} / \mathrm{g}$ ) and low costs. To make Si anode practical, two main problems need to be solved: huge volume change $(\sim 300 \%)$ during $\mathrm{Li}^{+}$insertion/extraction and low conductivity. One popular method is to fabricate the composite anode consisting of Si and carbonaceous materials. Because of good toughness, high electronic conductivity and high $\mathrm{Li}^{+}$ conductivity, carbonaceous materials cannot only improve the anode conductivity, but also inhibit the volume change of Si and particle aggregation during cycles, which finally improves the electrochemical properties of Si-based anode.

Compared with the traditional preparation methods of Si/C anode (Chapter2.3), EPD has been attracting increasing interest as a versatile, efficient and economical technique for the largescale preparation of coatings or films of ceramics, oxides and carbonaceous materials on conductive substrates ${ }^{[91]}$. It can be applied to any particles with small sizes $(<30 \mu \mathrm{m})$ in suspensions with relatively low solids loading. Generally, the deposition occurs on the surface of conductive substrate, but these days some researches have used porous non-conductive substrates to achieve a successful EPD process via infiltration/adsorption.

The factors that influence the quality of the film by EPD can be divided into two groups. One has focused on the physical properties of the particle and suspension, such as the total concentration, conductivity and $\mathrm{pH}$ value. These factors are usually interacting and influencing each other, which finally decide the size of the electric double layer of particles and the stability of the suspension. Zeta potential is chosen to reflect the combined influence of these factors. 
Besides, the settling rate can be used as a supplement from a macro view. Another group has been concerned with the dynamic parameters of EPD procedure, such as the applied voltage and deposition time.

Till now, many people have used EPD technique to fabricate CNTs ${ }^{[110]} / \mathrm{CNFs}$-containing

${ }^{[111,112]}$ or $\mathrm{SiO}_{2}$-containing structures ${ }^{[113,114]}$. However, few reports on EPD for Si-containing structures have been published.

Compared with the single-component EPD, the multi-component EPD is more complicated. On the one hand, each component has its own surface charge and mobility rate under a given condition; on the other hand, the interaction between different components may influence their original behavior during EPD process. Therefore, it's very difficult to obtain a homogeneous composite film by multi-component EPD.

In this section, a uniform $\mathrm{CNF}$ /Si composite film without binder was prepared by multicomponent EPD, which exhibits improved electrochemical properties. The influences of $\mathrm{pH}$ value, solvent, concentration, applied voltage and deposition time on the deposit film were studied and the dynamics model was built.

\subsection{Structural design and experiment}

\subsubsection{Structural design}

Carbon nanofibers (CNFs) and commercial Si nanoparticles (SiNPs) were chose as the raw materials. For the composite anode, a continuous conductive framework and well distribution of SiNPs is necessary for the improvement of electrochemical properties. During the charging/discharging process, the physical contact between Si and CNF should be maintained to make ion/electron-transfer fluent; meanwhile, the interspace of CNFs net can alleviate the impact of the volume change of SiNPs.

Therefore, two objectives would be achieved in this section.

Firstly, the feasibility of multi-component EPD for CNFs/Si system would be verified. There are at least two requirements. 1) The CNFs/Si suspensions with a large range of the concentration can keep stable or metastable; 2) the operation should be as simple and efficient as possible, especially in comparison with other traditional ways like CVD or ball milling.

Secondly, a series of composite anodes would be prepared by EPD, which has a target structure like this (Fig.5.1): a 3D-conductive net consisting of CNFs is formed directly on the $\mathrm{Cu}$ foil and SiNPs are randomly distributed in it. Such structure has some features: 1) the conductive 
net is intact and has a strong adhesive force with $\mathrm{Cu}$ foil without any binder; 2) no serious SiNPs aggregation happens; 3) the weight ratio of Si to CNFs and total loading can be adjusted simply, and in a specific range, the composite films can exhibit good electrochemical properties (long cycle life and high capacity).

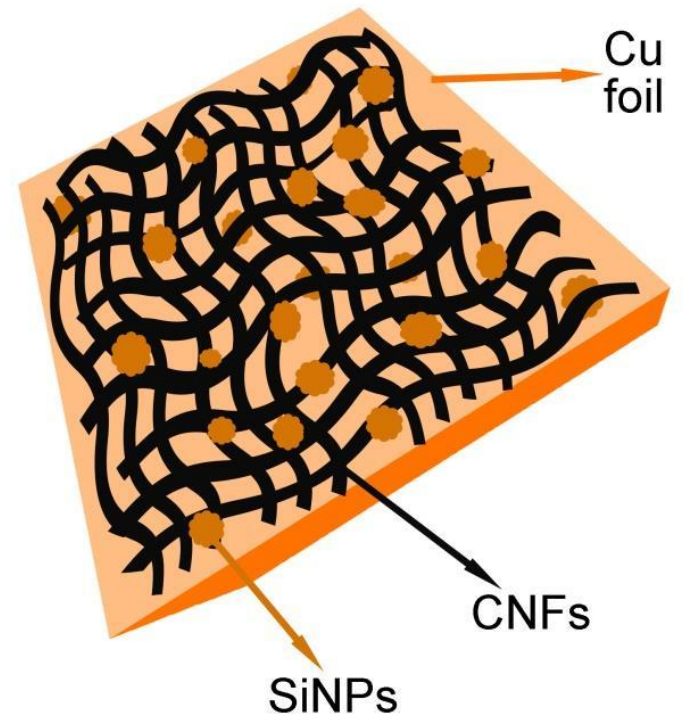

Fig.5.1: Structure diagram of CNFs/Si anode by multi-component EPD.

\subsubsection{Experiment}

The steps are listed as follow.

1) Carboxylation of CNFs. CNFs were refluxed in the mixture of concentrated nitric and sulfuric acids $\left(\mathrm{V}_{\mathrm{H} 2 \mathrm{SO} 4}: \mathrm{V}_{\mathrm{HCl}}=1: 2\right)$ for $3 \mathrm{~h}$ at $80^{\circ} \mathrm{C}$. After acid purification, CNFs were washed to neutral by deionized water and dried in air for $3 \mathrm{~h}$ at $100^{\circ} \mathrm{C}$.

2) Preparation of suspensions. The mixture of CNFs/Si with different weight ratios were dispersed into $50 \mathrm{~mL}$ ethanol followed by ultrasonication for $2 \mathrm{~h}$. $\mathrm{LiOH}$ and $\mathrm{HCl}$ were used to adjust the corresponding $\mathrm{pH}$ value of $1 \sim 11$.

3) Zeta potential measurement and EPD procedures. See Chapter4.

\subsection{Single-component EPD}

\subsubsection{Carboxylation of CNFs}

Carbon nanofibers (CNFs), consisting of curled-up graphite sheets, have been widely used in many fields such as hydrogen storage, secondary battery and medical equipment due to the light weight, high flexibility and intensity, excellent thermal conductivity and electrical 
conductivity ${ }^{[115,116]}$. However, CNFs are often entangled or aggregated, and have some defects and impurities such as the catalytic metal particles. To overcome the disadvantages, an effective way - chemical modification/purification - has been developed. A typical path is using acid reflux to oxidize the surface defects, shorten the fiber length and remove the impurities ${ }^{[117]}$, as shown in Fig.5.2. Three commonly used acid solutions ${ }^{[116]}$ are $\mathrm{HNO}_{3}, \mathrm{H}_{2} \mathrm{SO}_{4} / \mathrm{HNO}_{3}$ and $\mathrm{H}_{2} \mathrm{SO}_{4} / \mathrm{H}_{2} \mathrm{O}_{2}$. As a result, the carboxyl groups (-COOH) are introduced onto CNFs surface, leading to better dispersion in the polar solution. Because of high requirement on the suspension stability during EPD, surface modification of the pristine CNFs (p-CNFs) is necessary.

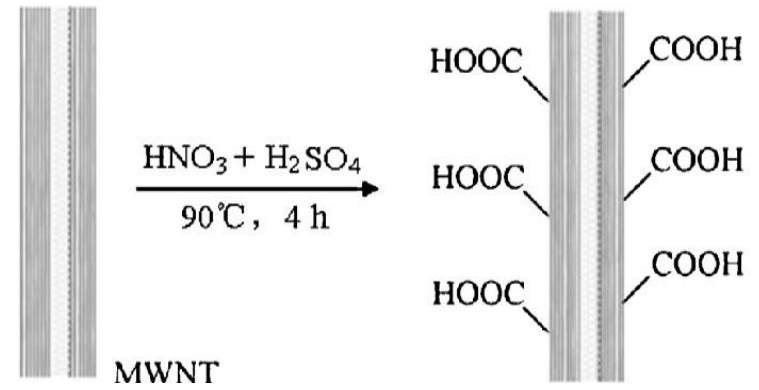

Fig.5.2 ${ }^{[117]}$ : Surface modification of CNFs in the acid solution

Different treatment conditions result in different degrees of modification, which can be quantitatively analyzed by the amount of $-\mathrm{COOH}$ groups on the surface.

As shown in Fig5.3a, p-CNFs have smooth surface with the length of tens of micrometers and diameter of $\sim 200 \mathrm{~nm}$. After acid treatment, the size is generally maintained but the surface becomes rough (Fig.5.3b). Some CNFs with opening-end can be also observed (inset Fig.5.3b), which is a typical characteristic of acid-treated CNFs.

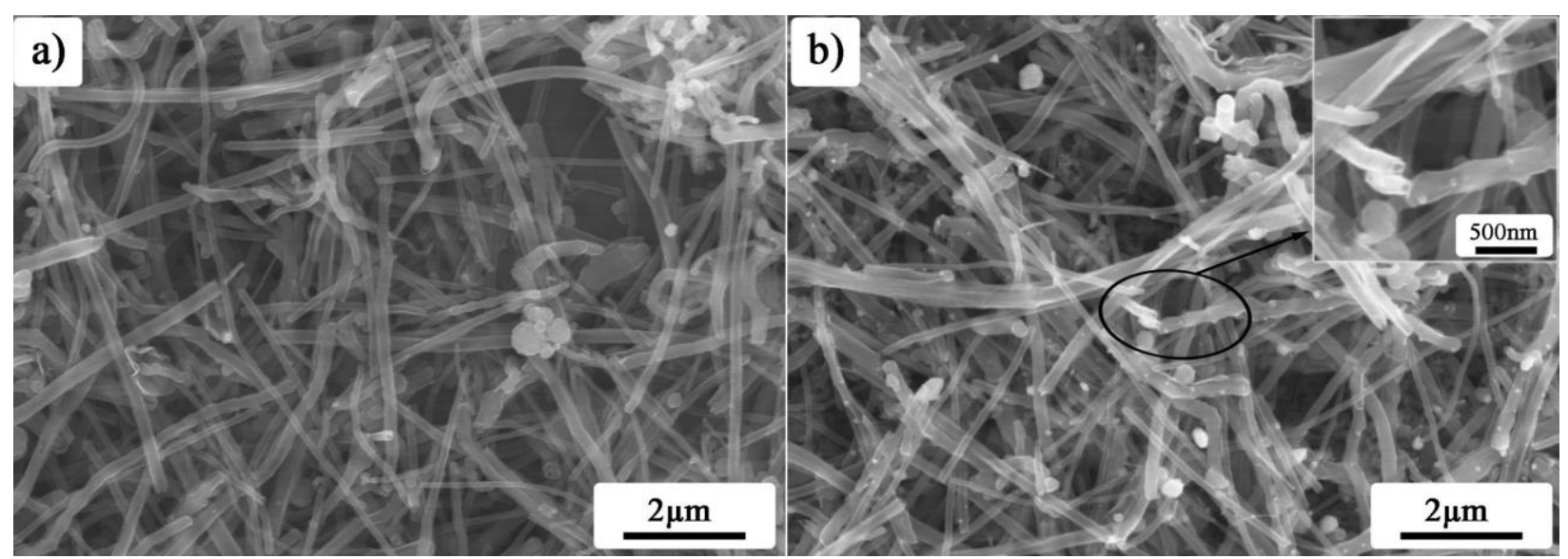

Fig. 5.3: SEM images of a) p-CNFs and b) pretreated CNFs in the mixed acid. 
Fig5.4 shows thermogravimetric curves of different CNFs, which can be divided into three parts: dehydration area due to the release of surface moisture $\left(0-100^{\circ} \mathrm{C}\right)$, reaction area due to the degradation of $-\mathrm{COOH}$ groups $\left(100-750^{\circ} \mathrm{C}\right)$, and stable area $\left(>750^{\circ} \mathrm{C}\right)$. The specific weight-loss ratios of each sample are listed in Table5.1. It's noticed that c-CNFs only have a small number of $-\mathrm{COOH}$ groups $(2.34 \%)$, and the content of carboxyl group will be increased to $6.79 \%$ after $2 \mathrm{~h}$ acid treatment.

Table5.1: Losing mass of CNFs with different acid treatment time.

\begin{tabular}{|c|c|c|c|}
\hline Sample & $\begin{array}{c}\text { Losing weight in } \\
100^{\circ} \mathrm{C} w \mathrm{wt} / \%\end{array}$ & $\begin{array}{c}\text { Losing weight in } \\
750^{\circ} \mathrm{C} \text { wt } / \%\end{array}$ & $\begin{array}{c}\text {-COOH content } \\
\text { (molar ratio) } \mathrm{x} / \%\end{array}$ \\
\hline c-CNFs & 3.4 & 11.1 & 2.34 \\
\hline CNFs-COOH $(0.5 \mathrm{~h})$ & 5.1 & 17.7 & 3.92 \\
\hline CNFs-COOH $(2 \mathrm{~h})$ & 4.5 & 25.0 & 6.79 \\
\hline
\end{tabular}

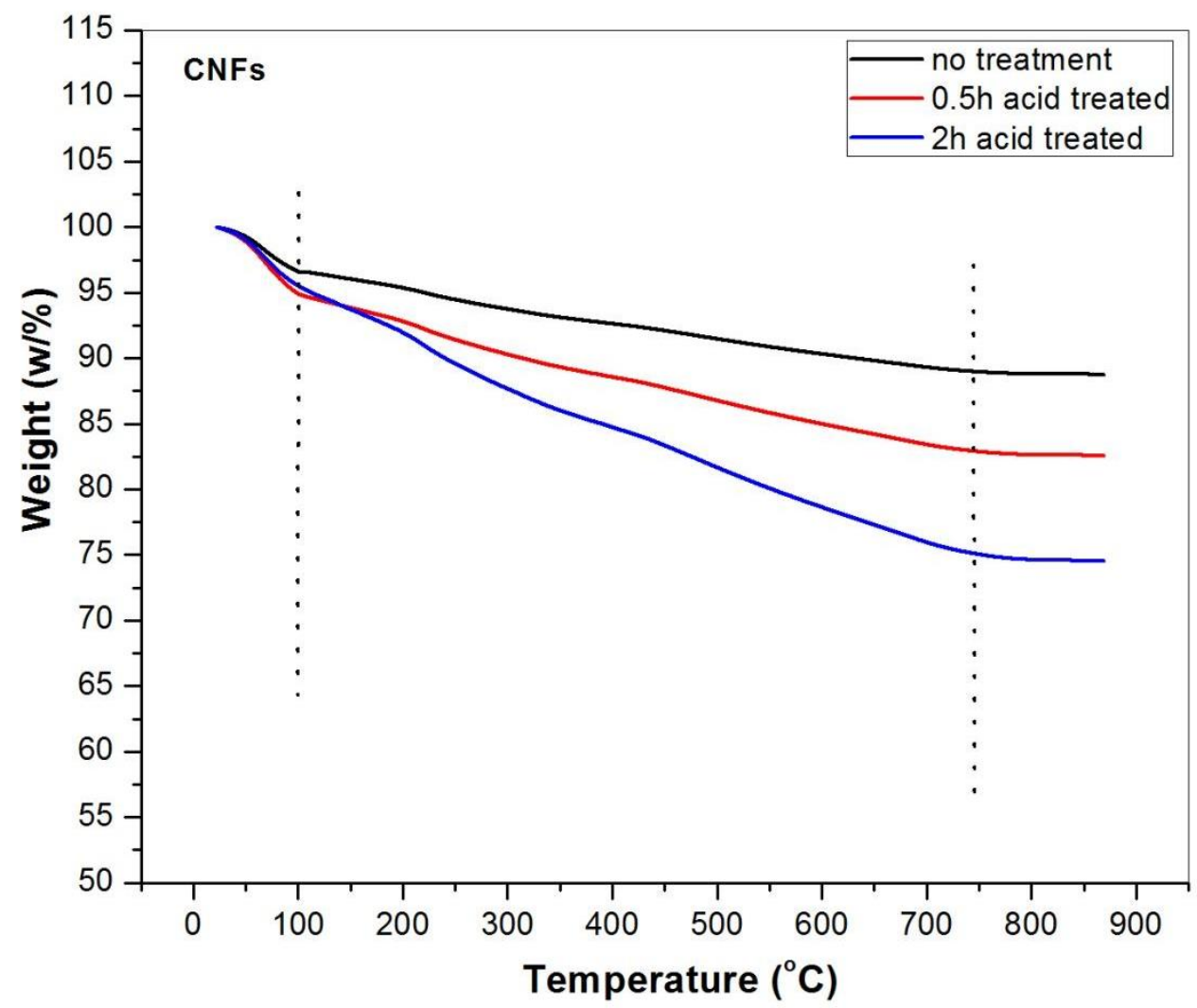

Fig5.4: Thermogravimetric curves of a) p-CNFs, b) CNFs treated by mixed acid refluxing (0.5h), c) CNFs treated by mixed acid refluxing (2h). 
Fig5.5 shows FTIR spectra of different CNFs, and the specific band assignments are listed in Table5.2.

Table5.2: Assignment of infrared absorptions for pure and acid-treated CNFs.

\begin{tabular}{|c|c|c|}
\hline Assignment & $\begin{array}{c}\text { Wavenumber } \\
\text { (literature) }{ }^{[118,119]} \\
\left(\mathrm{cm}^{-1}\right)\end{array}$ & $\begin{array}{c}\text { Wavenumber } \\
\text { (experiment) } \\
\left(\mathrm{cm}^{-1}\right)\end{array}$ \\
\hline absorbed water & 3450 & 3400 \\
\hline $\begin{array}{c}\mathrm{C}=\mathrm{O} \text { stretching carbonyl \& } \\
\text { carboxy }\end{array}$ & $1725-1714$ & 1720 \\
\hline $\mathrm{O}-\mathrm{H}$ bending & $1600-1630$ & 1630 \\
\hline $\mathrm{C}-\mathrm{C}$ vibrating & $1520-1530$ & 1530 \\
\hline $\begin{array}{l}\text { C-C stretching } \\
\text { C-O stretching }\end{array}$ & $1217-1188$ & 1200 \\
\hline $\begin{array}{l}\text { Isolated aromatic C-H out- } \\
\text { of-plane bending }\end{array}$ & $882-872$ & 810 \\
\hline
\end{tabular}

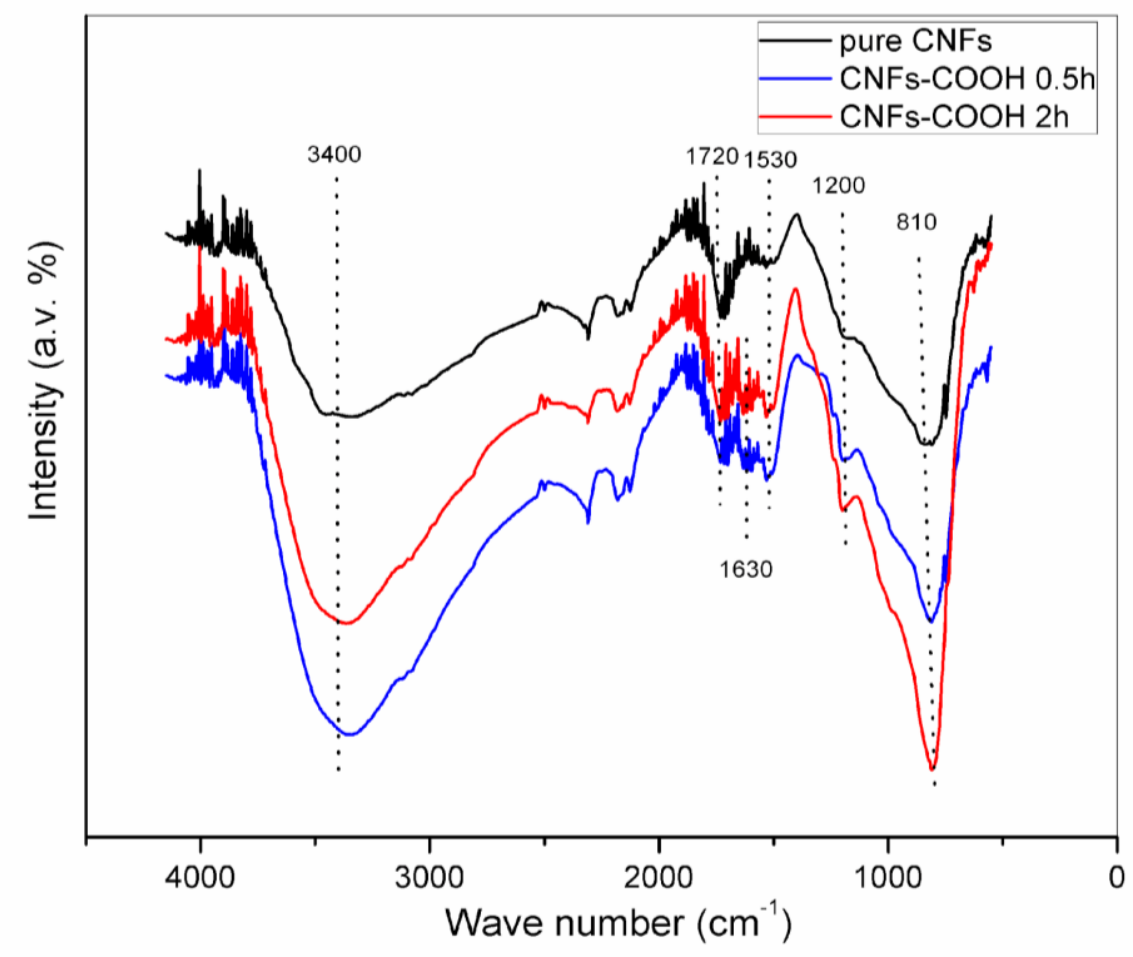

Fig.5.5: FTIR spectra of CNFs with or without surface modification 
For c-CNFs, the absorption at $3400 \mathrm{~cm}^{-1}$ are due to surface moisture and the peak at 1530 $\mathrm{cm}^{-1}$ can be assigned to the C-C skeleton vibration. Because of the existence of a little carboxyl groups, the absorptions at 1720 and $1200 \mathrm{~cm}^{-1}$ is observed, which are attributed to the $\mathrm{C}=\mathrm{O}$ stretching vibration and $\mathrm{C}-\mathrm{O}$ stretching vibration, respectively. After acid treatment, more carboxyl groups are introduced on the surface, the intensity of peak at $1630 \mathrm{~cm}^{-1}$ is enhanced, which is attributed to the $\mathrm{O}-\mathrm{H}$ bending vibration.

\subsubsection{EPD of CNFs}

\section{1) Zeta potential}

In a given solution, a charged particle can attract or repel the free ions to achieve the redistribution of free ions around the particle surface, leading to the formation of the electric double layer (EDL).

Based on the Gouy-Champan model ${ }^{[120]}$, the Debye length $\left(\kappa^{-1}\right)$, representing a distance from the charged surface to a point where the potential decreases to $33 \%$ of the surface potential, has been used to estimate the thickness of the electric double layer although it's actually smaller than the latter. $\kappa^{-1}$ can be expressed by Eq.5.1.

$$
\kappa^{-1}=\left(\frac{k_{B} T}{2 e^{2} z^{2} n_{\infty}}\right)^{1 / 2}
$$

where:

$\varepsilon=$ the dielectric permittivity of the solvent;

$\mathrm{k}_{\mathrm{B}}=$ the Boltzmann constant;

$\mathrm{T}=$ Kelvin temperature;

$\mathrm{e}=$ the electron charge;

$\mathrm{z}=$ the valence of the ions;

$\mathrm{n}_{\infty}=$ the bulk concentration of the ions;

Therefore, $\kappa^{-1}$ will be decreased as the increase of the concentration/valence of free ions if other physical parameters are fixed, and generally, $\kappa^{-1}$ is lower than $10 \mathrm{~nm}$ when the electrolyte concentration is low $(<0.1 \mathrm{M})$.

The potential distribution in the spherical EDL can be described by the Stern model and the Debye-Huckel Approximation ${ }^{[121]}$, as shown in Fig.5.6. If the particle radius (a) is much larger than $\left.\kappa^{-1}(\kappa \mathrm{a}\rangle 1\right)$, the potential distribution $(\psi)$ in the radial direction can be given by Eq.5.2. 


$$
\psi=\psi_{\mathrm{d}} \exp (-\kappa x)
$$

where:

$\psi_{\mathrm{d}}=$ the Stern plane potential;

$\mathrm{x}=$ the distance to the particle surface;

Therefore, as the decrease of $\kappa^{-1}, \psi$ will be also decreased.

(a)

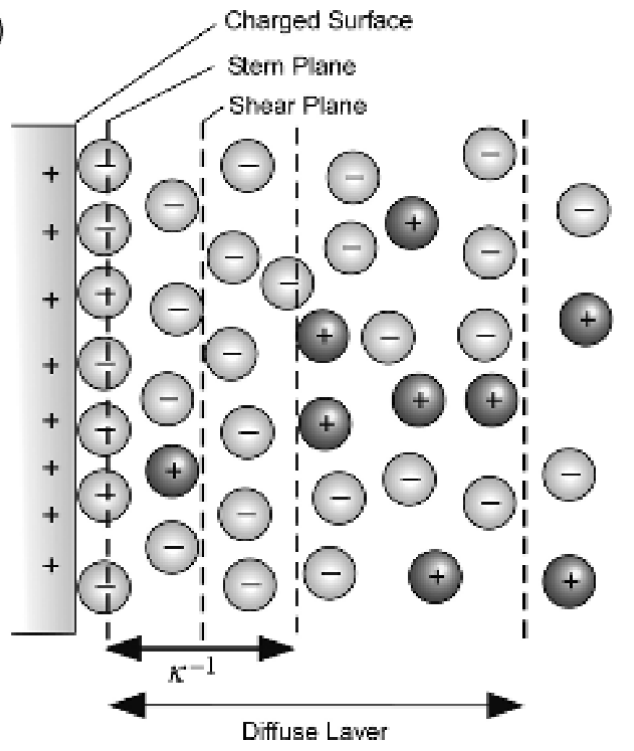

(b)

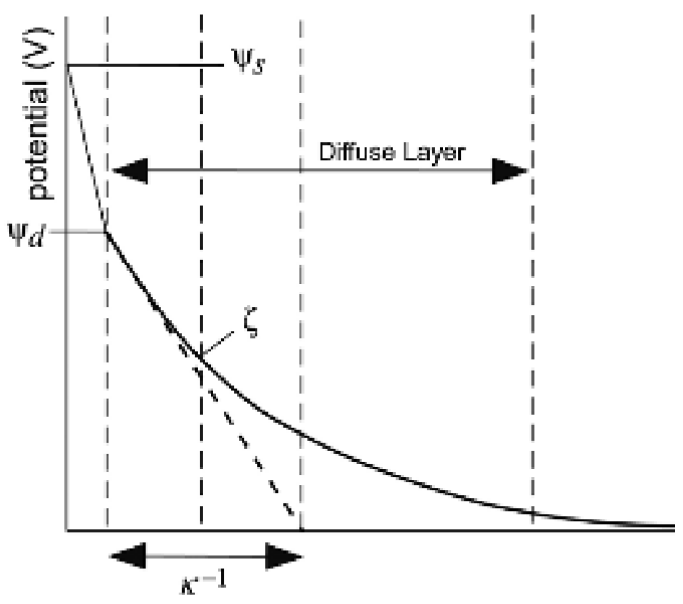

Fig.5.6 ${ }^{[121]}$ : a) diagram of the EDL according to the Stern model; b) diagram of the electric potential profile. The diffuse double layer starts from the Stern plane.

Combining with Eq.5.1 and Eq.5.2, $\psi$, including zeta potential, is mainly influenced by the free ions' concentration and valence in a given solution at room temperature. To obtain the relatively high zeta potential, the basic idea is to use low-valence ions as the electrolyte/pH modifier and keep the concentration of additives low. Therefore, in this chapter, $\mathrm{HCl}$ solution and $\mathrm{LiOH}$ is chose.

In ethanol, as shown in Fig5.7, the pristine CNFs (p-CNFs) show low stability with the maximum zeta potential values of $21 \mathrm{mV}$ at $\mathrm{pH} 0.25$ and $-18 \mathrm{mV}$ at $\mathrm{pH} 11$. The related I.E.P. value is about 5.5. After surface modification, $-\mathrm{COOH}$ groups are introduced, leading to the smaller I.E.P. and better stability due to the improved electrostatic repulsive force on CNFs surface. Two modified samples display a similar trend of $\mathrm{pH}$ effect on zeta potential, and more $\mathrm{COOH}$ groups lead to a more negative zeta potential value in the range of $\mathrm{pH} 7 \sim 11$.

Fig.5.8 shows the influence of solvents on zeta potential of CNFs-COOH (7\%). Except for ethanol, three representative solvents was chose and the related physical parameters are listed 
in Table5.3. Because CNFs concentration is very small $(1 \mathrm{mg} / \mathrm{mL})$, the influence of absolute viscosity can be ignored.

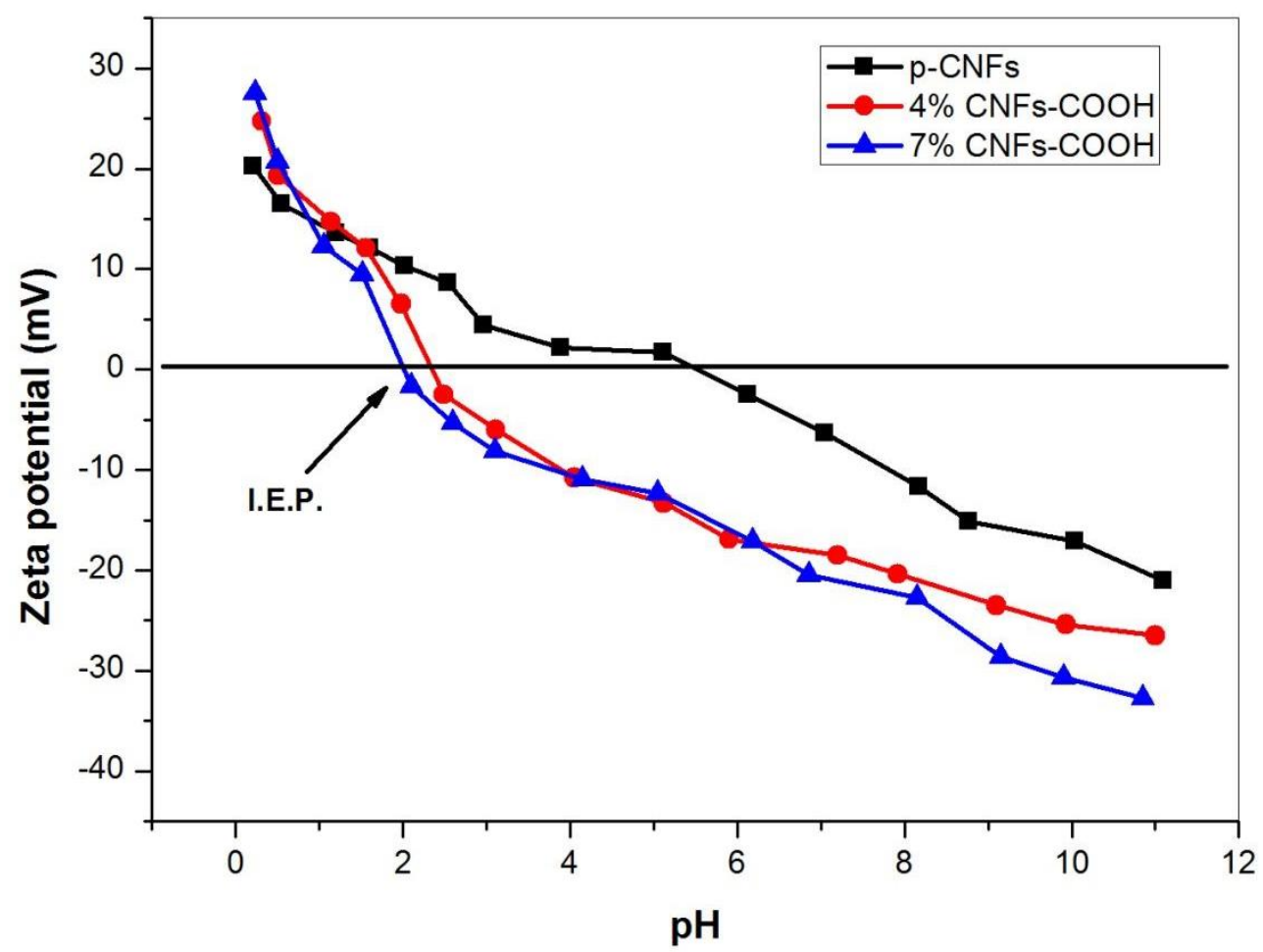

Fig5.7: Behavior of zeta potential of different CNFs-COOH at $\mathrm{pH}$ value of $0.5 \sim 11$. Table5.3: Physical parameters of solvents

\begin{tabular}{|c|c|c|c|}
\hline Solvent & $\begin{array}{c}\text { Dielectric } \\
\text { constant }\end{array}$ & $\begin{array}{c}\text { Absolute } \\
\text { Viscosity } \\
\left(@ 25^{\circ} \mathrm{C} \mathrm{cP}\right)\end{array}$ & $\begin{array}{c}\text { Electrical } \\
\text { conductivity } \\
(\mathrm{S} / \mathrm{cm})\end{array}$ \\
\hline Distilled Water & 79.7 & 0.89 & $10^{-6}$ \\
\hline Acetone & 20.7 & 0.33 & $5.0 \times 10^{-9}$ \\
\hline $\begin{array}{c}\text { N,N - Dimethylformamide } \\
\text { (DMF) }\end{array}$ & 36.7 & 0.82 & $6.0 \times 10^{-8}$ \\
\hline Ethanol (control group) & 22.4 & 1.08 & $1.4 \times 10^{-9}$ \\
\hline
\end{tabular}

Compared with ethanol, acetone has a little higher electrical conductivity but lower dielectric constant. With these two changes together, the electric double layer of CNFs is influenced little. As shown in Fig.5.8, the particle's surface charge in acetone is similar to that in 
ethanol, still leading to a metastable state in the range of $\mathrm{pH} 8 \sim 11$ and $\mathrm{pH} 0.25 \sim 0.5$. But in DMF, the suspension stability is decreased because DMF has much higher dielectric constant and electrical conductivity, making the EDL of CNFs thinner. If using water as the solvent, a stable suspension with high zeta potential (the absolute value $>35 \mathrm{mV}$ ) in the range of $\mathrm{pH} 7 \sim 11$ can be obtained, and the I.E.P. is decreased to 1.2.

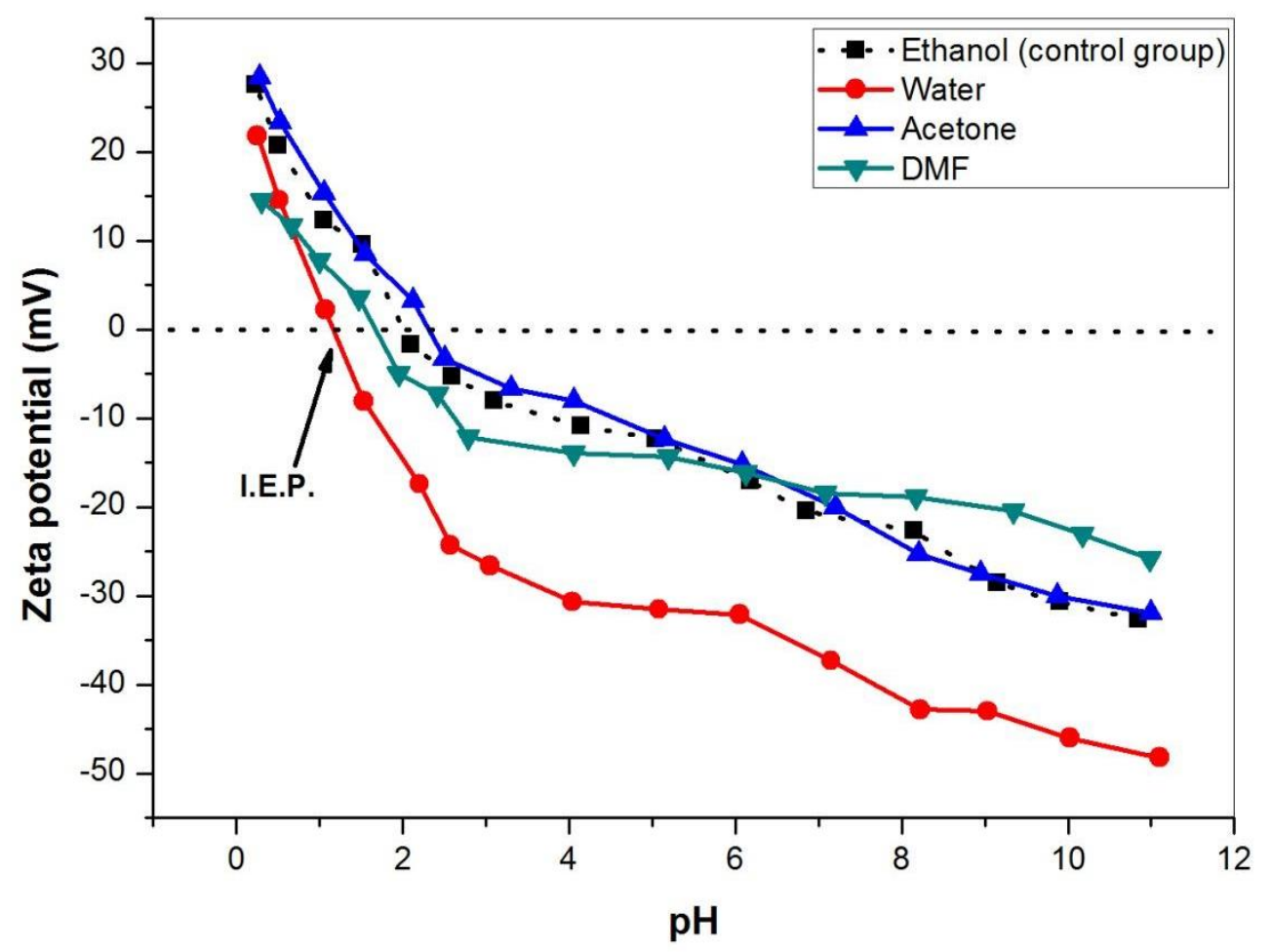

Fig.5.8: Zeta potential profiles of CNFs-COOH (7\%) in different solvents.

Fig.5.9 shows the behavior of the zeta potential of CNFs-COOH (7\%) with different concentrations in ethanol. It's noticed that both of the I.E.P. and the global stability (maximum absolute value of zeta potential) are influenced little by the concentration. But the $\mathrm{pH}$ range for the stable/metastable suspensions is changed. Below I.E.P., the suspensions with the concentration of $0.5,1$ and $2 \mathrm{mg} / \mathrm{mL}$ have the best stability at $\mathrm{pH} 0.3,0.9$ and 1.4 , respectively. The proper $\mathrm{pH}$ ranges over I.E.P. for a stable/metastable system with the concentration of $0.5,1$ and $2 \mathrm{mg} / \mathrm{mL}$ are $\mathrm{pH}$ 9 11, pH 7 11 and $\mathrm{pH}$ 5 10, respectively. 


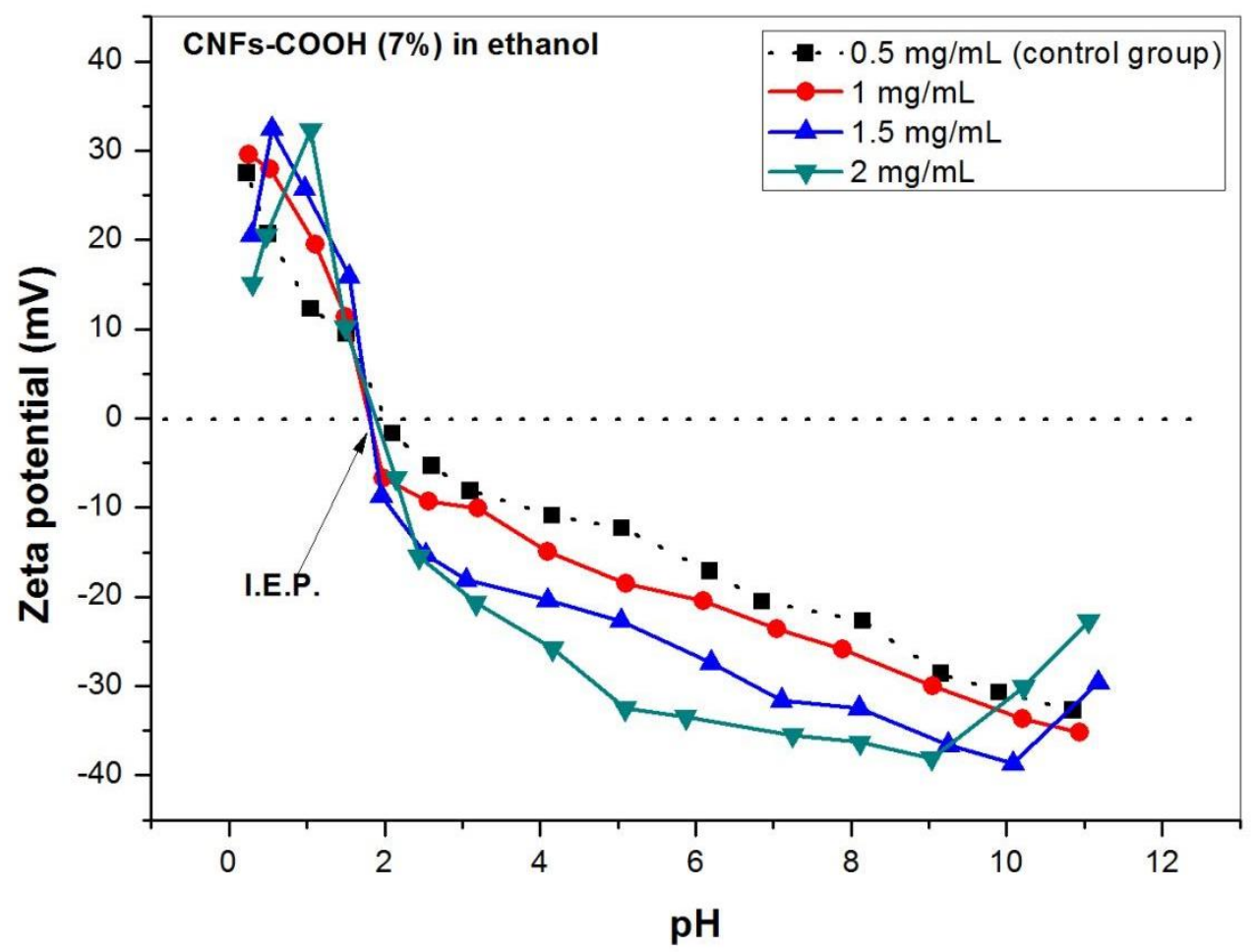

Fig.5.9: Zeta potential profiles of CNFs-COOH (7\%) with different concentrations

2) Settling rate

Settling rate cannot only represent the stability of the suspension, but also decide the uniformity of the final deposited layer, especially along the gravity direction. Generally, a suspension for EPD can be divided into three zones: homogeneous zone, settlement zone and supernatant zone. The evolution is shown in Fig.5.10. In the beginning, a homogenous suspension is prepared with the help of magnetic stirring or ultrasonic dispersion (Fig.5.10a). If the suspension is stable (|zeta potential| $>35 \mathrm{mV}$ ), the homogeneous zone is still dominant after a while of standing. At the same time, a small settlement zone at the bottom and a small supernatant zone on the top are observed. This state can be maintained for a long time (Fig.5.10b). If the suspension is not stable enough $(15 \mathrm{mV}<\mid$ zeta potential $\mid<35 \mathrm{mV})$, the homogeneous zone continually decreases in short-time standing, while the supernatant zone increases (Fig.5.10c). If the suspension is unstable (|zeta potential| $<15 \mathrm{mV}$ ), the homogeneous zone will finally disappear, and there are only settlement zone and supernatant zone left.

In a stable suspension with low solid concentration, the sedimentation process will compete with the electrophoretic mobility during EPD. 


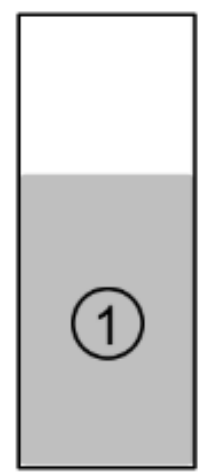

(a) $t=0$

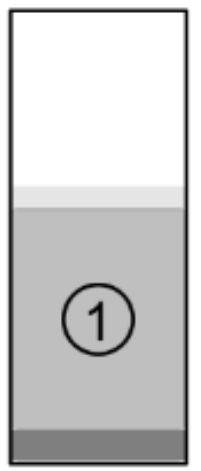

(b) $\mathrm{t}=0.5 \mathrm{t}_{0}$

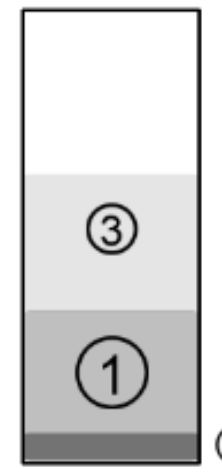

(c) $\mathrm{t}=\mathrm{t}_{0}$

1: homogeneous zone

2: settlement zone

3: supernatant zone

Fig.5.10: Diagram of the suspension evolution.

The settling rate $\left(\mathrm{V}_{\mathrm{s}}\right)$ can be expressed by the Stokes law ${ }^{[122]}$, as shown in Eq.5.3.

$$
\mathrm{V}_{\mathrm{s}}=\frac{2 \Delta \rho \mathrm{gr}^{2}}{9 \eta}
$$

where:

$\Delta \rho=$ the difference of density between the settled layer and the homogenous suspension;

$\mathrm{R}=$ the particle's diameter;

$\eta=$ viscosity of the solvent;

And the electrophoretic mobility $\left(\mu_{\mathrm{e}}\right)$ is related to the zeta potential by the Henry Equation ${ }^{[123]}$ (Eq.5.4).

$$
\mu_{\mathrm{e}}=\frac{2 \varepsilon \zeta \cdot \mathrm{f}(\kappa \cdot \mathrm{a})}{3 \eta}
$$

where:

$\varepsilon=$ the dielectric constant of the solvent

$\xi=$ zeta potential 
$\eta=$ viscosity of the solvent;

$\mathrm{f}(\kappa \cdot \mathrm{a})=$ Henry's function, $\kappa^{-1}=$ the Debye length, $\mathrm{a}=$ the particle radius, if $\kappa \mathrm{a}>>1, \mathrm{f}(\kappa \cdot \mathrm{a})=1.5$

(Smoluchowski approximation) ${ }^{[124]}$

Combining with Eq.5.3 and 5.4, Eq.5.5 can be obtained:

$$
\frac{V_{\mathrm{s}}}{\mu_{e}}=\frac{\Delta \rho g r^{2}}{3 \varepsilon \cdot \mathrm{f}(\kappa \cdot \mathrm{a})} \varsigma^{-1}
$$

From Eq.5.5, it's noticed that the settling rate is inversely proportional to the zeta potential.

It's difficult to measure the immediate settling rate in my lab; therefore, another parameter related with the settling rate is used to characterize the degree of stability: the relative sediment height (RSH), which can be expressed by Eq.5.6.

$$
\operatorname{RSH}(\%)=\frac{\text { Sediment Height }(\mathrm{mm})}{\text { Total Suspension Height }(\mathrm{mm})} \times \%
$$

\section{6}

Generally, smaller RSH for a given stable suspension means better stability.

Error always exists when calculating RSH because the boundary between homogeneous zone and settlement zone is not very clear. Therefore, the relative dynamic concentration $\left(\mathrm{C}_{\mathrm{rd}}\right)$ of homogeneous zone is used to decrease the errors. By using syringes, $5-10 \mathrm{~mL}$ suspension is extracted from the middle of homogeneous zone. After slowly drying in the vacuum oven, the remnants are weighed by the ultrahigh precision balance and $C_{r d}$ is calculated by Eq.5.7.

$$
\mathrm{C}_{\mathrm{rd}}(\%)=\frac{\text { Instant Concentration }}{\text { Initial Concentration }} \times \%
$$

For an unstable system, it makes no sense to calculate $\mathrm{RSH}$ or $\mathrm{C}_{\mathrm{rd}}$ because no one will use an unstable suspension to conduct EPD process.

For a metastable system, $\mathrm{RSH} / \mathrm{C}_{\mathrm{rd}}$ analysis depends on the situation.

Based on the zeta potential results in Part5.3.2, some $\mathrm{pH}$ values are chose for preparing metastable/stable CNFs-COOH (7\%) suspensions with the concentration of $1 \mathrm{mg} / \mathrm{mL}$ in ethanol

\begin{tabular}{|c|c|c|c|c|}
\hline \multirow[t]{2}{*}{ Particles } & \multirow[t]{2}{*}{$\mathrm{pH}$} & \multicolumn{2}{|c|}{$\begin{array}{c}\text { Zeta potential } \\
(\mathrm{mV})\end{array}$} & \multirow[t]{2}{*}{ State of stability } \\
\hline & & In ethanol & In water & \\
\hline
\end{tabular}
and water, as shown in Table5.4.

Table5.4: Zeta potential values for CNFs-COOH (7\%) in different suspensions 


\begin{tabular}{|c|c|c|c|c|}
\hline \multirow{5}{*}{$\mathrm{CNFs}-\mathrm{COOH}$} & 0.5 & 28 & 15 & \multirow{5}{*}{$\begin{array}{c}\text { zeta potential } \mid<35 \mathrm{mV} \text { : } \\
\text { Metastable and } \\
\text { flocculated. } \\
\text { |zeta potential } \mid>35 \mathrm{mV} \text { : } \\
\text { Very stable }\end{array}$} \\
\hline & 1 & 20 & I.E.P. & \\
\hline & 9 & -30 & -43 & \\
\hline & 10 & -34 & -46 & \\
\hline & 11 & -36 & -48 & \\
\hline
\end{tabular}
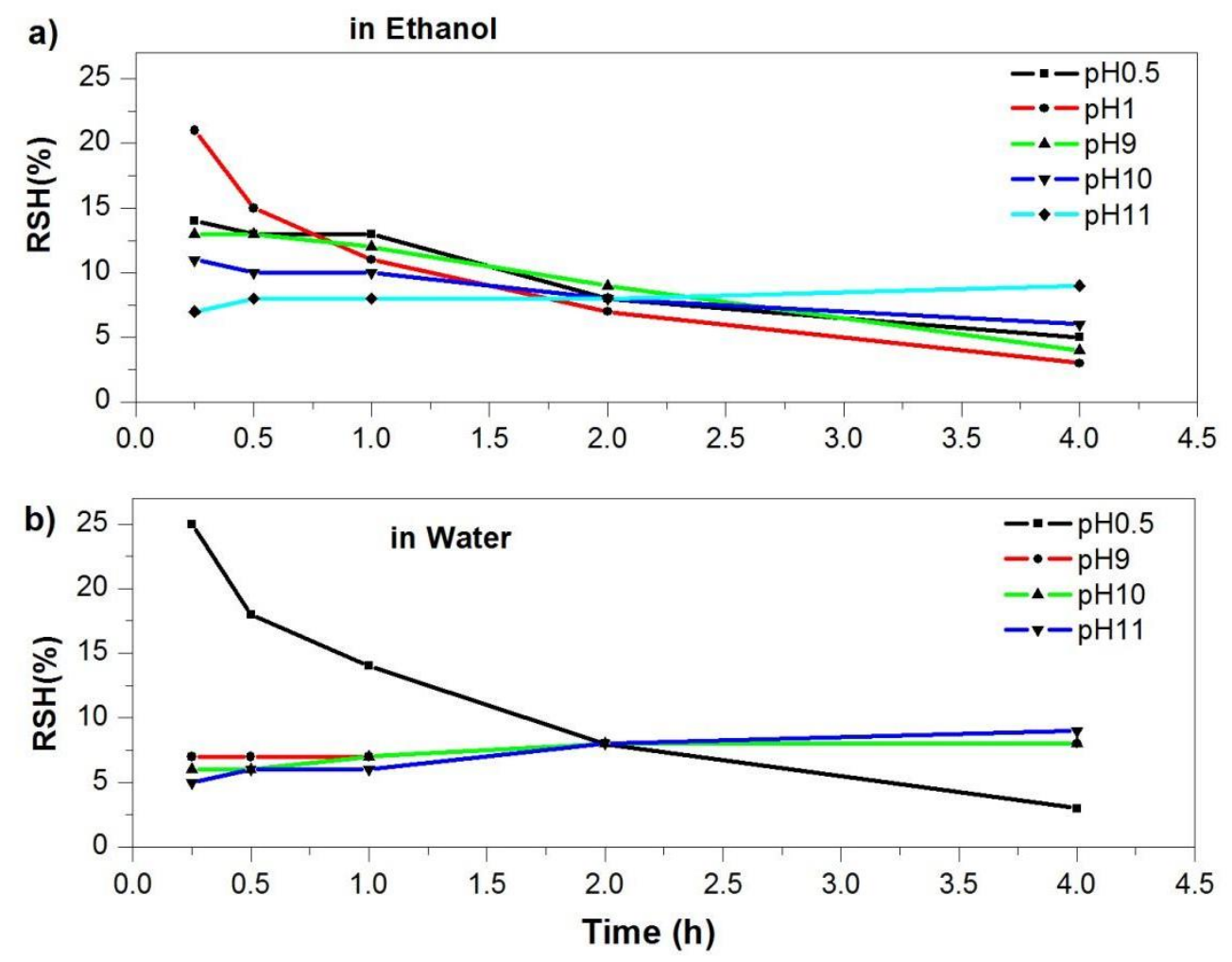

Fig.5.11: Profiles of RSH value versus standing time for CNFs-COOH (7\%) in different suspensions. CNFs concentration: $0.5 \mathrm{mg} / \mathrm{mL}$.

In ethanol at $\mathrm{pH} 1$, the $\mathrm{CNFs}-\mathrm{COOH}$ has the relatively low zeta potential $(20 \mathrm{mV})$, therefore, as shown in Fig.5.11a, the initial RSH is high (>20\%), and the flocculation at the bottom continues to occur, leading to the obvious decrease of RSH in 1 hour. The corresponding $\mathrm{C}_{\mathrm{rd}}$ is only $50 \%$, not suitable for EPD process. Other suspensions at $\mathrm{pH} 0.5, \mathrm{pH} 9, \mathrm{pH} 10$ and $\mathrm{pH} 11$ exhibit the increasing stability with the zeta potential of $28 \mathrm{mV},-30 \mathrm{mV},-34 \mathrm{mV}$, and $-36 \mathrm{mV}$, respectively. Their initial RSH values are lower than $15 \%$, and will change very little in 1 hour. 
The remnant concentration of each sample's homogeneous zone is about $0.35 \mathrm{mg} / \mathrm{mL}, 0.38$ $\mathrm{mg} / \mathrm{mL}, 0.4 \mathrm{mg} / \mathrm{mL}$ and $0.45 \mathrm{mg} / \mathrm{mL}$, respectively.

Better stability of CNFs-COOH suspensions can be obtained in water at $\mathrm{pH} 9 \sim 11$, as shown in Fig5.11b and Table5.5. The dynamic equilibrium between the settlement and homogenous zone can be kept at least 1 hour, and all the $\mathrm{C}_{\mathrm{rd}}$ values are $90 \%$.

Table5.5: $\mathrm{C}_{\mathrm{rd}}$ values for CNFs-COOH (7\%) in different suspensions.

\begin{tabular}{|c|c|c|c|c|c|}
\hline \multirow{2}{*}{$\begin{array}{c}\text { Standing } \\
\text { time } \\
(\mathrm{h})\end{array}$} & \multicolumn{5}{|c|}{$\mathrm{C}_{\mathrm{rd}}(\%)$} \\
\cline { 2 - 6 } & $\begin{array}{c}\text { Ethanol at } \\
\mathrm{pH} 0.5\end{array}$ & $\begin{array}{c}\text { Ethanol at } \\
\mathrm{pH} 1\end{array}$ & $\begin{array}{c}\text { Ethanol at } \\
\mathrm{pH} 9\end{array}$ & $\begin{array}{c}\text { Ethanol at } \\
\mathrm{pH} 10\end{array}$ & $\begin{array}{c}\text { Ethanol at } \\
\mathrm{pH} 11\end{array}$ \\
\hline 0.25 & 80 & 75 & 85 & 90 & 90 \\
\hline 0.5 & 75 & 60 & 80 & 90 & 90 \\
\hline 1 & 70 & 50 & 75 & 85 & 90 \\
\hline & Water at & Water at $\mathrm{pH} 1$ & Water at $\mathrm{pH} 9$ & $\begin{array}{c}\text { Water at } \\
\mathrm{pH} 10\end{array}$ & $\begin{array}{c}\text { Water at } \\
\mathrm{pH} 11\end{array}$ \\
\hline 0.25 & 70 & - & 90 & 90 & 90 \\
\hline 0.5 & 55 & - & 90 & 90 & 90 \\
\hline 1 & 45 & - & 90 & 90 & 90 \\
\hline
\end{tabular}

Summarizing the above results, the metastable/stable CNFs suspensions listed in Table5.6 can be chose for short-time single-component EPD.

Table5.6: (meta)stable suspensions for CNFs-COOH (7\%)

\begin{tabular}{|c|c|c|}
\hline Particle & Solvent & $\mathrm{pH}$ value \\
\hline \multirow{2}{*}{ CNFs-COOH (7\%) } & Ethanol & $0.5,9 \sim 11$ \\
\cline { 2 - 3 } & Water & $9 \sim 11$ \\
\hline
\end{tabular}

3) Applied voltage

CNFs-COOH(7\%) suspensions in ethanol were prepared with a concentration of 0.5 $\mathrm{mg} / \mathrm{mL}$, and EPD process was performed at $15-75 \mathrm{~V} / \mathrm{cm}$ for $10 \mathrm{~min}$. After the deposition, the yield of each sample was shown in Fig.5.12.

Firstly, higher suspension stability brings higher deposited mass under the same electric field. At $\mathrm{pH} 10,0.5$ and 1.5 , the suspension's zeta potential value is $-34 \mathrm{mV}, 28 \mathrm{mV}$ and $20 \mathrm{mV}$, 
respectively, and the corresponding maximum deposited mass of $1,0.8$ and $0.6 \mathrm{mg} / \mathrm{cm}^{2}$ can be obtained at $75 \mathrm{~V} / \mathrm{cm}$.

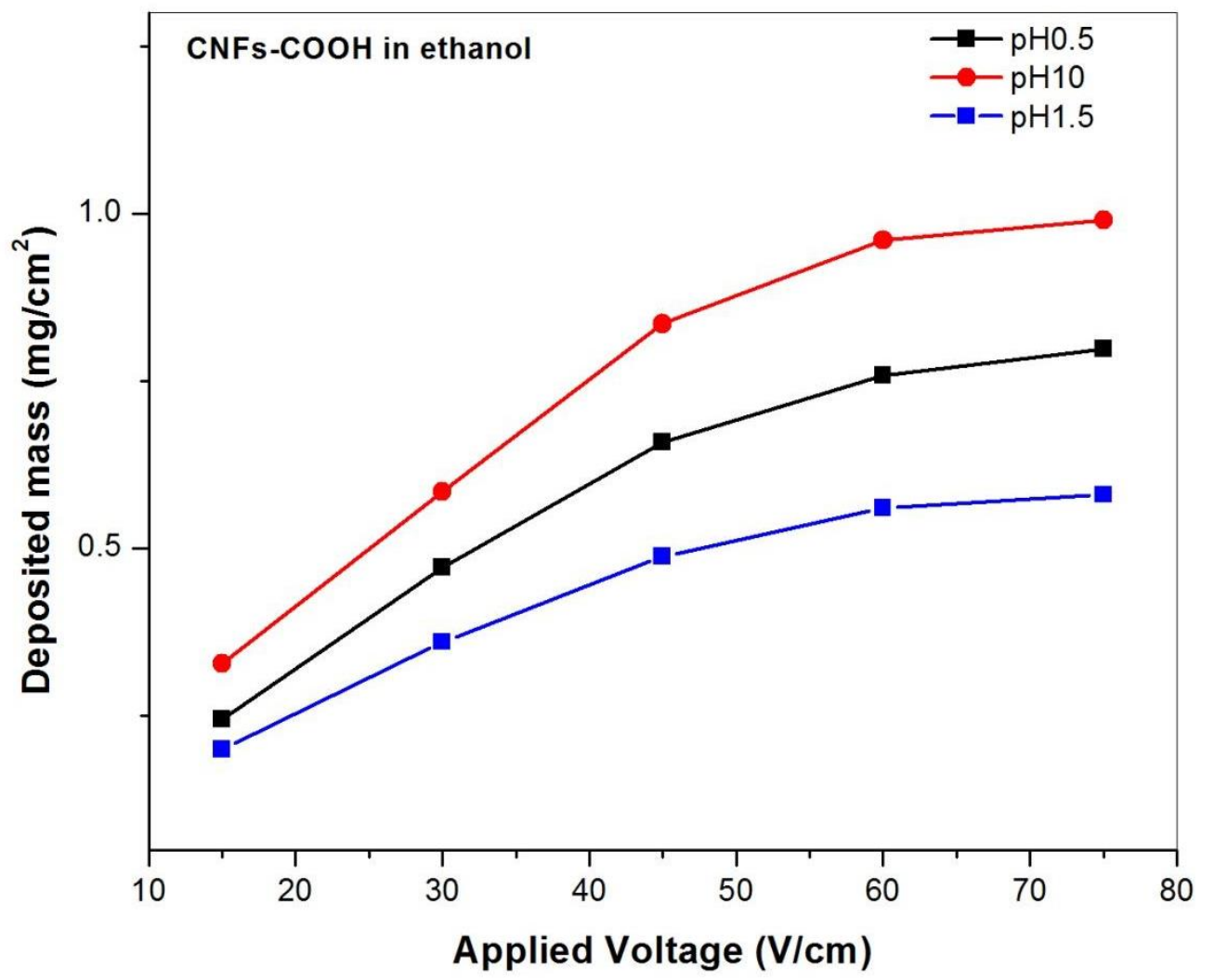

Fig.5.12: Profiles of the deposited mass (versus applied voltage) for CNFs-COOH suspension at different $\mathrm{pH}$ values. CNFs concentration: $0.5 \mathrm{mg} / \mathrm{mL}$.

Suspension stability ( $\mathrm{pH}$ value) also influences the uniformity of the deposited film

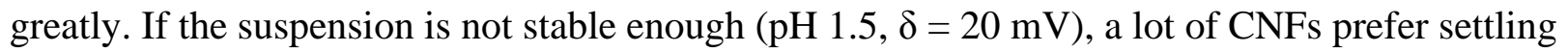
in the settlement zone to staying in the homogeneous zone. Although a small amount of CNFs can be deposited in the beginning of EPD, there are no enough CNFs for the following growth of the film. Finally, a broken film is obtained, as shown in Fig.5.13a. At pH0.5, the suspension stability is improved a little $\left(\delta=28 \mathrm{mV}, \mathrm{C}_{\mathrm{rd}, 0.25 \mathrm{~h}}=80 \%\right)$. A film without cracks can be prepared after 10 min EPD (Fig.5.13b), but the surface is uneven, meaning the distribution of CNFs is not uniform. When the suspension is stable $(\mathrm{pH} 10,|\delta|=34 \mathrm{mV})$, the concentration of homogeneous zone can keep unchanged for at least $0.5 \mathrm{~h}\left(\mathrm{C}_{\mathrm{rd}, 0.5 \mathrm{~h}}=90 \%\right)$, a uniform CNFs film with smooth surface can be obtained, as shown in Fig.5.13c. Considering the requirement on large-scale production for LIB anode by EPD in the future, the uniformity of the film is a very important precondition. Therefore, the best $\mathrm{pH}$ value of CNFs suspension in ethanol for EPD is 10. For the 
purpose of dynamics research, other suspensions with different $\mathrm{pH}$ values are also chose in this dissertation.

Secondly, in the same suspension, the deposition mass increase with the applied voltage, but the increasing trend is gradually slowing down. Because of the entanglement of CNFs in the deposited layer, the turbulence effect has little influence on the mass. For a given suspension, applied voltages can also influence surface morphology of the deposited layer greatly. Take the EPD process in a stable suspension at pH10 as the example, if the voltage is too low $(30 \mathrm{~V} / \mathrm{cm})$, a CNFs film with visible cracks is prepared due to the relatively slow deposition rate (Fig.5.14a). If increasing the voltage to $75 \mathrm{~V} / \mathrm{cm}$, although more CNFs are deposited in the same time and the integrity of the film is maintained, some irregularly aggregated CNFs at the surface can be observed. Therefore, the proper applied voltage for EPD in a stable CNFs suspension is around $45 \mathrm{~V} / \mathrm{cm}$.

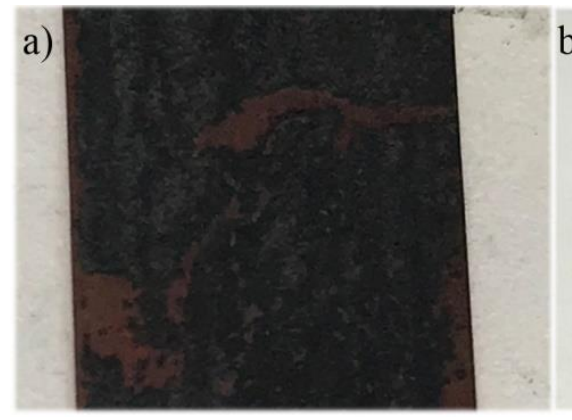

b)

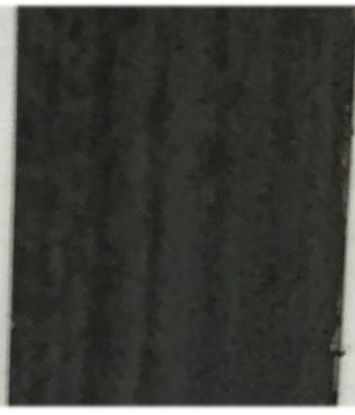

c)

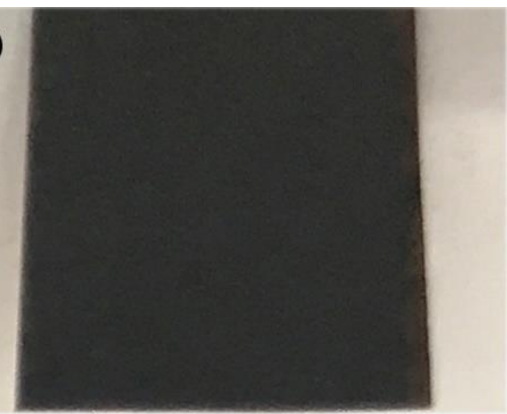

Fig.5.13: Photographs of deposited films on $\mathrm{Cu}$ foil after $10 \mathrm{~min}$ EPD in ethanol with different $\mathrm{pH}$ values: a) $\mathrm{pH} 1.5$, b) $\mathrm{pH} 0.5$, c) $\mathrm{pH} 10$. The applied voltage: $45 \mathrm{~V} / \mathrm{cm}$.

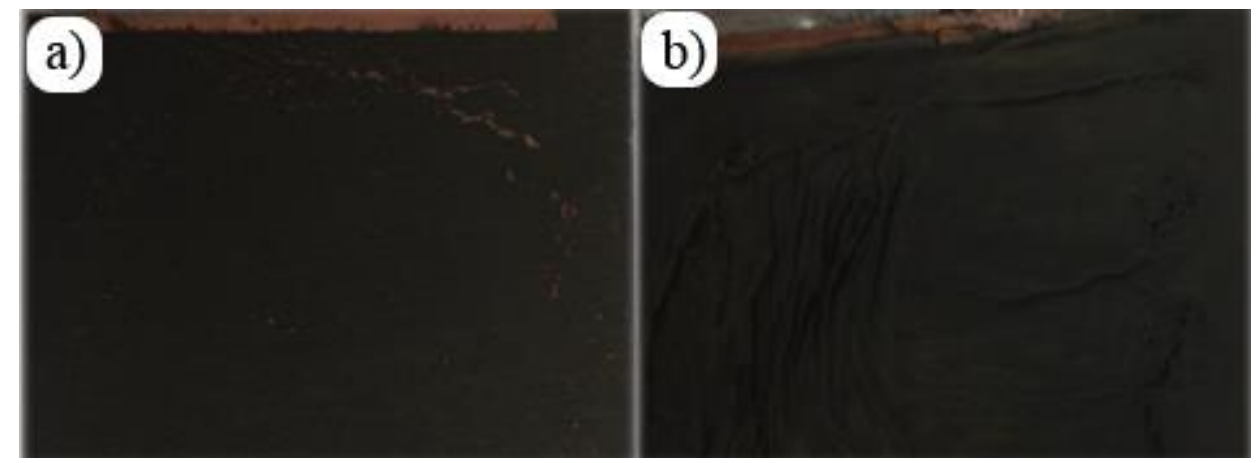

Fig.5.14: Photographs of deposited films on $\mathrm{Cu}$ foil after $10 \mathrm{~min}$ EPD in ethanol at pH10 with the applied voltage of a) $30 \mathrm{~V} / \mathrm{cm}$ and b) $75 \mathrm{~V} / \mathrm{cm}$.

4) Deposition time

Fig.5.15 shows the current changing with time in the voltage range of $30-60 \mathrm{~V} / \mathrm{cm}$. Firstly, all the current changing profiles have the similar shapes no matter what $\mathrm{pH}$ value or 
applied voltage is used. It indicates that although $\mathrm{pH}$ value and applied voltage can influence the film morphology greatly, they can influence the CNFs deposition mechanism little. The current decreases rapidly in several seconds $(<30 \mathrm{~s})$, indicating the beginning of the deposition process. Then, the decrease of the current becomes slower, indicating the growth of the CNFs layer. Because CNFs has the good conductivity $\left(\sim 10^{6} \mathrm{~S} / \mathrm{m}\right)$, the deposited layer wouldn't influence the substrate's conductivity too much; therefore, the decrease of the current should be attributed to the irreversibly consumption of the free ions in the solvent. It's also noticed that the current drop is slower in the acidic suspension (a little water included) than that in the basic suspension under the same electric field. After the formation of an intact film, the current tends to be constant, indicating that less CNFs are deposited with the increasing time due to weaker interaction between CNFs.

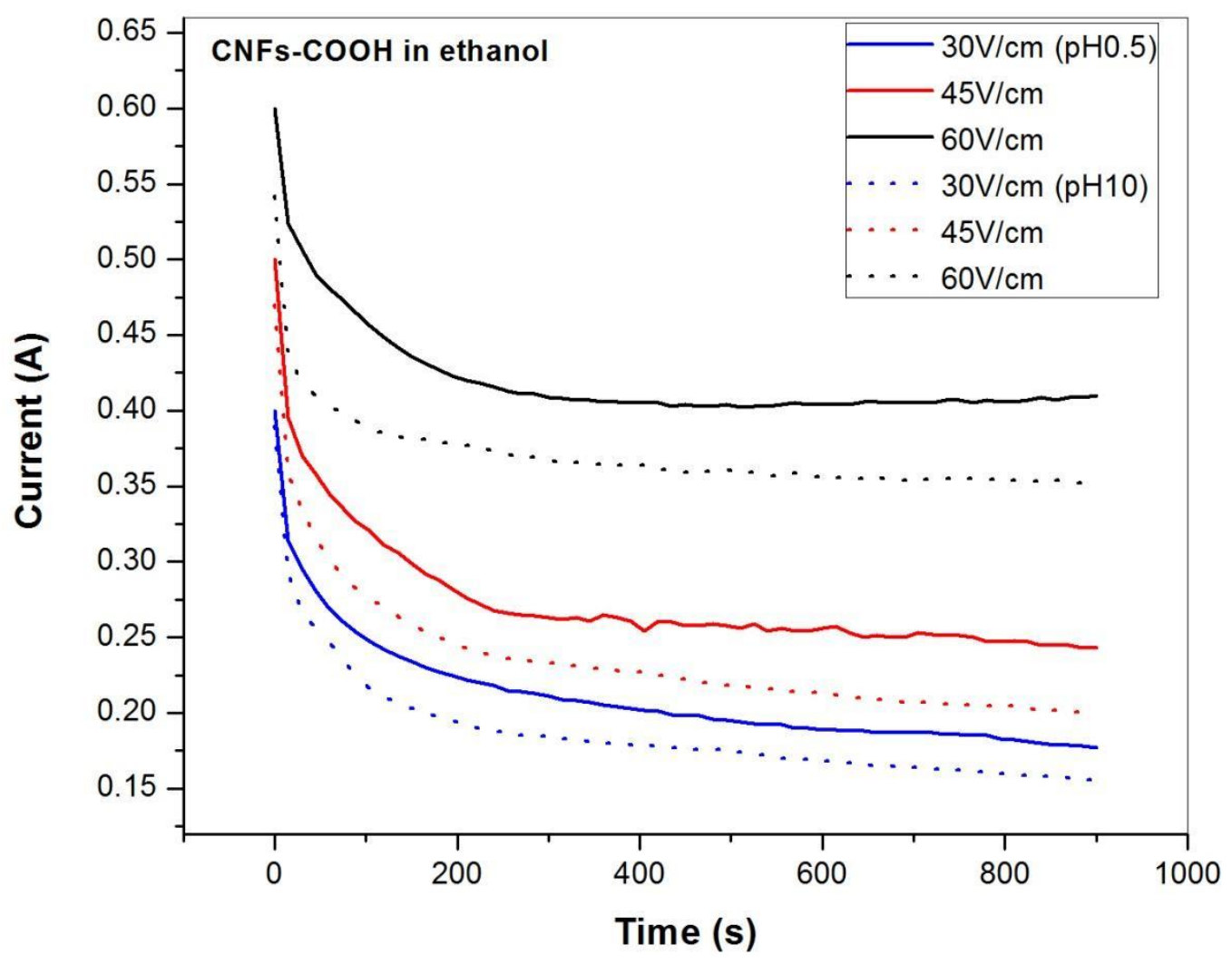

Fig.5.15: Profiles of current changing in different CNFs-COOH (7\%) suspensions with different applied voltages. CNFs concentration: $0.5 \mathrm{mg} / \mathrm{mL}$.

Under the given conditions (applied voltage: $45 \mathrm{~V} / \mathrm{cm}$ ), the relationship between deposition time and the loading per unit area is shown in Fig.5.16. On the one hand, the deposition mass increase with the applied voltage, but the increasing trend is gradually slowing 
down. Secondly, on the other hand, with the improvement of suspension stability, more CNFs can be deposited after 15 min EPD. At pH10, 0.5 and 1.5, the suspension's zeta potential value is $-34 \mathrm{mV}, 28 \mathrm{mV}$ and $20 \mathrm{mV}$, respectively, and the corresponding maximum deposited mass of $0.84,0.62$ and $0.42 \mathrm{mg} / \mathrm{cm}^{2}$ can be obtained.

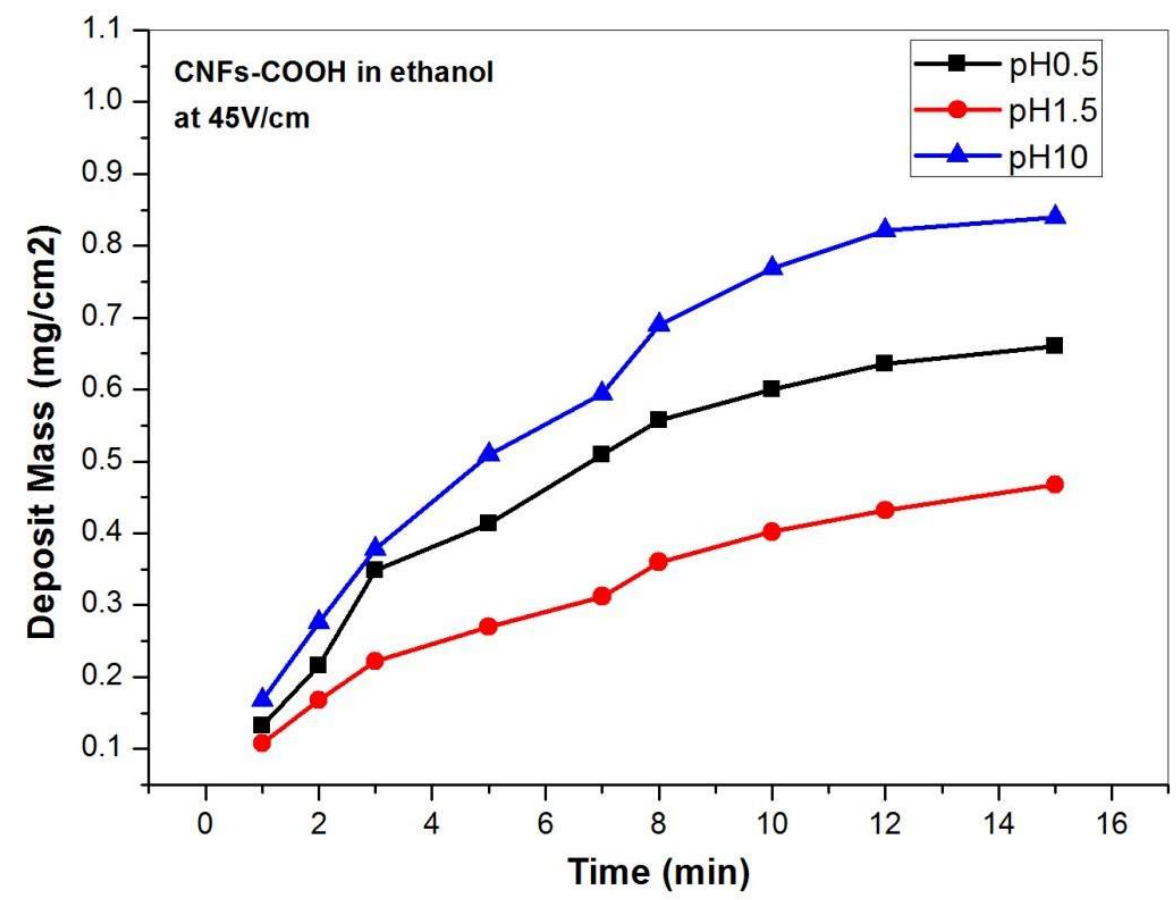

Fig.5.16: Profiles of deposited mass changing with time in different CNFs-COOH suspensions.

CNFs concentration: $0.5 \mathrm{mg} / \mathrm{mL}$.

5) Film morphology and electrochemical properties
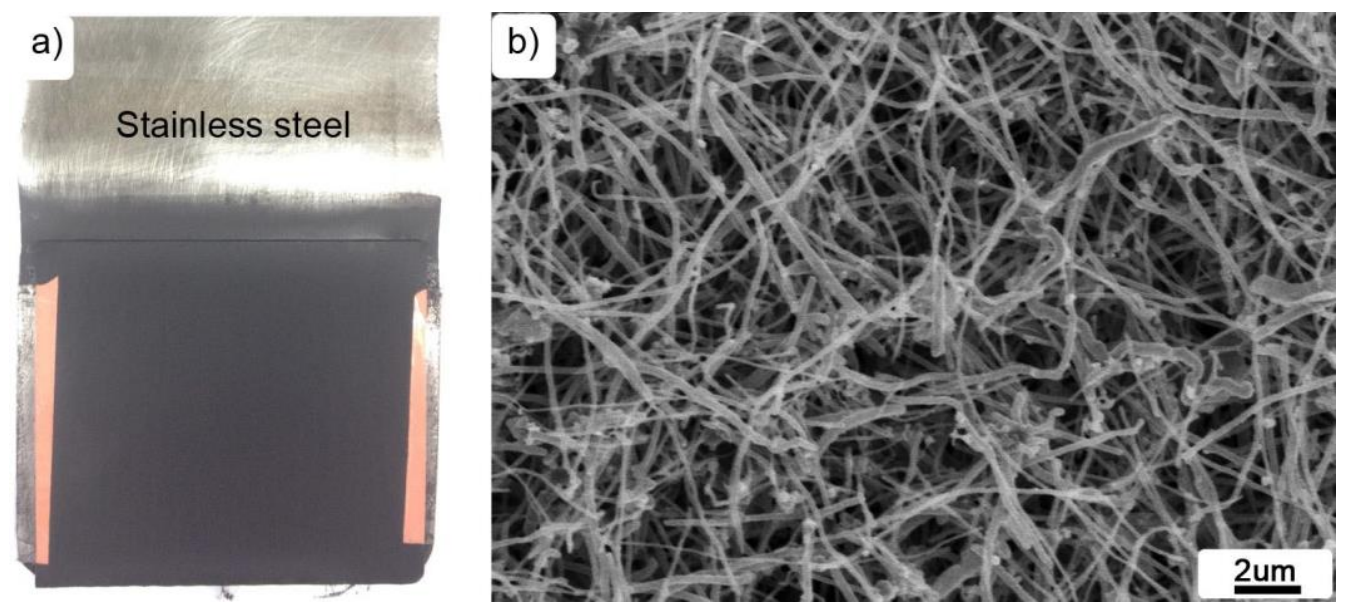

Fig.5.17: a) photograph of CNFs film (in ethanol, pH10, applied voltage: $45 \mathrm{~V} / \mathrm{cm}$ ); b) SEM image of CNFs film prepared by EPD in ethanol suspension with the concentration of $1 \mathrm{mg} / \mathrm{mL}$. 
A typical CNFs film is successfully prepared by $10 \mathrm{~min}$ EPD, as shown in Fig.5.17a. The film is uniform and integrated without any binder. The naked $\mathrm{Cu}$ foil margin can be observed because this place is used for the adhesive tape to fix $\mathrm{Cu}$ with the stainless steel substrate and no particles can be deposited during EPD. SEM image of the film is shown in Fig.5.17b. CNFs have the average length of tens of micrometers. They are interweaving rather than bunched up together to form a net-structure on the $\mathrm{Cu}$ surface, indicating a homogeneous deposition process. The voltage profile of CNFs-COOH vs. Li with a voltage range of 0.01-3 $\mathrm{V}$ at a current density of $400 \mathrm{mAh} / \mathrm{g}$ is showed in Fig.5.18a. The $1^{\text {st }}$ discharge and charge capacities are 328 and 277 $\mathrm{mAh} / \mathrm{g}$, respectively, indicating an initial coulombic efficiency (ICE) of $85 \%$. The formation of SEI should be responsible for the irreversible capacity loss. During the following cycles, all the voltage profiles exhibit the similar lithiation/delithiation platform and similar charge/discharge capacity. The cycling performance of the CNFs-COOH film is showed in Fig.5.18b. It still retains a reversible charge capacity of $280 \mathrm{mAh} / \mathrm{g}$ after 100 cycles and the coulombic efficiency almost keeps $100 \%$ after the first several cycles. 

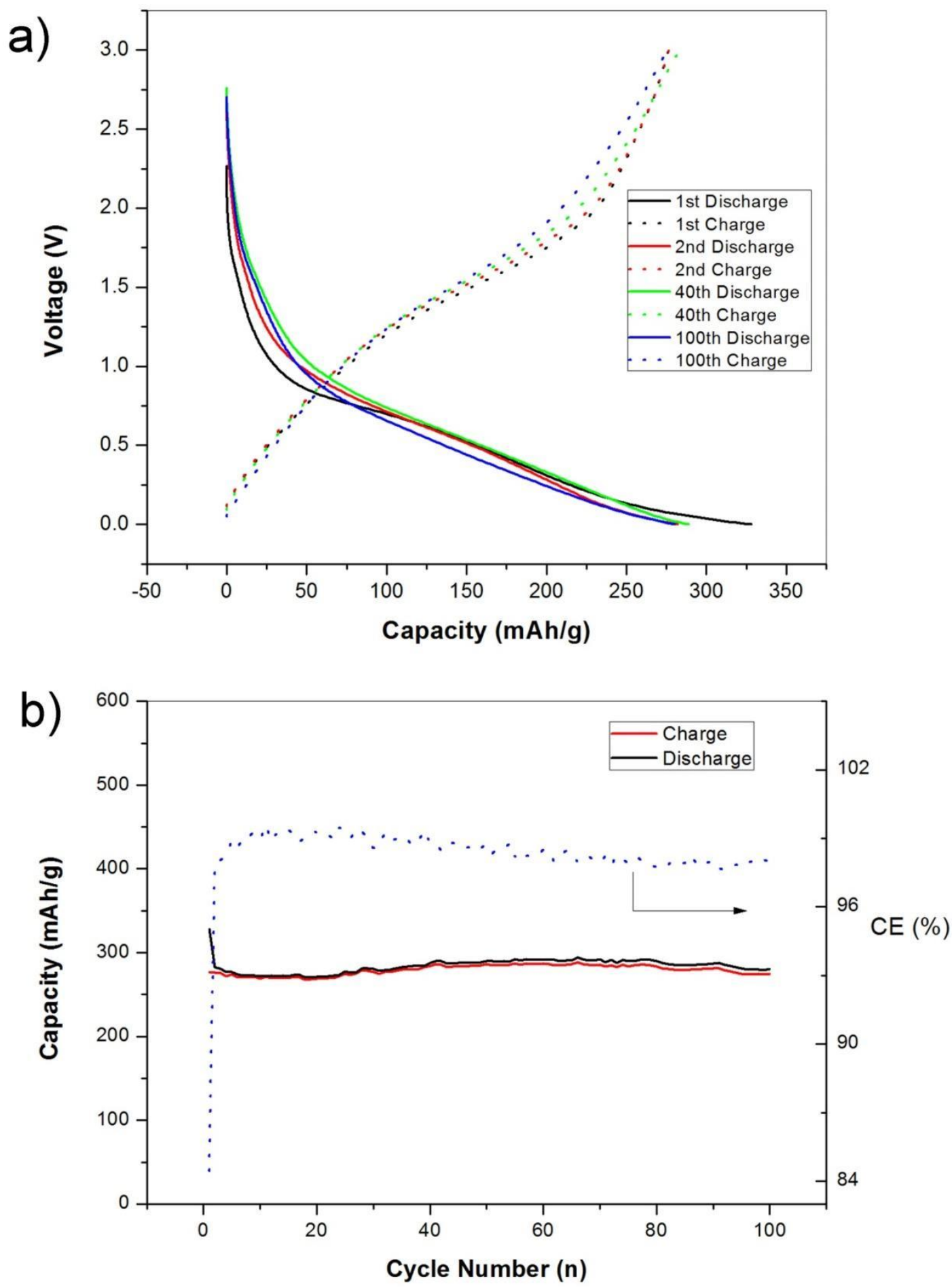

Fig.5.18: a) Galvanostatic discharge-charge curves for CNFs-COOH film; b) Cycling performance of CNFs-COOH film at the current rate of $400 \mathrm{~mA} / \mathrm{g}$.

\subsubsection{EPD of Si nanoparticles}

1) Zeta potential 
Generally, each commercial Si nanoparticle (c-SiNP) has a thin $\mathrm{SiO}_{2}$ layer on the surface, thus a little $-\mathrm{OH}$ groups in the solvent can be absorbed, leading to the protonation or deprotonation process depending on the $\mathrm{pH}$ value.

In the neutral non-aqueous suspension, an ethanol molecular can ionize and form an alkoxide ion, as shown in Eq.5.8.

$$
\mathrm{C}_{2} \mathrm{H}_{5} \mathrm{OH}+\mathrm{C}_{2} \mathrm{H}_{5} \mathrm{O}-\mathrm{H} \longleftrightarrow \mathrm{C}_{2} \mathrm{H}_{5} \mathrm{O}^{-}+\mathrm{C}_{2} \mathrm{H}_{5} \mathrm{OH}_{2}^{+} \quad 5.8
$$

If the $\mathrm{pH}$ value equals to the isoelectric point (I.E.P) value, c-SiNPs have no surface charge. If lower than the I.E.P value, excessive $\mathrm{H}^{+}$leads to the positive-charged surface with the positive zeta potential (protonation), and the reaction is expressed by Eq.5.9.

$$
\mathrm{Si}-\mathrm{OH}+\mathrm{H}^{+} \stackrel{\text { lower than I.E.P. }}{\longrightarrow} \mathrm{Si}-\mathrm{OH}_{2}^{+}
$$

If higher than the I.E.P value, the negative-charged surface can be obtained (deprotonation), and the equation is listed as Eq.5.10.

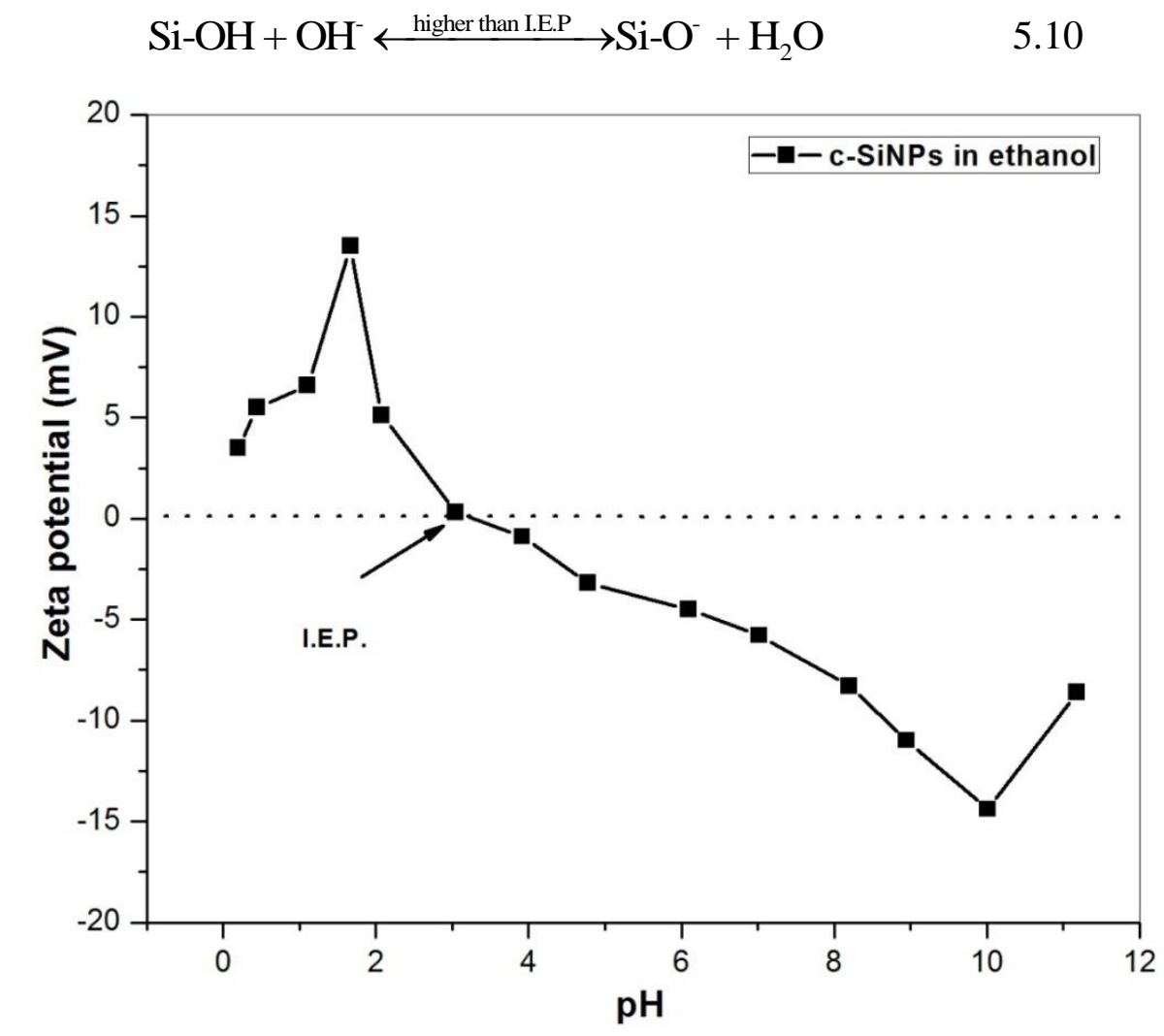

Fig.5.19: Profile of zeta potential of c-SiNPs in ethanol at different $\mathrm{pH}$ values (Si concentration:

$$
0.2 \mathrm{mg} / \mathrm{mL}) \text {. }
$$

Fig.5.19 shows the I.E.P. value of c-SiNPs in ethanol is about 3.1, which is higher than the values reported in the literature for pure $\mathrm{SiO}_{2}$ particles ${ }^{[125]}$, indicating less $-\mathrm{OH}$ groups on 
the c-SiNPs surface. The maximum absolute value of zeta potential is obtained at around $\mathrm{pH} 2$ or pH10, but still very small $(<15 \mathrm{mV})$, meaning that preparing a stable or metastable suspension of c-SiNPs in ethanol is impossible if only adjusting the $\mathrm{pH}$ value. Moreover, in the strong acidic condition, the absolute zeta potential value will decrease rapidly because the excessive cations/anions compress the particle's EDL. In the strong alkali condition, Si can react with $\mathrm{OH}^{-}$ and finally form silicate ions (Eq.5.11), leading to the decrease of the zeta potential value.

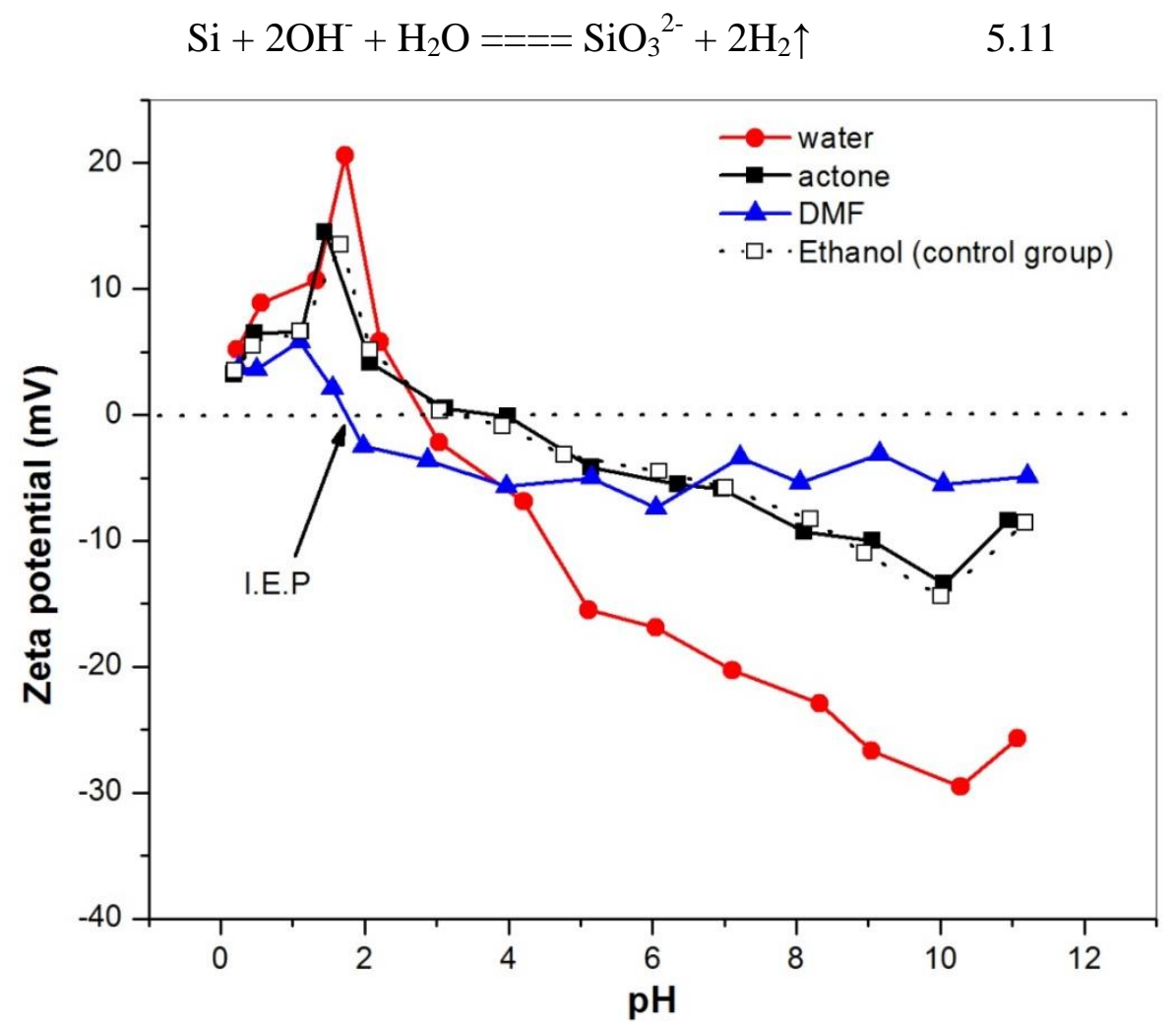

Fig.5.20: Profiles of zeta potential values for c-SiNPs in different suspensions (Si concentration:

$$
0.2 \mathrm{mg} / \mathrm{mL}) \text {. }
$$

As shown in Fig.5.20, c-SiNPs have almost exactly the same profile of zeta potential in acetone as that in ethanol. If ethanol is replaced by DMF, which has much higher dielectric constant and electrical conductivity, the double layer of Si becomes thinner. Therefore, more particles collision and aggregation occurs and the absolute values of zeta potential become smaller throughout the entire $\mathrm{pH}$ range. In aqueous suspension, its stability is relatively improved. For $\mathrm{pH}$ values below I.E.P., the maximum absolute value of zeta potential is about $22 \mathrm{mV}$ (around $\mathrm{pH}$ 2.1). For $\mathrm{pH}$ values above I.E.P., especially under the basic condition, the suspension can keep the metastable state, and the maximum zeta potential value is $-32 \mathrm{mV}$ at around $\mathrm{pH}$ 
10.5. However, no matter what kind of solvent is used, a stable $\mathrm{Si}$ suspension (|zeta potential| $>35$ $\mathrm{mV}$ ) cannot be prepared without any additives.

The influence of SiNPs concentration in ethanol on zeta potential is shown in Fig.5.21. Either I.E.P. or zeta potential value changes little in the range of $0.2-0.8 \mathrm{mg} / \mathrm{mL}$, meaning no obvious interaction between Si particles in ethanol.

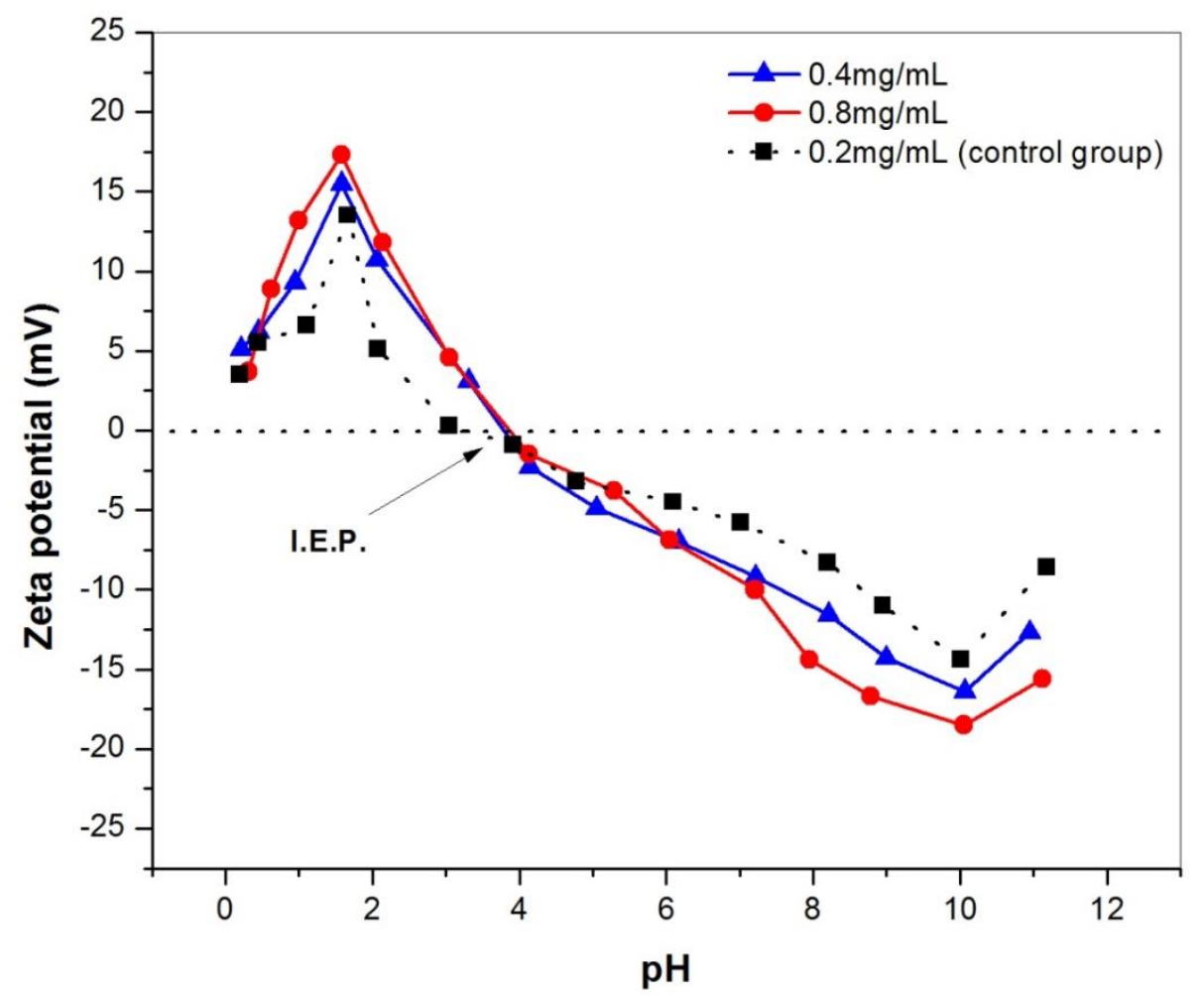

Fig.5.21: Profiles of zeta potential of c-SiNPs in ethanol with different concentrations.

2) Settling rate

As mentioned before, preparing a stable or metastable suspension of c-SiNPs in ethanol is impossible if adjusting $\mathrm{pH}$ value only. As shown in Fig.5.22, if magnetic stirring is stopped, the homogeneous zone will decrease rapidly and finally disappear in $15 \mathrm{~min}$. No stable homogenous zone means preparing a uniform SiNPs film onto the $\mathrm{Cu}$ foil in ethanol by simple EPD is impossible. SiNP surface modification or proper surfactants in the suspension are needed, which will be discussed later. 


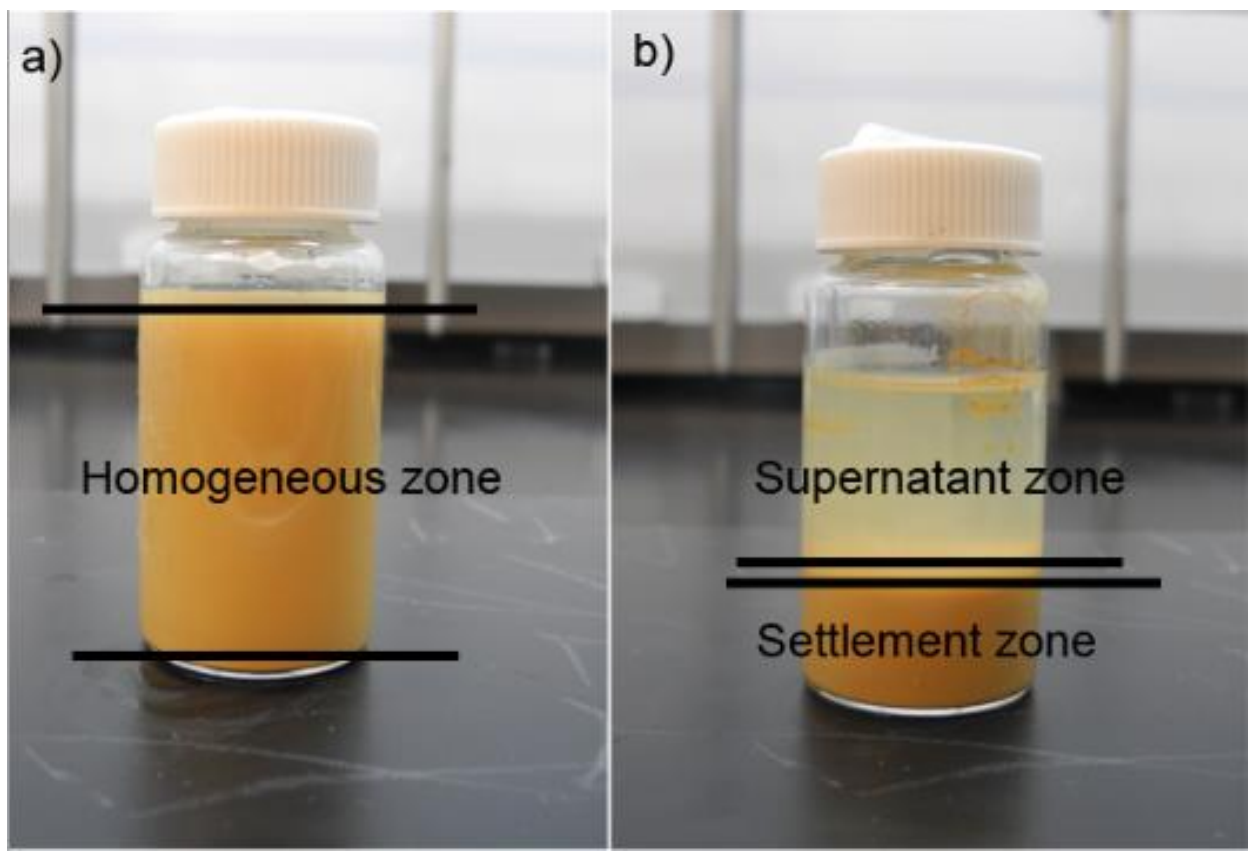

Fig.5.22: Photographs of c-SiNPs suspension in ethanol (0.2 $\mathrm{mg} / \mathrm{mL})$ a) without standing, b) with 15 min standing. $\mathrm{pH}$ value: 10 .

\subsection{Multi-component EPD for simple Si/CNFs-COOH system}

1) Zeta potential

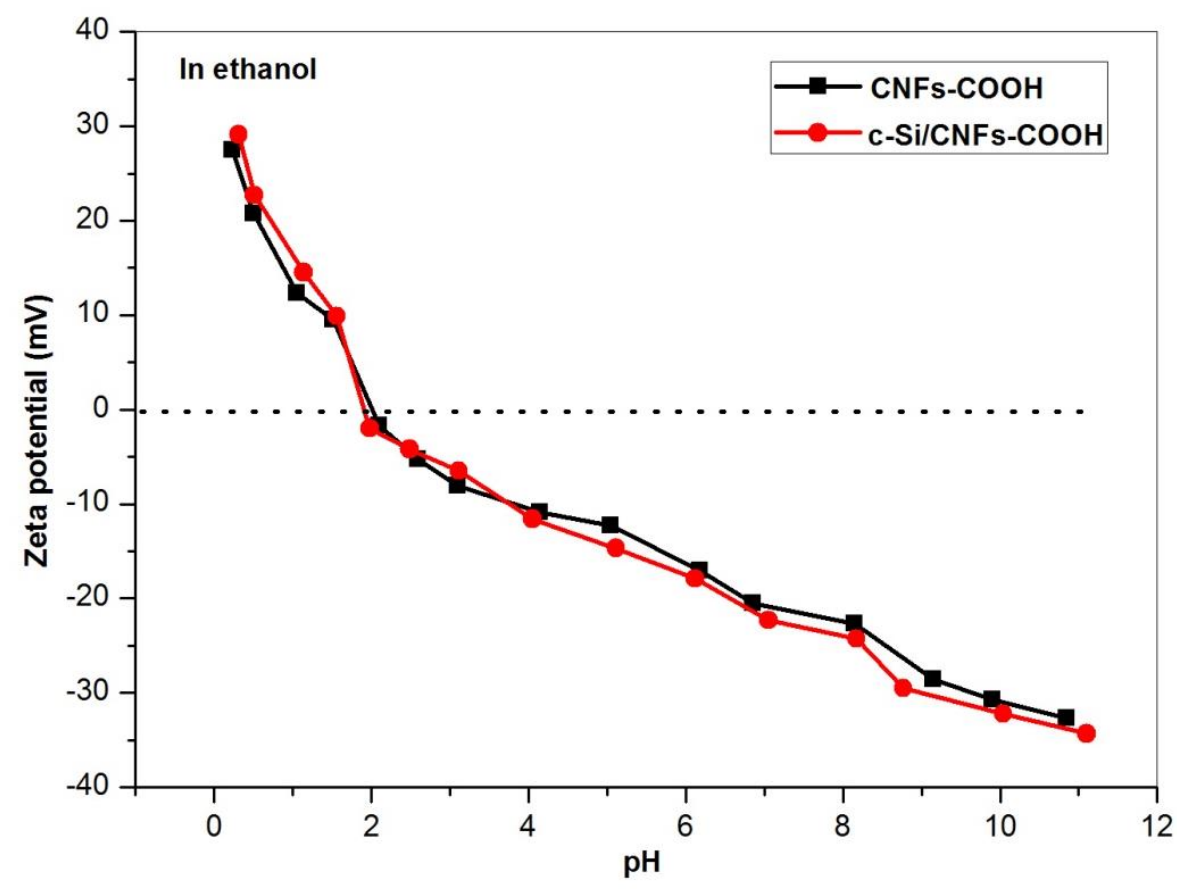

Fig.5.23: Profiles of zeta potential in different suspensions ( $\mathrm{pH}$ range: $0.5-11, \mathrm{CNFs}$ concentration: $0.5 \mathrm{mg} / \mathrm{mL}$, Si concentration: $0.2 \mathrm{mg} / \mathrm{mL}$ ). 
Compared with CNFs-COOH suspension, c-Si/CNFs-COOH suspension shows the highly similar zeta potential profile (Fig.5.23). Si particles just have a little influence on CNFs stability. Because c-Si has higher I.E.P. values (3.1) than that of CNFs-COOH in ethanol (2.1), it has the same surface charges as $\mathrm{CNFs}-\mathrm{COOH}$ at the $\mathrm{pH}$ range of $11-3.1$ and $0.5-2.1$, which is equivalent to increase the density of CNFs' surface charges and leads to better stability.

If improving Si concentration unilaterally, the influence of Si on the stability of suspension becomes more visible, as shown in Fig.5.24. When Si concentration is lower than 0.4 $\mathrm{mg} / \mathrm{mL}$, it's beneficial to improve the suspension stability at $\mathrm{pH} 0.5-1$ or $5-11$. But if $\mathrm{Si}$ concentration is too high $(0.8 \mathrm{mg} / \mathrm{mL})$, the serious aggregation of Si particles can also accelerates the sedimentation of CNFs, and the zeta potential values are decreased.

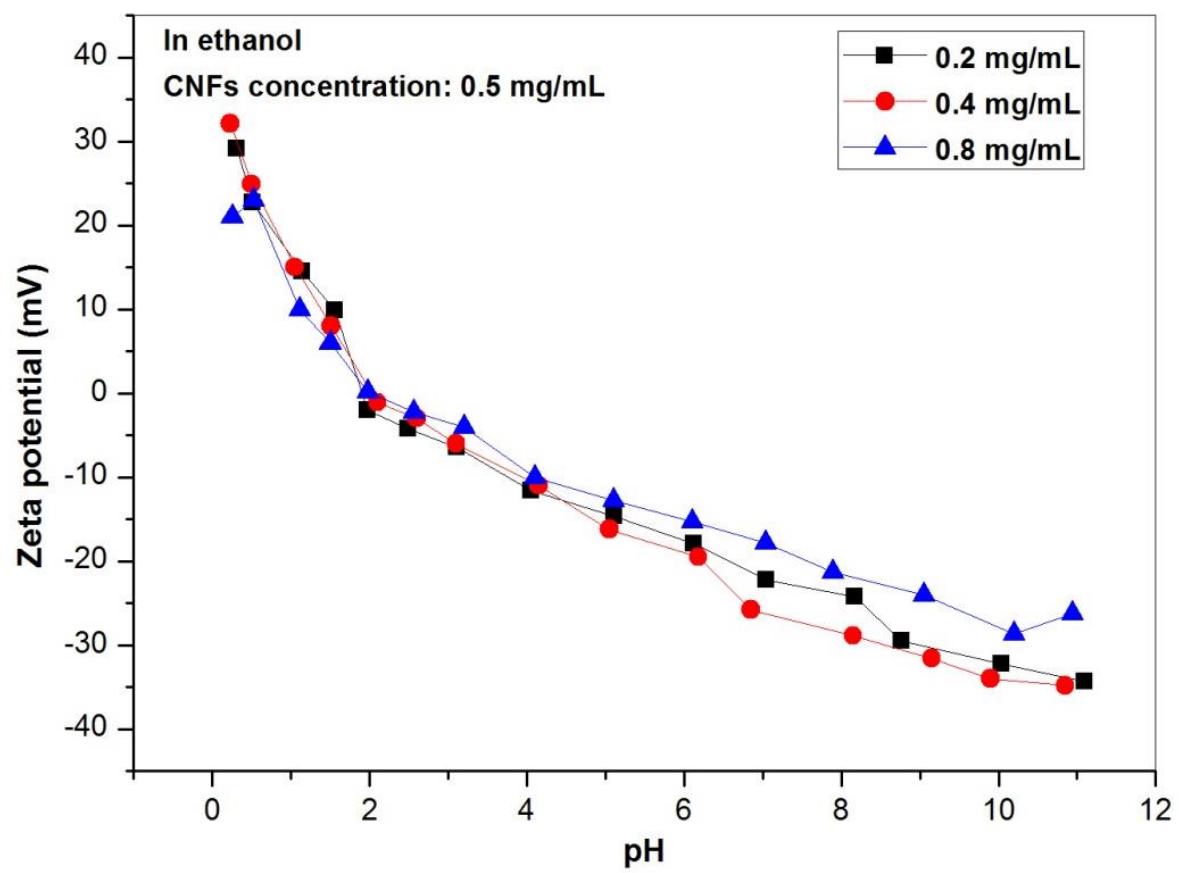

Fig.5.24: Profiles of zeta potential in c-Si/CNFs-COOH suspensions with different Si contents (CNFs concentration: $0.5 \mathrm{mg} / \mathrm{mL}$ ).

Fig.5.25 shows the influence of total concentration on suspension stability. Generally, higher concentration leads to higher stability at $\mathrm{pH} 1$ and $\mathrm{pH} 4-9$. But in the strong acid or strong alkaline suspension, high concentration and excessive charges means the decrease of particle's EDL size and suspension stability. 


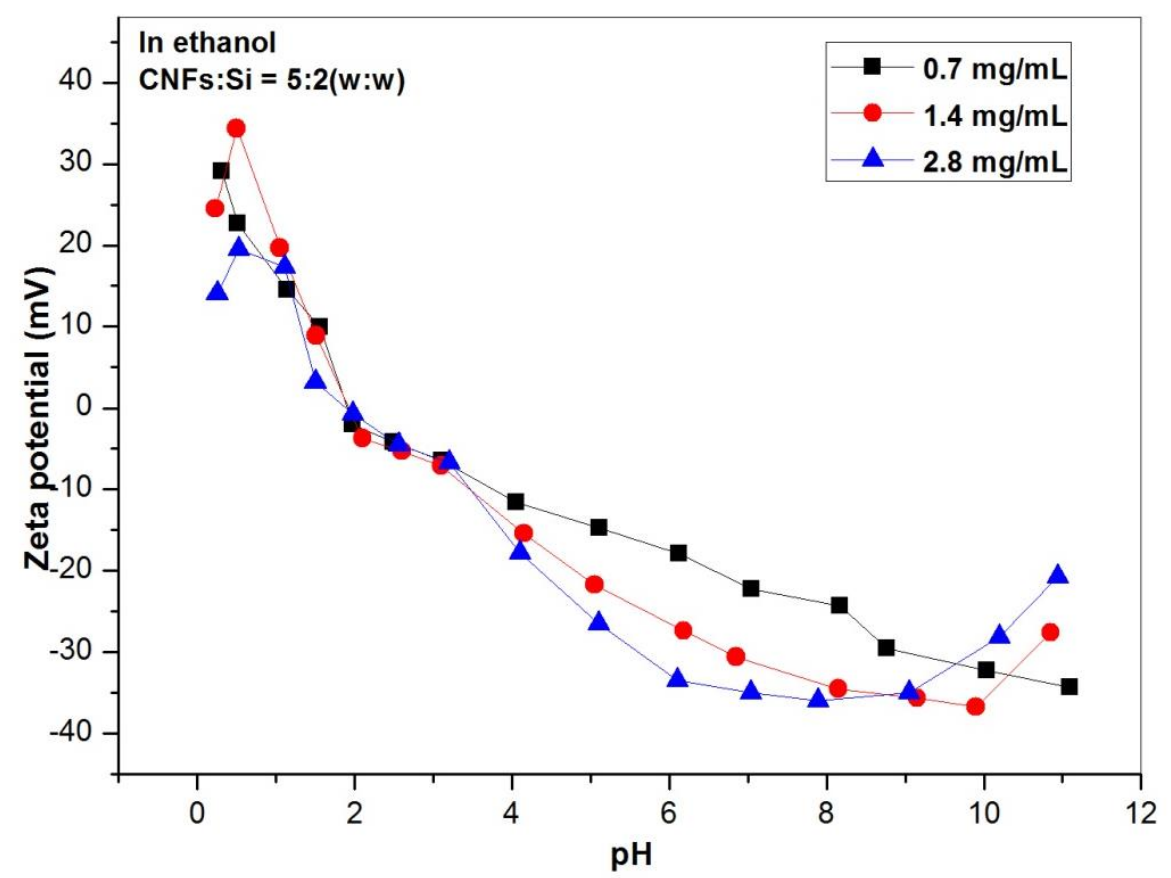

Fig.5.25: Profiles of zeta potential in c-Si/CNFs-COOH suspension with different total concentrations (weight ratio of CNFs to $\mathrm{Si}=5 / 2$ )

2) Settling rate

Based on the zeta potential analysis, some $\mathrm{pH}$ values are chose for preparing metastable/stable c-Si/CNFs-COOH suspensions in ethanol, as shown in Table5.7. Table5.7: Zeta potential values for $\mathrm{c}-\mathrm{Si} / \mathrm{CNFs}-\mathrm{COOH}$ in ethanol at different $\mathrm{pH}$ values

\begin{tabular}{|c|c|c|c|}
\hline Particles & $\mathrm{pH}$ & $\begin{array}{c}\text { Zeta potential } \\
(\mathrm{mV})\end{array}$ & State of stability \\
\hline \multirow{3}{*}{$\begin{array}{l}\text { c-Si/CNFs-COOH(7\%) } \\
(0.4 \mathrm{mg} / \mathrm{mL}+1 \mathrm{mg} / \mathrm{mL})\end{array}$} & 1 & 34.4 & \multirow{3}{*}{$\begin{array}{c}\mid \text { zeta potential } \mid<35 \mathrm{mV} \\
\text { metastable } \\
\text { |zeta potential } \mid>35 \mathrm{mV} \\
\text { stable }\end{array}$} \\
\hline & 9 & -35.6 & \\
\hline & 10 & -36.7 & \\
\hline
\end{tabular}




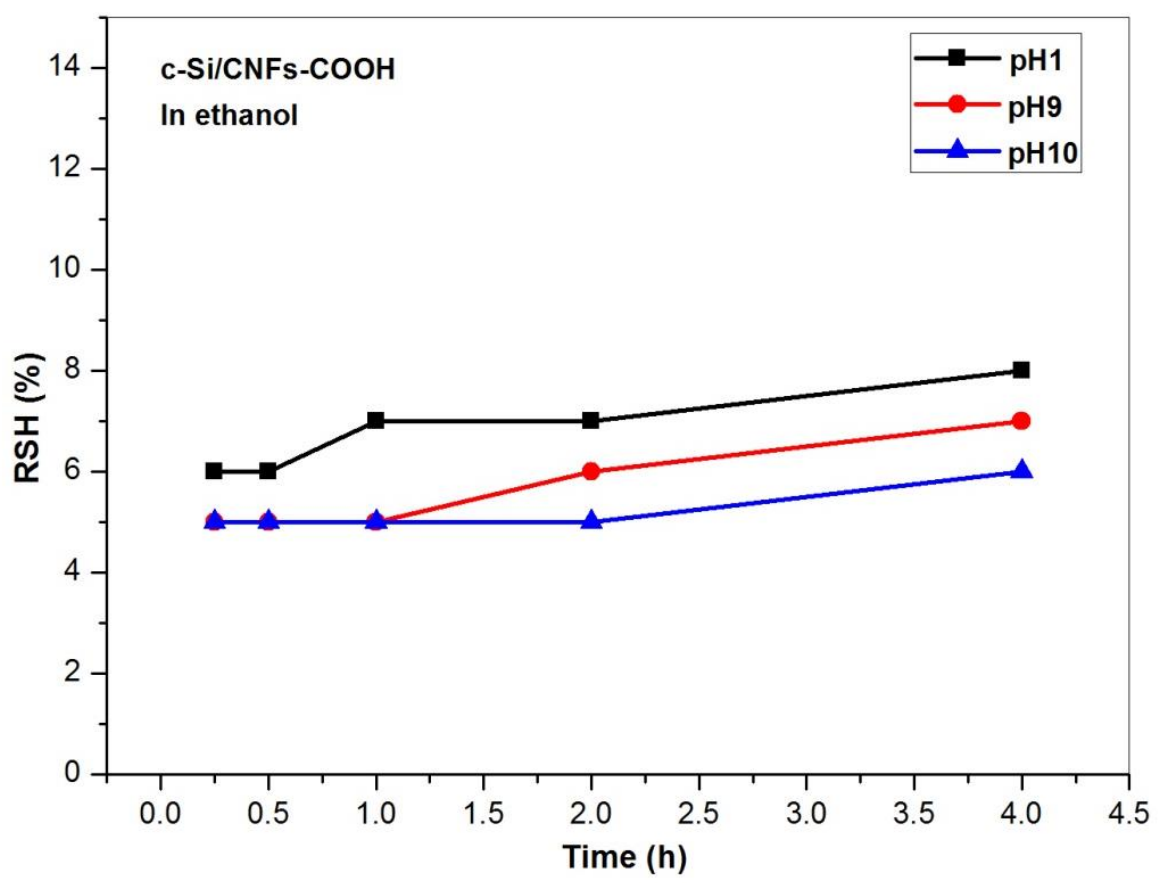

Fig.5.26: Profiles of RSH value versus standing time for c-Si/CNFs-COOH suspensions at different $\mathrm{pH}$ values.

Because of the relatively high zeta potential values at $\mathrm{pH} 1, \mathrm{pH} 9$ and $\mathrm{pH} 10$, all the suspensions' initial RSH values are very low (6\%, 5\% and 5\%, respectively), and increase a little after $4 \mathrm{~h}$ standing ( $8 \%, 7 \%$ and $6 \%$, respectively). It's noticed that the RSH values have no change after $1 \mathrm{~h}$ standing at $\mathrm{pH} 9$ and $\mathrm{pH} 10$. The corresponding $\mathrm{C}_{\mathrm{rd}}$ values are listed in Table5.8. The remnant concentration of each sample's homogeneous zone at $\mathrm{pH} 1, \mathrm{pH} 9$ and $\mathrm{pH} 10$ is about $1.05 \mathrm{mg} / \mathrm{mL}, 1.12 \mathrm{mg} / \mathrm{mL}$ and $1.2 \mathrm{mg} / \mathrm{mL}$, respectively.

Table5.8: $\mathrm{C}_{\mathrm{rd}}$ values for c-Si/CNFs-COOH suspensions at different $\mathrm{pH}$ values.

\begin{tabular}{|c|c|c|c|}
\hline \multirow{2}{*}{$\begin{array}{c}\text { Standing } \\
\text { time } \\
(\mathrm{h})\end{array}$} & $\mathrm{pH} 1$ & $\mathrm{pH} 9$ & $\mathbf{p H 1 0}$ \\
\cline { 2 - 4 } & 85 & 85 & $\mathbf{9 0}$ \\
\hline 0.25 & 80 & 85 & $\mathbf{9 0}$ \\
\hline 0.5 & 75 & 80 & $\mathbf{8 5}$ \\
\hline 1 & 85 & & in ethanol \\
\hline
\end{tabular}

Although the RSH value of the c-Si/CNFs-COOH suspension at $\mathrm{pH} 1$ is small and the corresponding $\mathrm{C}_{\mathrm{rd}}$ value is high, the obvious stratification can be observed after $1 \mathrm{~h}$ standing, as 
shown in Fig.5.27. In the single-component system, SiNPs have faster settling rate than CNFs, but in the multi-component system, SiNPs' settling rate is decreased greatly by the space block of CNFs, while CNFs have faster settling rate. As a result, most CNFs are locating the lower part of the homogeneous zone, leading to non-uniform film in the vertical direction during EPD.

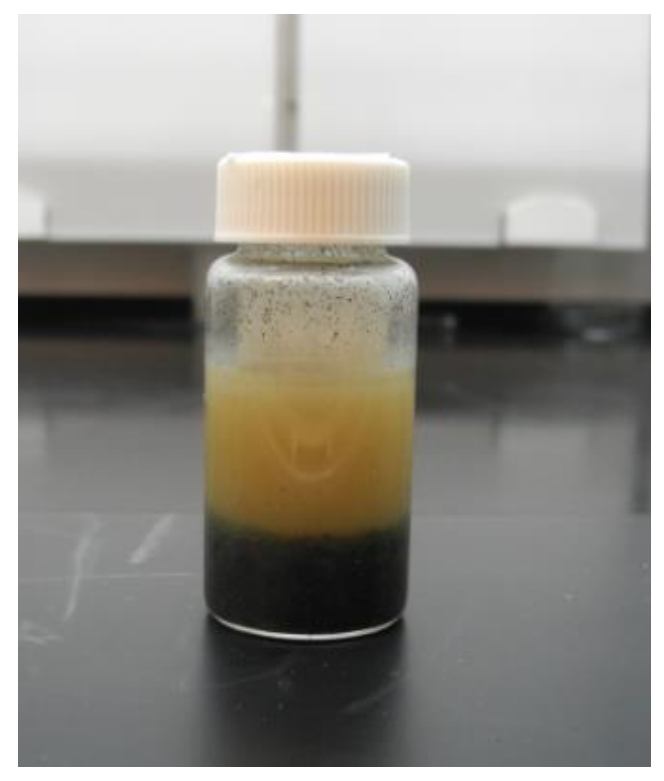

Fig.5.27: photograph of c-Si/CNFs-COOH suspension at $\mathrm{pH} 1$ after $1 \mathrm{~h}$ standing.

Summarizing the above results, the proper $\mathrm{pH}$ range for short-time EPD in c-Si/CNFs$\mathrm{COOH}$ suspensions is $9-10$ and the best value is 10 .

3) Applied voltage

Suspensions consisting of CNFs-COOH and c-Si $(0.5+0.2 \mathrm{mg} / \mathrm{mL}, 1+0.4 \mathrm{mg} / \mathrm{mL})$ were prepared in ethanol at $\mathrm{pH} 10$, and EPD process was performed at $15-75 \mathrm{~V} / \mathrm{cm}$ for $10 \mathrm{~min}$. After the deposition, the yield of each sample was shown in Fig.5.28.

The composite films have higher deposit density than CNFs film under the same electric field. At $45 \mathrm{~V} / \mathrm{cm}$, the deposited mass in the composite suspension with the total concentration of $0.7 \mathrm{mg} / \mathrm{mL}$ is $0.92 \mathrm{mg} / \mathrm{cm}^{2}$, nearly $10 \%$ higher than pure CNFs film $\left(0.84 \mathrm{mg} / \mathrm{cm}^{2}\right)$. If doubling the concentration, the deposited mass increases to $1.12 \mathrm{mg} / \mathrm{cm}^{2}$, a little but not double. Similar results are obtained at $75 \mathrm{~V} / \mathrm{cm}$. The deposited mass in the composite suspension $(0.7 \mathrm{mg} / \mathrm{mL})$ is $1.06 \mathrm{mg} / \mathrm{cm}^{2}$, about $10 \%$ higher than CNFs film $\left(0.96 \mathrm{mg} / \mathrm{cm}^{2}\right)$, and it increases to $1.28 \mathrm{mg} / \mathrm{cm}^{2}$ in the high-concentration composite suspension $(1.4 \mathrm{mg} / \mathrm{mL})$. It's noticed that the increasing trend of deposited mass with the applied voltage in the same suspension becomes slower. 


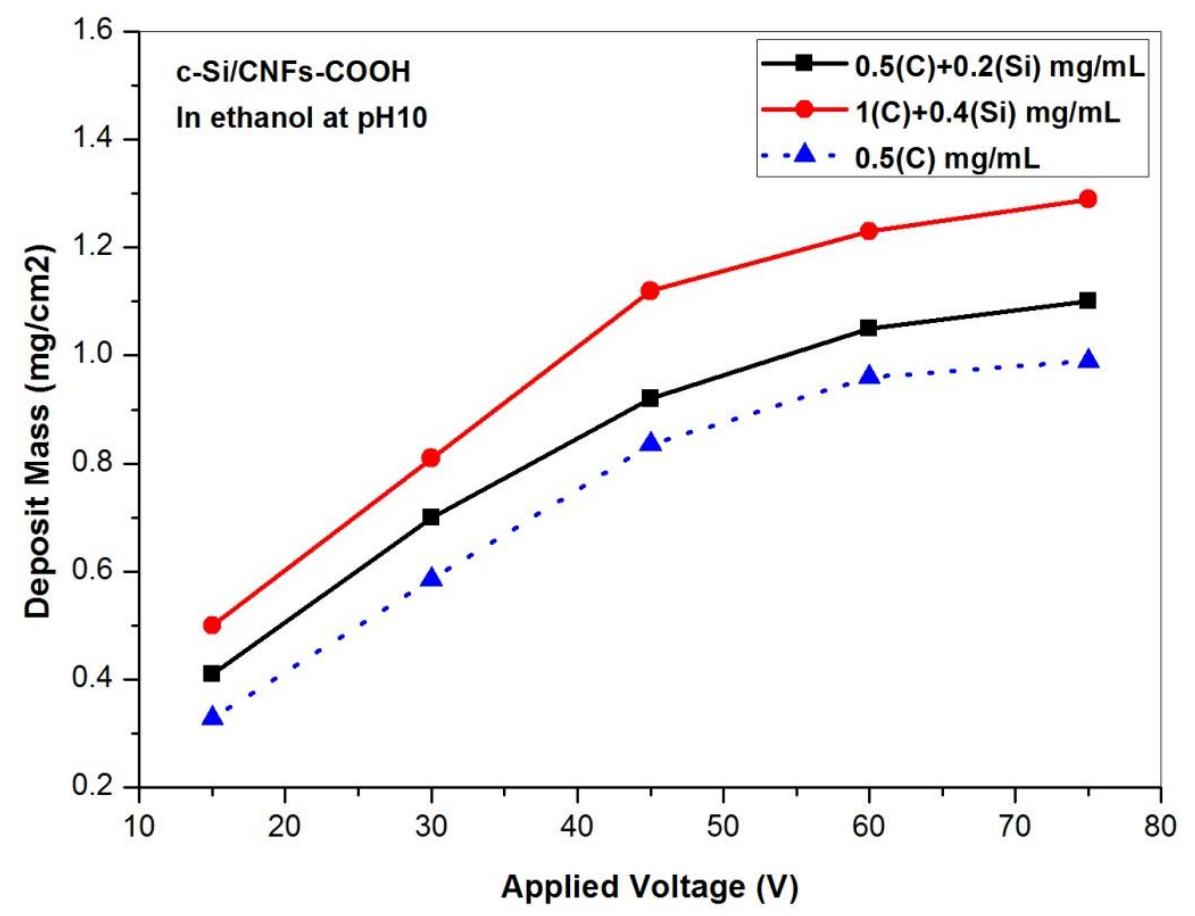

Fig.5.28: Profiles of the deposited mass (versus applied voltage) for CNFs-COOH suspension at different $\mathrm{pH}$ values. CNFs concentration: $0.5 \mathrm{mg} / \mathrm{mL}$.

4) Deposition time and growth mechanism

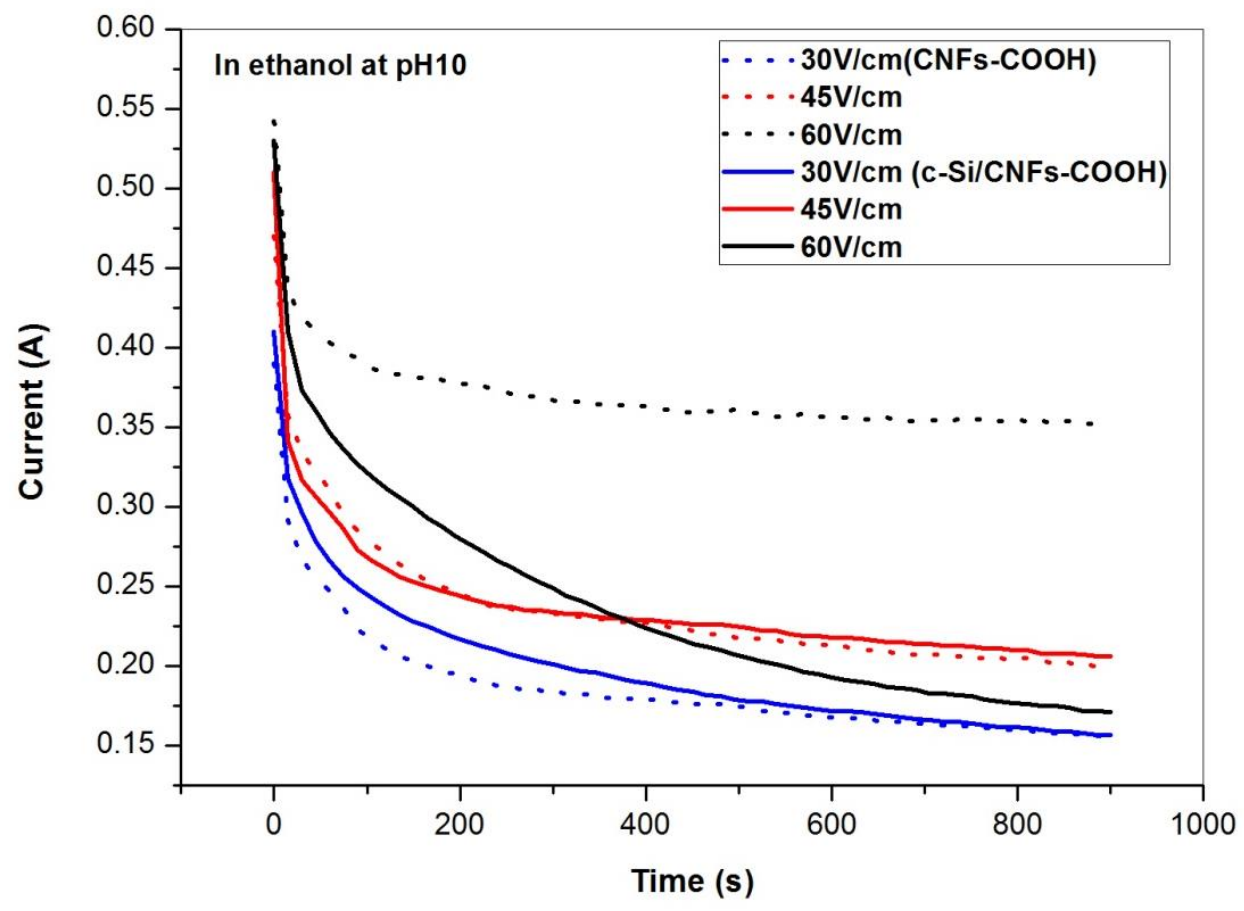

Fig.5.29: Profiles of current changing in c-Si/CNFs-COOH suspensions with different applied voltages. Total concentration: $0.5 \mathrm{mg} / \mathrm{mL} \mathrm{CNFs}+0.2 \mathrm{mg} / \mathrm{mL} \mathrm{Si}$. 
As shown in Fig.5.29, the current changing with time in c-Si/CNFs-COOH suspension looks similar to that obtained in CNFs suspension when the applied voltage is not too high $(<45$ $\mathrm{V} / \mathrm{cm}$ ), indicating little influence of $\mathrm{c}-\mathrm{Si}$ on the movement of CNFs and deposition. Therefore, the growth of the composite layer should be similar to the growth of CNFs film. SiNPs are randomly deposited along with the growth of CNFs film. If the applied voltage is higher (>45 $\mathrm{V} / \mathrm{cm}$ ), there is a clear distinction between different current changing profiles. After the rapid decrease of the current in the first several seconds $(<30 \mathrm{~s})$, the decrease trend in the composite suspension is still high, meaning the obvious increase of the film resistance with deposition time.

Based on the current changing profiles, the possible growth mechanism of c-Si/CNFs$\mathrm{COOH}$ film is shown in Fig.5.30. In the composite suspension at $\mathrm{pH}$ 10, CNFs are dispersed well and keep stable in short time standing $(<1 \mathrm{~h})$. Influenced by the space effect of CNFs, the settling rate of SiNPs slows down and SiNPs are locating around CNFs. Each Si nanoparticle doesn't have enough functional groups $(-\mathrm{OH})$ on the surface, so it's hard to avoid the aggregation of SiNPs during standing or deposition process. If a low electric field is applied (low-voltage EPD), CNFs with negative-charged surface in dilute suspension immediately move to the positive electrode. Their surface charges are neutralized when CNFs are close enough to the electrode, and then a loose deposit film is preliminarily formed. During this process, a small amount of SiNPs with negative surface look like riding CNFs coattails, which are deposited around CNFs randomly and have little influence on either CNFs deposition or the film conductivity. As a result, the growth of the composite film is highly same to the growth of CNFs film. As the increase of time, more CNFs are deposited onto the surface of as-deposited film and less free ions in the suspension are left. Finally, an intact film mainly is formed, mainly consisting of CNFs and some aggregated Si particles distributed in the interspace of CNFs.

If a high electric field is applied, the total deposition (movement) rate is quicker. However, the entanglement among long-chain CNFs also becomes serious, leading to more increase of SiNPs deposition rate than that of CNFs. Therefore, more SiNPs but less CNF are deposited at the beginning, forming a poor-conductive layer at the surface of $\mathrm{Cu}$ foil and leading to the decrease of current during deposition. As deposition time increasing, the film's conductivity becomes lower and the inner electric field becomes weaker, making SiNPs' movement too slow to be deposited, but some CNFs can still be deposited with gravity effect and inertia effect thanks to their size. 


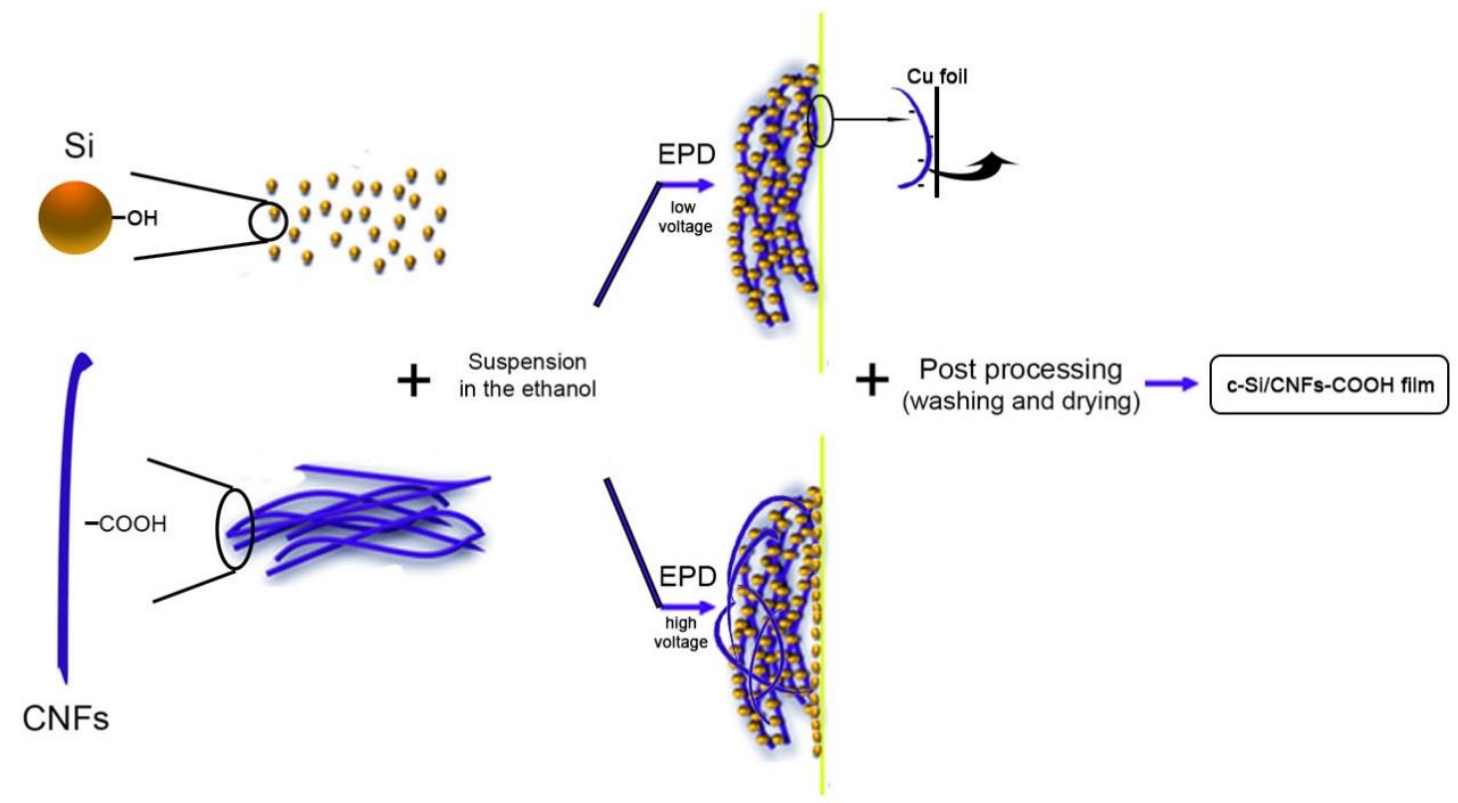

Fig.5.30: Diagram of the growth of the film on $\mathrm{Cu}$ foil with different voltages in c-Si/CNFs$\mathrm{COOH}$ suspension

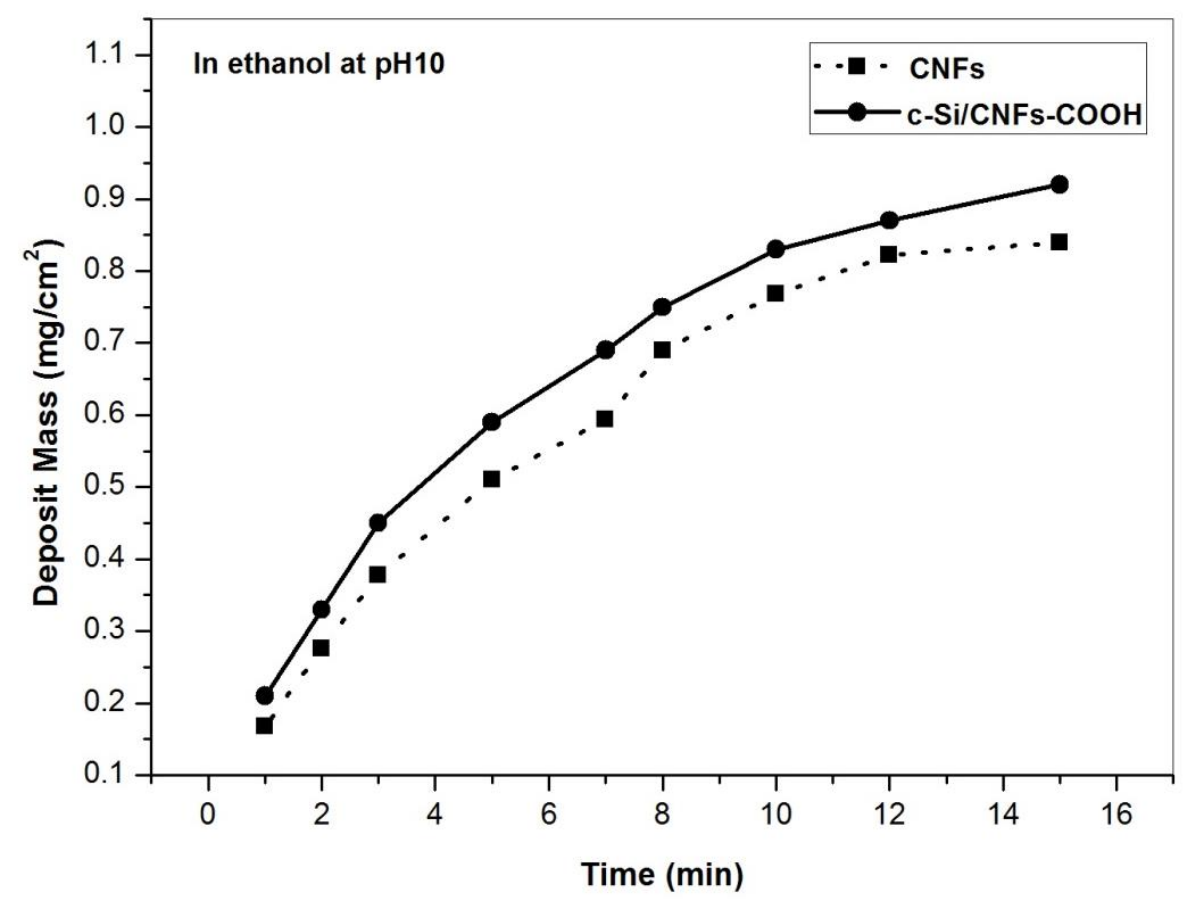

Fig.5.31: Profiles of deposited mass changing with time in c-Si/CNFs-COOH suspensions. Total concentration: $0.2 \mathrm{mg} / \mathrm{mL}(\mathrm{Si})+0.5 \mathrm{mg} / \mathrm{mL}(\mathrm{C})$.

At $45 \mathrm{~V} / \mathrm{cm}$, the relationship between deposition time and the loading per unit area is shown in Fig.5.31. Compared with CNFs film, the c-Si/CNFs-COOH composite film has higher 
deposited mass under the same conditions. The deposited mass also increases with the deposition time, but the increasing trend are gradually slowing down. After $10 \mathrm{~min}$ EPD and $15 \mathrm{~min}$ EPD, the deposition density of 0.83 and $0.92 \mathrm{mg} / \mathrm{cm}^{2}$ can be obtained.

5) Morphology and electrochemical properties

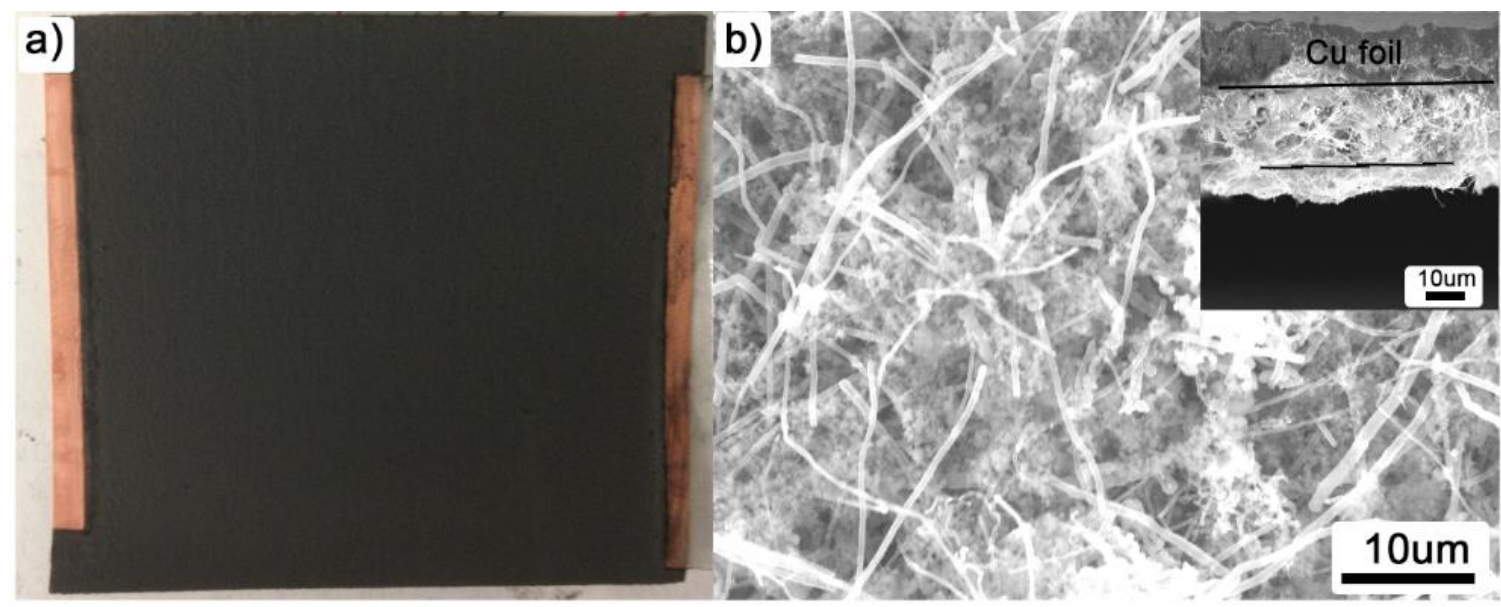

Fig.5.32: a) photograph of a composite film on $\mathrm{Cu}$ foil $\left(4 \times 3.5 \mathrm{~cm}^{2}\right)$. EPD conditions: suspension concentration: $0.5 \mathrm{mg} / \mathrm{mL}$ CNFs-COOH + $0.2 \mathrm{mg} / \mathrm{mL}$ c-Si; $\mathrm{pH}=10$; applied voltage: $45 \mathrm{~V} / \mathrm{cm}$; Deposition time: $10 \mathrm{~min}$. b) SEM image of the composite film.
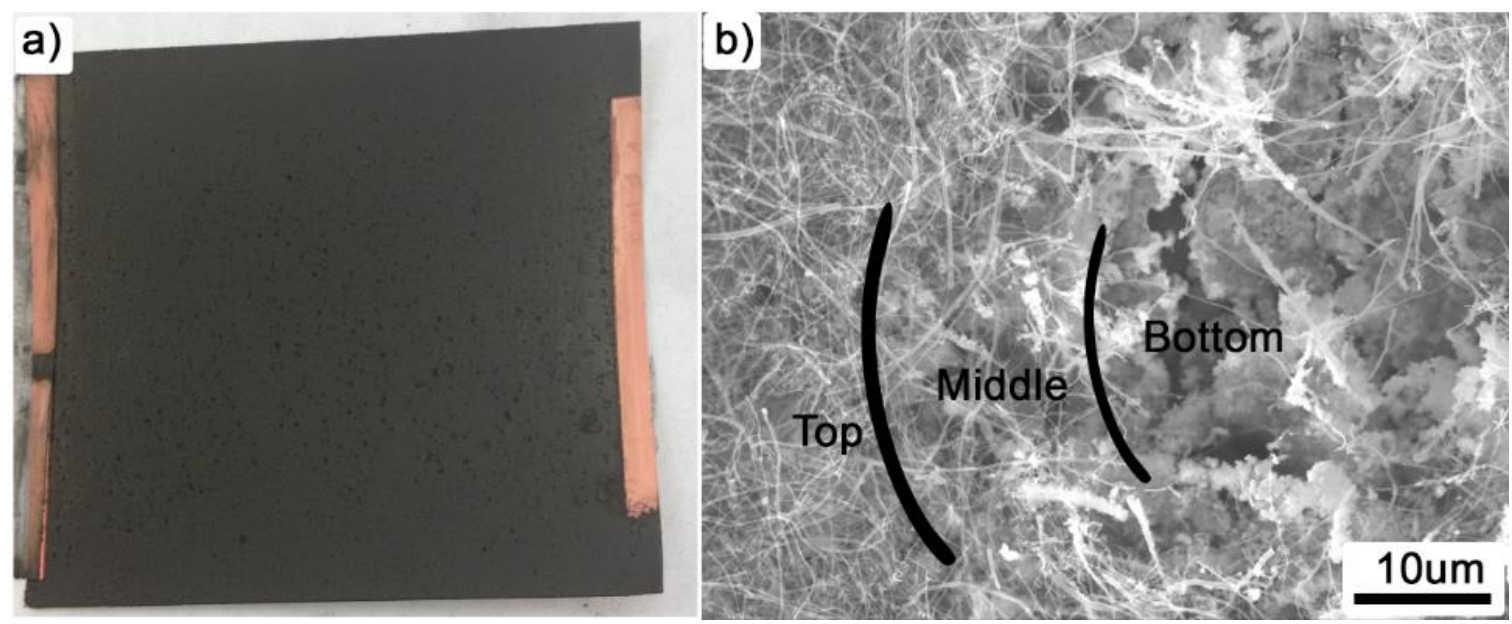

Fig.5.33: a) photograph of a composite film on $\mathrm{Cu}$ foil $\left(4 \times 3.5 \mathrm{~cm}^{2}\right)$. EPD conditions: suspension concentration: $0.5 \mathrm{mg} / \mathrm{mL}$ CNFs-COOH $+0.2 \mathrm{mg} / \mathrm{mL}$ c-Si; $\mathrm{pH}=10$; applied voltage: $60 \mathrm{~V} / \mathrm{cm}$; Deposition time: $10 \mathrm{~min}$. b) SEM image of the composite film. A c-Si/CNFs-COOH composite film is prepared by homogeneous EPD in ethanol, as shown in Fig.5.32a. The film is uniform with smooth surface, and no crack can be observed. The SEM image (Fig.5.30b) shows CNFs intertwist with each other to fabricate a continuous conductive skeleton for the anode. SiNPs aggregation is serious and most particles are 
distributed randomly among the interspace of CNFs. The thickness of the film (insert in Fig.5.32b) is about $25 \mu \mathrm{m}$.

Based on the growth mechanism analysis, the applied voltage has great influence on the structure and morphology of the composite film. As shown in Fig.5.33a, an integrated composite film can be also obtained under the high electric field, but its surface becomes rough and some pores are on it, which is related to the hydrolysis reaction of trace water in the suspension. This reaction becomes more serious with high applied voltage, and a large number of $\mathrm{H}_{2}$ bubbles appear at the surface of positive electrode, producing some pores during the growth of the film. Fig.5.33b is a SEM image of the pore wall, exhibiting non-uniform distribution of CNFs and SiNPs in the vertical direction. At the bottom of the film, plenty of SiNPs are deposited with very few CNFs skeleton. In the middle, aggregated SiNPs are locating in the CNFs net. On the top, only CNFs can be observed and few SiNPs are deposited.

The voltage profile of $\mathrm{c}-\mathrm{Si} / \mathrm{CNF}-\mathrm{COOH}$ vs. $\mathrm{Li}$ with a voltage range of $0.01-3 \mathrm{~V}$ at a current density of $400 \mathrm{mAh} / \mathrm{g}$ is showed in Fig.5.34a. The $1^{\text {st }}$ discharge and charge capacities are 990 and $620 \mathrm{mAh} / \mathrm{g}$, respectively, indicating an initial coulombic efficiency (ICE) of 63\%. The formation of SEI should be responsible for the irreversible capacity loss. High platform at $2.2 \mathrm{~V}$ during the first discharging should be caused by the lithiation of $\mathrm{CuO}_{\mathrm{x}}{ }^{[126]}$. During the following cycles, all the voltage profiles exhibit the similar lithiation/delithiation platform. 
a)
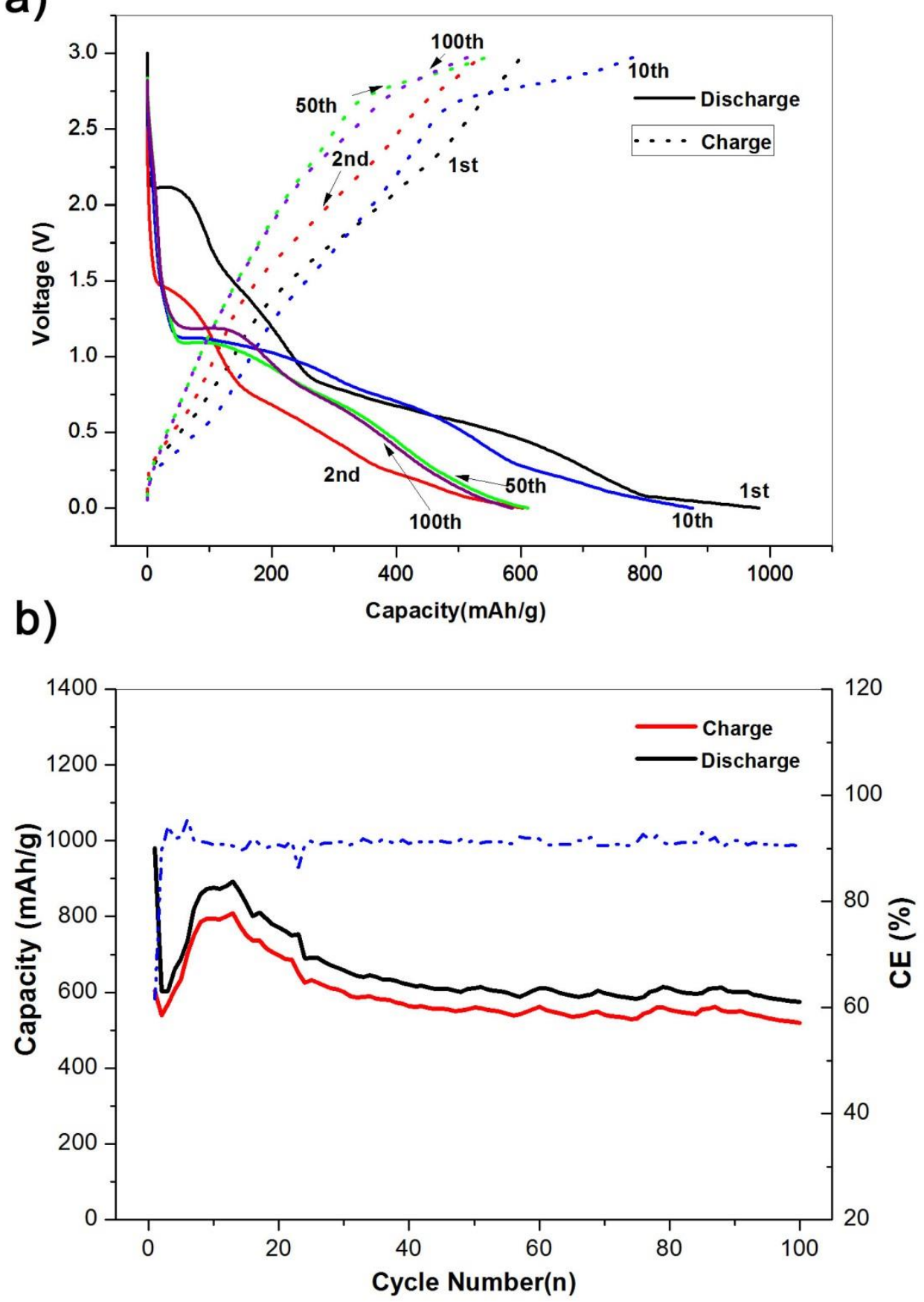

Fig.5.34: Galvanostatic discharge-charge curves for the CNFs/Si composite film; b) cycling performance of the Si/CNFs composite film.

The cycling performance of the CNFs-COOH film is showed in Fig5.34b. After the first cycle, the discharge and charge capacities rapidly decrease to 580 and $530 \mathrm{mAh} / \mathrm{g}$ in the second cycle, respectively; then increase slowly to 870 and $790 \mathrm{mAh} / \mathrm{g}$ in 18 cycles. During the following cycles, the discharge/charge capacities drop slowly again. After 100 cycles, the 
discharge capacity of $610 \mathrm{mAh} / \mathrm{g}$ can be obtained. This variation tendency indicates the gradual activation of SiNPs in the composite film. Because the inner aggregated SiNPs have no enough contact with CNFs, not all the SiNPs can be lithiated in the short time. Some new SiNPs are continuously exposed during cycles, leading to unstable SEI layer and irreversible consumption of Si anode. Fig.5.35 shows the surface morphology of the composite film after 50 cycles. A large number of cracks on the top can be observed. Therefore, the coulombic efficiency is only about $90 \%$ during cycles.

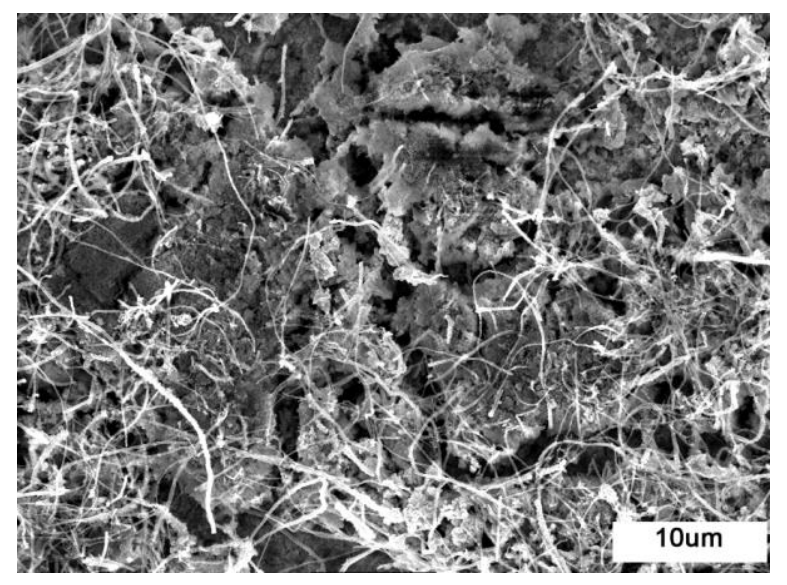

Fig.5.35: SEM image of the film after 50 cycles

Based on the structure features of Si/CNFs films, either increasing the applied voltage or improving Si content can cause worse electrochemical properties. Fig.5.36 shows the influence of high voltage on cycling performance. The $1^{\text {st }}$ discharge and charge capacity are $239 \mathrm{mAh} / \mathrm{g}$ and $169 \mathrm{mAh} / \mathrm{g}$, respectively, and the ICE is about 69\%. In the following cycles, the composite even exhibits lower capacity ( $<180 \mathrm{mAh} / \mathrm{g}$ ) than that of pure CNFs (Fig.5.18b). Such bad electrochemical property is mainly caused by the composite microstructure feature (Fig.5.33a). The Si layer locating at the bottom of the composite film cannot only prohibit the electron/ $\mathrm{Li}^{+}$ transfer during charging/discharging process, but also has huge volume effect to weaken the adhesive force with $\mathrm{Cu}$ foil. As a result, little SiNPs are activated during cycles, which have negative effect on the lithiation/delithiation process of CNFs and lead to low capacity. 


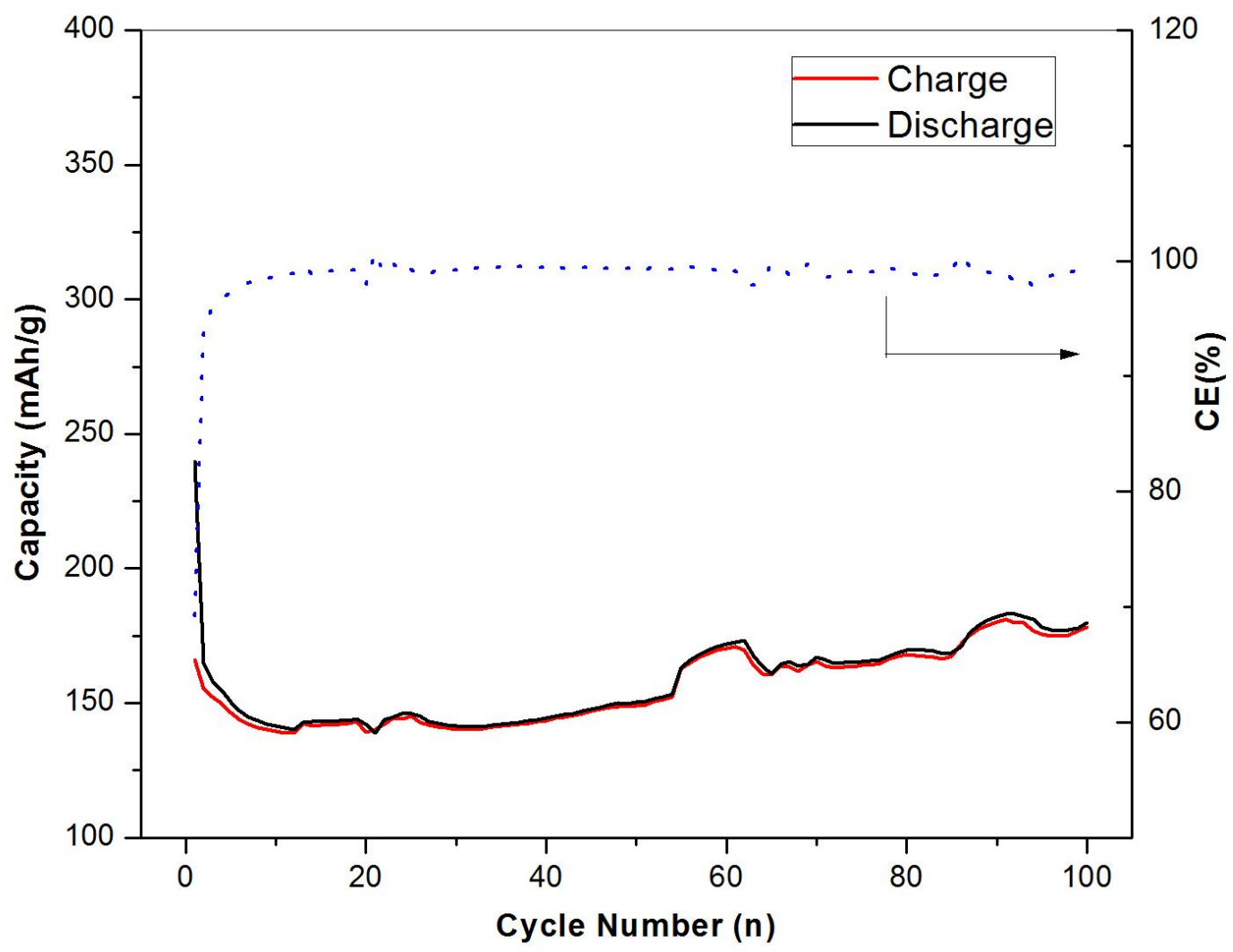

Fig.5.36: cycling performance of the composite film prepared under high electric filed $(75 \mathrm{~V} / \mathrm{cm})$ at the current rate of $400 \mathrm{~mA} / \mathrm{g}$.

As shown in Fig.5.37, if improving the initial Si concentration from $0.2 \mathrm{mg} / \mathrm{mL}$ to 0.4 $\mathrm{mg} / \mathrm{mL}$, Si aggregation become much more serious, and CNFs net has little effect on inhibiting the breakage of the structure, leading to the rapid decrease of the cycle performance of the film (Fig.5.37b).
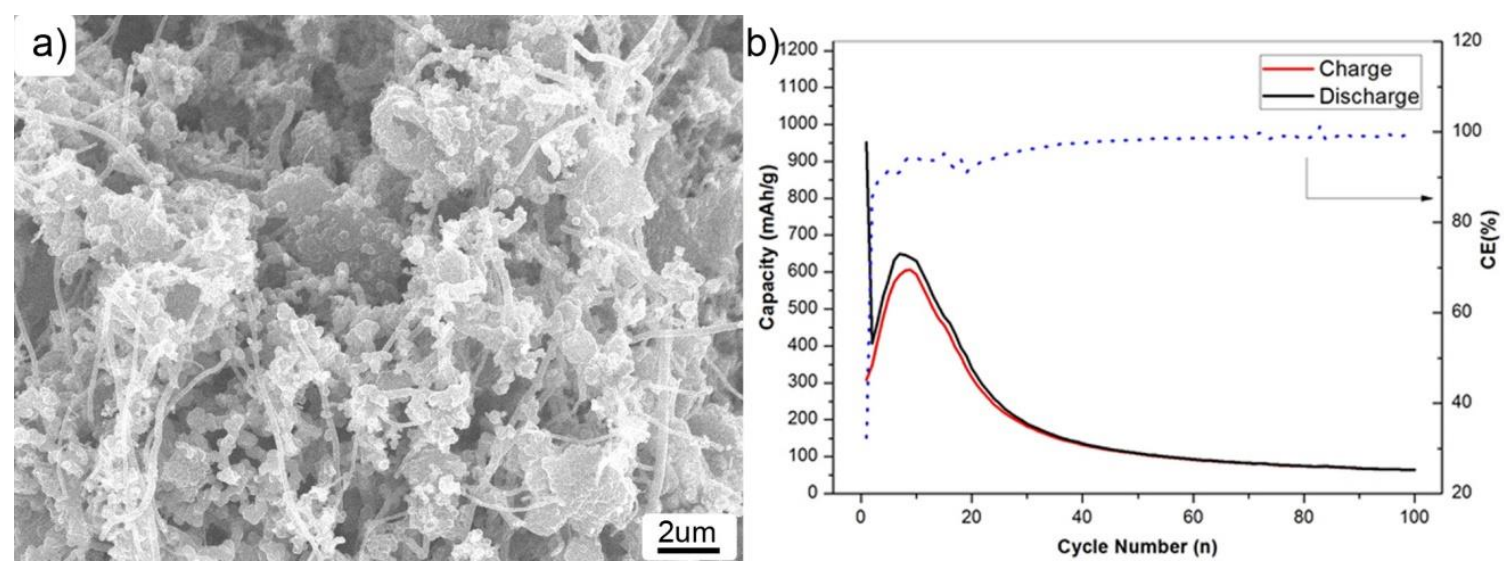

Fig.5.37: a) SEM image of the Si/CNFs film with high Si content; b) the corresponding cycle performance at the current rate of $400 \mathrm{~mA} / \mathrm{g}$. 


\subsection{Summary}

In this chapter, the stability of $\mathrm{Si} / \mathrm{CNFs}$ suspensions and their deposition dynamics during multi-component EPD were studied systematically. Si/CNFs composite films without any binder were prepared in proper suspensions by multi-component EPD. The results show:

1) EPD of CNFs

The stability of CNFs suspension in ethanol was improved after the introduction of $\mathrm{COOH}$ by acid refluxing method. In ethanol at $\mathrm{pH} 9 \sim 11$ and $\mathrm{pH} 0.5$, CNFs-COOH suspensions with the concentration of $0.5 \mathrm{mg} / \mathrm{mL}$ have relatively high zeta potential value $(>25 \mathrm{mV})$, which can keep stable in a short time $(<1 \mathrm{~h})$. If considering the influence of $\mathrm{pH}$ value on the uniformity and the integrity of the final deposited film, the suspension at $\mathrm{pH} 10$ is the best choice for short-time EPD. Higher concentration $(<2 \mathrm{mg} / \mathrm{mL})$ makes the suspension more stable but cannot make the deposited mass increasing proportionately. The deposited mass increases with the applied voltage and deposition time. However, the growth rate of the film slows down as the increase of the deposition time and excessive voltage $(>60 \mathrm{~V} / \mathrm{cm})$ can lead to serious aggregation of CNFs on the film surface. The proper voltage for EPD of CNFs is around $45 \mathrm{~V} / \mathrm{cm}$ and the time is around $10 \sim 15 \mathrm{~min}$. Under such conditions, a uniform and dense CNFs film with the maximum deposition density of 0.84 $\mathrm{mg} / \mathrm{cm}^{2}$ can be obtained.

\section{2) $\mathrm{EPD}$ of $\mathrm{Si} / \mathrm{CNFs}$}

Although Si suspensions in ethanol at pH $0.5-11$ are not stable, stable Si/CNFs suspensions can be prepared in ethanol at pH $9 \sim 10$ because a small amount of SiNPs $(<0.8$ $\mathrm{mg} / \mathrm{mL})$ have little influence on CNFs surface charge $(0.5 \mathrm{mg} / \mathrm{mL})$ and their settlement can be inhibited by the space effect of CNFs, making the multi-component EPD possible. The deposited mass of the Si/CNFs film increases with the deposition time and applied voltage. If the applied voltage is low $(<60 \mathrm{~V} / \mathrm{cm})$, SiNPs deposition and CNFs deposition are relatively independent. If the voltage is higher than $60 \mathrm{~V} / \mathrm{cm}$, the porous structure of the composite film is formed due to the turbulence effect, and more bulk SiNPs are deposited at the bottom with improved deposition rate. Therefore, the optimal conditions for preparing uniform and dense Si/CNFs films by EPD are using the composite suspension at pH10 with the external electric field of $45 \mathrm{~V} / \mathrm{cm}$. After 15 min deposition, the deposited mass of $0.92 \mathrm{mg} / \mathrm{cm}^{2}$ can be obtained. 
3) Preparation of Si/CNFs films with improved electrochemical properties by multicomponent EPD

A uniform Si/CNFs composite with the thickness of 25 um was prepared in ethanol at pH10 by 10-min multicomponent EPD. The initial weight ratio of Si to CNFs is $2 / 5$. CNFs fabricate the continuous conductive net, while the aggregated SiNPs are randomly distributed in it. The deposited mass is about $0.83 \mathrm{mg} / \mathrm{cm}^{2}$. The film exhibits good cycle performance with the capacity of $610 \mathrm{mAh} / \mathrm{g}$ after 100 cycles, but the corresponding Coulombic efficiency is only $90 \%$, meaning SiNPs distribution should be improved further to make SEI layer more stable during cycles. 


\section{Chapter 6}

\section{MULTI-COMPONENT EPD OF MODIFIED- Si/CNFs COMPOSITION ANODE FOR LIB}

\subsection{Introduction}

As the future demands on power and energy density in the field of portable device and electric vehicle increase, lighter, smaller, and long-lasting LIB is needed. Si is the most promising anode material with a theoretical specific capacity of 4,200 mAh/g. However, pure $\mathrm{Si}$ anode is still far away from commercialization due to poor conductivity and huge volume change during cycles.

The most popular way to achieve the use of $\mathrm{Si}$ in LIB is introducing carbonaceous materials into $\mathrm{Si}$-based anode. A large number of $\mathrm{Si} / \mathrm{C}$ composite materials have been prepared (Chapter2.3). Besides the introduction of $\mathrm{C}$, some functional groups have been also introduced onto Si surface via surface modification to enhance the physical contact between Si and $\mathrm{C}^{[127-}$ ${ }^{128]}$, which greatly increase the anode cycle life.

More importantly, the functional groups can directly influence the stability of Sicontaining suspension via influencing the EDL of $\mathrm{Si}$, and leads to different mobility rates and deposition rates of Si during EPD. Therefore, the surface modification of $\mathrm{Si}$ is beneficial to the design of microstructure of $\mathrm{C} / \mathrm{Si}$ composite and EPD dynamics analysis.

In this section, based on the results in Part3, some Si/CNFs composite films with specific microstructures are prepared by EPD. The influence of Si surface modification on suspension stability, film growth and morphology are studied. The electrochemical properties of films with different Si particles are analyzed.

\subsection{Structural design and experiment}

\subsubsection{Structural design}

$\mathrm{CNFs}$ and commercial Si nanoparticles (SiNPs) were chose as the raw materials.

There are two main problems for the $\mathrm{c}-\mathrm{Si} / \mathrm{CNFs}-\mathrm{COOH}$ composite films prepared in Part3: 1) no strong link between CNFs and SiNPs; 2) serious Si aggregation. During 
charging/discharging cycles, although the integrity of the film can be maintained well, inner SiNPs easily lose the electrical contact with CNFs. Meanwhile, no stable SEI layer is formed in many same areas. Therefore, this part mainly focuses on Si distribution and interaction between CNFs and SiNPs.

Two objectives should be achieved in this section.

Firstly, different functional groups such as hydroxyl $(-\mathrm{OH})^{[129]}$ or amino $\left(-\mathrm{NH}_{2}\right)^{[130]}$ would be introduced onto Si surface, and each modification method has the positive influence on the stability of suspension and the film quality after EPD. The requirement on the method of Si surface modification is simple and efficient.

Secondly, several composite films with specific microstructures would be prepared by EPD with the help of Si surface modification. The microstructure depends on the experimental conditions, and has at least one feature as follow: 1) well distribution of Si in the CNFs net and no serious aggregation; 2) strong interaction between Si and CNFs during EPD. The electrochemical properties of these films, such as specific capacity, ICE or cycle life, should be improved a lot.

\subsubsection{Experiment}

The steps are listed as follow.

1) Hydroxylation of SiNPs $(\mathrm{Si}-\mathrm{OH}){ }^{[129]}$. SiNPs were firstly immersed into HF solution for $0.5 \mathrm{~h}$, then refluxed in the piranha solution $\left(1: 2 \mathrm{v} / \mathrm{v} \mathrm{H}_{2} \mathrm{SO}_{4}: \mathrm{H}_{2} \mathrm{O}_{2}\right)$ for $30 \mathrm{~min}$ at $80^{\circ} \mathrm{C}$. In the end, they were washed to neutral by deionized water and dried in vacuum oven for $3 \mathrm{~h}$ at $100^{\circ} \mathrm{C}$.

2) Amination of SiNPs $\left(\mathrm{Si}-\mathrm{NH}_{2}\right){ }^{[130]}$. After the hydroxylation of SiNPs, the particles are immediately transferred into the mixture of APTES and ethanol $(1: 15 \mathrm{v} / \mathrm{v})$. After $3 \mathrm{~h}$, all the particles were took out and rinsed by ethanol to remove the excessive APTES. In the end, they were dried in a vacuum oven for $3 \mathrm{~h}$ at $100^{\circ} \mathrm{C}$.

3) Preparation of suspensions. The mixture of modified-Si/CNFs-COOH with different weight ratios were dispersed into $50 \mathrm{~mL}$ ethanol followed by ultrasonication for $2 \mathrm{~h}$. $\mathrm{LiOH}$ and $\mathrm{HCl}$ were used to adjust the corresponding $\mathrm{pH}$ value of 1 11. Different surfactants and electrolyte additives were also used to improve the stability of suspensions.

4) Zeta potential measurement and EPD procedures. See Chapter4. 


\subsection{Surface modification of SiNPs}

Si nanoparticles (SiNPs) have the average size of 50 100 nm, as shown in Fig.6.1a, and the surface treatment didn't change the size or morphology of SiNPs, as shown in Fig.6.1b and c.

a)

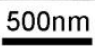

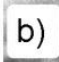

b)

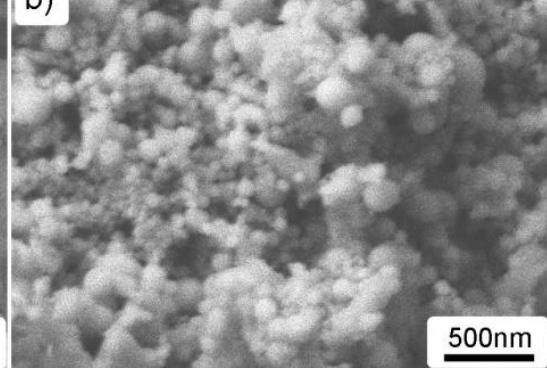

c)

Fig.6.1: $\mathrm{SEM}$ images of a) c-SiNPs, b) Si-OH particles and c) $\mathrm{Si}-\mathrm{NH}_{2}$ particles.

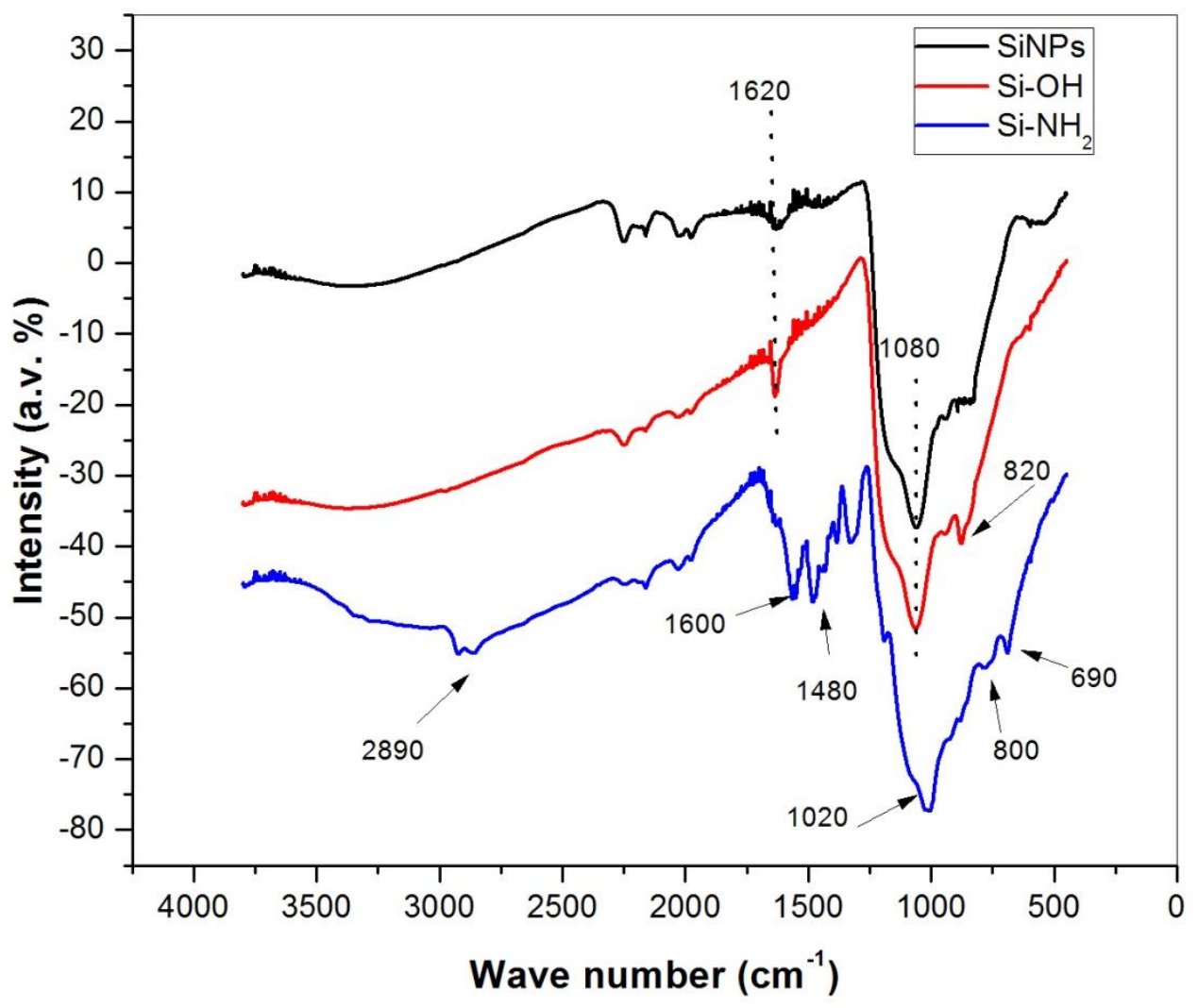

Fig.6.2: FTIR spectra of SiNPs before and after surface modification

Fig.6.2 shows the FTIR spectra of SiNPs and modified-Si, and the corresponding absorption peaks are summarized in Table6.1. For SiNPs, a strong Si-O-Si stretching peak at $1080 \mathrm{~cm}^{-1}$ is observed, indicating the presence of $\mathrm{SiO}_{2}$ layer on the surface. It's noticed that this peak is almost unchanged after surface treatment, meaning the modification indeed occur at the 
surface only. The peak at $1620 \mathrm{~cm}^{-1}$ can be assigned to $-\mathrm{OH}$ bending vibration from the physically absorbed water. For $\mathrm{Si}-\mathrm{OH}$, a new peak at $820 \mathrm{~cm}^{-1}$ corresponding to the $\mathrm{Si}-\mathrm{OH}$ groups can be observed, confirming the successful introduction of $-\mathrm{OH}$ groups. For $\mathrm{Si}-\mathrm{NH}_{2}$, the new peaks at $690 \mathrm{~cm}^{-1}$ and $2890 \mathrm{~cm}^{-1}$ are attributed to $\mathrm{Si}-\mathrm{C}$ and $-\mathrm{CH}_{2}$ groups from the residual APTMS, respectively. The peak at $1480 \mathrm{~cm}^{-1}$ is attributed to the deformation vibration of $-\mathrm{NH}_{2}$ groups. The peaks at $3200 \mathrm{~cm}^{-1}$ corresponding to $\mathrm{NH}_{2}$ stretching vibration is not obvious because it overlaps with $-\mathrm{OH}$ stretching vibrations.

Table6.1: Assignment of infrared absorptions for SiNPs and modified-Si.

\begin{tabular}{|c|c|c|c|}
\hline \multirow[t]{2}{*}{ Assignment } & \multirow[t]{2}{*}{$\begin{array}{c}\text { Wavenumber } \\
\text { (literature }^{[131]} \text { ) } \\
\left(\mathrm{cm}^{-1}\right)\end{array}$} & $\begin{array}{c}\text { Wavenumber } \\
\text { (experiment) } \\
\left(\mathrm{cm}^{-1}\right)\end{array}$ & $\begin{array}{c}\text { Wavenumber } \\
\text { (experiment) } \\
\left(\mathrm{cm}^{-1}\right)\end{array}$ \\
\hline & & $\mathrm{Si}-\mathrm{NH}_{2}$ & $\mathrm{Si}-\mathrm{OH}$ \\
\hline$-\mathrm{CH}_{2}$ & $2850-2945$ & 2890 & - \\
\hline $\mathrm{O}-\mathrm{H}$ bending & $1600-1630$ & 1600 & 1620 \\
\hline N-H deformation & $1430-1500$ & 1480 & - \\
\hline $\mathrm{Si}-\mathrm{O}-\mathrm{Si}$ & $1010-1190$ & 1020 & 1080 \\
\hline $\mathrm{Si}-\mathrm{OH}$ & $800-900$ & 800 & 820 \\
\hline Si-C & $670-760$ & 690 & - \\
\hline
\end{tabular}
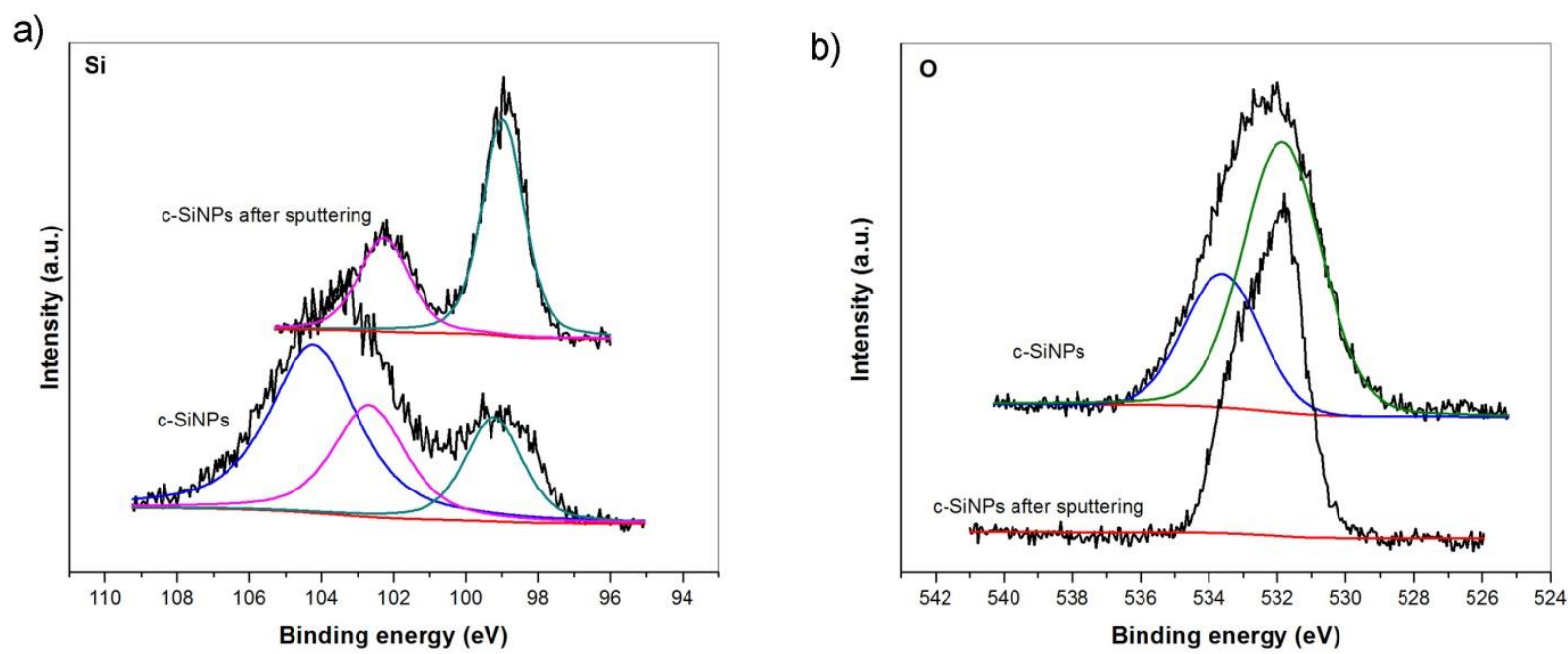

Fig.6.3: XPS spectra of c-SiNPs 
Fig.6.3 shows the XPS spectra of the pristine SiNPs, confirming the presence of a $\mathrm{SiO}_{2}$ layer on the surface. Concerning Si 2p spectrum firstly (Fig.6.3a), three peaks can be observed: one at $\sim 99.3 \mathrm{eV}$ corresponding to the bulk $\mathrm{Si}$, another one at $\sim 102.3 \mathrm{eV}$ corresponding to Si-O-H, and the last one at $\sim 104.3 \mathrm{eV}$ corresponding to $\mathrm{SiO}_{2}$. After $10 \mathrm{~min}$ Ar sputtering treatment, the peak at $\sim 99.3 \mathrm{eV}$ becomes much stronger but the peak at $\sim 104.3 \mathrm{eV}$ disappears, meaning the silica layer is removed. From O 1s spectrum (Fig.6.3b), it's also noticed that the peak at $\sim 533.7$ $\mathrm{eV}$ assigned to $\mathrm{SiO}_{2}$ disappears after 10 min sputtering.

a)
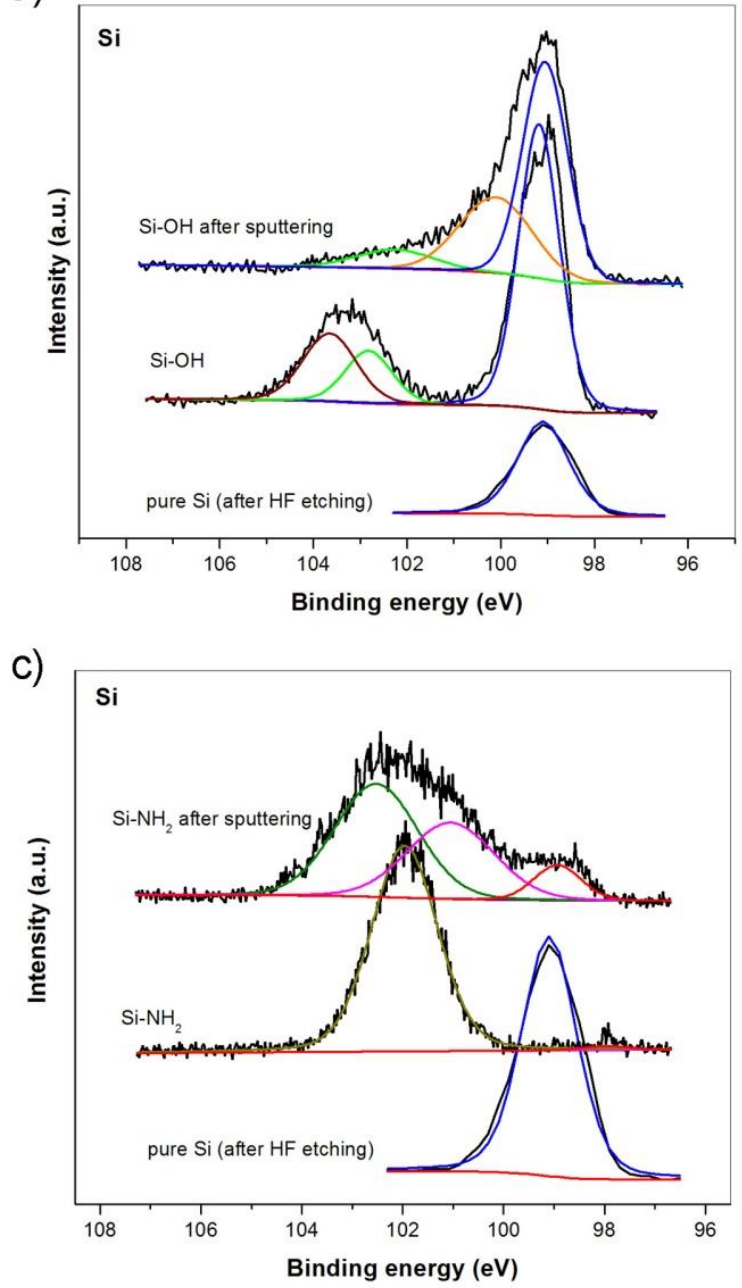

b)

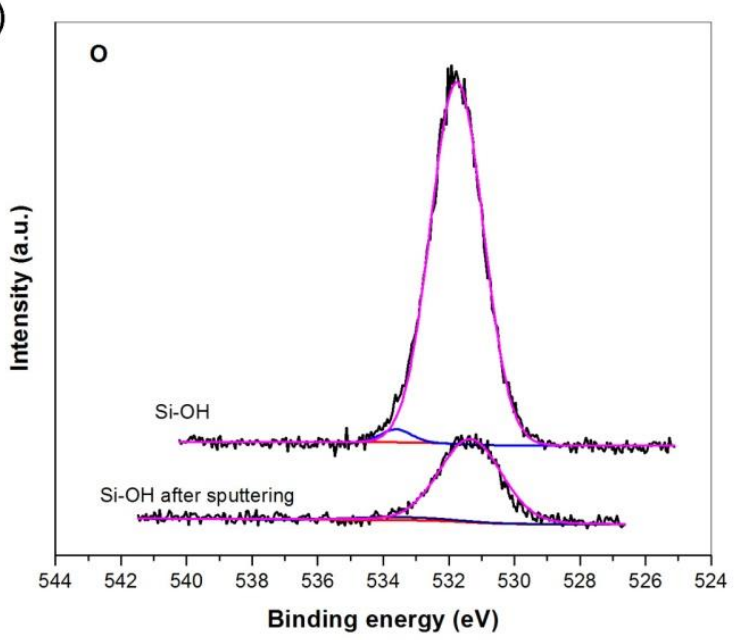

d)

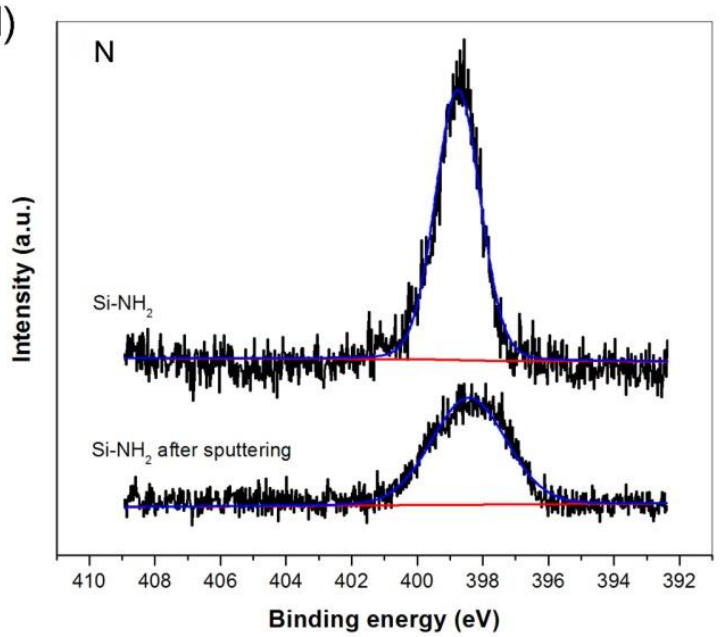

Fig.6.4: XPS spectra of a) and b) $\mathrm{Si}-\mathrm{OH}, \mathrm{c}$ ) and d) $\mathrm{Si}_{-} \mathrm{NH}_{2}$.

Fig.6.4 shows the XPS spectra of $\mathrm{Si}-\mathrm{OH}$ and $\mathrm{Si}-\mathrm{NH}_{2}$. Firstly, the $\mathrm{SiO}_{2}$ layer will be removed by $\mathrm{HF}$ etching method before surface modification, so only one peak at $\sim 99 \mathrm{eV}$ attributed to bulk Si can be observed (Fig.6.4a and 6.4c). After the introduction of -OH groups, the peak at $\sim 102.3 \mathrm{eV}$ from $\mathrm{Si} 2 \mathrm{p}$ spectrum (Fig.6.4a) and the peak at $\sim 533.6 \mathrm{eV}$ from O $1 \mathrm{~s}$ 
spectrum (Fig.6.4b) can be observed, which is assigned to $\mathrm{Si}-\mathrm{OH}$ and -OH groups, respectively. Besides, $\mathrm{SiO}_{2}$ is re-formed on the surface (the peak at $\sim 103.6 \mathrm{eV}$ ). After sputtering treatment, the peaks related to $\mathrm{Si}-\mathrm{O}-\mathrm{H}$ and $\mathrm{SiO}_{2}$ are weakened or disappear, indicating the modification reaction is limited to the surface area only. As shown in Fig.6.4c, after the introduction of $-\mathrm{NH}_{2}$ groups, the peak at $101.8 \mathrm{eV}$ assigned to $\mathrm{Si}-\mathrm{N}-\mathrm{H}$ can be observed but the peak corresponding to bulk $\mathrm{Si}$ disappears, indicating all the surface SiNPs react with APTMS to form the $-\mathrm{Si}-\mathrm{N}$ - bond. The peak at $\sim 398.2 \mathrm{eV}$ from N 1s spectrum (Fig.6.4d) corresponding to $\mathrm{NH}_{2}$ can be also observed. After 10 min sputtering, both of the peak at $101.8 \mathrm{eV}$ and the peak at $398.2 \mathrm{eV}$ become weaker and wider, and the inner $\mathrm{Si}$ is exposed again (the peak at $98.7 \mathrm{eV}$ ).

\subsection{EPD of modified-SiNPs}

1) Zeta potential

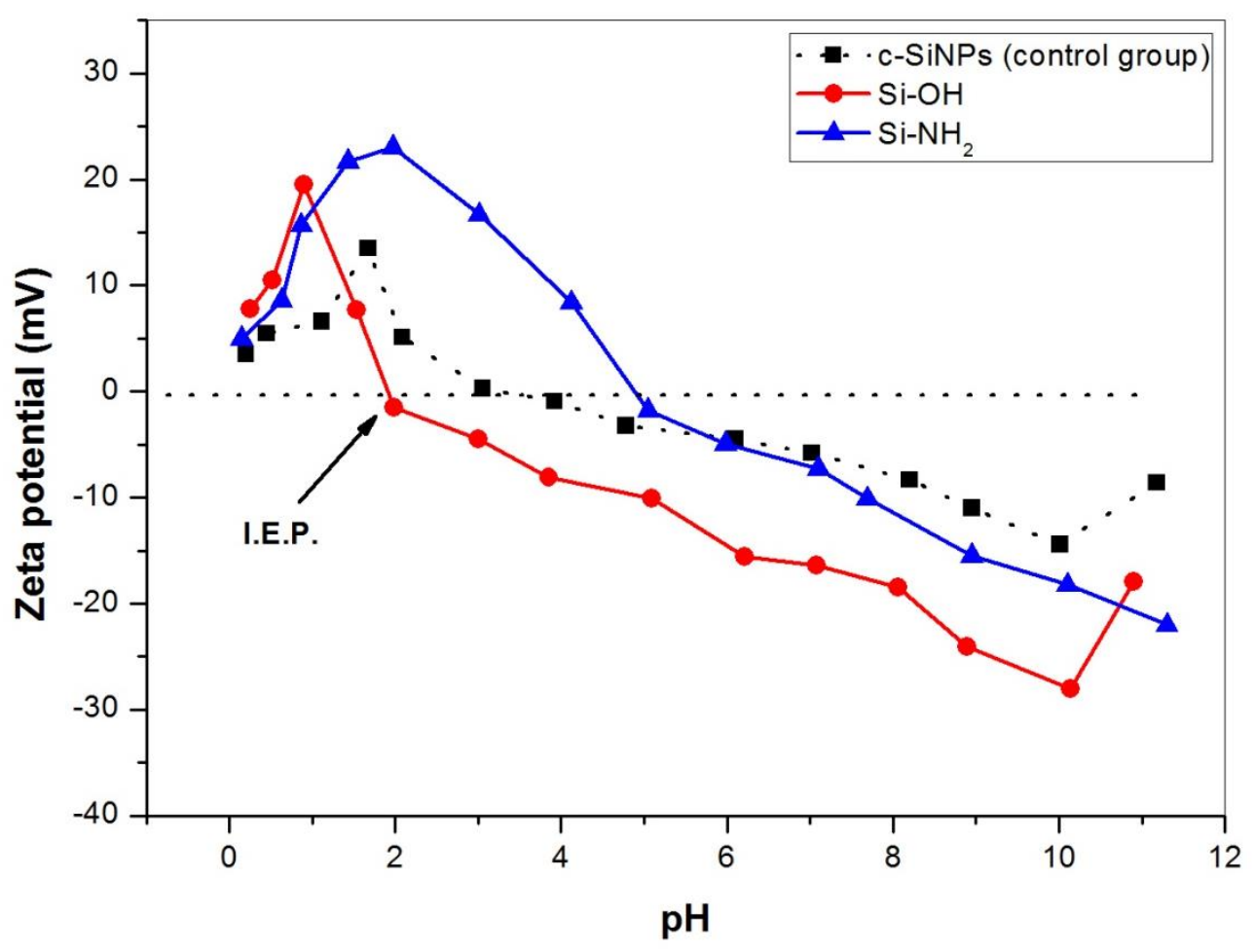

Fig.6.5: Zeta potential profiles of different Si particles in ethanol

Fig.6.5 shows the influence of surface modification on SiNPs zeta potential in ethanol.

On the one hand, the I.E.P. value is changed after introducing functional groups. Compared with c-SiNPs, Si-OH has lower I.E.P. value (2.1) because of more-OH dissociation. In theory, a particle with $-\mathrm{NH}_{2}$ group should have the I.E.P. value of higher 7 because of $-\mathrm{NH}_{2}$ dissociation; 
however, there may be some remaining - $\mathrm{OH}$ groups locating on the $\mathrm{Si}-\mathrm{NH}_{2}$ surface. Due to the synergistic effect, $\mathrm{Si}-\mathrm{NH}_{2}$ has the I.E.P. value of 5.3, higher than other samples. On the other hand, both $\mathrm{Si}-\mathrm{OH}$ and $\mathrm{Si}-\mathrm{NH}_{2}$ suspensions show better stability than c-SiNPs in ethanol. For Si$\mathrm{OH}$ suspension, the maximum absolute value of zeta potential is about $21 \mathrm{mV}$ at $\mathrm{pH} 1.4$ and 28 $\mathrm{mV}$ at $\mathrm{pH} 10.2$, respectively. And the metastable zone in basic condition seems wider than that in acidic condition. For $\mathrm{Si}-\mathrm{NH}_{2}$ suspension, the maximum absolute value is similar to that in $\mathrm{Si}-\mathrm{OH}$ suspension, about $25 \mathrm{mV}$ at pH 2.4 and $24 \mathrm{mV}$ at pH 11, respectively, but the metastable zone in acidic condition is wider than that in basic condition. Unluckily, like c-SiNPs, no matter what $\mathrm{pH}$ value is, no stable Si suspension with higher zeta potential $(>35 \mathrm{mV})$ can be obtained even after surface treatment.

If using water as the solvent, a stable suspension with high zeta potential $(>35 \mathrm{mV})$ can be obtained by adjusting $\mathrm{pH}$ value, as shown in Fig.6.6. For $\mathrm{Si}-\mathrm{OH}$, the proper $\mathrm{pH}$ value is $1.5 \sim 1.8$ and $8.5 \sim 9.5$; For $\mathrm{Si}_{-} \mathrm{NH}_{2}$, the proper $\mathrm{pH}$ value is $1.5 \sim 2.5$ and $9 \sim 11$.

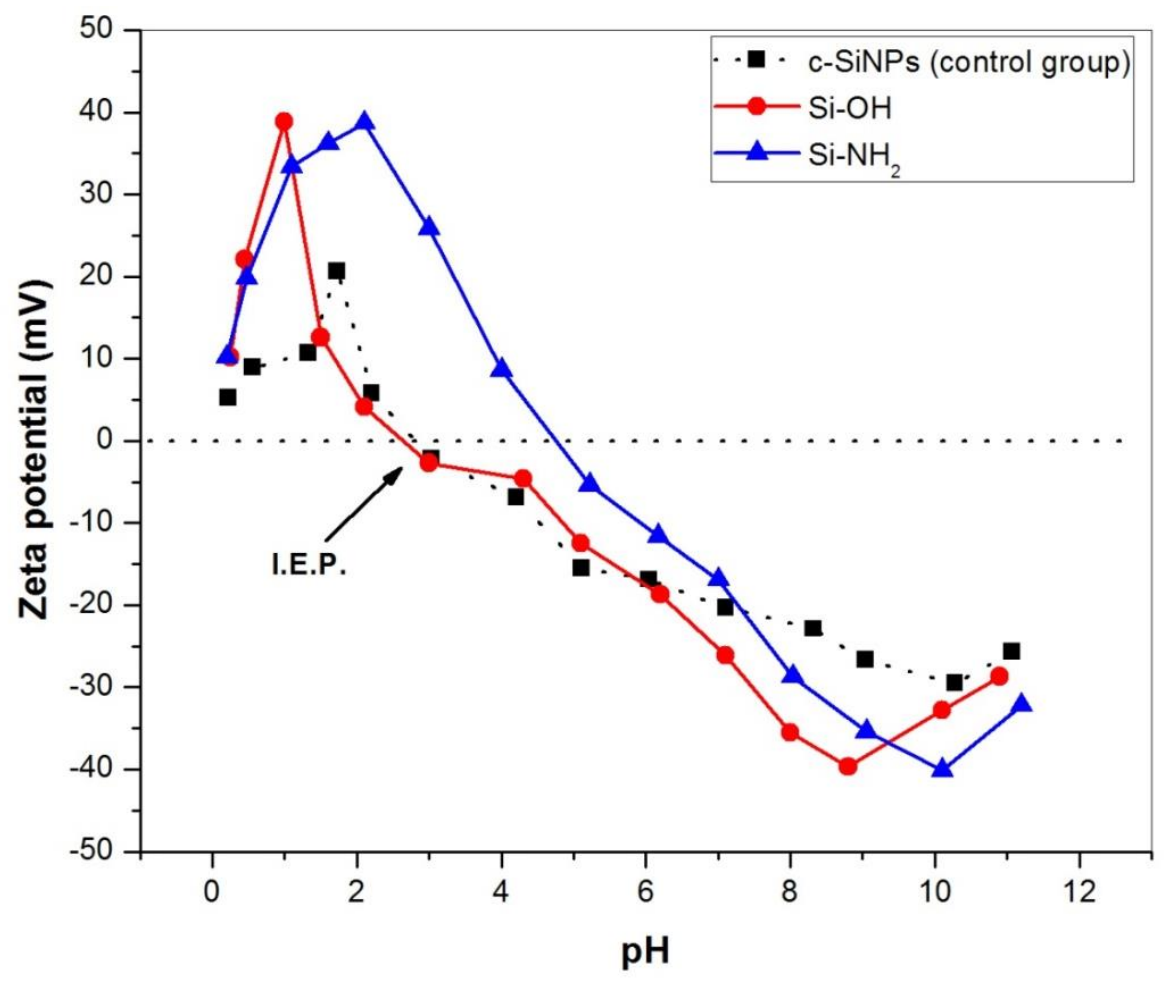

Fig.6.6: Zeta potential profiles of different Si particles in water

Fig.6.7 shows the zeta potential profiles of $\mathrm{Si}-\mathrm{OH}$ in different organic solvents.

Compared with ethanol system, the particle behavior changes little in acetone, while becomes less stable in DMF. The same results can be obtained in different $\mathrm{Si}-\mathrm{NH}_{2}$ suspensions, as shown 
in Fig.6.8. It's still very hard to prepare a stable suspension for modified-Si in organic solvents without any stabilizer.

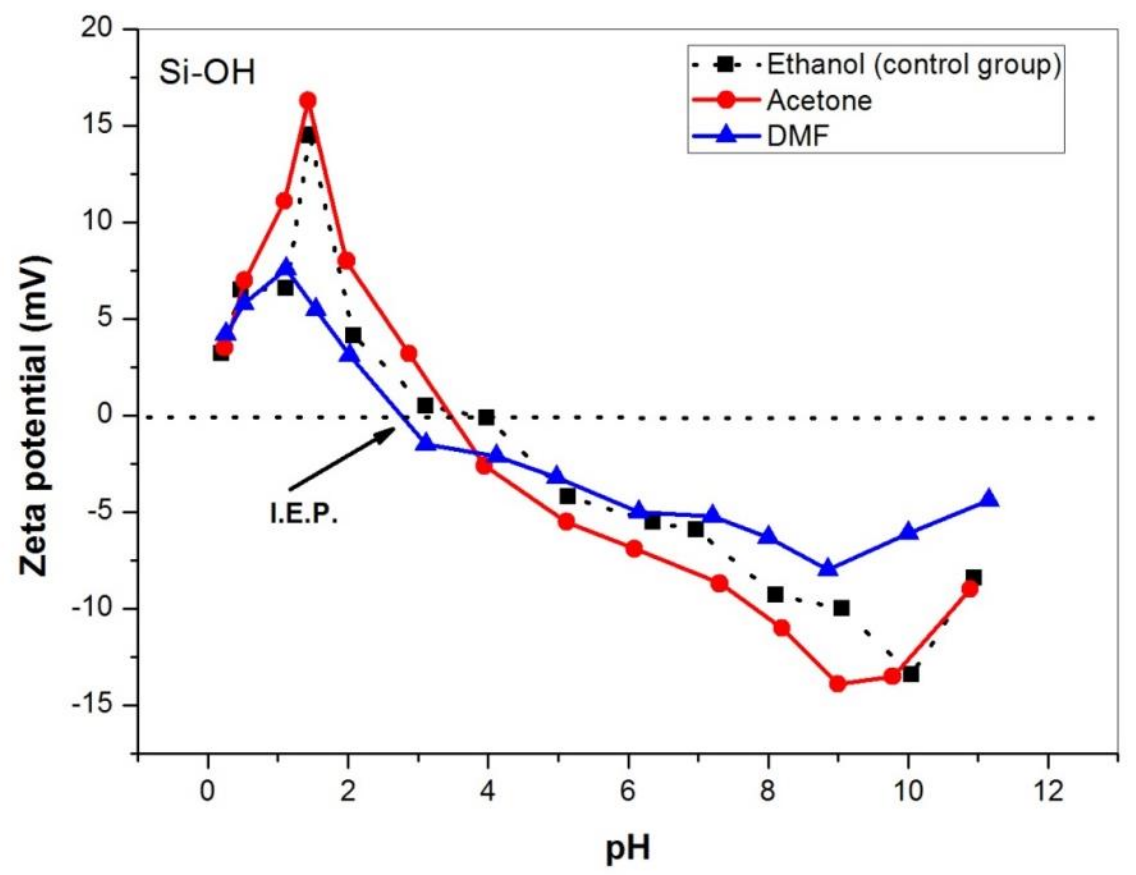

Fig.6.7: Zeta potential profiles of Si-OH suspension in different organic solvents

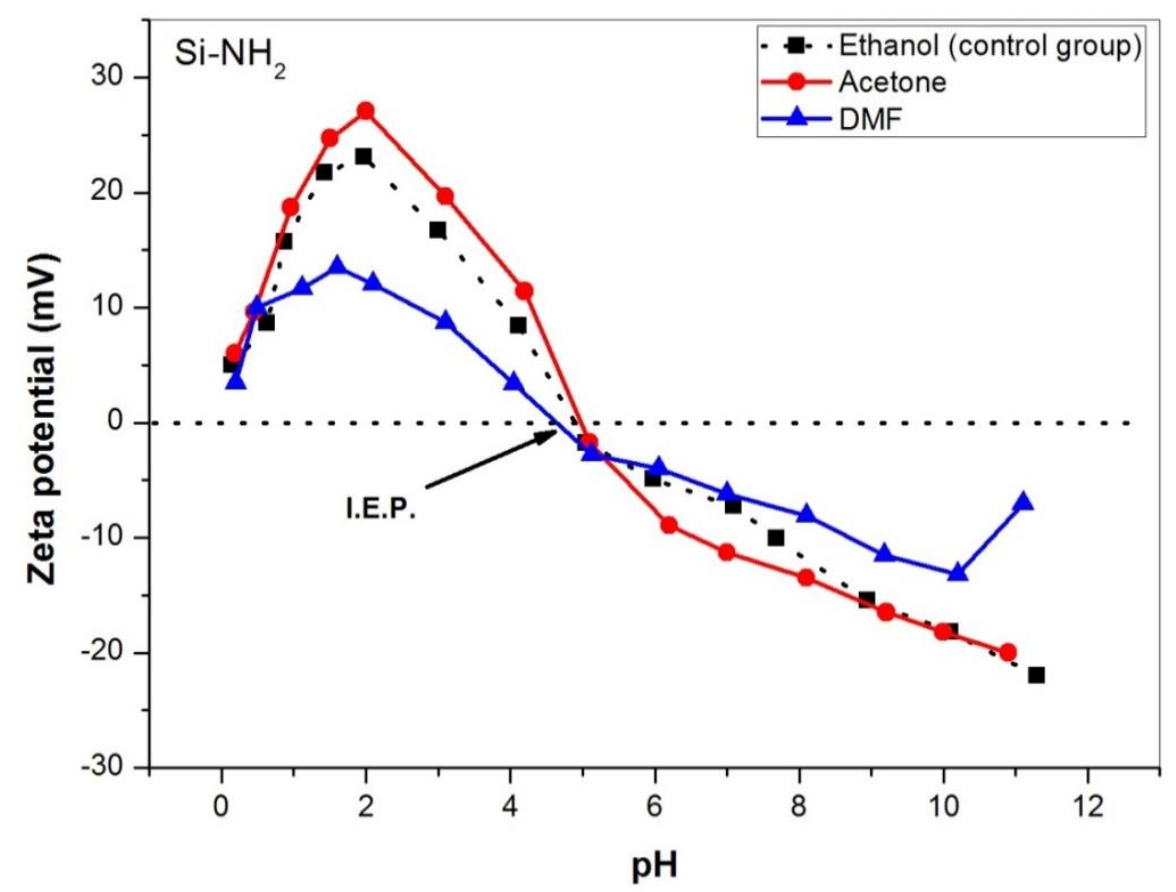

Fig.6.8: Zeta potential profiles of $\mathrm{Si}-\mathrm{NH}_{2}$ suspension in different organic solvents 
Similar to c-SiNPs system, if the suspension of modified-Si has low concentrations $(<0.8$ $\mathrm{mg} / \mathrm{mL}$ ), the changes of particle concentration has little impact on zeta potential distribution throughout the entire $\mathrm{pH}$ range, as shown in Fig.6.9.

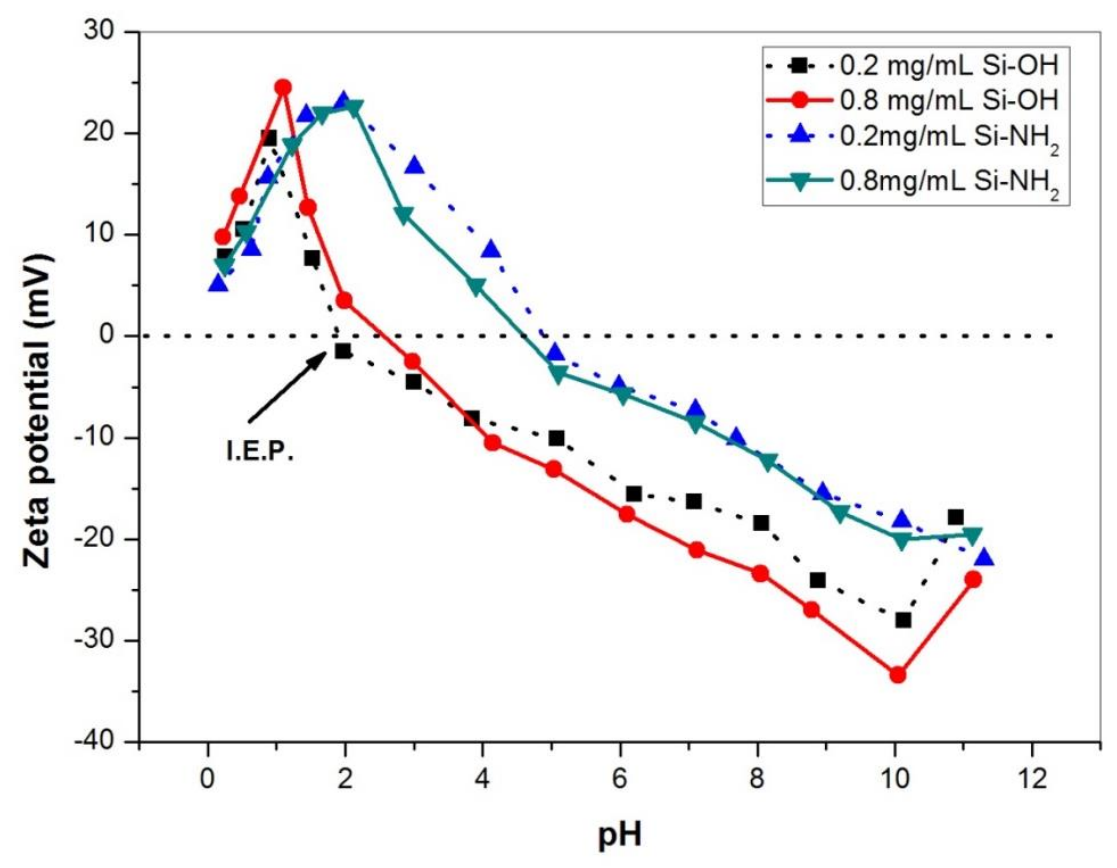

Fig.6.9: Zeta potential profiles of Si suspension in ethanol with different concentrations

Besides, in the most cases, the absolute value of zeta potential is decreased in the strong alkaline suspension, especially for $\mathrm{Si}-\mathrm{OH}$, which is caused by the reaction between $\mathrm{Si}$ and free $\mathrm{OH}^{-}$in ethanol (Eq.5.11).

1) Settling rate

It only makes sense for stable or metastable suspension to discuss the settling rate, therefore, based on the zeta potential profiles, some specific $\mathrm{pH}$ values are chose for $\mathrm{Si}-\mathrm{OH}$ and $\mathrm{Si}-\mathrm{NH}_{2}$, respectively, as shown in Table.6.2.

Table.6.2: Zeta potential values for $\mathrm{Si}-\mathrm{OH}$ and $\mathrm{Si}-\mathrm{NH}_{2}$ in different suspensions

\begin{tabular}{|c|c|c|c|c|}
\hline \multirow{3}{*}{ Particles } & \multirow{2}{*}{$\mathrm{pH}$} & \multicolumn{2}{|c|}{$\begin{array}{c}\text { Zeta potential } \\
(\mathrm{mV})\end{array}$} & \multirow{2}{*}{ State of stability } \\
\cline { 3 - 4 } & & In ethanol & In water & \\
\hline \multirow{3}{*}{ Si-OH } & 1 & 20 & 39 & |zeta potential|<35 \\
\cline { 2 - 4 } & 8 & -19 & -36 & $\mathrm{mV}:$ \\
\cline { 2 - 4 } & 9 & -24 & -40 & Metastable and \\
\hline
\end{tabular}




\begin{tabular}{|c|c|c|c|c|}
\hline & 10 & -28 & -33 & \multirow{5}{*}{$\begin{array}{c}\text { flocculated. } \\
\text { |zeta potential|>35 } \\
\mathrm{mV}: \\
\text { Very stable }\end{array}$} \\
\hline \multirow{4}{*}{$\mathrm{Si}-\mathrm{NH}_{2}$} & 1.5 & 22 & 36 & \\
\hline & 2 & 23 & 39 & \\
\hline & 3 & 17 & 25 & \\
\hline & 10 & -18 & -40 & \\
\hline
\end{tabular}

The RSH profile can better describe the difference of stability between metastable suspensions than zeta potential, as shown in Fig.6.10. Firstly, for each metastable Si-OH suspension in ethanol, the initial $\mathrm{RSH}$ is high $(>10 \%)$ and will decrease with the increase of standing time, implying no balance state between the homogeneous zone and settlement zone. At $\mathrm{pH} 1, \mathrm{pH} 8$ or $\mathrm{pH} 9$, the $\mathrm{RSH}$ decreases rapidly even in the beginning. Combining with the related $\mathrm{C}_{\mathrm{rd}}$ values (Table6.3), a serious flocculation of Si-OH should occur continuously at the bottom. The initial Si-OH concentration in the homogeneous zone is $0.4 \mathrm{mg} / \mathrm{mL}$. After $1 \mathrm{~h}$ standing, all the remnant concentrations at $\mathrm{pH} 1, \mathrm{pH} 8$ and $\mathrm{pH} 9$ are less than $0.25 \mathrm{mg} / \mathrm{mL}$. At $\mathrm{pH} 10$, the stability is a little improved, $\mathrm{C}_{\mathrm{rd}}$ still decreases with the standing time at a relative slow rate, equaling to $70 \%$ after $1 \mathrm{~h}$.

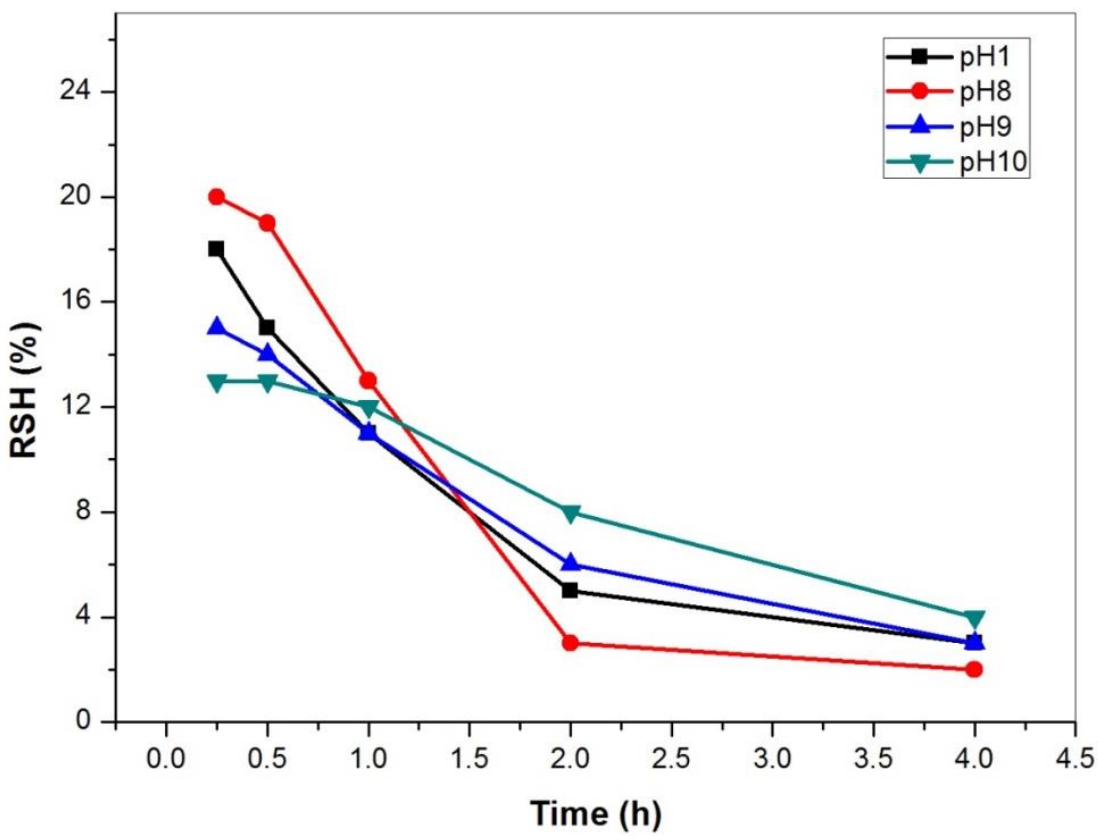

Fig.6.10: Profiles of RSH value versus standing time for $\mathrm{Si}-\mathrm{OH}$ suspensions at different $\mathrm{pH}$ values in ethanol.

Table6.3: $\mathrm{C}_{\mathrm{rd}}$ values for $\mathrm{Si}-\mathrm{OH}$ suspension in ethanol. 


\begin{tabular}{|c|c|c|c|c|}
\hline \multirow{2}{*}{$\begin{array}{c}\text { Standing time } \\
(\mathrm{h})\end{array}$} & \multicolumn{4}{|c|}{$\mathrm{C}_{\mathrm{rd}}(\%)$} \\
\cline { 2 - 5 } & $\begin{array}{c}\text { Suspension at } \\
\mathrm{pH} 1\end{array}$ & $\begin{array}{c}\text { Suspension at } \\
\mathrm{pH} 8\end{array}$ & $\begin{array}{c}\text { Suspension at } \\
\mathrm{pH} 9\end{array}$ & $\begin{array}{c}\text { Suspension at } \\
\mathbf{p H 1 0}\end{array}$ \\
\hline 0.25 & 70 & 65 & 75 & $\mathbf{8 0}$ \\
\hline 0.5 & 55 & 55 & 60 & $\mathbf{7 5}$ \\
\hline 1 & 45 & 40 & 55 & $\mathbf{7 0}$ \\
\hline
\end{tabular}

However, for $\mathrm{Si}-\mathrm{NH}_{2}$ suspensions in ethanol, all of them prefer to the unstable state. As shown in Fig6.11 and Table6.4, both of RSH and $\mathrm{C}_{\mathrm{rd}}$ values change greatly for each sample in one hour, and the concentration of the homogeneous zone decreases by at least $45 \%$. If increasing the standing time ( $>2 \mathrm{~h}$ ), the RSH values tend to be stable, meaning the possibility for short-time EPD in the homogeneous zone, but $\mathrm{C}_{\mathrm{rd}}$ values may be too low $(<50 \%)$ to obtain the dense deposited film with high loading.

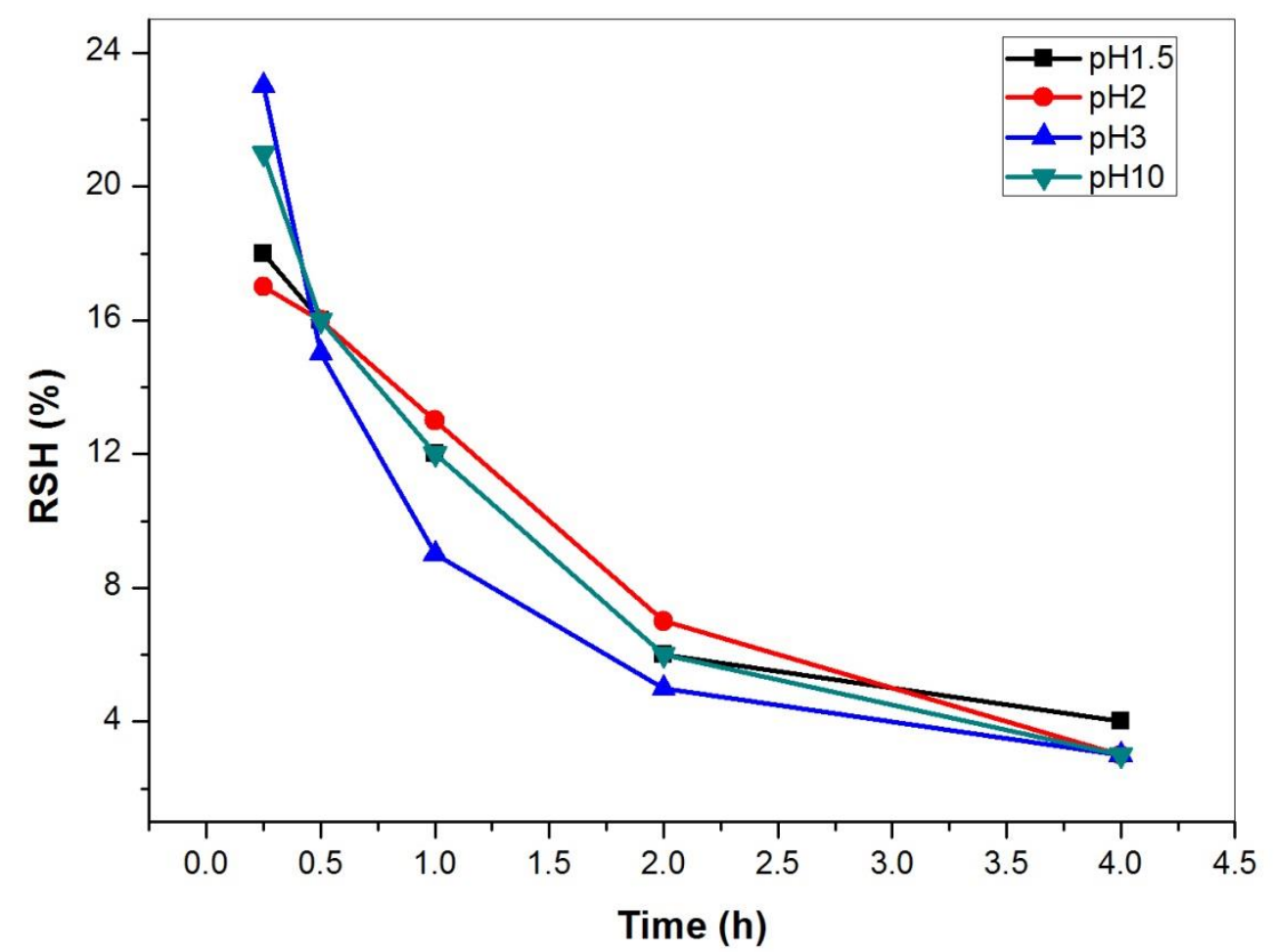

Fig.6.11: Profiles of $\mathrm{RSH}$ value versus standing time for $\mathrm{Si}_{-} \mathrm{NH}_{2}$ suspensions at different $\mathrm{pH}$ values in ethanol.

Table6.4: $\mathrm{C}_{\mathrm{rd}}$ values for $\mathrm{Si}-\mathrm{NH}_{2}$ suspension in ethanol 


\begin{tabular}{|c|c|c|c|c|}
\hline \multirow{2}{*}{$\begin{array}{c}\text { Standing time } \\
(\mathrm{h})\end{array}$} & \multicolumn{4}{|c|}{$\mathrm{C}_{\mathrm{rd}}(\%)$} \\
\cline { 2 - 5 } & $\mathrm{p}$ Suspension at & $\begin{array}{c}\text { Suspension at } \\
\mathrm{pH} 2\end{array}$ & $\begin{array}{c}\text { Suspension at } \\
\mathrm{pH} 3\end{array}$ & $\begin{array}{c}\text { Suspension at } \\
\mathrm{pH} 10\end{array}$ \\
\hline 0.25 & 70 & 75 & 65 & 70 \\
\hline 0.5 & 60 & 65 & 50 & 60 \\
\hline 1 & 50 & 55 & 40 & 55 \\
\hline
\end{tabular}

Generally, the range of zeta potential (absolute value) for a metastable suspension is 15 $35 \mathrm{mV}$, but based on the settling rate test, only those with higher zeta potential (absolute value) than $25 \mathrm{mV}$ can be used for the short-time EPD when the standing time is less than $1 \mathrm{~h}$. This conclusion can be further confirmed in the stable aqueous suspension of $\mathrm{Si}-\mathrm{OH}$ or $\mathrm{Si}-\mathrm{NH}_{2}$.

For the Si-OH aqueous suspensions at pH1 and pH9, they seem very stable with small initial RSH values (<10), as shown in Fig6.12. With the increase of standing time, the RSH even increases a little and then keeps unchanged, indicating the long-time stability. From Table6.5, it shows more particles can stay in the homogeneous zone in $1 \mathrm{~h}$ if the suspension is stable (|zeta potential| $>35 \mathrm{mV}$ ). The corresponding $\mathrm{C}_{\mathrm{rd}}$ values are $80 \%, 75 \%$ and $85 \%$ at $\mathrm{pH} 1, \mathrm{pH} 8$ and $\mathrm{pH} 9$, respectively. The similar results can be obtained for $\mathrm{Si}-\mathrm{NH}_{2}$ aqueous suspensions, as shown in Fig.6.13 and Table6.6. In the most stable suspension (at pH10), the initial $\mathrm{RSH}$ value is about $5 \%$, and the $\mathrm{C}_{\mathrm{rd}}$ value is a constant $(90 \%)$ in one hour. 


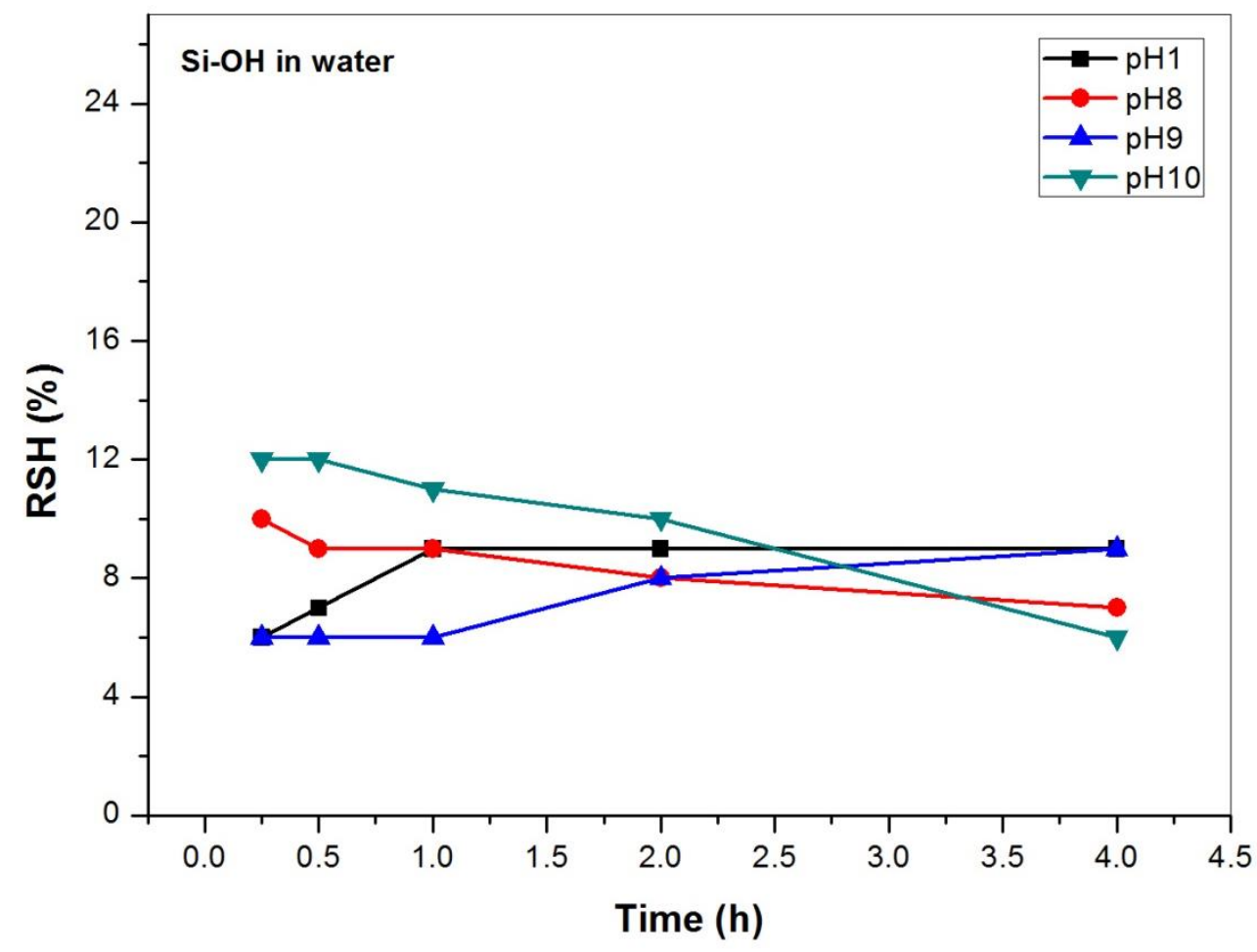

Fig.6.12: Profiles of RSH value versus standing time for $\mathrm{Si}-\mathrm{OH}$ suspensions in water. Table6.5: $\mathrm{C}_{\mathrm{rd}}$ values for $\mathrm{Si}-\mathrm{OH}$ suspension in water

\begin{tabular}{|c|c|c|c|c|}
\hline \multirow{2}{*}{$\begin{array}{c}\text { Standing time } \\
(\mathrm{h})\end{array}$} & $\begin{array}{c}\text { Suspension at } \\
\mathrm{pH} 1\end{array}$ & $\begin{array}{c}\text { Suspension at } \\
\mathrm{pH} 8\end{array}$ & $\begin{array}{c}\text { Suspension at } \\
\mathrm{pH} 9\end{array}$ & $\begin{array}{c}\text { Suspension at } \\
\mathrm{pH} 10\end{array}$ \\
\hline 0.25 & 80 & 80 & 85 & 80 \\
\hline 0.5 & 80 & 75 & 85 & 75 \\
\hline 1 & 80 & 75 & 85 & 60 \\
\hline
\end{tabular}




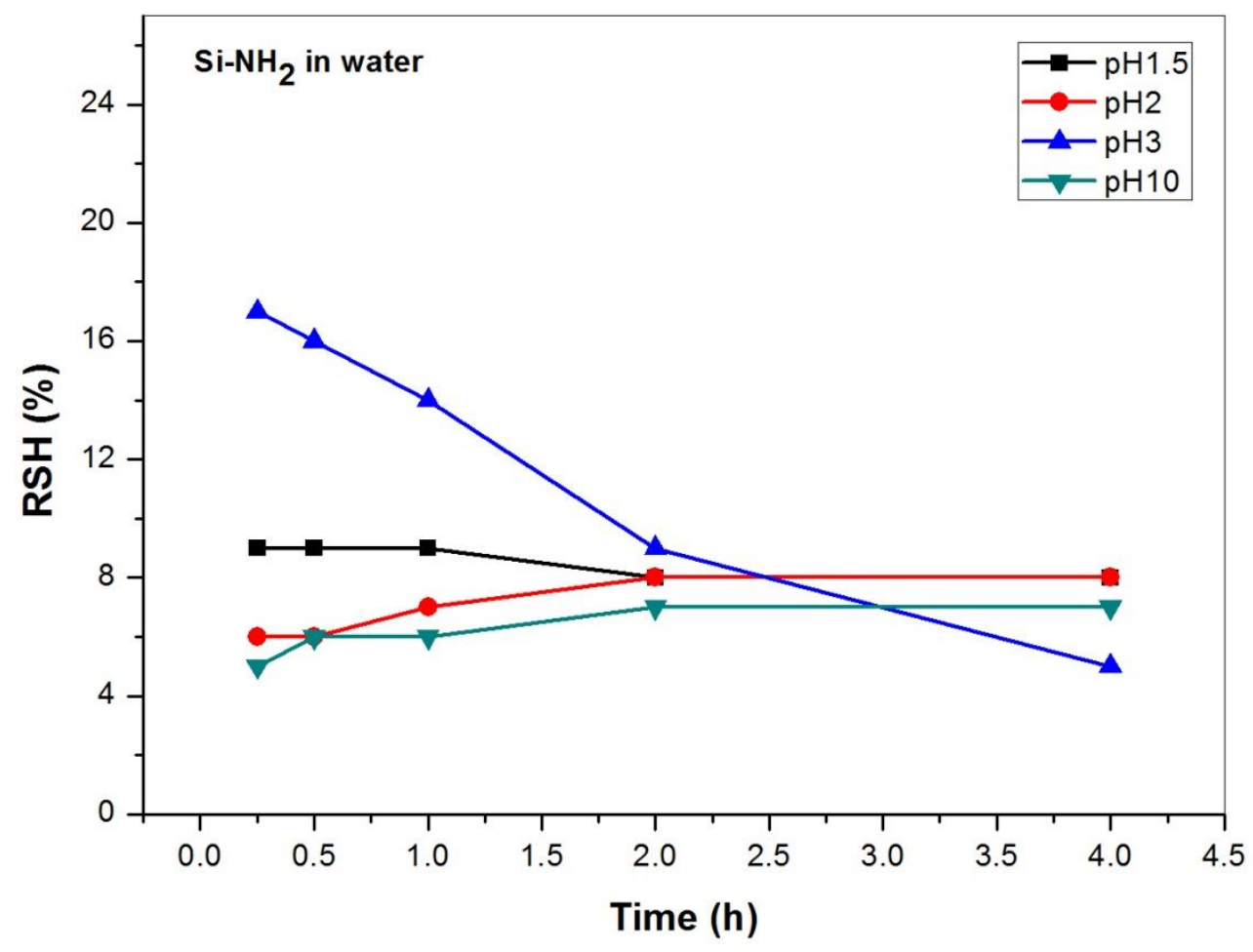

Fig.6.13: Profiles of $\mathrm{RSH}$ value versus standing time for $\mathrm{Si}-\mathrm{NH}_{2}$ suspensions in water. Table6.6: $\mathrm{C}_{\mathrm{rd}}$ values for $\mathrm{Si}-\mathrm{NH}_{2}$ suspension in water

\begin{tabular}{|c|c|c|c|c|}
\hline \multirow{2}{*}{$\begin{array}{c}\text { Standing time } \\
(\mathrm{h})\end{array}$} & \multicolumn{4}{|c|}{$\mathrm{C}_{\mathrm{rd}}(\%)$} \\
\cline { 2 - 5 } & $\begin{array}{c}\text { Suspension at } \\
\mathrm{pH} 1.5\end{array}$ & $\begin{array}{c}\text { Suspension at } \\
\mathrm{pH} 2\end{array}$ & $\begin{array}{c}\text { Suspension at } \\
\mathrm{pH} 3\end{array}$ & $\begin{array}{c}\text { Suspension at } \\
\mathrm{pH} 10\end{array}$ \\
\hline 0.25 & 85 & 85 & 70 & 90 \\
\hline 0.5 & 80 & 85 & 60 & 90 \\
\hline 1 & 80 & 80 & 50 & 90 \\
\hline
\end{tabular}

Overall, if the deposition time is less than $0.5 \mathrm{~h}$, some metastable/stable suspensions for modified-Si particles listed in Table6.7 can be used for single-component EPD.

Table6.7: $\mathrm{pH}$ range for single-component EPD process.

\begin{tabular}{|c|c|c|}
\hline Particle & Solvent & $\mathrm{pH}$ value \\
\hline \multirow{2}{*}{$\mathrm{c}-\mathrm{SiOH}$} & Ethanol & 10 \\
\cline { 2 - 3 } & Water & $1,8 \sim 10$ \\
\hline $\mathrm{c}-\mathrm{SiNH}_{2}$ & Ethanol & None \\
\hline
\end{tabular}




\begin{tabular}{|l|l|l|}
\hline & Water & $2 \sim 3,10$ \\
\hline
\end{tabular}

\section{2) Applied Voltage}

$\mathrm{Si}-\mathrm{OH}$ and $\mathrm{Si}-\mathrm{NH}_{2}$ Suspensions in ethanol were prepared respectively with a concentration of $0.4 \mathrm{mg} / \mathrm{mL}$, and EPD process was performed at $15-75 \mathrm{~V} / \mathrm{cm}$ for $10 \mathrm{~min}$. After the deposition, the yield of each sample was measured, as shown in Fig.6.14 and 6.15.

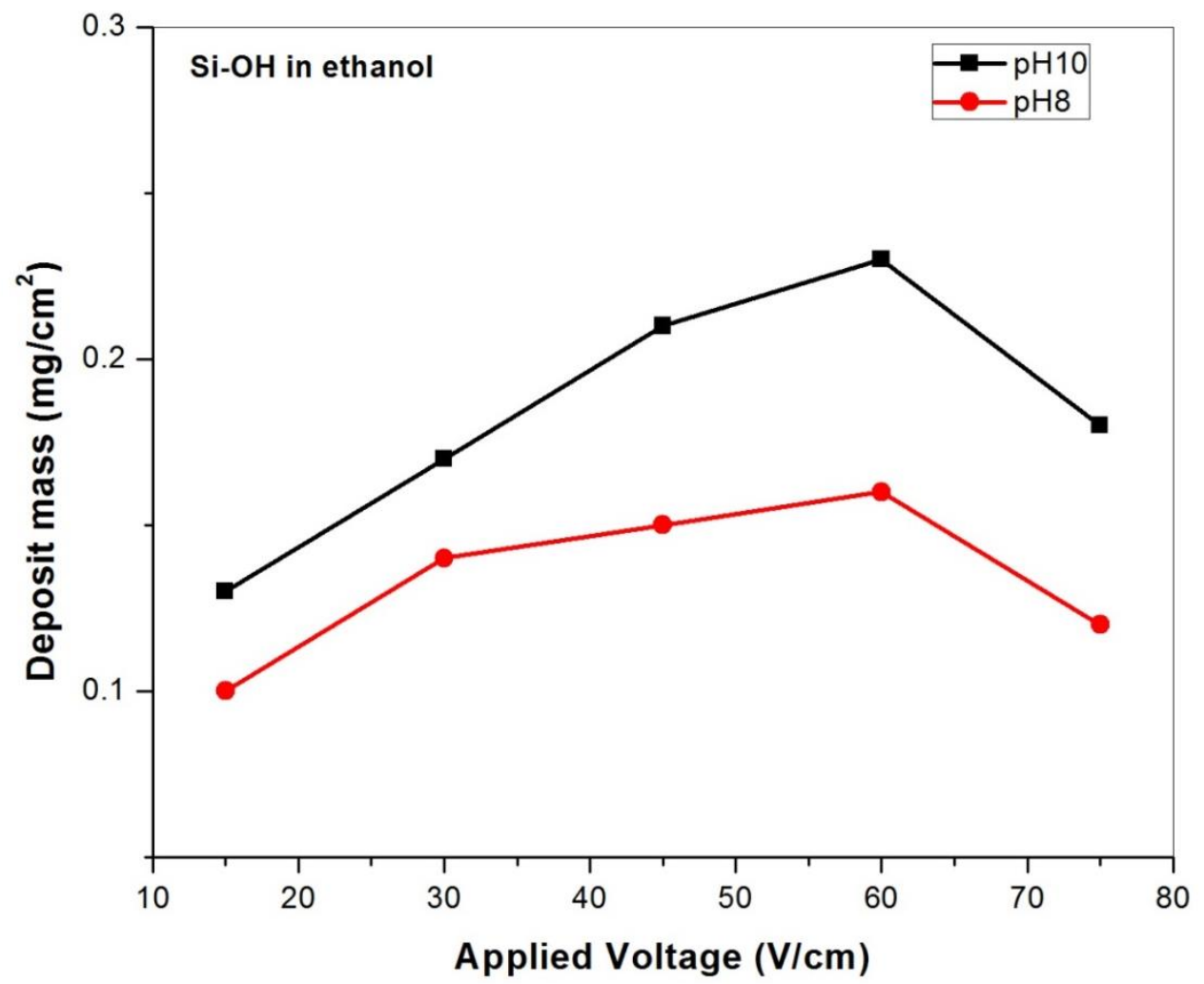

Fig.6.14: Profiles of deposited mass versus applied voltage for Si-OH EPD in ethanol

For Si-OH system (Fig.6.14), the deposition mass increase with the applied voltage (15$60 \mathrm{~V} / \mathrm{cm}$ ) and the maximum value of $0.24 \mathrm{mg} / \mathrm{cm}^{2}$ can be obtained at $60 \mathrm{~V} / \mathrm{cm}$ (pH10). However, the increasing trend is gradually slowing down, which is caused by two reasons. Firstly, particles have faster mobility rate at higher voltage so that they don't have enough time to find the best locations to fabricate a dense structure. Secondly, a stronger electric field leads to faster increase of the ethanol temperature, so the turbulence effect around the substrate becomes more serious, inhibiting the normal deposition process. If the voltage is too high $(75 \mathrm{~V} / \mathrm{cm})$, a large number of bubbles can be observed near the substrate after 5 min EPD, damaging the deposited layer and leading to the decrease of the deposition mass. Besides, under the same electric field, the 
suspension stability can also impact the deposition mass. In a suspension at $\mathrm{pH}$, the absolute value of zeta potential decreases from $28 \mathrm{mV}$ to $19 \mathrm{mV}$, and the maximum value decreases from $0.24 \mathrm{mg}$ to $0.14 \mathrm{mg}$.

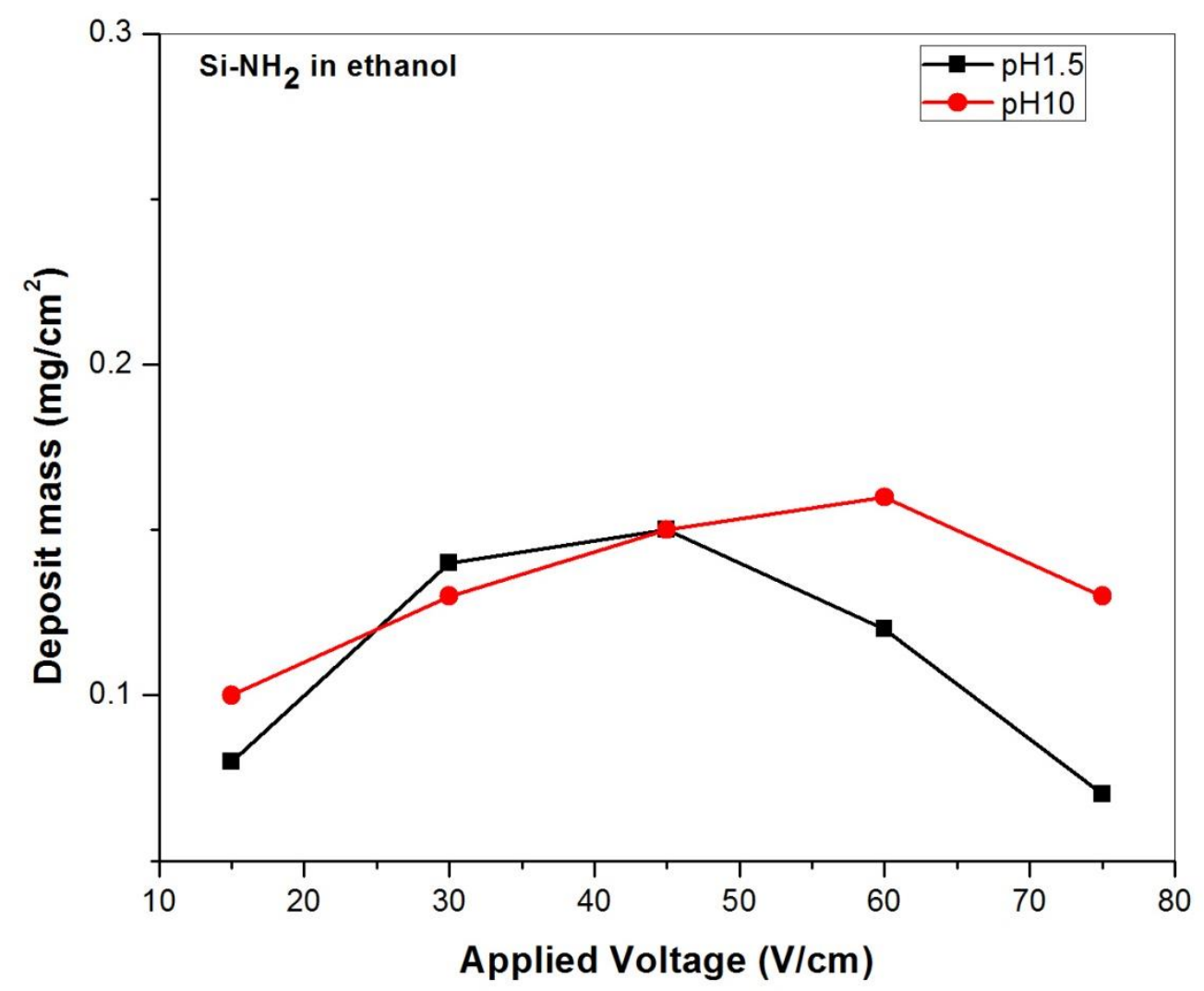

Fig.6.15: Profiles of the deposited mass versus applied voltage in ethanol for $\mathrm{Si}_{-} \mathrm{NH}_{2} \mathrm{EPD}$ (standing time for the suspension: $2 \mathrm{~h}$ )

For Si-NH $\mathrm{NH}_{2}$ system (Fig.6.15), the changing trend of the deposition mass is similar to that showed in Fig.6.14 if the suspension is alkaline, and the maximum value is about $0.16 \mathrm{mg}$. Under the acidic condition, $\mathrm{HCl}$ is used to adjust the $\mathrm{pH}$ value and a small amount of water is simultaneously introduced. Therefore, the electrolysis of water always accompanies by the deposition process, producing some gas bubbles near the substrate and aggravating the turbulence effect, especially at high voltages $(>45 \mathrm{~V} / \mathrm{cm})$. As a result, the maximum deposition mass is about $0.14 \mathrm{mg} / \mathrm{cm}^{2}$ at $45 \mathrm{~V} / \mathrm{cm}$. 
a)

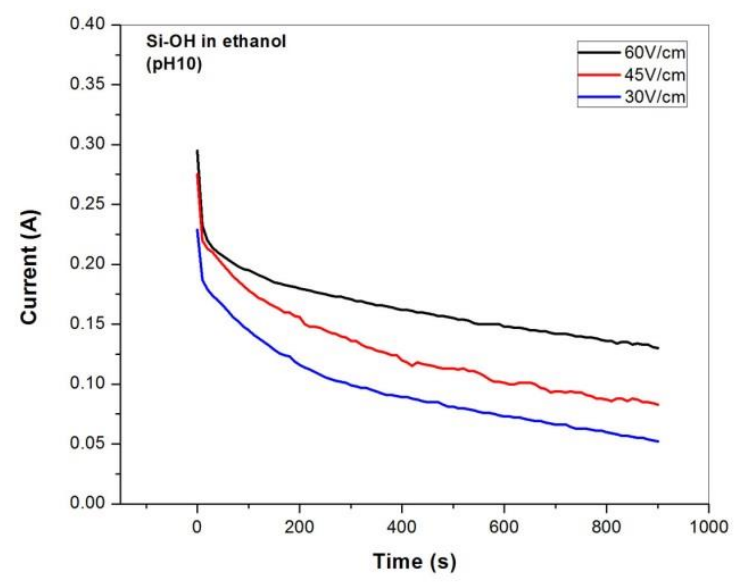

b)

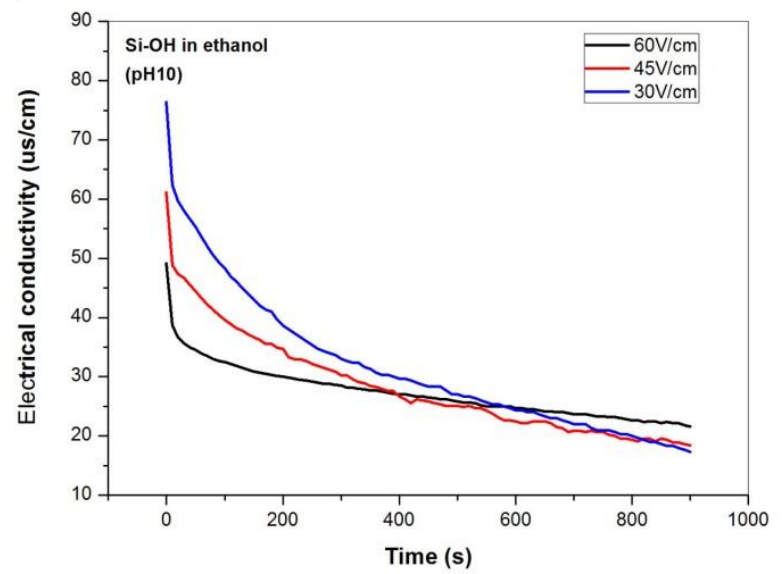

c)

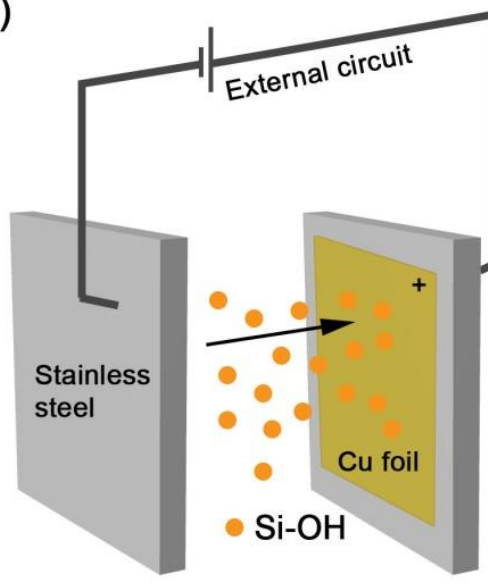

Stage 1

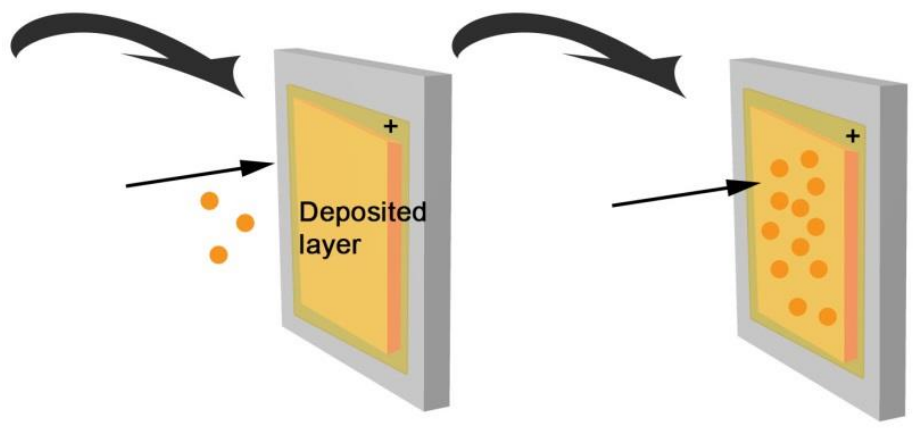

Stage 2

Stage 3

Fig.6.16: a) Current-time profiles and b) electrical conductivity - time profiles in Si-OH suspension (ethanol) with different applied voltages; c) diagram of the movement and deposition of $\mathrm{Si}-\mathrm{OH}$ in ethanol.

Under a given electric field $(30-60 \mathrm{~V} / \mathrm{cm})$, the current/electrical conductivity changing with time can describe the film-formation process, as shown in Fig.6.16. For each sample, the current/electrical conductivity changing can be divided into three stages. In the first few seconds, the current and electrical conductivity decreases sharply, indicating the start of the deposition of $\mathrm{Si}-\mathrm{OH}$ on the substrate $(\mathrm{Cu})$ surface (Fig.6.16c stage1). Higher voltage makes more particles deposited in shorter time. Then in the following minutes $(\sim 3-5 \mathrm{~min})$, the current and electrical conductivity continues to decrease at a moderate rate, indicating the growth of a non-conductive deposited layer (Fig.6.16c stage2). After a thick layer is formed, a few Si particles still move forward to the electrode by the driving of the electric field, and some of them can infiltrate the 
layer and stay in the pores or cracks (Fig.6.16c stage3). As a result, the deposition mass will increase a little, and the current and electrical conductivity will decrease slowly.

Fig.6.17 shows the current/electrical conductivity changing with time at different voltages in the $\mathrm{Si}-\mathrm{NH}_{2}$ suspension ( $\mathrm{pH} 1.5$ ). The profile's changing tendency at $30 \mathrm{~V} / \mathrm{cm}$ or $45 \mathrm{~V} / \mathrm{cm}$ is similar to the one discussed in Fig.6.16, which means the formation of the $\mathrm{Si}-\mathrm{NH}_{2}$ layer also follow the three-stage growth mechanism. Because $\mathrm{Si}_{-} \mathrm{NH}_{2}$ is positive charged in ethanol, the deposition process should occur on the negative electrode. But at $60 \mathrm{~V} / \mathrm{cm}$, the second stage is very short ( 100s), meaning the growth of the layer is slow. It should be caused by the serious turbulence effect due to the presence of water, which is consistent with the result in Fig.6.15.
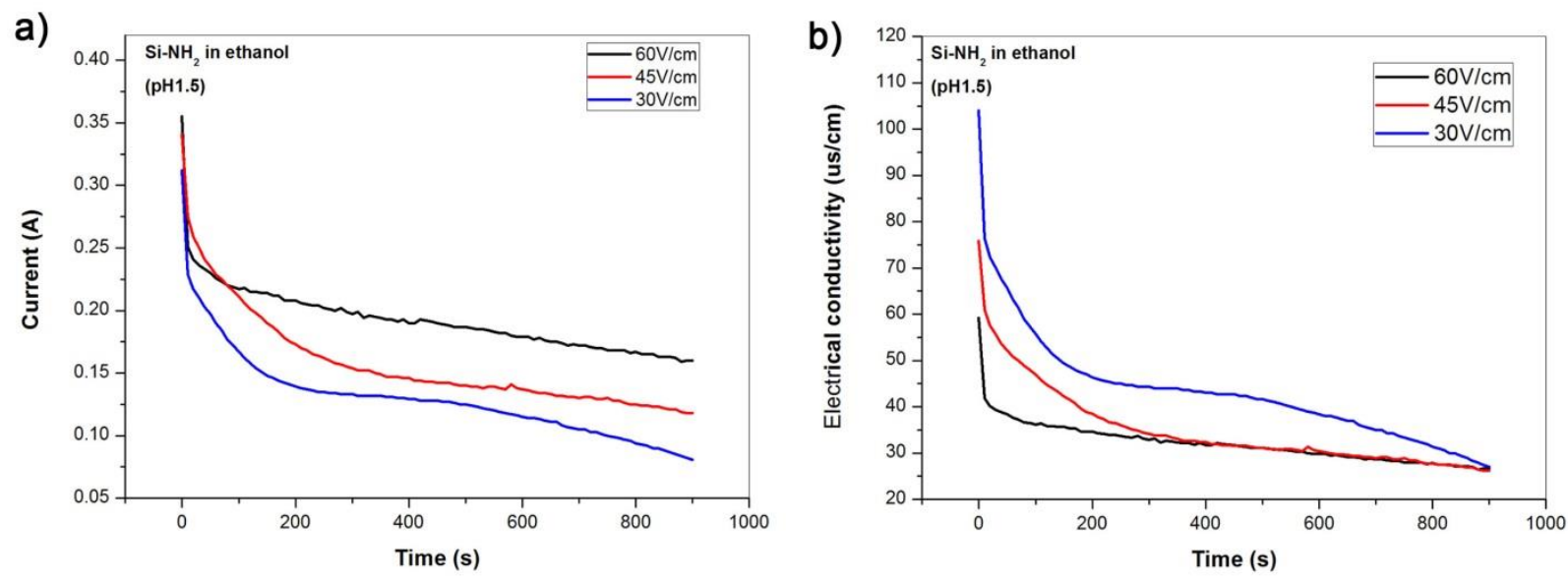

Fig.6.17: a) Current-time profiles and b) electrical conductivity - time profiles in $\mathrm{Si}-\mathrm{NH}_{2}$ suspension (ethanol) with different applied voltages.

3) Deposition time

Generally, in a given suspension, the deposition mass increase with the deposition time in the constant voltage mode, which can be described by an empirical equation (Eq.2.12).

$$
\frac{d Y}{d t}=f \mu c E S
$$

where:

$\mathrm{Y}=$ the yield;

$\mathrm{t}=$ the deposition time;

$\mu=$ the electrophoretic mobility;

$\mathrm{E}=$ the electric field strength;

$\mathrm{c}=$ the concentration of the suspension;

$\mathrm{S}=$ the electrode surface 
$\mathrm{f}=$ dynamics parameter

Combining with Eq.3.4 ( $\mathrm{ka}>>1$ ), a new equation (6.1) is obtained.

$$
\frac{d Y}{d t}=f \frac{\varepsilon \xi \mathrm{c} S}{\eta} E
$$

where:

$\varepsilon=$ the dielectric constant of the solvent

$\xi=$ zeta potential

$\eta=$ viscosity of the solvent

In an ideal condition, $\varepsilon, \xi, \eta$ and $\mathrm{E}$ is constant, and $\mathrm{c}$ can be also considered as a constant because it's much larger than the density of the deposited layer, therefore, the yield shows a linear relationship for the deposition time.

But in reality, $\mathrm{E}$ is changing constantly during EPD, and sometimes the decrease of $\mathrm{c}$ cannot be ignored. Therefore, Eq.6.1 is changed to

$$
\frac{d Y}{d t}=k_{f} S c(t) E(t)
$$

where:

$$
k_{f}=f \frac{\varepsilon \xi}{\eta}
$$

$\mathrm{c}(\mathrm{t})=$ the real-time concentration of the suspension

$\mathrm{E}(\mathrm{t})=$ the real-time electric field strength

The equivalent electric circuit of EPD process is shown in Fig.6.18. Four resistors are connected in series, representing the substrates $\left(R_{c}\right)$, suspension $\left(R_{s}\right)$, deposited layer $\left(R_{d}\right)$, and the external resistance $\left(\mathrm{R}_{0}\right)$. Therefore, E should be written as

$$
E=E_{0}+E_{s}+E_{d}+E_{c}=I\left(R_{0}+R_{s}+R_{d}+R_{c}\right) \quad 6.3
$$




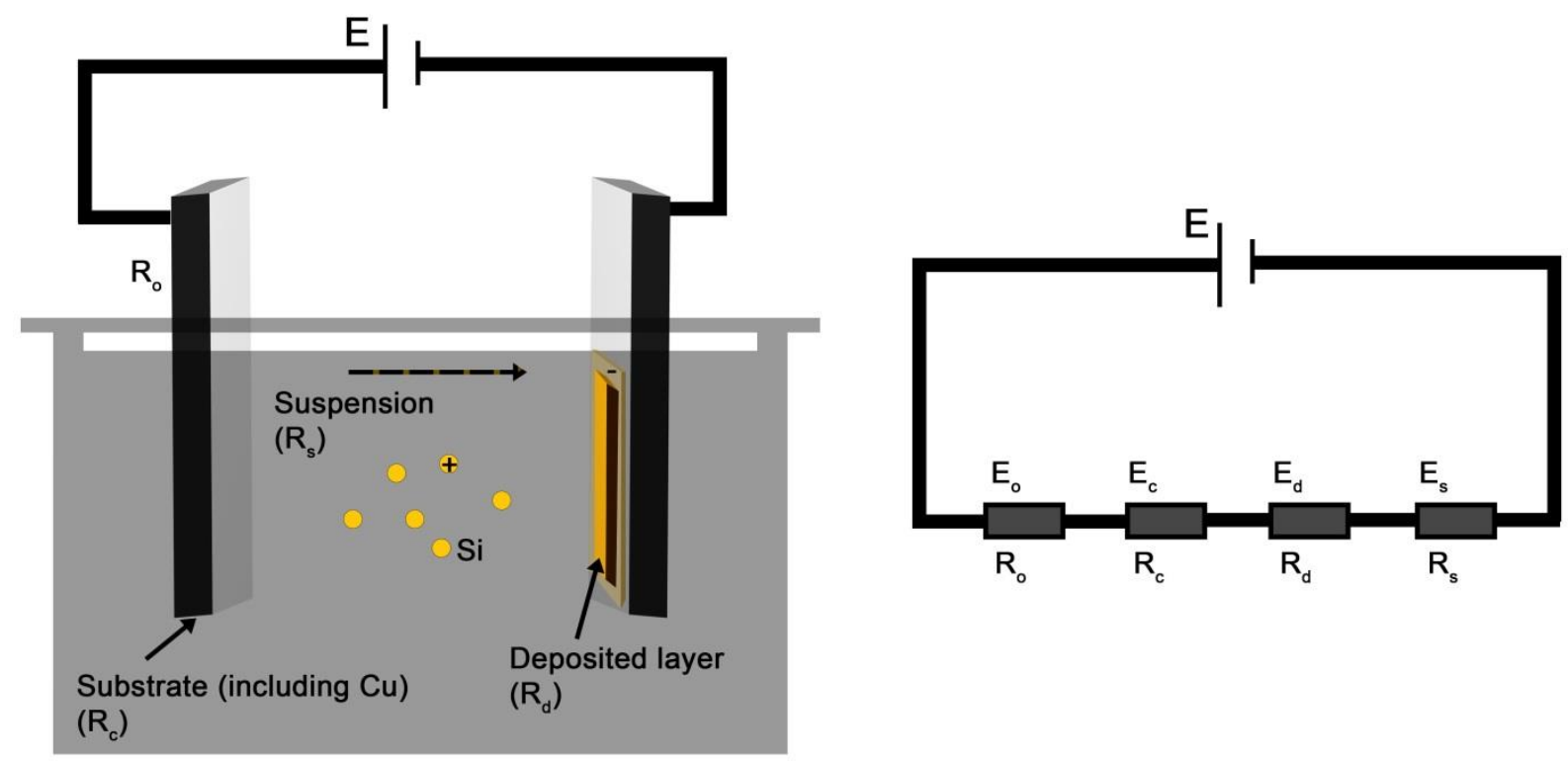

Fig.6.18: The equivalent electric circuit of the EPD cell

In the constant voltage mode, $\mathrm{E}$ is a constant (the applied voltage). $\mathrm{R}_{0}$ and $\mathrm{R}_{\mathrm{c}}$ changes very little. $R_{d}$ increases with the time due to the growth of the non-conductive deposited layer. The real-time electric field strength during EPD can be simply represented by $\mathrm{E}_{\mathrm{s}}$

$$
E_{s}=E(t)=I(t) R_{s}=\frac{I(t)}{\Lambda S} \quad 6.4
$$

where:

$\Lambda=$ the conductivity of the suspension,

$\mathrm{I}(\mathrm{t})=$ the real-time current

Inserting Eq.4.4 into Eq.6.2 gives

$$
\frac{d Y}{d t}=\frac{k_{f}}{\Lambda} c(t) I(t)
$$

If the suspension is metastable, $\mathrm{c}(\mathrm{t})$ should be influenced by both the settlement process and the deposition process, which can be expressed by Eq.6.6

$$
c(t)=c_{0}-c_{s}(t)-c_{d}(t) \quad 6.6
$$

where:

$\mathrm{c}_{0}=$ the initial concentration of the suspension

$c_{s}(t)=$ the real-time concentration of the settlement zone

$\mathrm{c}_{\mathrm{d}}(\mathrm{t})=$ the real-time concentration of the deposited layer 
In a metastable/stable system, the settling rate can be considered as the constant for a while. Therefore, $\mathrm{c}_{\mathrm{s}}(\mathrm{t})$ can be expressed by Eq.6.7

$$
c_{s}(t)=k_{s} t
$$

where:

$$
k_{s}=v_{s}=\frac{2 \Delta \rho g^{2}}{9 \eta}
$$

As mentioned before, the initial concentration of $\mathrm{Si}-\mathrm{OH}$ or $\mathrm{Si}-\mathrm{NH}_{2}$ in ethanol used here is $0.4 \mathrm{mg} / \mathrm{mL}$ and the suspension volume is $50 \mathrm{~mL}$, so the total mass of Si particles is $20 \mathrm{mg}$. The substrate ( $\mathrm{Cu}$ foil) area is $2 \times 2 \mathrm{~cm}^{2}$ and the maximum deposited mass (Fig.6.22 and 6.23) is no more than $0.3 \mathrm{mg} / \mathrm{cm}^{2}$, indicating less than $1.2 \mathrm{mg}$ of $\mathrm{Si}$ are deposited every time. Therefore, the effect of the deposition process on $\mathrm{c}(\mathrm{t})$ can be ignored, and Eq.6.5 can be simplified $c(t)=c_{0}-k_{s} t \quad 6.8$

Inserting Eq.6.8 into Eq.6.5 gives

$$
\frac{d Y}{d t}=\frac{k_{f}}{\Lambda}\left(c_{0}-k_{s} t\right) I(t)
$$

Integrating Eq.6.9 gives

$$
Y=\mathrm{a} \int_{0}^{t} I(t)-b \int_{0}^{t} t I(t)
$$

where:

$\mathrm{a}=\frac{k_{f}}{\Lambda} c_{0}$ (for a given system, $\mathrm{a}$ is a constant and is not influenced by the applied voltage or EPD); $\mathrm{b}=\frac{k_{f} k_{s}}{\Lambda}($ settlement coefficient $)$

Therefore, the deposited mass can be estimated by measuring the current changing with the deposition time. Based on the three-stage growth mechanism of the deposited layer (Fig.6.16), most deposition occurs in the stage 2 and stage 3 . To simplify the model, we ignore the deposition of a small amount of particles in the stage 1 and assume the current has a linear relationship with the deposition time in each stage (when $\mathrm{t}>30 \mathrm{~s}$ ):

$$
I(t)=I_{0}-A t
$$

where:

$\mathrm{I}_{0}=$ the initial current as the deposition occurs; 
A: the correction coefficient on the electric field.

Inserting Eq.6.12 into 6.11gives

$$
Y=y_{0}+a I_{0} t-\frac{1}{2}\left(\mathrm{I}_{0} \mathrm{~b}+\mathrm{aA}\right) \mathrm{t}^{2}+\frac{1}{3} \mathrm{Abt}^{3} \quad 6.13
$$

Eq.6.13 can describe the deposition process of the Si suspension in ethanol for a short time.

For Si-OH system in ethanol, as shown in Fig.6.19, the linear relationship between the current and the deposition time is defined:

$$
\begin{array}{lll}
\text { Stage } 2: I=0.218-3.576 \times 10^{-4} t & R^{2}=0.9700 & 6.14 \\
\text { Stage } 3: I=0.164-9.726 \times 10^{-6} t & R^{2}=0.9879 & 6.15
\end{array}
$$

And the related parabolic deposition kinetic is:

$$
\begin{array}{lll}
\text { Stage } 2: Y=0.0165+0.0995 \mathrm{t}-0.0159 t^{2}+7.826 \times 10^{-4} t^{3} & R^{2}=0.9899 & 6.16 \\
\text { Stage } 3: Y=0.0931+0.0403 t-3.04 \times 10^{-3} t^{2}+7.055 \times 10^{-5} t^{3} & R^{2}=0.9917
\end{array}
$$

For $\mathrm{Si}-\mathrm{NH}_{2}$ system, as shown in Fig.6.20, the linear relation between the current and the deposition time is:

$$
\begin{array}{lll}
\text { Stage } 2: I=0.253-4.018 \times 10^{-4} t & R^{2}=0.9816 & 6.18 \\
\text { Stage }: I=0.170-5.672 \times 10^{-4} t & R^{2}=0.9741 & 6.19
\end{array}
$$

And the related parabolic deposition kinetic is:

$$
\begin{array}{ll}
\text { Stage } 2: Y=0.0113+0.0873 t-0.0213 t^{2}+2.17 \times 10^{-3} t^{3} & R^{2}=0.9957 \\
\text { Stage } 3: Y=0.1342+0.0032 t+8.9676 \times 10^{-4} t^{2}-4.789 \times 10^{-5} t^{3} & R^{2}=0.9833
\end{array}
$$

Unlike Eq.6.26, 6.27 and 6.30, Eq.6.31 has the positive square term and the negative cubic term, indicating $\mathrm{b}<0$. It should be related to the turbulence effect. Although the applied voltage is not too high, the electrolysis of the water becomes serious in the acidic condition as the increase the deposition time and the ethanol will be also heated. Therefore, more bubbles are generated. They peel off particles from the deposited layer and making the re-mixture of particles between the homogenous zone and the settlement zone. As a result, the real-time concentration near the substrate may even be bigger than that in settlement zone, leading to the negative $\mathrm{k}_{\mathrm{s}}$ and $\mathrm{b}$. 

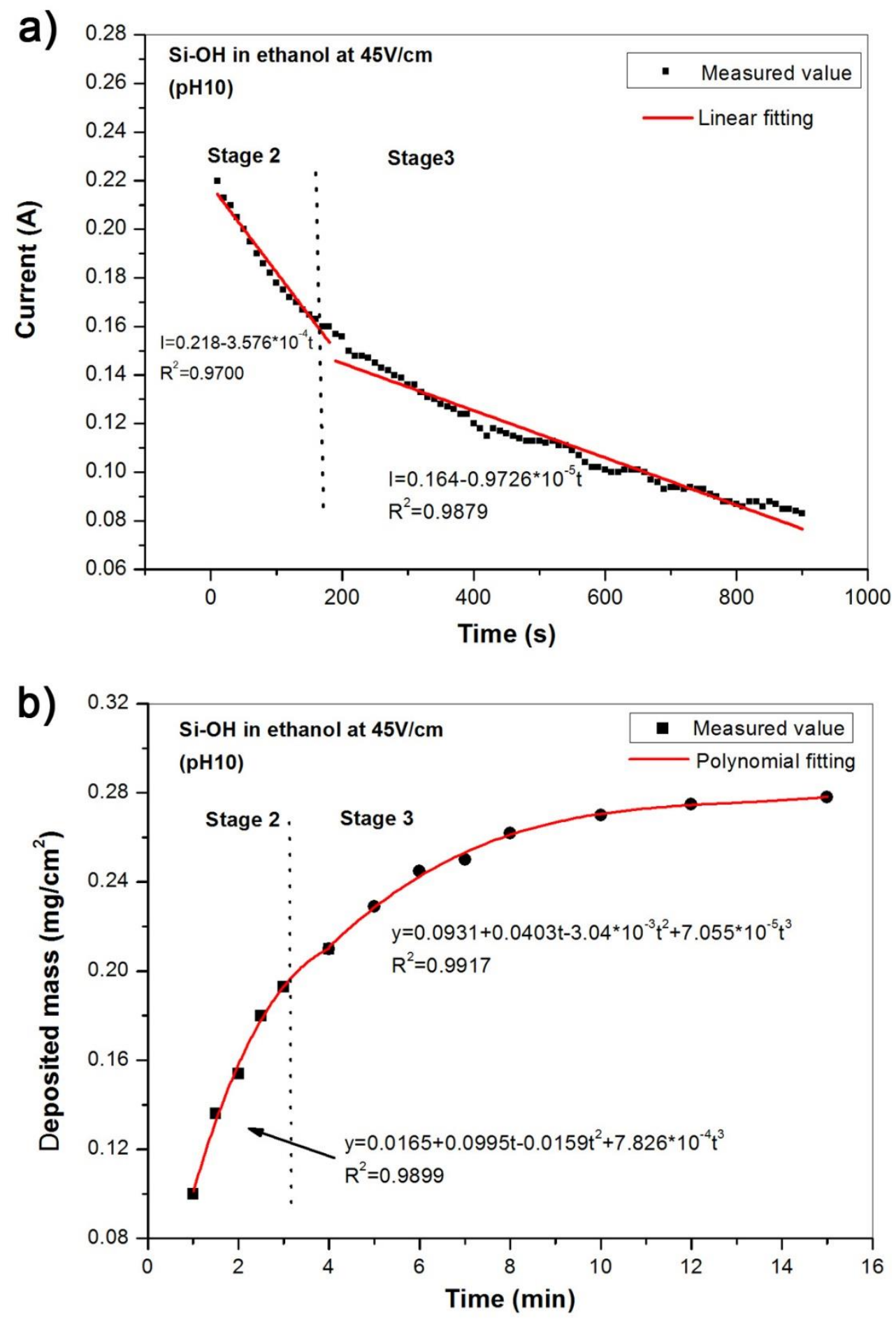

Fig.6.19: Profiles of a) current versus time and deposited mass versus time in $\mathrm{Si}-\mathrm{OH}$ suspension 

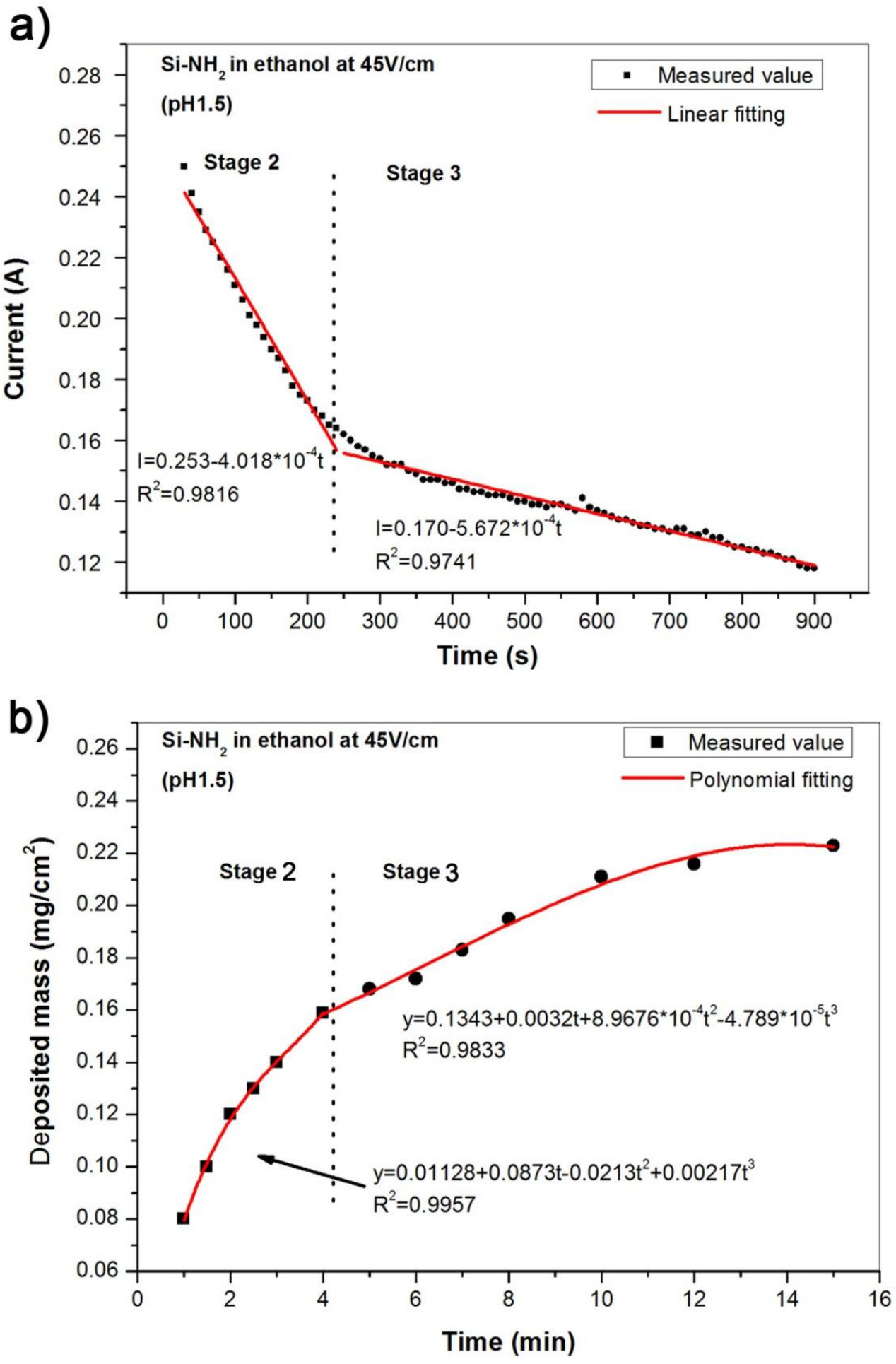

Fig.6.20: Profiles of a) current versus time and deposited mass versus time in $\mathrm{Si}^{-\mathrm{NH}_{2}}$ suspension 


\subsection{EPD of modified-Si/CNFs in ethanol}

Two kinds of multi-component suspensions were prepared: the one consisting of Si-OH and CNFs-COOH (7\%) and another one consisting of $\mathrm{Si}-\mathrm{NH}_{2}$ and $\mathrm{CNFs}-\mathrm{COOH}(7 \%)$. Unless mentioned otherwise, the concentrations of CNFs-COOH and modified-Si are $0.5 \mathrm{mg} / \mathrm{mL}$ and $0.2 \mathrm{mg} / \mathrm{mL}$, respectively.

1) Zeta potential

As shown in Fig.6.21, Si-OH/CNFs-COOH has the relative high zeta potential (|zeta potential $\mid>25 \mathrm{mV})$ over a wide $\mathrm{pH}$ range $(8-11)$ in ethanol, and the maximum absolute value is about $36 \mathrm{mV}$ at $\mathrm{pH} 11$. It's noticed that the zeta potential profile of Si-OH/CNFs-COOH is highly similar to that of CNFs-COOH. Because of the low concentration of each component and poor interaction between $-\mathrm{OH}$ and $-\mathrm{COOH}$ groups, the ionization process of $\mathrm{Si}-\mathrm{OH}$ and $\mathrm{CNFs}-\mathrm{COOH}$ is relatively independent. Meanwhile, the charged $\mathrm{Si}-\mathrm{OH}$ can be considered as a special free ion around CNFs to increase the electrostatic repulsion between CNFs, leading to a little improvement of stability in comparison with pure CNFs-COOH suspension.

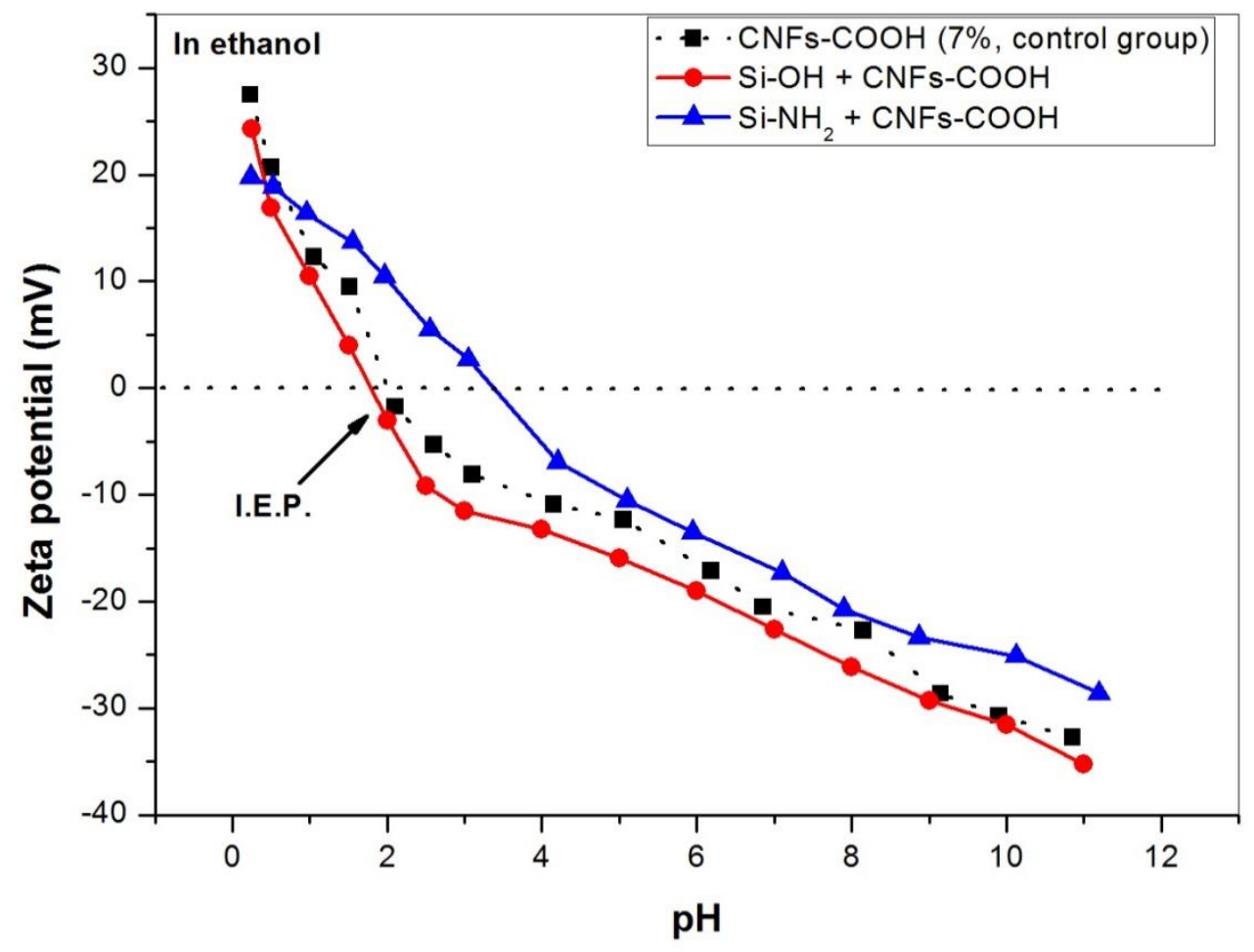

Fig.6.21: Profiles of zeta potential values in different CNFs/Si suspension (ethanol) 
In the $\mathrm{Si}-\mathrm{NH}_{2} / \mathrm{CNF}$ s-COOH suspension, except for free charged $\mathrm{Si}-\mathrm{NH}_{2}$ and $\mathrm{CNFs}-$ $\mathrm{COOH}$, some Si particles can locate on the CNFs surface via the electrostatic attraction between $-\mathrm{NH}_{2}$ and $-\mathrm{COOH}$ groups, leading to the decrease of surface charge density of CNFs and reducing the repulsive force between CNFs. Therefore, as shown in Fig.6.21, although the changing tendency of zeta potential profile is similar to the others, the global stability is decreased. The metastable state can be only obtained at $\mathrm{pH} 10-11$, and the maximum absolute value is about $30 \mathrm{mV}$ at $\mathrm{pH} 11$.

The functional group of Si can influence the zeta potential of multi-component aqueous suspensions in the same way, as shown in Fig.6.22. To be specific, a stable Si-OH/CNFs-COOH suspension can be obtained at pH $5-11$, and the zeta potential can be up to $-46 \mathrm{mV}$ at $\mathrm{pH} 9$. If $\mathrm{pH}>9$, free $-\mathrm{OH}^{-}$are too excessive and the electric double layers of charged particles become thinner, leading to the decrease of the zeta potential. In the $\mathrm{Si}-\mathrm{NH}_{2} / \mathrm{CNFs}-\mathrm{COOH}$ suspension, a stable state can be obtained at $\mathrm{pH} 7-11$, and the maximum absolute value is about $42 \mathrm{mV}$ at $\mathrm{pH} 11$.

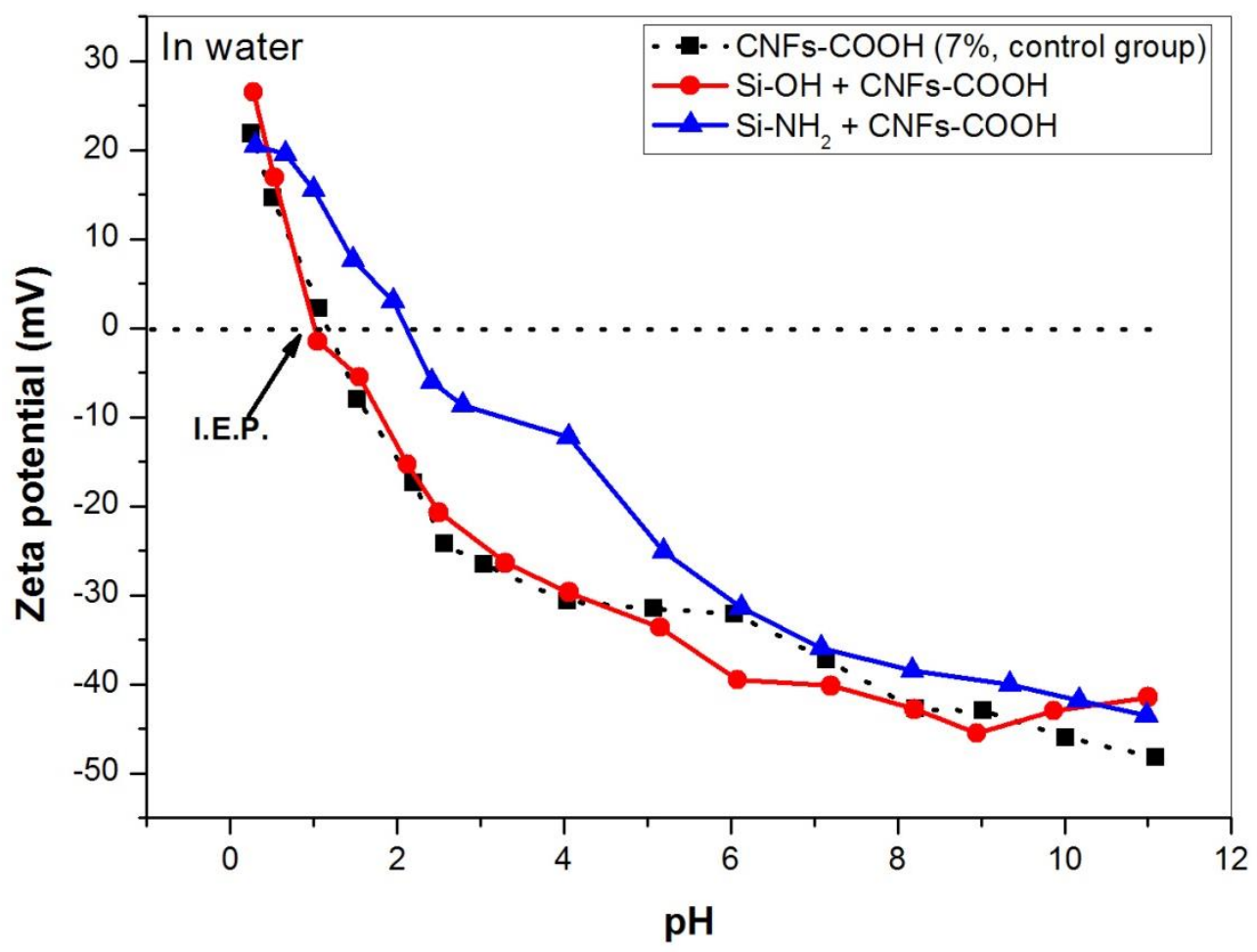

Fig.6.22: Profiles of zeta potential values in different CNFs/Si suspension (water)

Fig.6.23 shows the influence of the composite concentration on zeta potential in ethanol. For Si-OH/ CNFs-COOH suspensions, the concentration cannot change the I.E.P. value (2.2), 
and has no influence on the zeta potential around I.E.P. At pH $1-1.5$ and $\mathrm{pH} 3-10$, the absolute value of zeta potential will increase a little as the increase of the concentration. But if the concentration is too high $(1.8 \mathrm{mg} / \mathrm{mL})$, under the strong acidic $(\mathrm{pH} 0.5-1)$ or strong basic $(\mathrm{pH} 10-11.5)$ conditions, the absolute value of zeta potential will decrease due to more collision of particles.

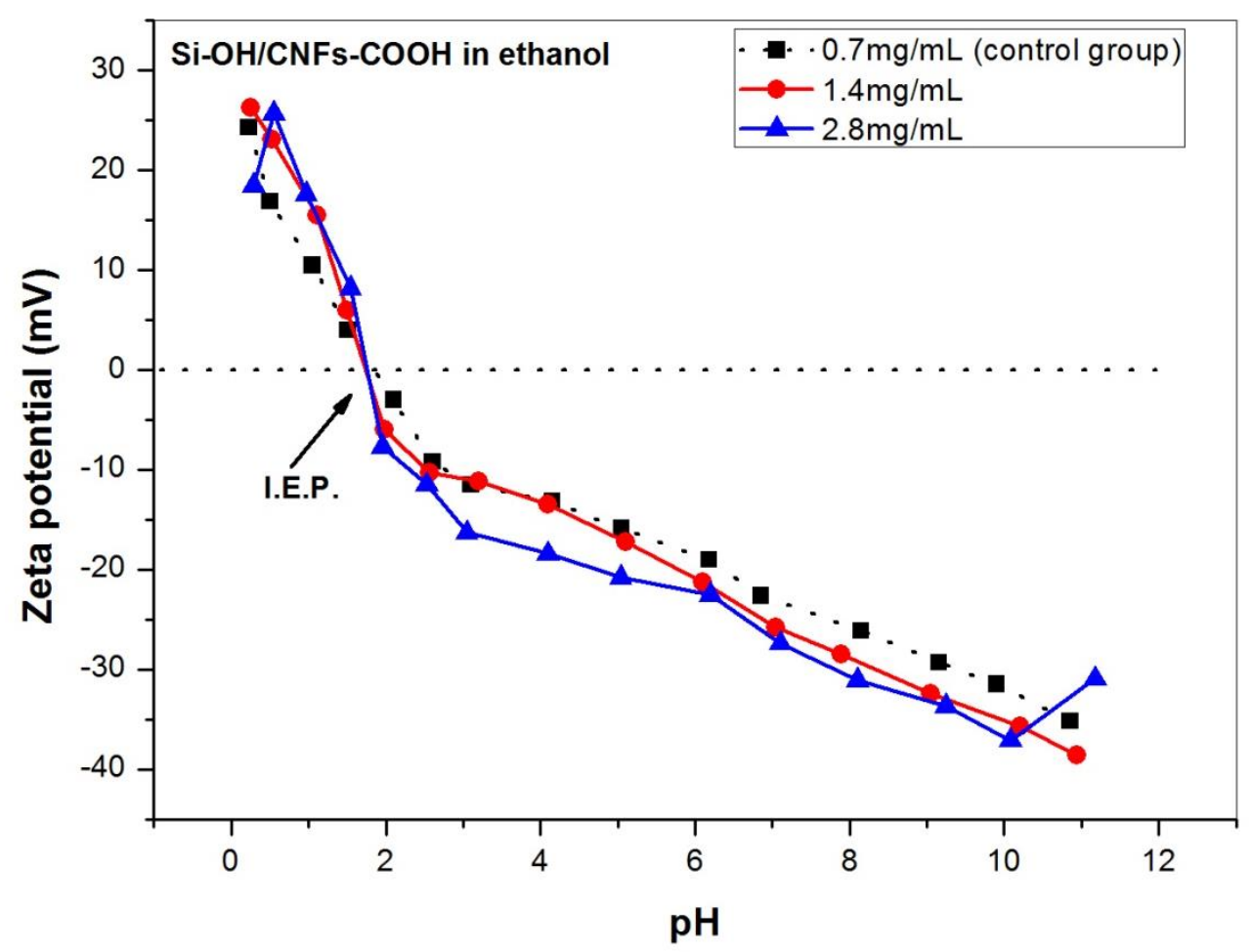

Fig.6.23: Profiles of zeta potential versus $\mathrm{pH}$ value in $\mathrm{Si}-\mathrm{OH} / \mathrm{CNFs}-\mathrm{COOH}$ suspension with different concentration.

For $\mathrm{Si}-\mathrm{NH}_{2} / \mathrm{CNF}-\mathrm{COOH}$ suspensions, the identical changing tendency can be also observed when the $\mathrm{pH}$ value is lower than I.E.P (3.5), as shown in Fig.6.24. Under the strong alkali conditions $(\mathrm{pH}>9)$, too high concentration is harmful to the suspension stability. 


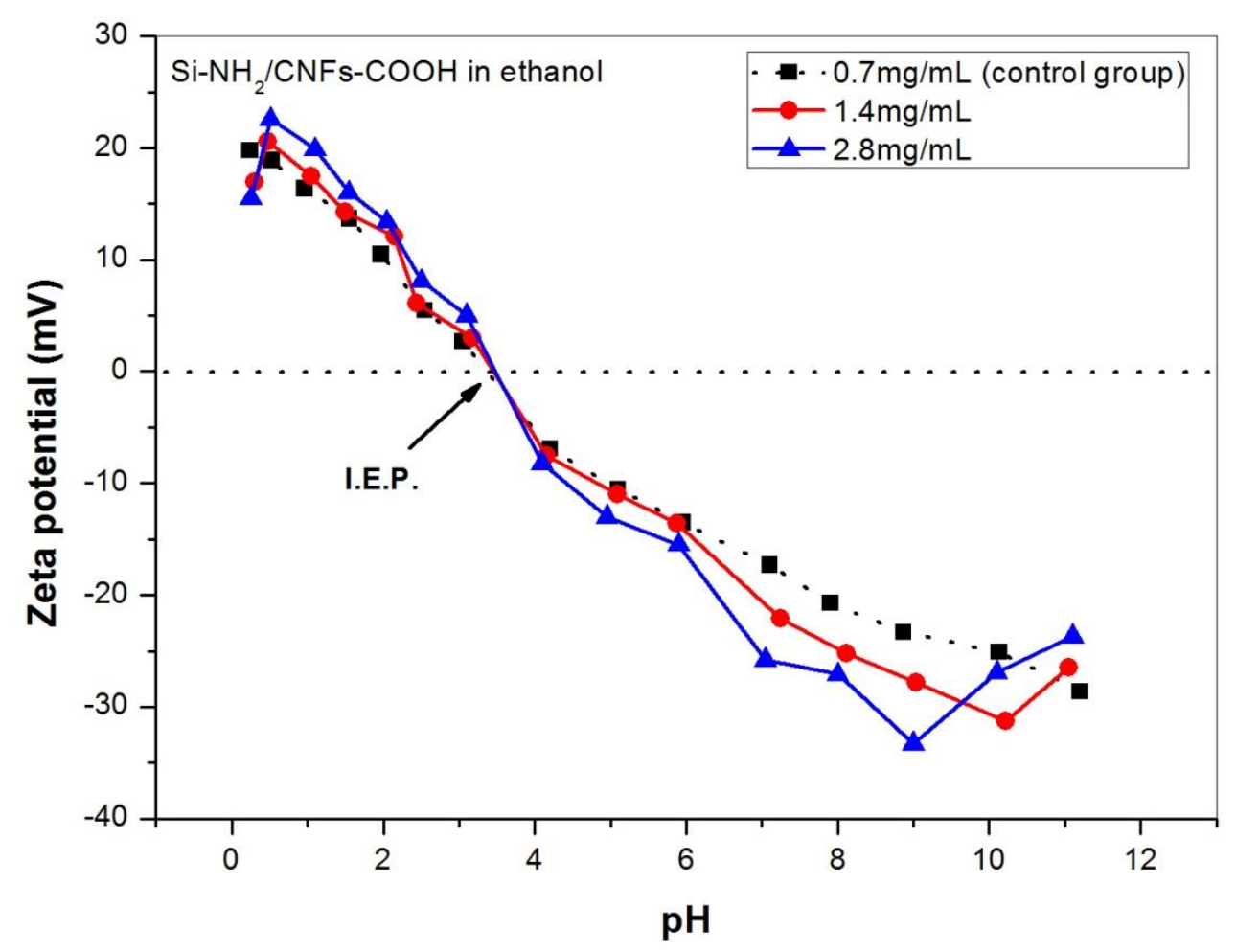

Fig.6.24: Profiles of zeta potential versus $\mathrm{pH}$ value in $\mathrm{Si}-\mathrm{NH}_{2} / \mathrm{CNFs}-\mathrm{COOH}$ suspension with different concentration.

If the ratio of modified-Si to $\mathrm{CNFs}-\mathrm{COOH}$ is changed, the zeta potential profile will be also changed, as shown in Fig.6.25. It's found that the absolute value of zeta potential increases with the ratio of $\mathrm{Si}-\mathrm{OH}$ to $\mathrm{CNFs}-\mathrm{COOH}$ at the same $\mathrm{pH}$, but decreases with the ratio of $\mathrm{Si}_{-} \mathrm{NH}_{2}$ to $\mathrm{CNFs}-\mathrm{COOH}$. Based on the interaction among different functional groups, in a given solvent, the increase of $\mathrm{Si}-\mathrm{OH}$ can be equivalent to the increase of $-\mathrm{COOH}$ groups on the CNFs surface, while the increase of $\mathrm{Si}-\mathrm{NH}_{2}$ is equivalent to the reduce of $-\mathrm{COOH}$ groups. As mentioned in Part3, more - $\mathrm{COOH}$ groups means more surface charge in the suspension. Therefore, more $\mathrm{Si}$ $\mathrm{OH}$ or less $\mathrm{Si}-\mathrm{NH}_{2}$ groups with a fixed CNFs concentration is beneficial to improve the suspension stability in a wide $\mathrm{pH}$ range $(0.5-10)$. 

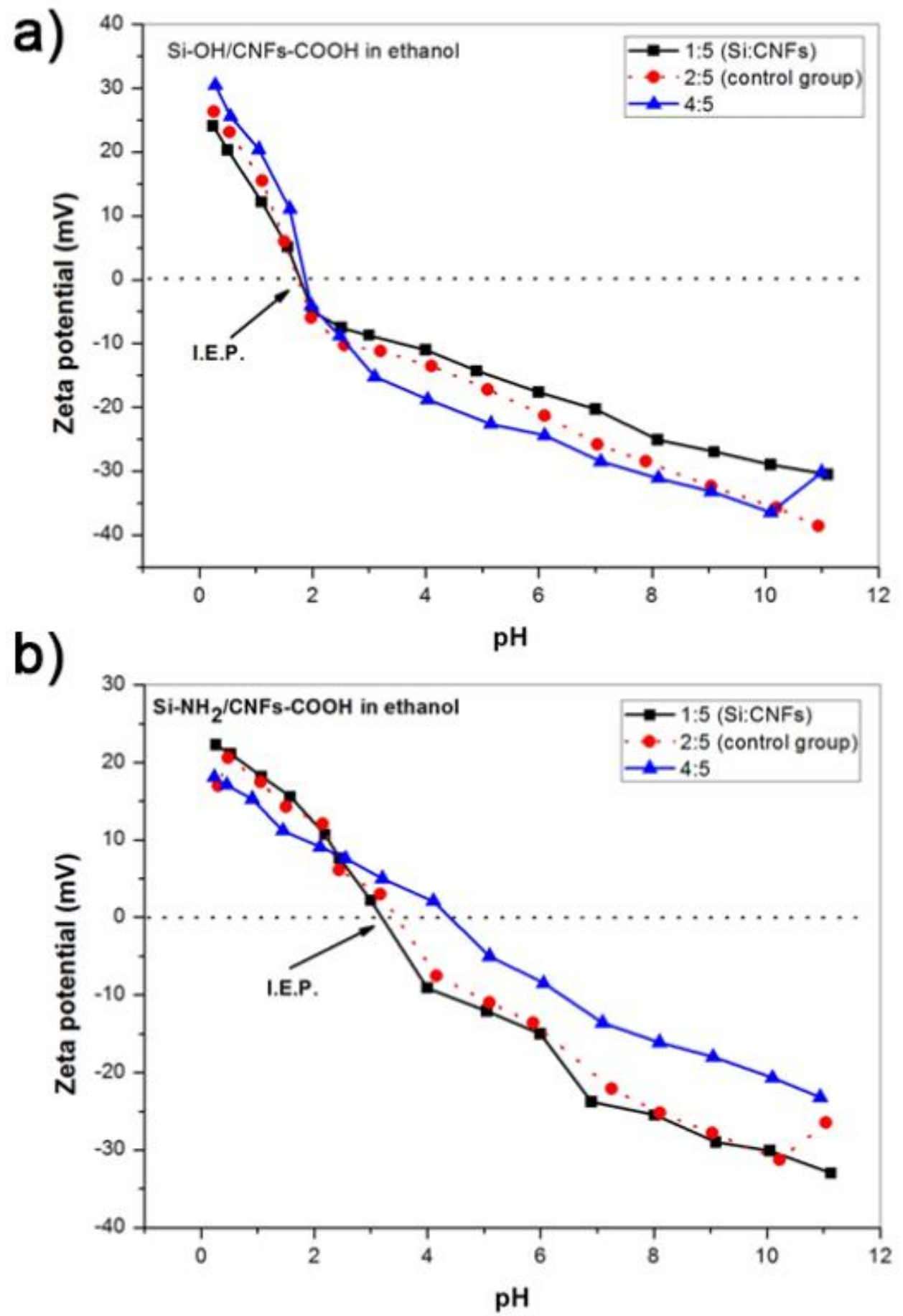

Fig.6.25: Profiles of zeta potential versus $\mathrm{pH}$ values in modified-Si/CNFs-COOH suspension with different ratio of Si to C.

2) Settling rate 
Based on the zeta potential results, some $\mathrm{pH}$ values are chose for preparing metastable/stable multi-component suspensions with different concentrations in ethanol, as shown in Table6.8

Table6.8 Zeta potential values for modified-Si/CNFs in different suspensions (ethanol)

\begin{tabular}{|c|c|c|c|c|}
\hline Particles & $\begin{array}{l}\text { Concentration } \\
\text { in ethanol } \\
(\mathrm{mg} / \mathrm{mL})\end{array}$ & $\mathrm{pH}$ & $\begin{array}{l}\text { Zeta potential } \\
\qquad(\mathrm{mV})\end{array}$ & State of stability \\
\hline \multirow{3}{*}{$\begin{array}{c}\text { Si-OH/CNFs- } \\
\mathrm{COOH}\end{array}$} & \multirow[t]{3}{*}{$0.4 / 1$} & 0.5 & 23 & \multirow{6}{*}{$\begin{array}{c}\text { |zeta potential } \mid<35 \mathrm{mV} \text { : } \\
\text { Metastable and } \\
\text { flocculated. } \\
\text { |zeta potential } \mid>35 \mathrm{mV}: \\
\text { Very stable }\end{array}$} \\
\hline & & 9 & -32 & \\
\hline & & 10 & -35 & \\
\hline \multirow{3}{*}{$\begin{array}{c}\text { Si-NH } 2 / C N F s- \\
\mathrm{COOH}\end{array}$} & \multirow[t]{3}{*}{$0.4 / 1$} & 0.5 & 21 & \\
\hline & & 9 & -28 & \\
\hline & & 10 & -32 & \\
\hline
\end{tabular}
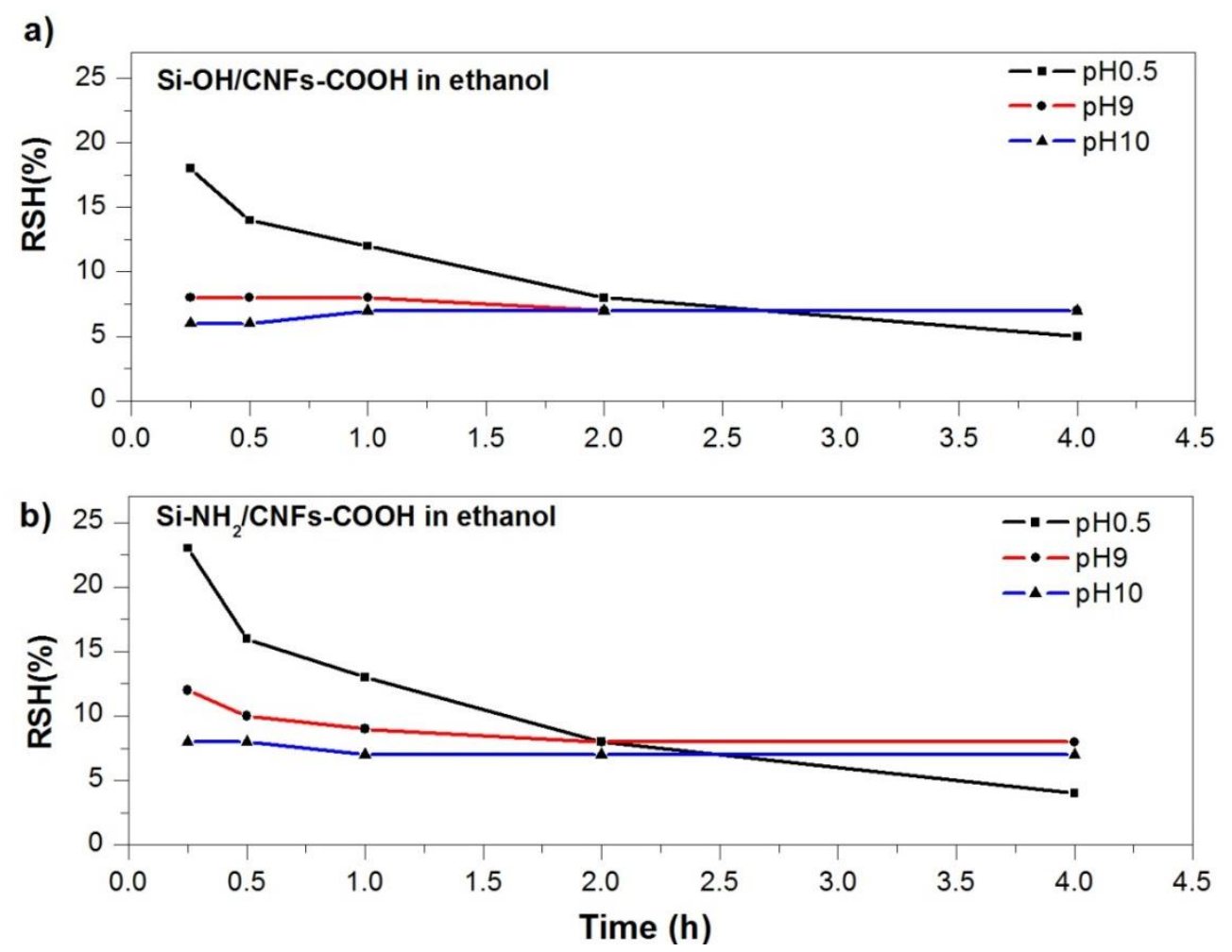

Fig.6.26: Profiles of RSH value versus standing time for different suspensions in ethanol.

For Si-OH/CNFs-COOH composite in ethanol, as shown in Fig.6.26a, the suspensions at pH9 and pH10 exhibit good stability for a long time with the initial RSH of $8 \%$ and $6 \%$, and the 
corresponding $\mathrm{C}_{\mathrm{rd}}$ after $1 \mathrm{~h}$ is $85 \%$ and $90 \%$ (Table6.9). At $\mathrm{pH} 0.5$, the particle settlement is serious because of low zeta potential. Considering the relatively independence between $\mathrm{Si}-\mathrm{OH}$ and CNFs-COOH in ethanol, each component settles with its own settling rate, leading to the separation of Si and carbon settlement zones like Fig.6.27, so the RSH value here makes no sense.

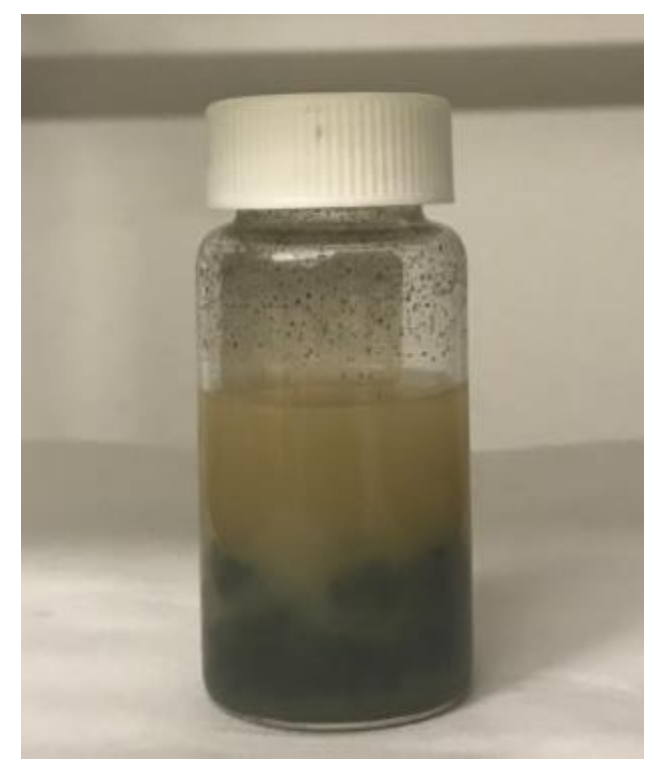

Fig.6.27: Photograph of Si-OH/CNFs-COOH suspension in ethanol at $\mathrm{pH} 0.5$ after $1 \mathrm{~h}$ standing.

For $\mathrm{Si}-\mathrm{NH}_{2} / \mathrm{CNFs}-\mathrm{COOH}$ system, as shown in Fig.6.26b, at $\mathrm{pH} 0.5$, $\mathrm{pH} 9$ and $\mathrm{pH} 10$, the initial RSH value is $23 \%, 12 \%$ and $7 \%$, respectively, and it changes to $13 \%, 9 \%$ and $6 \%$ after $1 \mathrm{~h}$ standing, indicating the sample at $\mathrm{pH} 10$ has an improved stability. These three samples' $\mathrm{C}_{\mathrm{rd}}$ values are $55 \%, 75 \%$ and $85 \%$, respectively.

Table6.9: $\mathrm{C}_{\mathrm{rd}}$ values for different composite suspensions in ethanol.

\begin{tabular}{|c|c|c|c|c|c|c|}
\hline \multirow{3}{*}{$\begin{array}{l}\text { Standing } \\
\text { time } \\
\text { (h) }\end{array}$} & \multicolumn{6}{|c|}{$\mathrm{C}_{\mathrm{rd}}(\%)$} \\
\hline & \multicolumn{2}{|c|}{ Ethanol at $\mathrm{pH} 0.5$} & \multicolumn{2}{|c|}{ Ethanol at $\mathrm{pH} 9$} & \multicolumn{2}{|c|}{ Ethanol at pH10 } \\
\hline & $\begin{array}{l}\mathrm{Si}-\mathrm{OH} \\
/ \mathrm{CNFs}- \\
\mathrm{COOH}\end{array}$ & $\begin{array}{l}\mathrm{Si}_{-\mathrm{NH}_{2}} \\
/ \mathrm{CNFs}- \\
\mathrm{COOH}\end{array}$ & $\begin{array}{l}\mathrm{Si}-\mathrm{OH} \\
/ \mathrm{CNFs}- \\
\mathrm{COOH}\end{array}$ & $\begin{array}{l}\mathrm{Si}_{-\mathrm{NH}_{2}} \\
/ \mathrm{CNFs}- \\
\mathrm{COOH}\end{array}$ & $\begin{array}{l}\mathrm{Si}-\mathrm{OH} \\
/ \mathrm{CNFs}- \\
\mathrm{COOH}\end{array}$ & $\begin{array}{l}\mathrm{Si}_{-\mathrm{NH}_{2}} \\
/ \mathrm{CNFs}- \\
\mathrm{COOH}\end{array}$ \\
\hline 0.25 & - & 80 & 90 & 85 & 90 & 90 \\
\hline 0.5 & - & 70 & 85 & 80 & 90 & 85 \\
\hline 1 & - & 55 & 85 & 75 & 90 & 85 \\
\hline
\end{tabular}


Summarizing the above results, the suspensions at $\mathrm{pH} 9-10$ are good for short-time multi-component EPD, or else the non-homogenous film is prepared.

\section{3) Applied Voltage}

Based on the analysis of multi-component suspension stability, $\mathrm{Si}-\mathrm{OH} / \mathrm{CNF}$ suspensions at $\mathrm{pH} 10$ and $\mathrm{Si}-\mathrm{NH}_{2} / \mathrm{CNFs}$ suspension at $\mathrm{pH} 0.5$ in ethanol were prepared respectively with a concentration of $0.7 \mathrm{mg} / \mathrm{mL}$ ( weight ratio of Si to CNFs: 2/5). It's noticed that the latter system has the relatively high initial RSH and low zeta potential, leading to the rapid decrease of the concentration in the homogeneous zone in the first 2 hours once the suspension is prepared. Therefore, $2 \mathrm{~h}$ standing time is necessary if using $\mathrm{Si}-\mathrm{NH}_{2} / \mathrm{CNF}$ acidic suspension for EPD procedure. EPD process was performed at $15-75 \mathrm{~V} / \mathrm{cm}$ for $10 \mathrm{~min}$. After the deposition, the yield of each sample was measured, as shown in Fig.6.28.

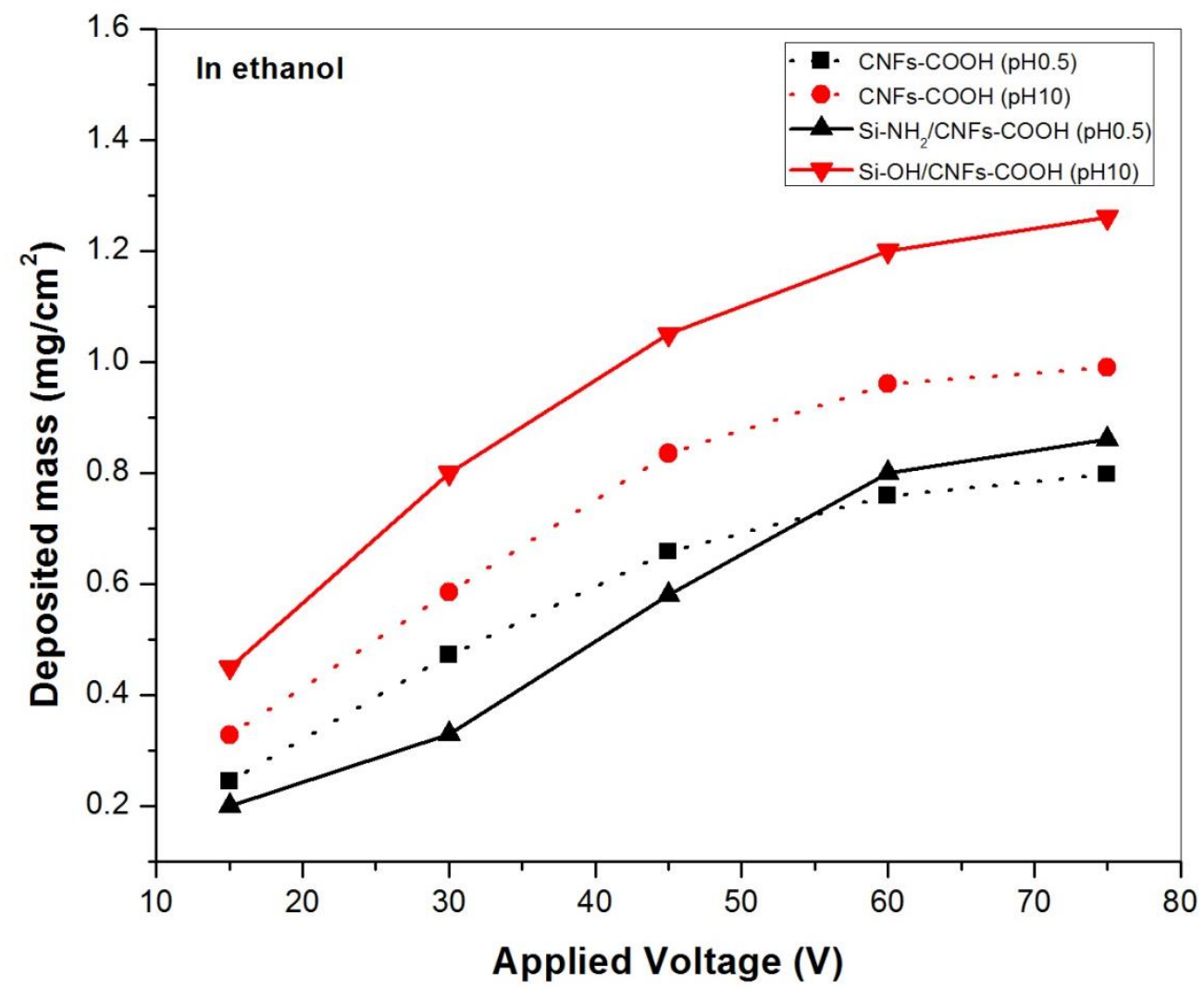

Fig6.28: Profiles of the deposited mass versus applied voltage in modified-Si/CNFs suspensions.

Fig.6.28 shows the applied voltage's effect on the deposited layer. In the Si-OH/CNFs$\mathrm{COOH}$ suspension at $\mathrm{pH} 10$, the deposited mass is higher than that in the $\mathrm{CNFs}-\mathrm{COOH}$ suspension under the same electric field because of the similar stability and the simultaneous 
deposition of $\mathrm{Si}-\mathrm{OH}$ particles. It also increases with the applied voltage and the maximum value at $75 \mathrm{~V} / \mathrm{cm}$ is about $1.22 \mathrm{mg} / \mathrm{cm}^{2}$. However, excessive voltage is not good for the uniformity of the deposited film. Under the electric field of $45 \mathrm{~V} / \mathrm{cm}$, the final film has smooth surface without any visible pores or cracks (Fig.6.29a). If increasing the voltage to $75 \mathrm{~V} / \mathrm{cm}$, although more particles are deposited in the same time, they don't have enough time to adjust their location on the substrate to form a dense film because of high deposition rate and turbulence effect ${ }^{[91]}$, finally, a film with non-uniform distribution of Si-OH/CNFs is formed (Fig.6.29b). Therefore, the applied voltage during EPD must strike a balance between the deposited mass and film morphology. The proper voltage here should be around $45 \mathrm{~V} / \mathrm{cm}$.

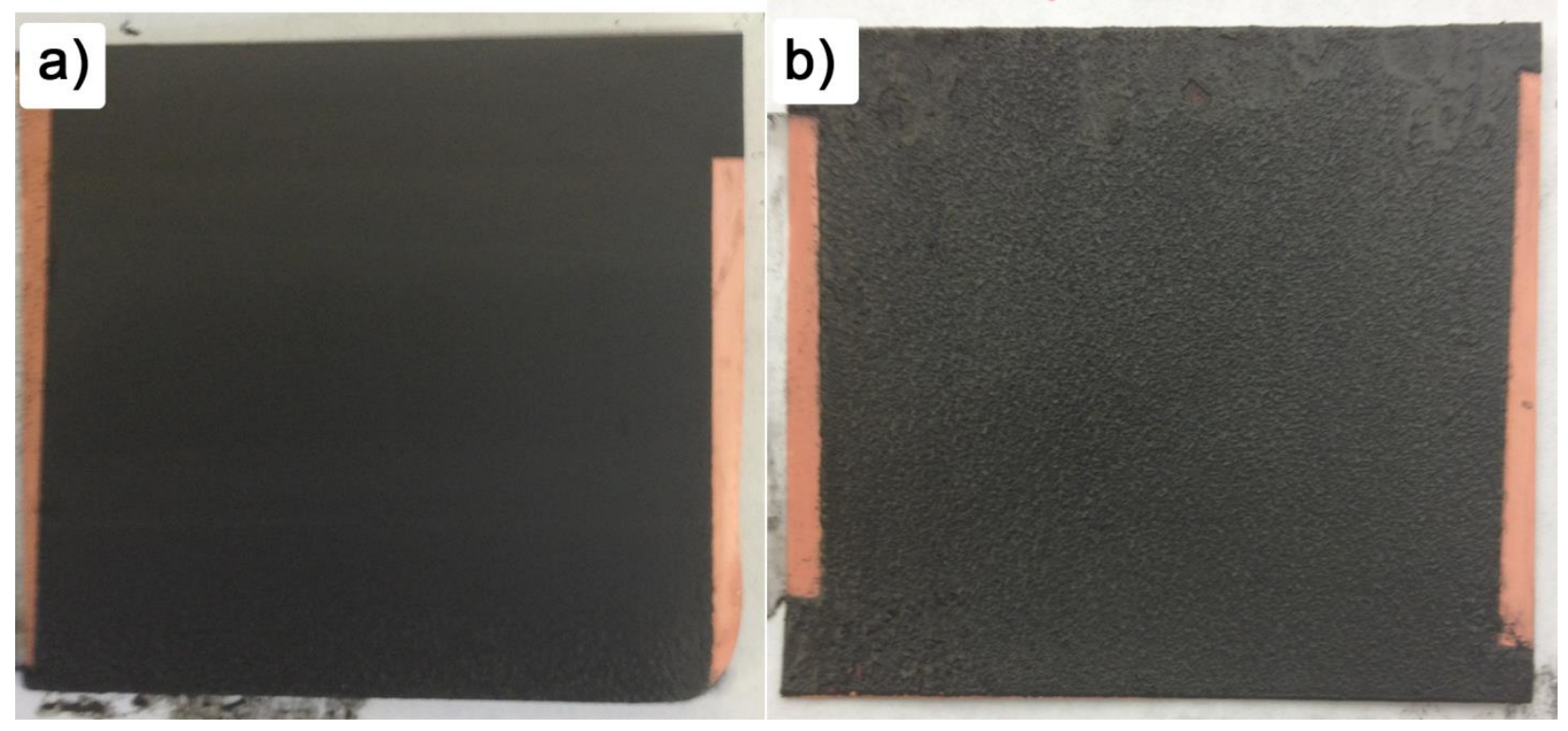

Fig.6.29: Photographs of Si-OH/CNFs deposition film after 10min EPD in ethanol at pH10 with different applied voltages. a) $45 \mathrm{~V} / \mathrm{cm}$, b) $75 \mathrm{~V} / \mathrm{cm}$.

At $\mathrm{pH} 0.5$, the $\mathrm{Si}-\mathrm{NH}_{2} / \mathrm{CNFs}-\mathrm{COOH}$ suspension (zeta potential: $21 \mathrm{mV}$ ) is less stable than the CNFs-COOH one (zeta potential: $28 \mathrm{mV}$ ) with the same concentration; therefore, the deposited mass under the same electric field becomes lower. If the voltage is high enough, the faster initial deposition rate can partly overcome the negative influence of the continuous settlement, leading to an improved deposited mass for a short-time EPD. The maximum value of $0.82 \mathrm{mg} / \mathrm{mL}$ is obtained at $75 \mathrm{~V} / \mathrm{cm}$. Similarly, the excessive voltage also causes non-uniform of distribution of particles. What's worse, high applied voltage during EPD in the strong acidic suspension means more serious hydrolysis reaction and more bubbles near the conductive substrate. As a result, the adhesive force between the porous film and $\mathrm{Cu}$ foil is weak, and the 
film is likely to fall off during moving, shaking or other after-treatment process, as shown in Fig.6.30. After 10min EPD, two films are taken out of the suspension immediately, and the 10s fast-jitter test is applied. It's found the one prepared under higher electric field $(75 \mathrm{~V} / \mathrm{cm})$ is totally damaged, while another one keeps the integrity well. Therefore, for EPD of Si$\mathrm{NH}_{2} / \mathrm{CNFs}-\mathrm{COOH}$ in the strong acidic condition, the applied voltage must be lower than 60 $\mathrm{V} / \mathrm{cm}$.
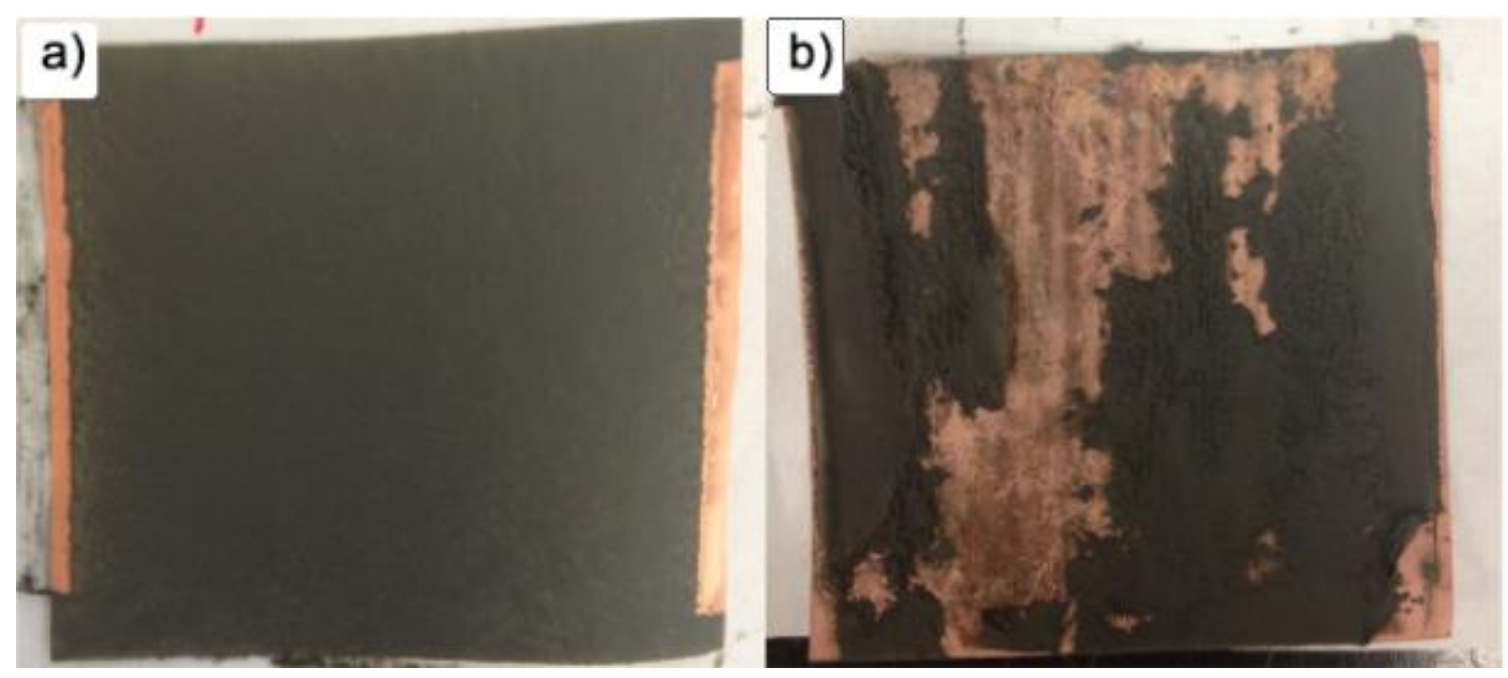

Fig.6.30: Photograph of Si-NH$/ \mathrm{NHFs}_{2} \mathrm{COOH}$ deposition films (a: $60 \mathrm{~V} / \mathrm{cm}$, b: $75 \mathrm{~V} / \mathrm{cm}$ ) after $10 \mathrm{~s}$ fast-jitter test.

The profiles of the current changing with time at different voltages in the Si-OH /CNFs$\mathrm{COOH}$ suspension (pH10) are shown in Fig.6.31. The introduction of Si makes the deposited layer having lower conductivity, leading to lower current during EPD in comparison with pure CNFs deposition at the same electric field. At $30 \mathrm{~V} / \mathrm{cm}$ or $60 \mathrm{~V} / \mathrm{cm}$, when the decrease trend of the current looks similar that in CNFs suspension (> 400s), meaning less SiNPs are deposited onto the composite surface. At $45 \mathrm{~V} / \mathrm{cm}$, the current is continuously decreasing during the whole EPD process, indicating more SiNPs are deposited. The possible reason for the continuous $\mathrm{Si}$ deposition is that the balance between Si settling rate with deposition rate can be obtained under such electric field. 


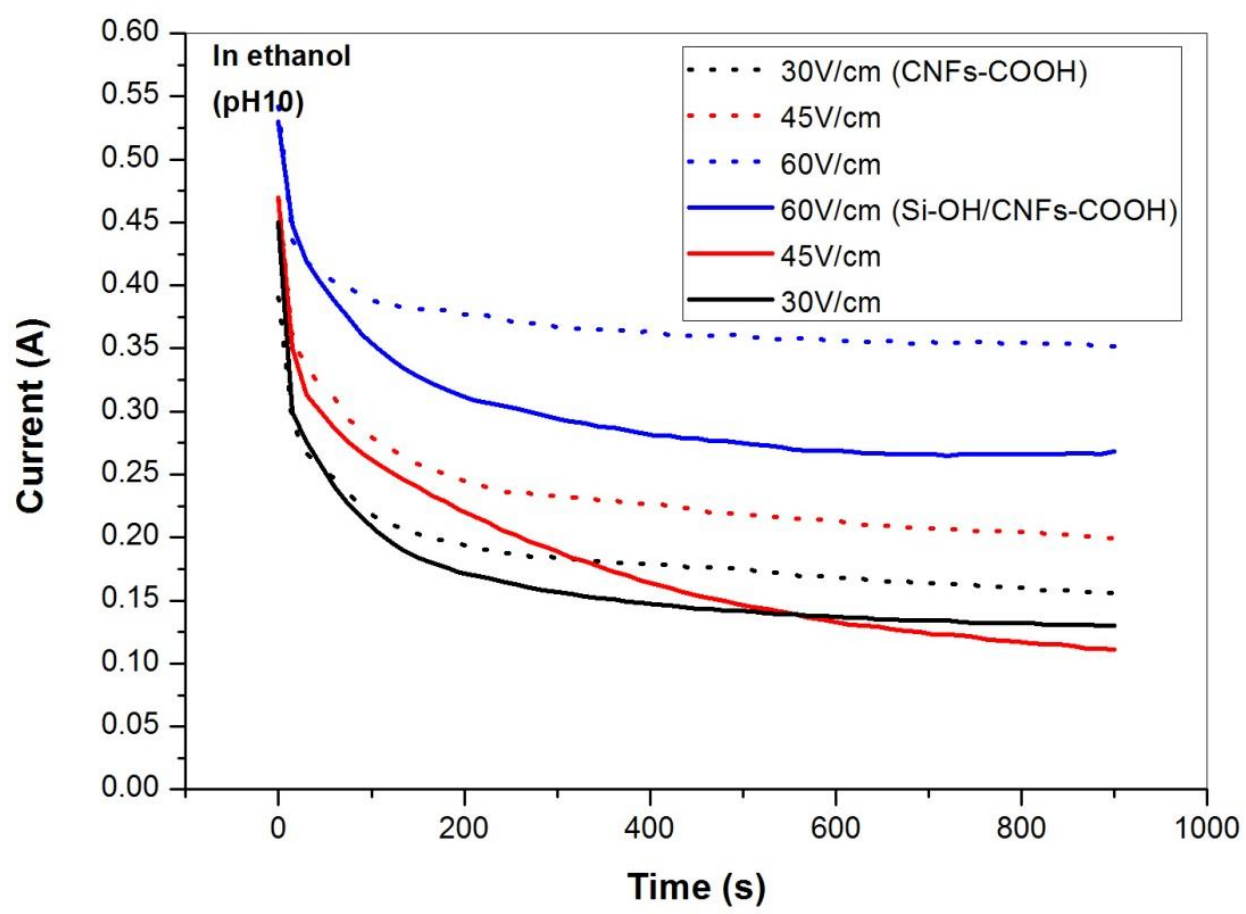

Fig.6.31: Profile of current versus time in $\mathrm{Si}-\mathrm{OH} / \mathrm{CNFs}-\mathrm{COOH}$ suspension

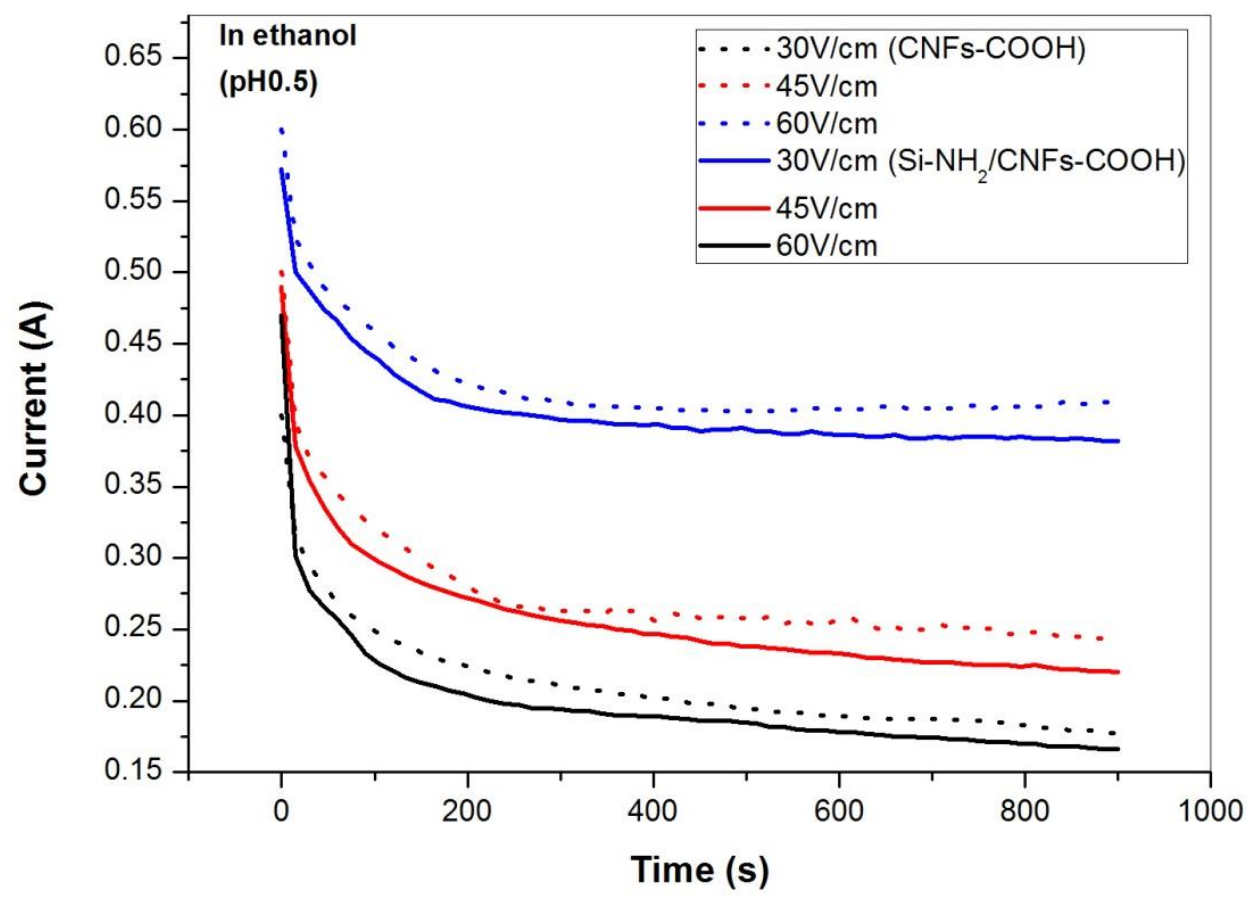

Fig.6.32: Profile of current versus time in $\mathrm{Si}-\mathrm{NH}_{2} / \mathrm{CNFs}-\mathrm{COOH}$ suspension

Fig.6.32 shows the current changing with time at different voltages in the $\mathrm{Si}-\mathrm{NH}_{2} / \mathrm{CNFs}$ $\mathrm{COOH}$ suspension (pH0.5). Each profile's changing tendency is highly similar to the one in the 
CNFs suspension, which means the formation of the $\mathrm{Si}-\mathrm{NH}_{2} / \mathrm{CNF}$ s layer also follow the threestage growth mechanism. Because of the interaction between $-\mathrm{NH}_{2}$ groups and $-\mathrm{COOH}$ groups, some SiNPs are locating along the surface of CNFs, leading to lower conductivity of the CNFs, and smaller current value at the same applied voltage in comparison with CNFs deposition.

Fig.6.33 shows the influence of time on the deposited mass in $\mathrm{Si}-\mathrm{OH} / \mathrm{CNF}-\mathrm{COOH}$ suspensions. The existence of Si-OH improves the stability of CNFs in the composite suspension, so the deposited mass of $0.94 \mathrm{mg} / \mathrm{mL}$ and $1.22 \mathrm{mg} / \mathrm{mL}$ after 10 and $15 \mathrm{~min}$ deposition are larger than those obtained in the CNFs suspension $(0.75 \mathrm{mg} / \mathrm{mL}, 0.84 \mathrm{mg} / \mathrm{mL})$. However, the introduction of $\mathrm{Si}-\mathrm{NH}_{2}$ makes the stability of the CNFs decreased a little, the corresponding deposited mass become lower in comparison with that in CNFs suspension with the same deposition time. The deposited mass after $10 \mathrm{~min}$ and $15 \mathrm{~min}$ deposition decreases from 0.58 $\mathrm{mg} / \mathrm{mL}$ and $0.62 \mathrm{mg} / \mathrm{mL}$ to $0.52 \mathrm{mg} / \mathrm{mL}$ and $0.56 \mathrm{mg} / \mathrm{mL}$, respectively.

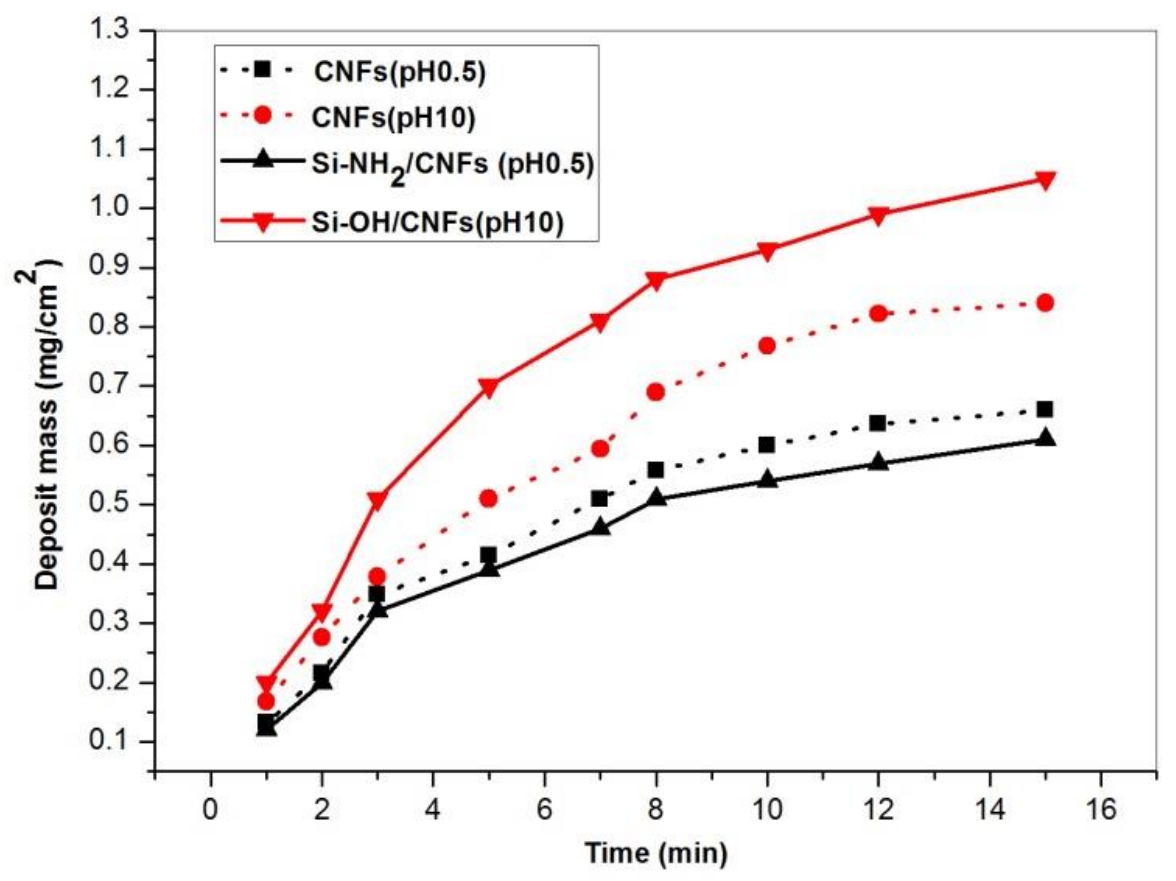

Fig.6.33: Profiles of deposited mass versus time in different suspensions

\subsection{Preparation of Si/CNFs composite film with honeycomb structure}

The composite film consisting of Si-OH and CNFs with honeycomb structure can be prepared by homogeneous EPD with the help of lithium borate $\left(\mathrm{Li}_{2} \mathrm{~B}_{4} \mathrm{O}_{7}\right)$ in ethanol at $\mathrm{pH} 10$.

1) Si film on $\mathrm{Cu}$ foil 


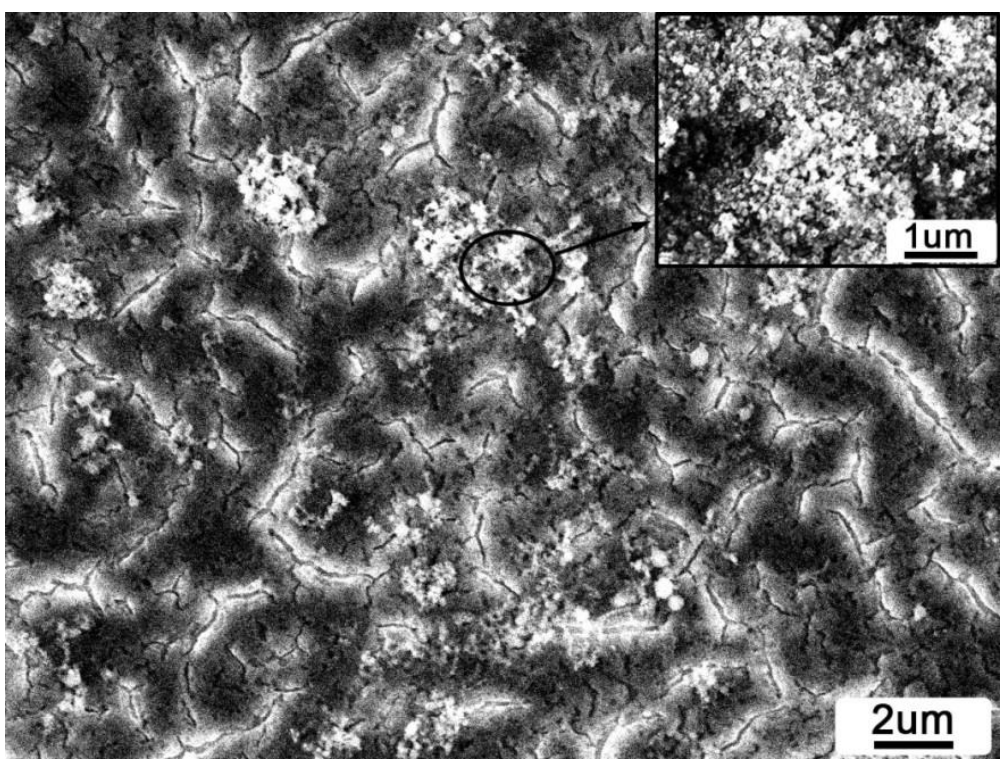

Fig.6.34: SEM image of Si-OH film on $\mathrm{Cu}$ foil.

As the control test, a Si-OH film was prepared firstly by EPD, as shown in Fig.6.34. The film can cover the whole $\mathrm{Cu}$ substrate but also has many cracks. From the broken surface of the film (the insert image), the aggregation of a large number of Si particles can be observed.

Considering the poor conductivity of $\mathrm{Si}$, such microstructure greatly inhibits the diffusion of $\mathrm{Li}^{+}$ and makes the lithiation/delithiation process hard for the inner part.

Fig.6.35a shows the cycling performance of the $\mathrm{Si}-\mathrm{OH}$ film. The first discharge capacity is about $1900 \mathrm{mAh} / \mathrm{g}$ at the current rate of $400 \mathrm{~mA} / \mathrm{g}$, much lower than the theoretical specific capacity (4200 $\mathrm{mAh} / \mathrm{g}$ ), indicating the formation of $\mathrm{Li}_{2} \mathrm{Si}$ in the end. The first charge capacity is about $600 \mathrm{mAh} / \mathrm{g}$ and the initial CE is only 32\%, indicating the seriously irreversible consumption of $\mathrm{Li}^{+}$due to the formation of SEI. After the first cycle, the discharge/charge capacity is decreased rapidly and very soon is lower than $200 \mathrm{mAh} / \mathrm{g}$. It's related to by the collapse of the film structure and the loss of the contact between $\mathrm{Si}$ and $\mathrm{Cu}$ due to the volume change effect during cycles. Fig.6.35b shows the voltage profiles of different cycles. During the first discharge process, the voltage platform from $1 \mathrm{~V}$ to $0.5 \mathrm{~V}$ is corresponding to the formation of SEI, and the following slant platform $(0.5-0.1 \mathrm{~V})$ should be attributed to the lithiation of Si. The first delithiation process starts with $0.6 \mathrm{~V}$, higher than the literature data. After the first cycles, the platform of the SEI formation disappears and only very short lithiation/delithiation platforms can be observed, exhibiting the discharge capacity of 310, 190 and $177 \mathrm{mAh} / \mathrm{g}$ at the $2^{\text {nd }}, 40^{\text {th }}$, and $100^{\text {th }}$ cycle, respectively. 

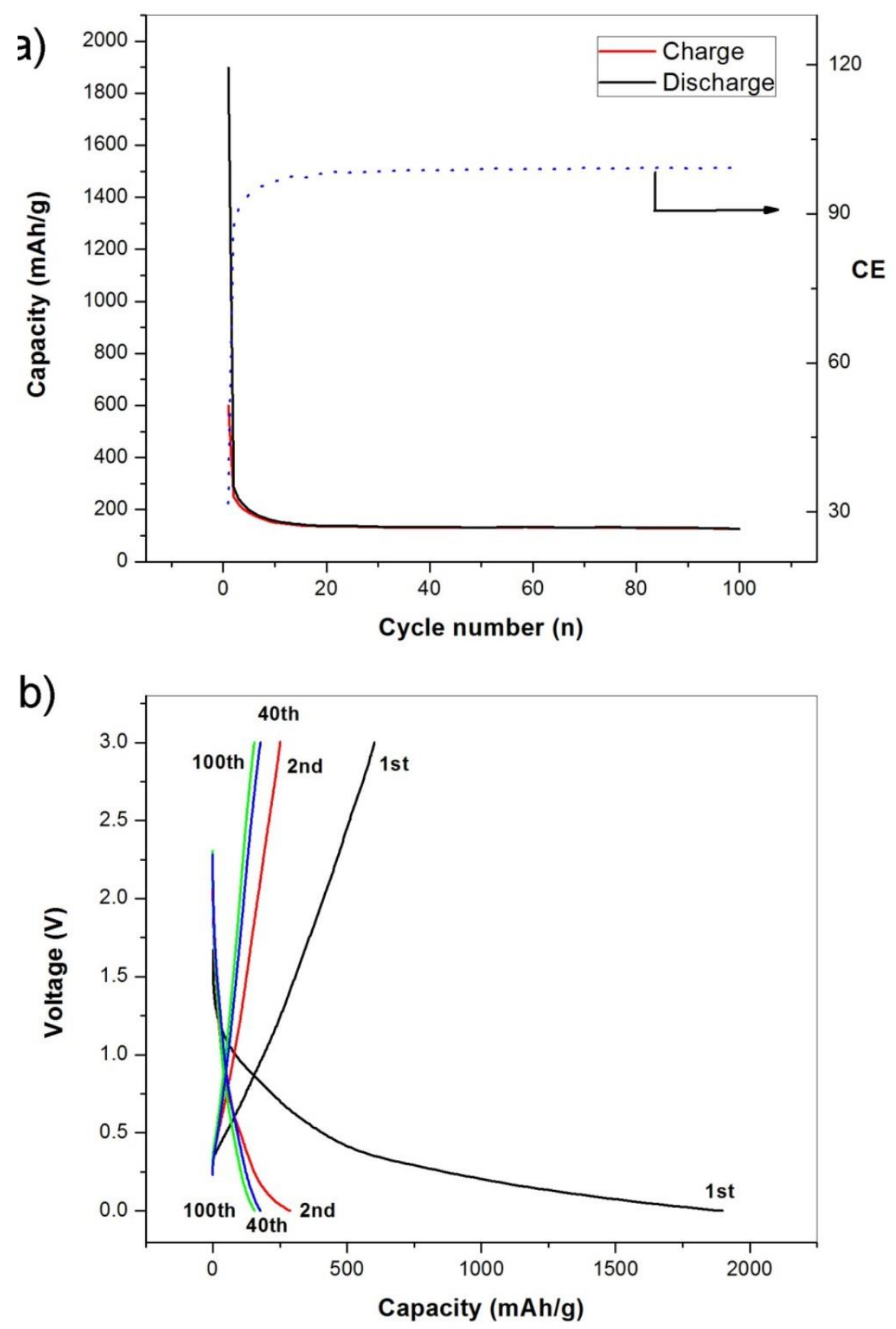

Fig.6.35: a) cycle performance of Si-OH film; b) galvanostatic discharge-charge curves for the Si/CNFs film.

2) Morphology of Si/CNFs film with honeycomb structure 
A typical composite film is successfully prepared by $10 \mathrm{~min}$ EPD, as shown in Fig.6.36. At the low magnification (Fig.6.36a), the film has the intact net-structure consisting of the twisted CNFs and Si particles. No exposed $\mathrm{Cu}$ substrate can be observed. The insert image shows the film has good flexibility, good mechanical strength and good adhesion with the $\mathrm{Cu}$. At the high magnification (Fig.6.36b), it shows the non-uniform distribution of Si in the film. Si particles prefer gathering together in the interspace of the net structure to being along with CNFs, which is related to the repulsive force between $\mathrm{Si}$ and $\mathrm{CNFs}$ due to $-\mathrm{OH}$ groups at the Si surface and $-\mathrm{COOH}$ groups at the CNFs surface. Therefore, most CNFs still have the smooth surface after the deposition. Fig.6.36c shows the film has an uneven surface with the thickness of $25-35$ $\mu \mathrm{m}$, and Fig.6.36d confirms that Si distribution is still non-uniform in the vertical direction.

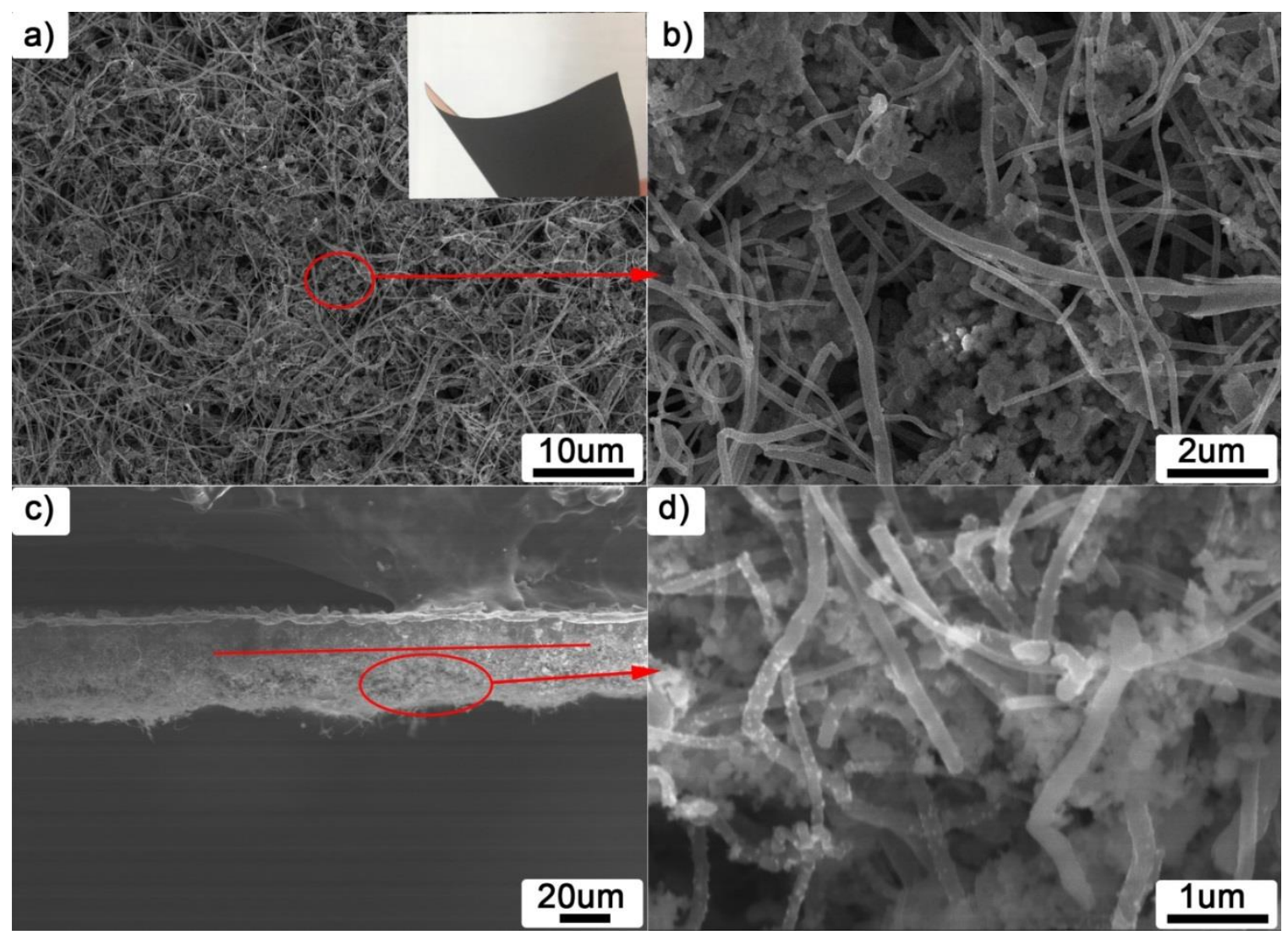

Fig.6.36: a) low-magnification and b) high-magnification SEM images of the CNFs/Si film; c) lower-magnification and d) high-magnification SEM images of the cross section of the composite film.

TGA and the corresponding DTG curves (the derivative of the TGA), as shown in Fig.6.37, can provide more accurate content of each component of the film. It can be divided into four mass loss sections. The first one below $150^{\circ} \mathrm{C}$ is due to the release of the surface moisture. 
Then, the degradation of carboxyl group happens, which reaches its maximum loss rate at around $200^{\circ} \mathrm{C}$, and completes at about $400^{\circ} \mathrm{C}$. The third section in the range of $400^{\circ} \mathrm{C}$ to $750^{\circ} \mathrm{C}$ is attributed to the pyrolysis of CNFs. Different sizes and defects distribution of CNFs lead to different loss rates. The sample retains about $22 \mathrm{wt} \%$ after reaching $750^{\circ} \mathrm{C}$. Over this temperature, the increase of the mass can be observed, which is might be caused by the formation of the thin layer of $\mathrm{SiO}_{\mathrm{x}}$. Ignoring the minor formation of $\mathrm{SiO}_{\mathrm{x}}$ during the test below $750^{\circ} \mathrm{C}$, the $\mathrm{Si}$ content in the composite can thus be estimated as $22 \mathrm{wt} \%$. Based on the initial specific capacities of Si$\mathrm{OH}$ film and CNFs-COOH film as discussed before, the maximum theoretical specific capacity of the composite film is about $630 \mathrm{mAh} / \mathrm{g}$.

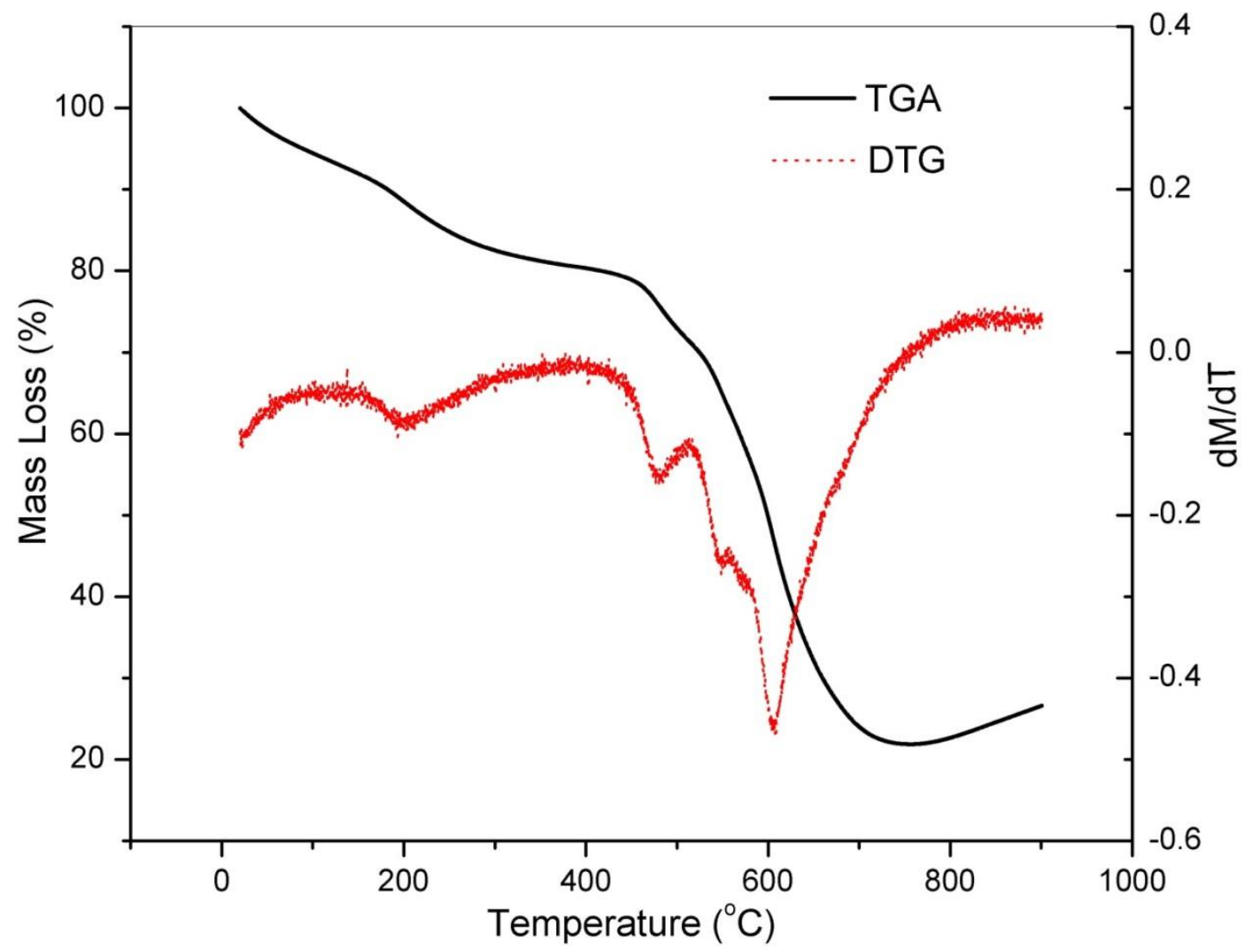

Fig.6.37: TGA profile of Si/CNFs composite

In order to further realize the microstructure, the morphology evolution of the film has been studied, as shown in Fig. 6.38 and 6.39. A deposit layer with the mesh pattern is formed in a very short time (Fig. 6.38a), which exhibits discontinuous pores ranging from $20 \sim 35 \mu \mathrm{m}$. The magnified SEM image (Fig. 6.39a and b) shows CNFs are interweaved into a dense net and SiNPs are mixed with them simultaneously. Few SiNPs or CNFs are found in the pores. As time 
advance, the number of mesh decreases (Fig. 6.38b) and the layer become thicker with a little more Si (Fig.6.39c and d). When the deposited time is extended to $10 \mathrm{~min}$ (Fig6.38c), large pores nearly disappear while massive accumulation of the composite in some regions happens. Over 10 min, the growth of the deposit layer becomes slower, as shown in Fig. 6.38d. Considering the uniformity of the microstructure, 5 10 min EPD is a better choice.

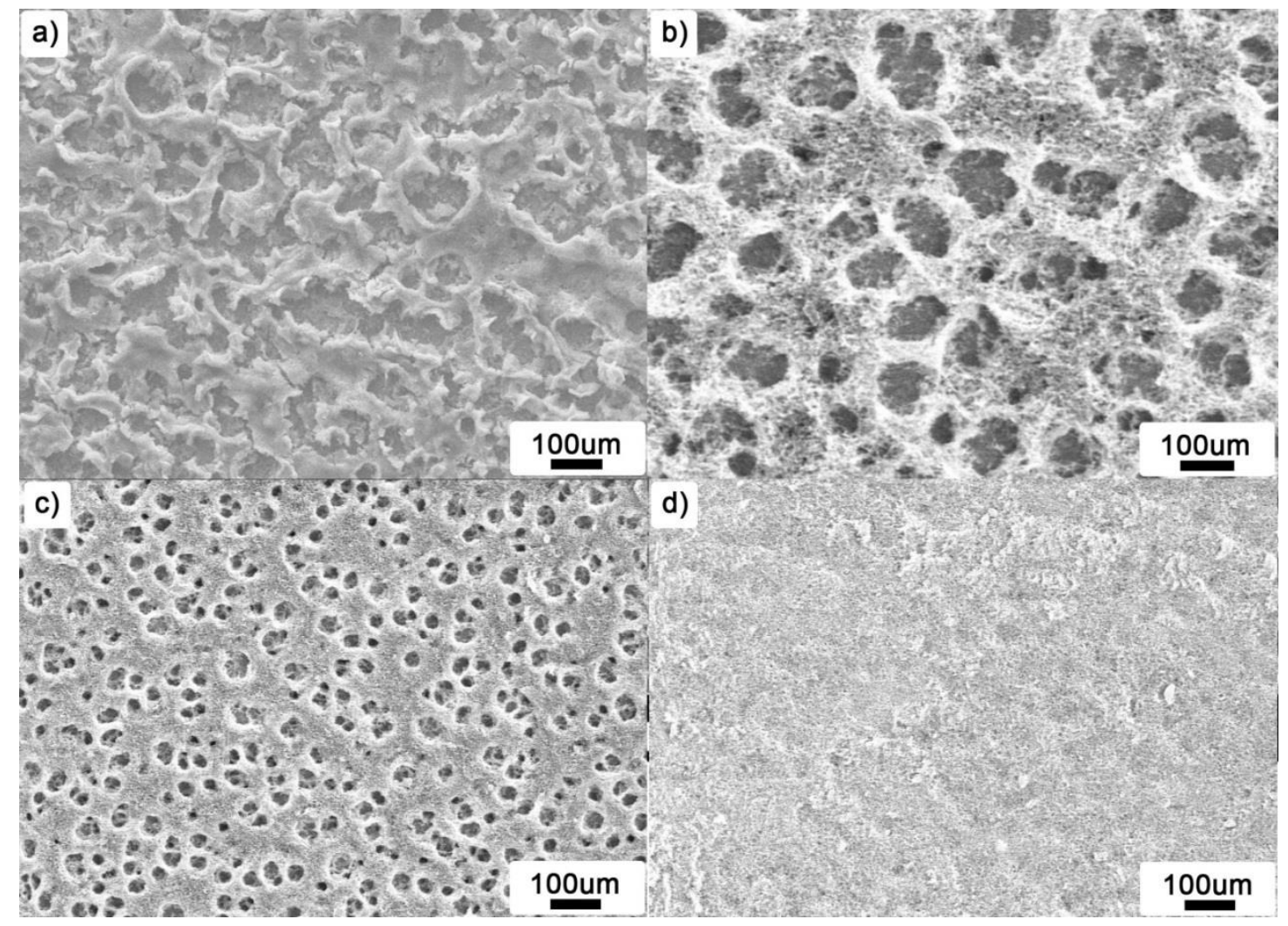

Fig.6.38: SEM images of Si/CNFs composite film with different deposition time. a) 1min, b) 3 $\min$, c) $10 \mathrm{~min}$, d) $15 \mathrm{~min}$.

It's believed that the formation of such microstructure is with relation to the electrolytes. If only LiOH used, the deposit with the irregular pattern instead of the mesh (Fig. 6.40a) happens at the beginning, which includes a large number of SiNPs attaching to the loose CNFs. After 10 min, as shown in Fig.6.40b, the porous film is formed with the similar surface micro-morphology (Fig.6.40c) to the previous one. However, its cross-section SEM image (Fig. 6.40d) shows different characteristics. The inhomogeneous distribution of SiNPs along a line perpendicular to the copper foil can be observed. Especially at the bottom of the film, the SiNPs with few CNFs are severely agglomerated, indicating the initial mobility rate of Si is higher than that of CNFs. The introduction of a small amount of $\mathrm{Li}_{2} \mathrm{~B}_{4} \mathrm{O}_{7}$, an electrolyte salt, may improve the quality of 
the film from two aspects with little effect on $\mathrm{pH}$ value of the suspension. One side, $\mathrm{B}_{4} \mathrm{O}_{7}{ }^{2-}$ has faster mobility rate than negative charged SiNPs because of higher electric charge density, which leads to "shield" Si and make Si "waiting for" CNFs in the early stage of deposition. On the other side, the existence of $\mathrm{B}_{4} \mathrm{O}_{7}{ }^{2-}$ makes the particle's diffusion layer thicker, resulting in the increase of the repulsive force among the deposited tangled CNFs and upcoming deposited ones and finally forming the mesh pattern.

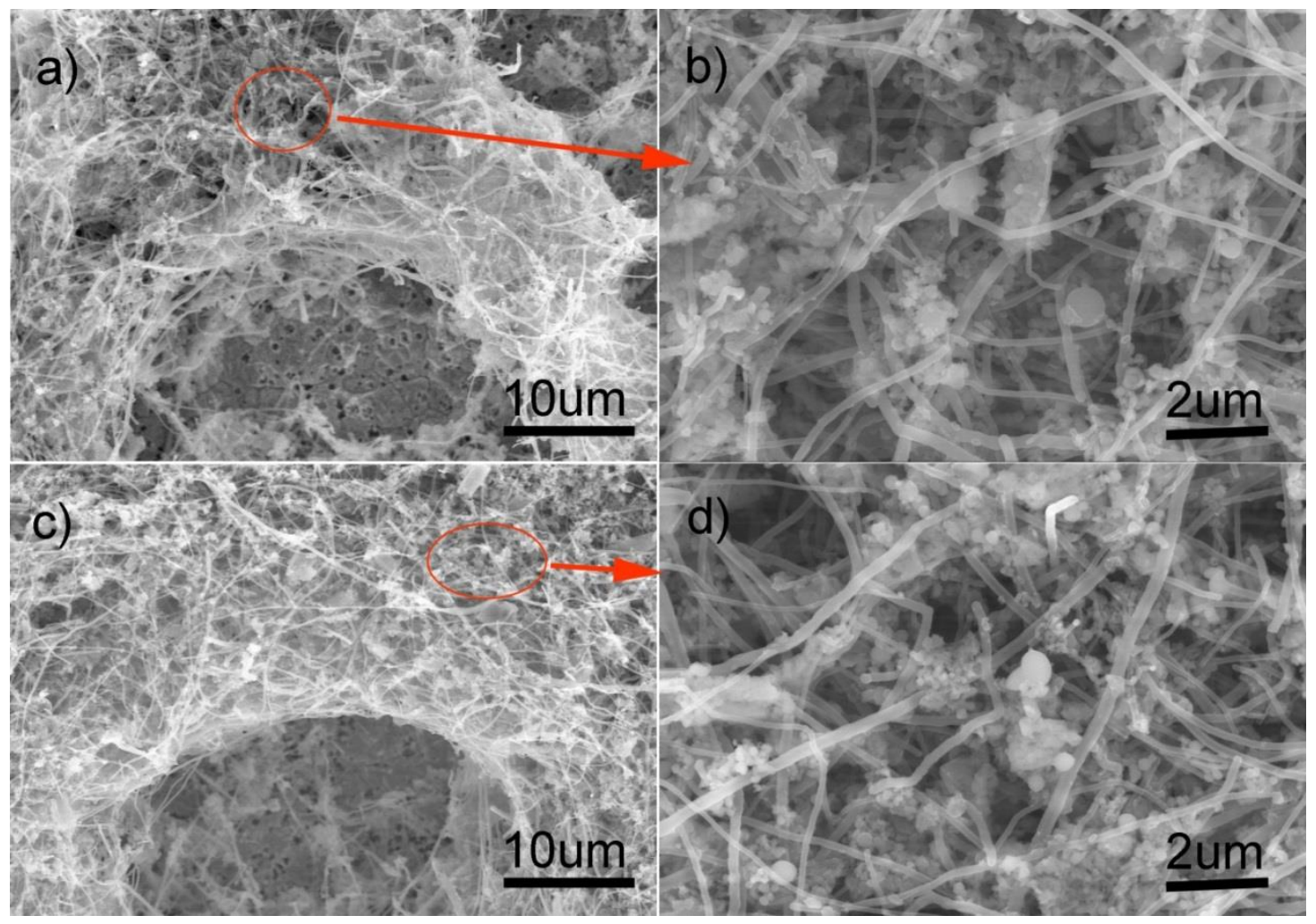

Fig.6.39: SEM images of the Si/CNFs composite film after (a, b) $1 \mathrm{~min}$ and (c, d) 3min EPD 


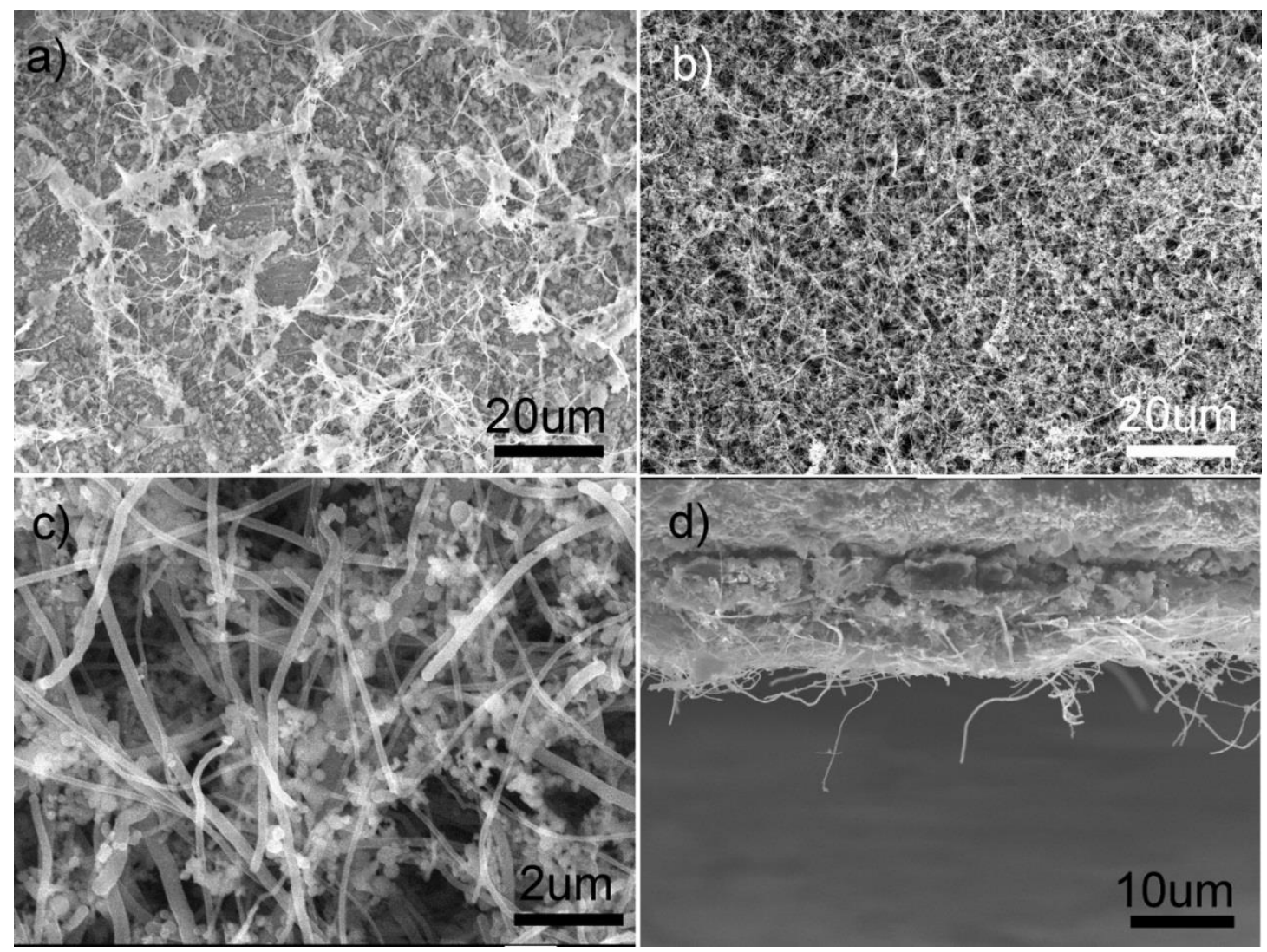

Fig.6.40: SEM images of the Si/CNFs composite film without the assistance of lithium borate after a) $1 \mathrm{~min}$, b, c) $10 \mathrm{~min}$ EPD, d) the cross-section image of the film after $10 \mathrm{~min}$ EPD.

Generally, salt additives influence the deposited layer via two ways. Firstly, different ion's size can change the thickness of the electric double layer of the charged particles, leading to different zeta potential values. As a result, the suspension stability/the settling rate of particles is changed, which can greatly influence the morphology and uniformity of the deposited layer. Secondly, as the increase of the free ions' concentration, the mobility rate of particles in the suspension will be changed greatly. For the multi-component system, it can influence the content of each component in the deposited film, as shown in Fig.6.42. If $\mathrm{LiClO}_{4}$ is added, the composite film becomes non-uniform (Fig.6.42a, b). The cracks and bumps on the surface can be observed at the same time. If $\mathrm{Li}_{2} \mathrm{CO}_{3}$ is used, the composite film looks similar as that prepared with the additive of $\mathrm{Li}_{2} \mathrm{~B}_{4} \mathrm{O}_{7}$. The morphology difference may be caused by $\mathrm{Li}+$ concentration. Although both $\mathrm{Li}_{2} \mathrm{CO}_{3}$ and $\mathrm{LiClO}_{4}$ have larger negative ions than $\mathrm{OH}^{-}, \mathrm{Li}_{2} \mathrm{CO}_{3}$ can provide more $\mathrm{Li}^{+}$in comparison with $\mathrm{LiClO}_{4}$, leading to easier neutralization of negative-charged $\mathrm{Si}$ and $\mathrm{CNFs}$ when deposition happens and better distribution of CNFs net. 


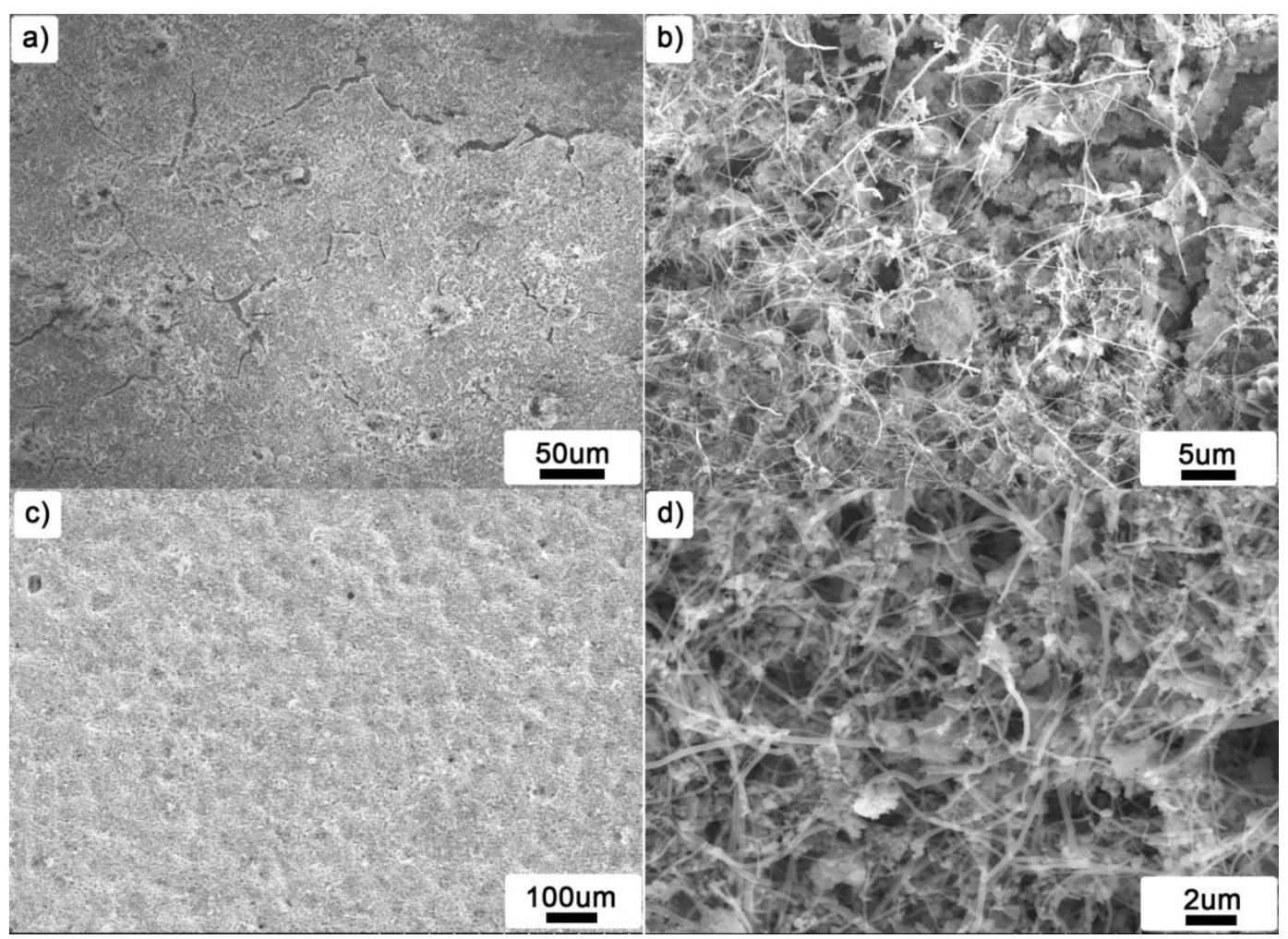

Fig.6.41: SEM images of Si-OH/CNFs composite at a) high-magnification and b) low magnification with $\mathrm{LiClO}_{4}$ additives; SEM images of Si/CNFs composite at c) highmagnification and d) low-magnification with $\mathrm{Li}_{2} \mathrm{CO}_{3}$ additives.

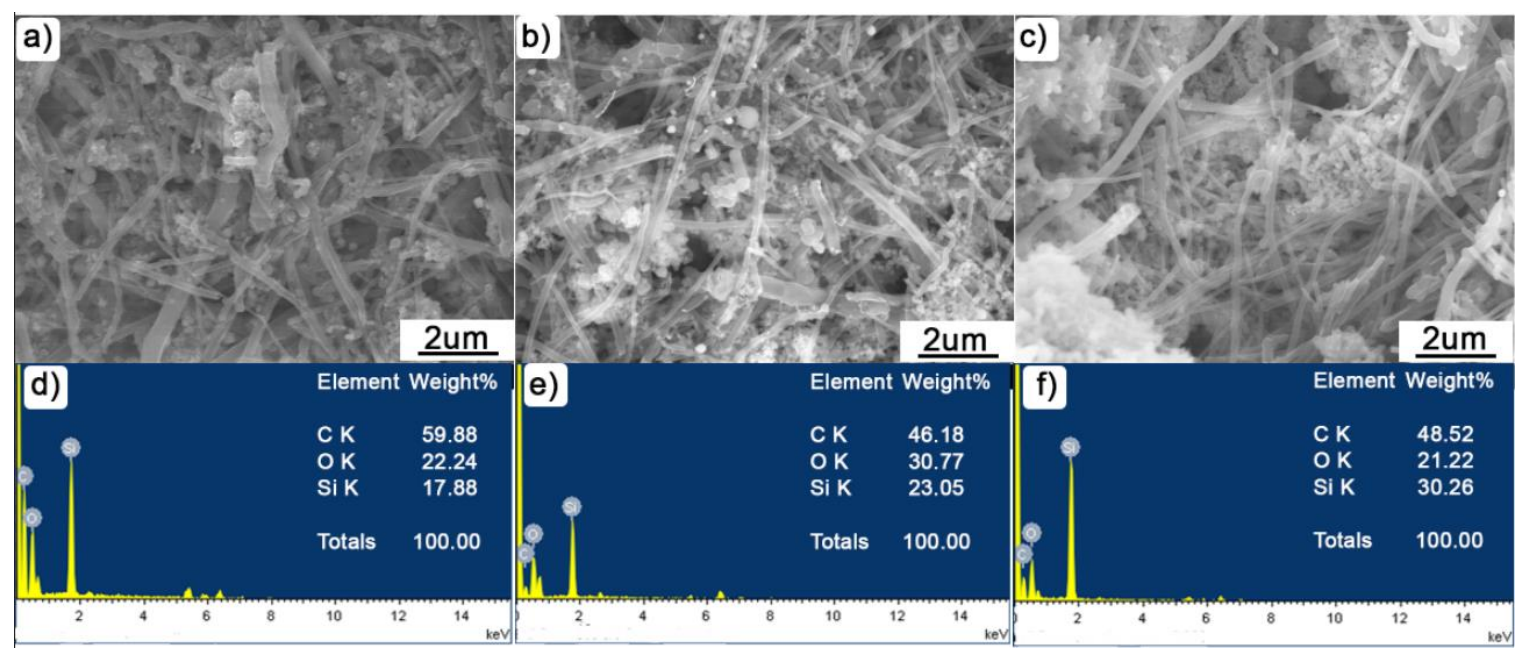

Fig.6.42: SEM and EDX images of Si-OH/CNFs-COOH composite films with the applied voltages of a, d) $30 \mathrm{~V} / \mathrm{cm}, \mathrm{b}$, e) $45 \mathrm{~V} / \mathrm{cm}$ and c, f) $60 \mathrm{~V} / \mathrm{cm}$.

For EPD of Si-OH/CNFs-COOH in ethanol, as discussed before, if considering the integrity and uniformity of the final film, $\mathrm{pH} 10$ is the best choice for a stable multi-component suspension, and the proper applied voltage is around $45 \mathrm{~V} / \mathrm{cm}$. Actually, the film's component 
and microstructure can be influenced a little by applied voltage $(30 \sim 60 \mathrm{~V})$ if $\mathrm{pH}$ value is fixed to 10, as shown in Fig.6.42. Firstly, applied voltage cannot change the basic structure of the composite. SiNPs still are distributed randomly in the continuous CNFs skeleton. As the increase of the voltage from $30 \mathrm{~V} / \mathrm{cm}$ (Fig.6.42a) to $45 \mathrm{~V} / \mathrm{cm}$ (Fig.6.42b), the microstructure keeps unchanged and the Si content increases a little. At $60 \mathrm{~V} / \mathrm{cm}$, higher voltage leads to faster Si migrating rate and weaker space effect of CNFs on Si distribution during deposition, therefore, the aggregation of SiNPs becomes more serious (Fig.6.42c).

In order to adjust the morphology of the film, some kinds of surfactants are introduced, as shown in Fig.6.43 and 6.44. After adding TX-100, the film is still intact without any cracks. CNFs net are changed little, while the aggregated SiNPs among CNFs become loose due to the space effect of TX-100. If using ionic surfactant, the film morphology is changed a lot. With SDS additive (anionic surfactant, Fig.6.44a and b), more CNFs are intertwisting with each other due to the decrease of the size of EDL, leading to the formation of broken conductive net. If adding quaternary ammonium compound (cationic surfactant, Fig.6.44c and d) into the suspension, more Si particles are deposited at the bottom of film due to the reduced surface charges.

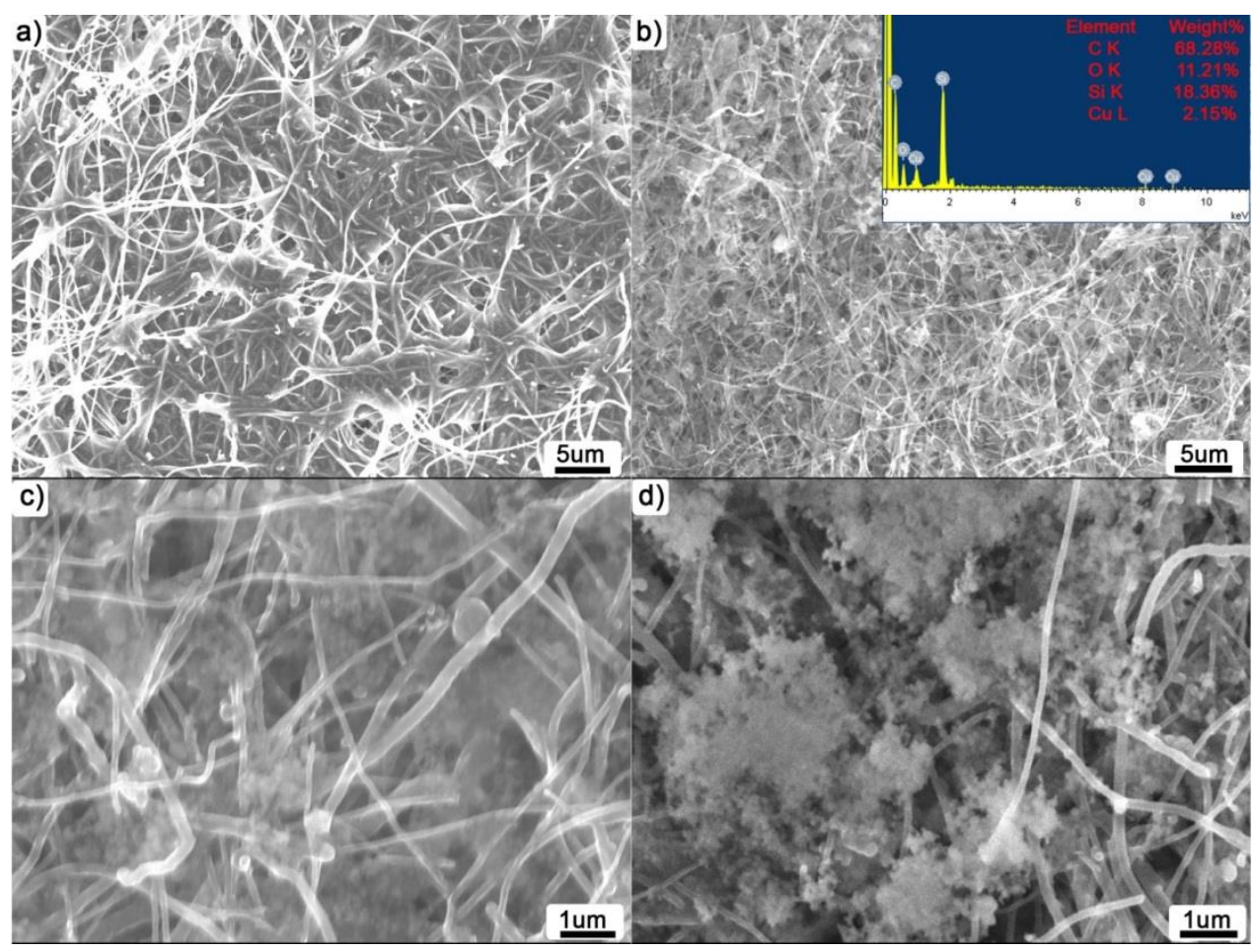

Fig.6.43 SEM images of a) CNFs film, b, c, d) Si/CNFs films at different magnification with TX-100 additive. 


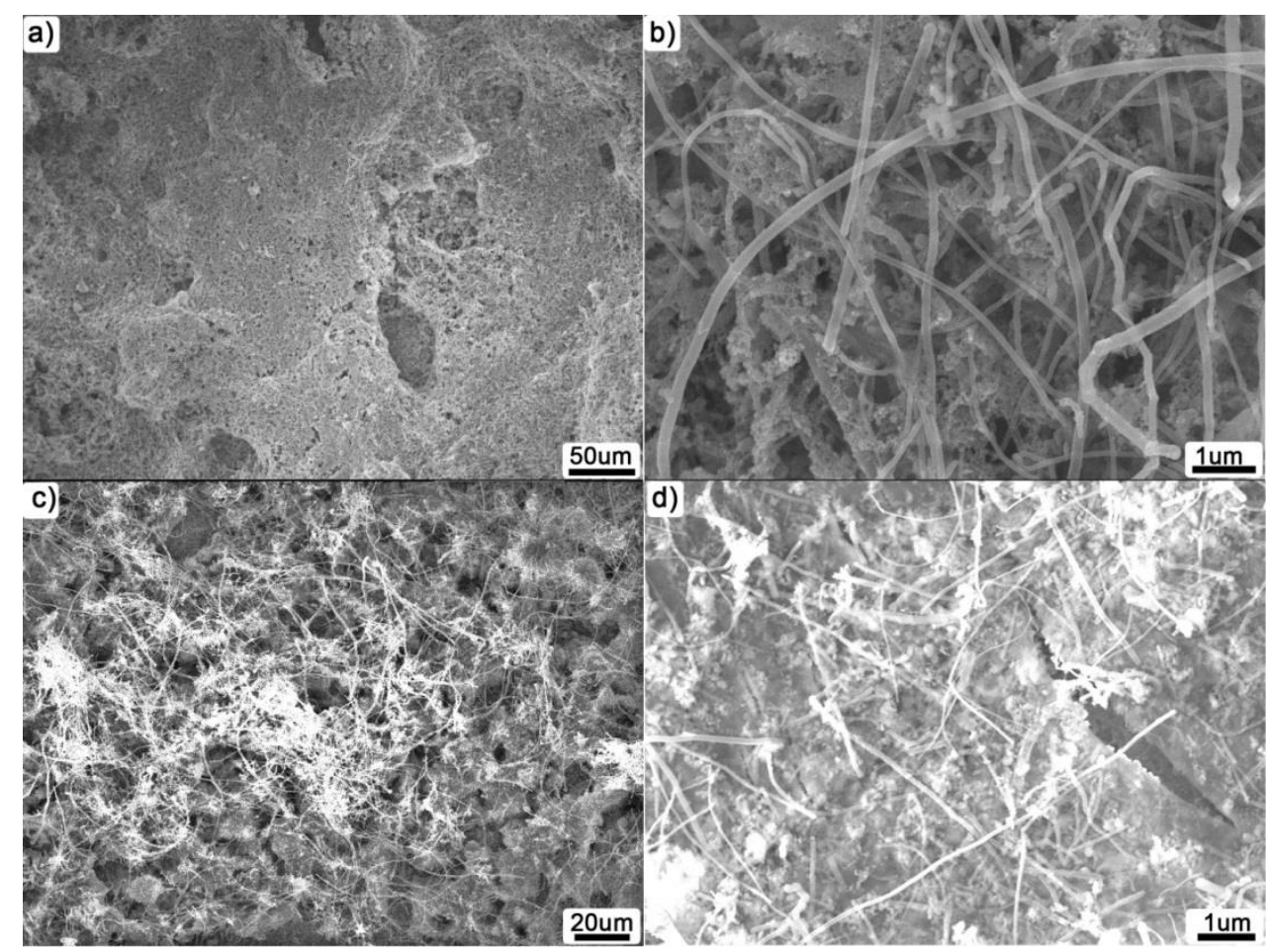

Fig.6.44 SEM images of Si/CNFs composite a, b) with the additive of SDS and c, d) with the additive of quaternary ammonium compound at different magnifications;

3) Electrochemical properties

The voltage profile of the composite film at the current rate of $400 \mathrm{~mA} / \mathrm{g}$ is shown in Fig.6.45. The film has the $1^{\text {st }}$ discharge capacity of $1070 \mathrm{mAh} / \mathrm{g}$, much larger than the theoretical value $(630 \mathrm{mAh} / \mathrm{g})$. The excess part should be related to the decomposition of the electrolyte. The $1^{\text {st }}$ charge capacity is $580 \mathrm{mAh} / \mathrm{g}$ and the ICE is only $54.2 \%$. There is a main platform starting with $0.45 \mathrm{~V}$ on the first discharge curve possibly due to the formation of SEI and $\mathrm{Li}_{\mathrm{x}} \mathrm{Si}$ alloying. In the second cycle, the discharge and charge capacity is about $570 \mathrm{mAh} / \mathrm{g}$ and $490 \mathrm{mAh} / \mathrm{g}$, and the $\mathrm{CE}$ is $86 \%$. The sloped platform starting with $1.1 \mathrm{~V}$ indicates the continuous growth of the SEI layer. However, all the charge profiles have much higher delithiation platform than the literature data, which is consistent with the results of the $\mathrm{CV}$ profiles (Fig.6.45b). In the first cycle, a cathodic peak around $0.45 \mathrm{~V}$ and an anodic peak around $1.6 \mathrm{~V}$ can be observed, and these two peaks become much wider during the following cycles. Meanwhile, a new anodic peak around $0.6 \mathrm{~V}$ appears which should be attributed to the extraction of $\mathrm{Li}^{+}$from the $\mathrm{Li}_{\mathrm{x}} \mathrm{Si} / \mathrm{LiC}_{\mathrm{y}}$ alloy. The impurity in the composite film is the main reason for the high delithiation platform and broad peaks. In the alkali suspension, negative-charged Si-OH particles move toward to the positive electrode $(\mathrm{Cu}$ foil) during the deposition process. At the 
same time, the corrosion of $\mathrm{Cu}$ cannot be avoided. Some $\mathrm{Cu}$ atoms are oxidized to $\mathrm{Cu}_{2} \mathrm{O}$ and the mixture of $\mathrm{CuO}$ and $\mathrm{Cu}(\mathrm{OH})_{2}$, finally forming a passivation layer between $\mathrm{Cu}$ foil and the composite layer. The inert layer makes the transport of $\mathrm{Li}^{+}$harder, which can inhibit the normal growth of the SEI layer and lithiation/delithiation process.
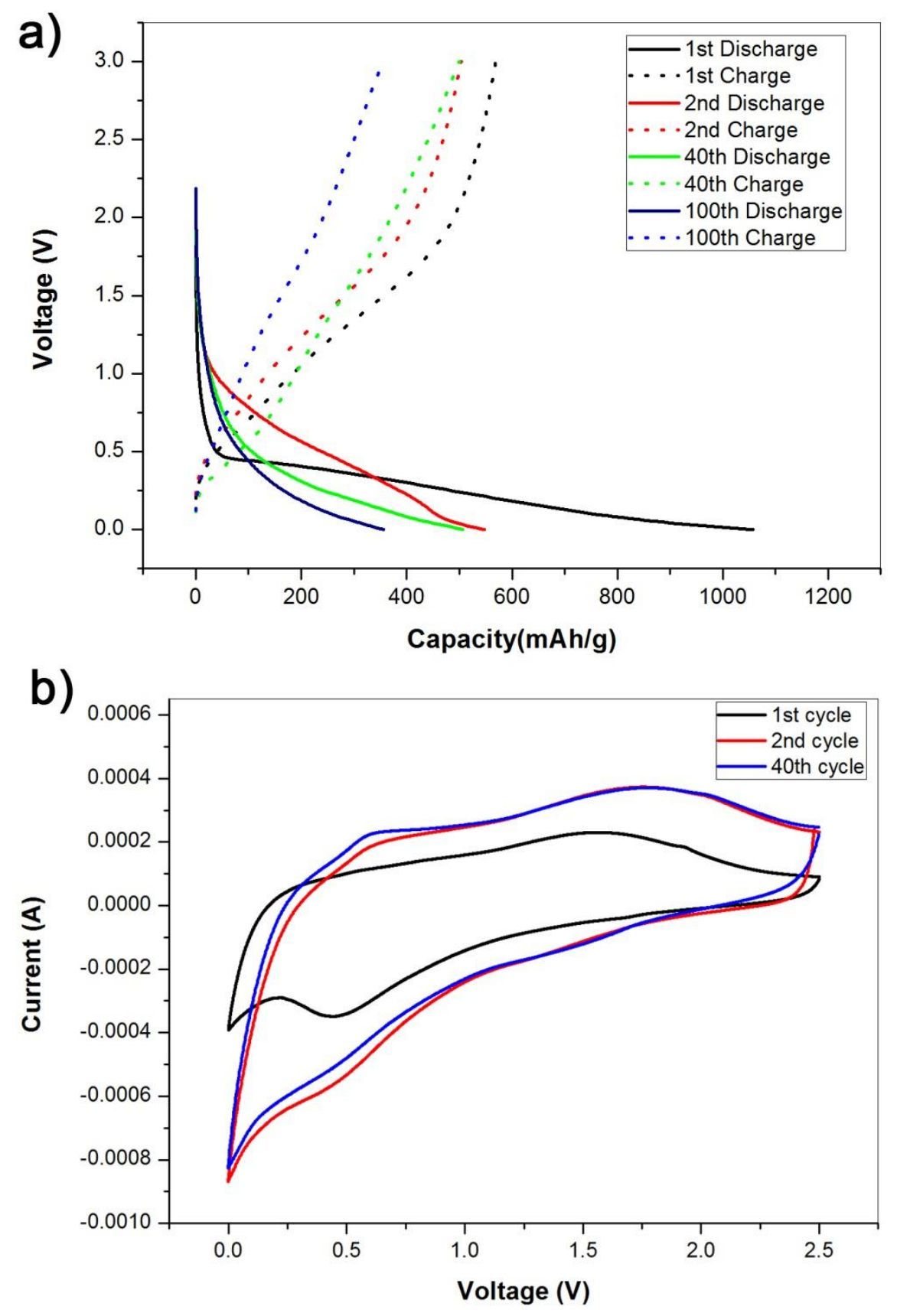

Fig.6.45: a) Galvanostatic discharge-charge curves for the CNFs/Si composite film; b) cyclic voltammetry profiles of the Si/CNFs composite film. 
Removing the inert layer by using the proper acidic solution, the "real" voltage profiles and CV profiles of the composite film can be obtained, as shown in Fig6.46.
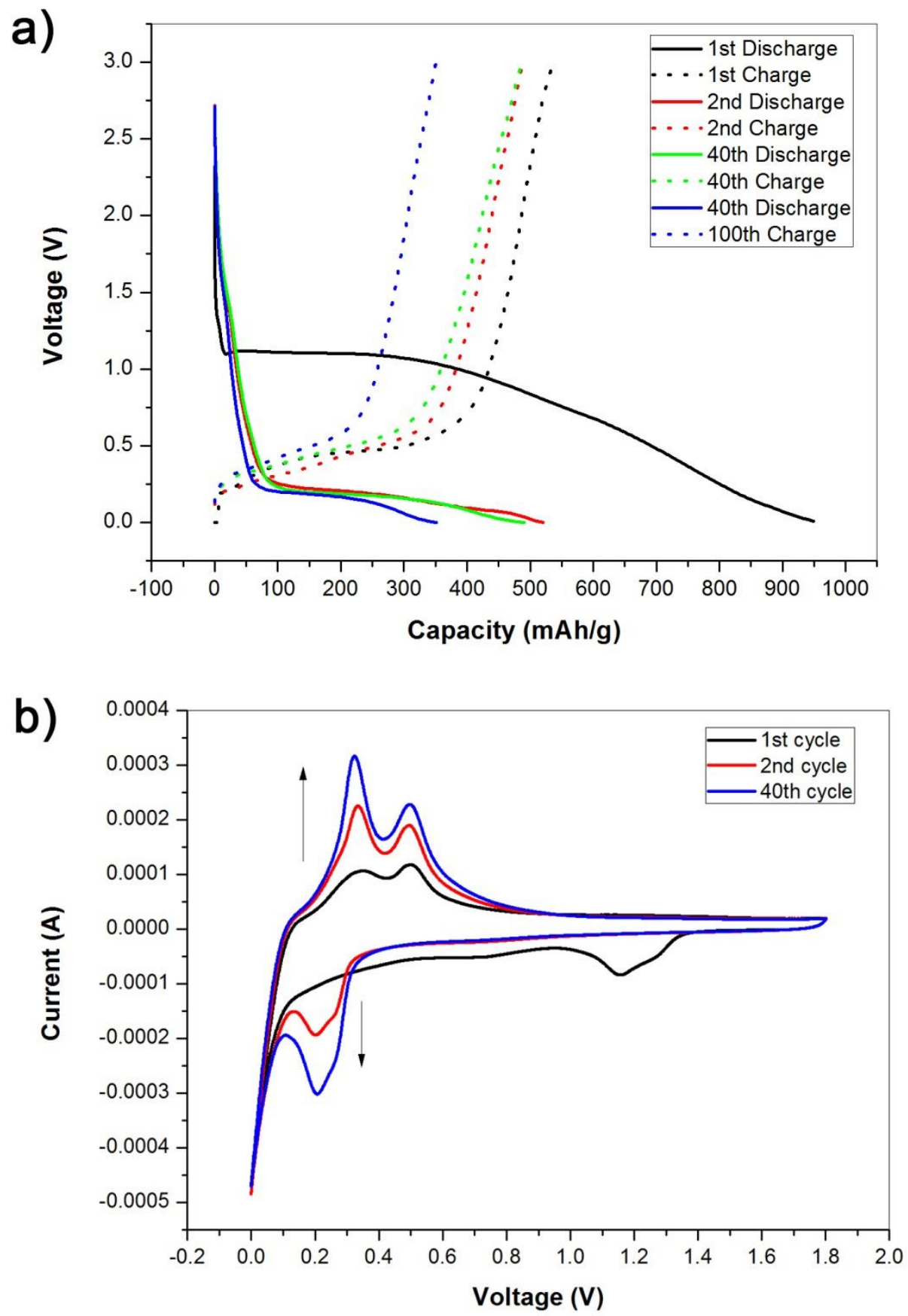

Fig.6.46: a) Galvanostatic discharge-charge curves for the CNFs/Si composite film after washing;

b) cyclic voltammetry profiles of the Si/CNFs composite film after washing.

Compared with the film without washing, the $1^{\text {st }}$ discharge and charge capacities are decreased a little to $1040 \mathrm{mAh} / \mathrm{g}$ and $535 \mathrm{mAh} / \mathrm{g}$, while the ICE almost keeps unchanged. A 
main flat region at $1.1 \mathrm{~V}$ on the $1^{\text {st }}$ discharge should be assigned to the formation of SEI layer, and drops gradually as more $\mathrm{Li}^{+}$alloying with $\mathrm{Si} / \mathrm{C}$. On the following discharge curves, the high voltage platform disappears and only one region at $0.2-0.3 \mathrm{~V}$ corresponding to the conversion of amorphous $\mathrm{Si}$ and $\mathrm{C}$ to $\mathrm{Li}_{\mathrm{x}} \mathrm{Si} / \mathrm{LiC}_{\mathrm{y}}$ can be observed. Similarly, there is only one platform at 0.2 $-0.5 \mathrm{~V}$ corresponding to the extraction of $\mathrm{Li}^{+}$from $\mathrm{Li}_{\mathrm{x}} \mathrm{Si} / \mathrm{LiC}$ y on each charge curve, which indicates high stability of the inner battery. From the CV curve, the cathodic peak around $1.1 \mathrm{~V}$ during the $1^{\text {st }}$ discharge is assigned to the formation of a SEI layer, which disappears in the following cycles. It means the SEI layer is completely formed in the $1^{\text {st }}$ cycle and keeps stable. Another cathodic peak around $0.25 \mathrm{~V}$ is assigned to the formation of the amorphous $\mathrm{Li}_{\mathrm{x}} \mathrm{Si}$ and $\mathrm{LiC}_{\mathrm{y}}$. Two anodic peaks at $0.35 \mathrm{~V}$ and $0.5 \mathrm{~V}$ can be found on each charge curve, which are corresponding to the transformation of $\mathrm{Li}_{\mathrm{x}} \mathrm{Si} / \mathrm{LiC}_{\mathrm{y}}$ to amorphous $\mathrm{Si}$ and CNFs. It's noticed that the intensity of the current increases with the cycle numbers, which may be related to the gradual activation of Si particles during the test.

As shown in Fig.6.47a, after the first several cycles, the discharge/charge capacity of the composite film remains stable and the $\mathrm{CE}$ value almost keeps $100 \%$. A reversible discharge/charge capacity of $500 \mathrm{mAh} / \mathrm{g}$ after 60 cycles can be obtained, much higher than that of Si film or CNFs film. One reason for the improvement of the cyclability is CNFs net-structure can effectively improve the film conductivity and provide enough space to accommodate $\mathrm{Si}$ volume change during lithiation/delithiation to maintain the integrity of the structure. However, after 60 cycles, the capacity drops slowly as the increase of the cycle number, and the discharge/charge capacity is only $360 \mathrm{mAh} / \mathrm{g}$ in the $100^{\text {th }}$ cycle. It indicates the link between $\mathrm{Si}$ and CNFs is not strong enough. Although the integral structure can be maintained, the aggregated Si particles may lose the contact with CNFs, leading to the damage of the conductive framework and the loss of the active materials.

The rate performance of the composite film is shown in Fig6.47b. With the increasing of the current rate from 400 to 800, 1600 and $3200 \mathrm{~mA} / \mathrm{g}$, the specific capacity decreases from 460 to 280,260 and $250 \mathrm{mAh} / \mathrm{g}$, respectively. When the current rate returns to $400 \mathrm{~mA} / \mathrm{g}$, the capacity can be returned to $430 \mathrm{mAh} / \mathrm{g}$ after 90 cycles. Generally, at a high current rate, the time for $\mathrm{Li}^{+} /$electron transport in the active material is very limited and the conductivity is the key on the lithiation/delithiation process. Therefore, poor link between CNFs and $\mathrm{Si}$ in the composite film leads to its bad rate performance. 

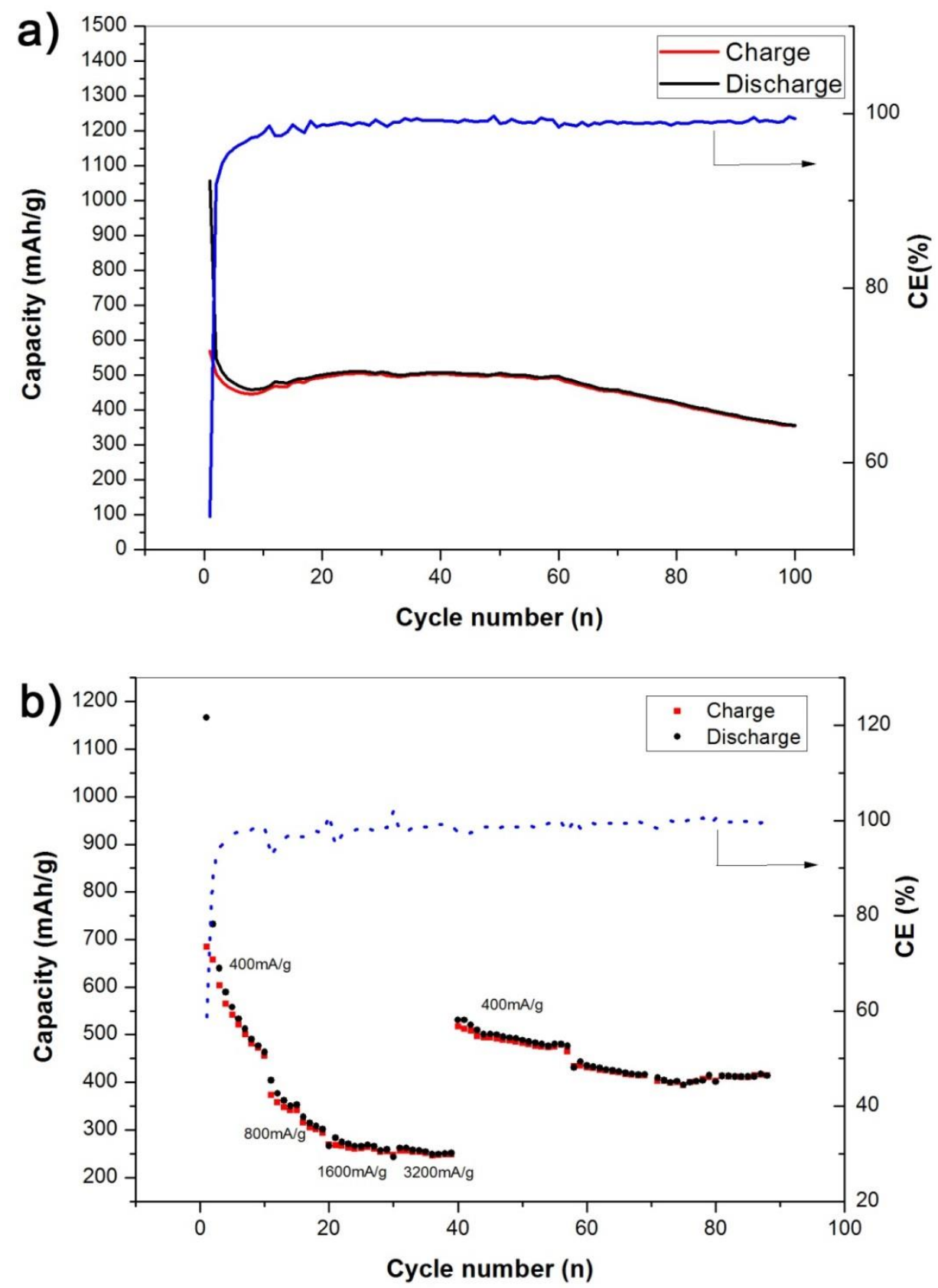

Fig.6.47: a) cycling performance and b) rating performance of the Si/CNFs film after washing.

To further understand the effect of cycling on the microstructure of the composite film, a half cell in the charge state after 60 cycles was disassembled. The SEM image (Fig.6.48a) clearly shows that the film is well retained without any obvious crack, and membranoid substances in some areas are also observed, which might belong to the SEI layer. Si particles are found to be wrapped by such membranoid substances to stay close to CNFs at high magnification (Fig. 6.48b). The cross-section image (Fig. 6.48c) indicates the film's thickness changes little, still 
around $30 \mu \mathrm{m}$, which demonstrates that the meshed porous structure can effectively relieve the stress from volume change of Si particles during lithiation and delithiation process, and the magnified image (Fig.6.48d) shows no aggregated Si particles are exposed at the CNFs surface. All the images verify that this composite film has great structure stability and keeps good electric contacting between $\mathrm{CNFs}-\mathrm{COOH}$ and $\mathrm{Si}-\mathrm{OH}$ in the first 60 cycles.

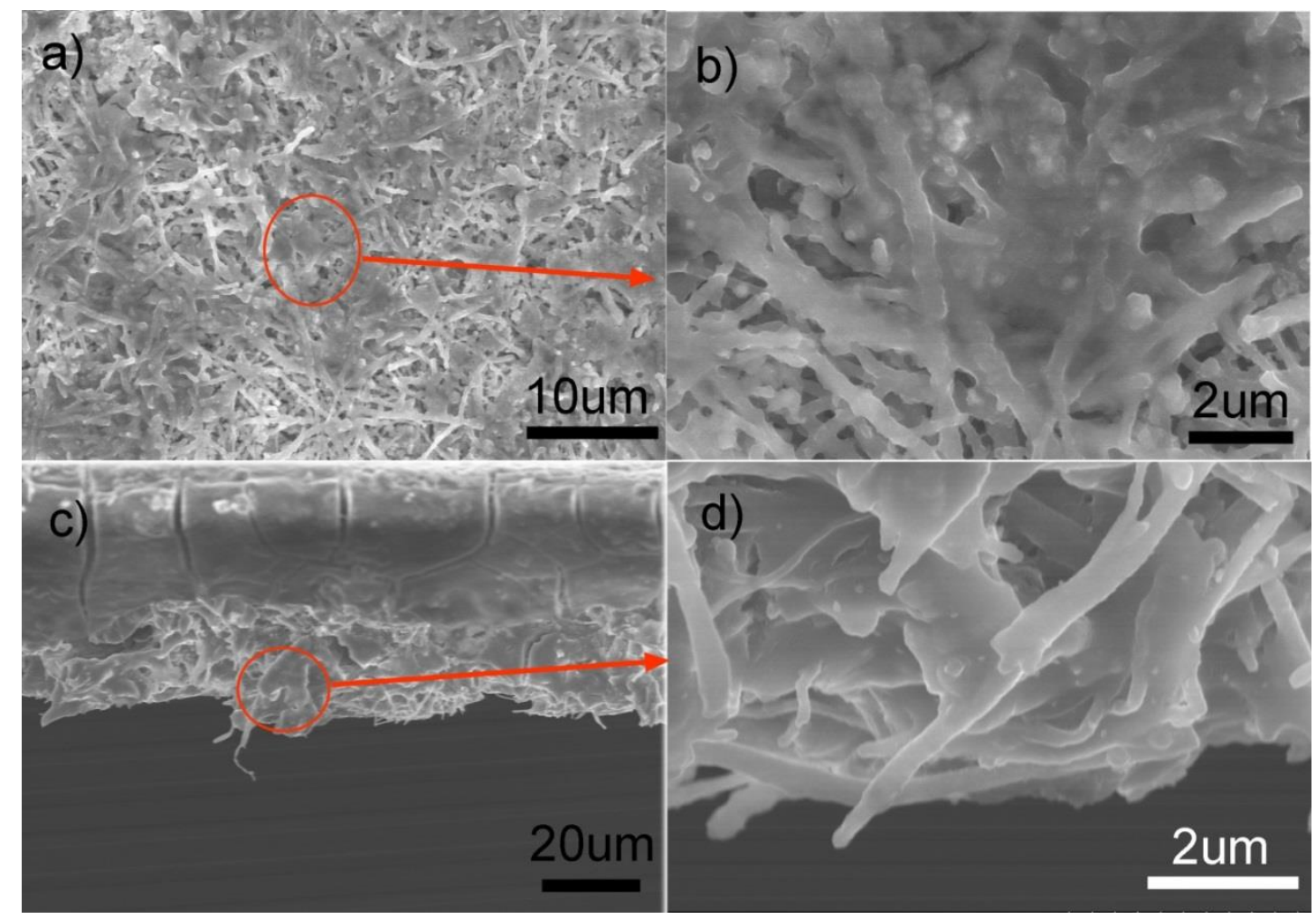

Fig.6.48: SEM images of $\mathrm{CNFs/Si} \mathrm{composite} \mathrm{after} 60$ cycles. a, b) top view, c, d) cross section.

Fig.6.49 shows the influence of applied voltage on film's cycling performance. At low applied voltage (30 V/cm), the deposited film has less Si content (Fig.6.42d), therefore, the $1^{\text {st }}$ discharge capacity is decreased from $1040 \mathrm{mAh} / \mathrm{g}$ to $914 \mathrm{mAh} / \mathrm{g}$. Meanwhile, less Si content means better conductivity of the film, relieved volume effect and more stable SEI layer, leading to higher $1^{\text {st }}$ charge capacity (635 mAh/g) and higher ICE (69\%). In the following cycles, the Coulombic efficiency rapidly increases to $100 \%$ and keeps unchanged. After 100 cycles, the discharge capacity is $336 \mathrm{mAh} / \mathrm{g}$, which is still higher than that of pure CNFs $(280 \mathrm{mAh} / \mathrm{g})$. At high applied voltage (60 V/cm), although the deposited film has higher Si content (Fig.6.42f), serious aggregation of SiNPs affects the film cycling performance in a negative way. The $1^{\text {st }}$ cycle discharge and charge capacity are $1200 \mathrm{mAh} / \mathrm{g}$ and $711 \mathrm{mAh} / \mathrm{g}$, respectively, and the ICE is very low $(57 \%)$. Starting with the $2^{\text {nd }}$ cycle, the discharge and charge capacities are decreased 
to around $280 \mathrm{mAh} / \mathrm{g}$ and change little in the following 100 cycles, meaning the capacity of the composite film mainly comes from CNFs rather than SiNPs. Therefore, for Si-OH/CNFs-COOH system, $45 \mathrm{~V} / \mathrm{cm}$ is the best applied voltage value in ethanol at $\mathrm{pH} 10$ to achieve both high uniformity of the film and improved electrochemical performance.

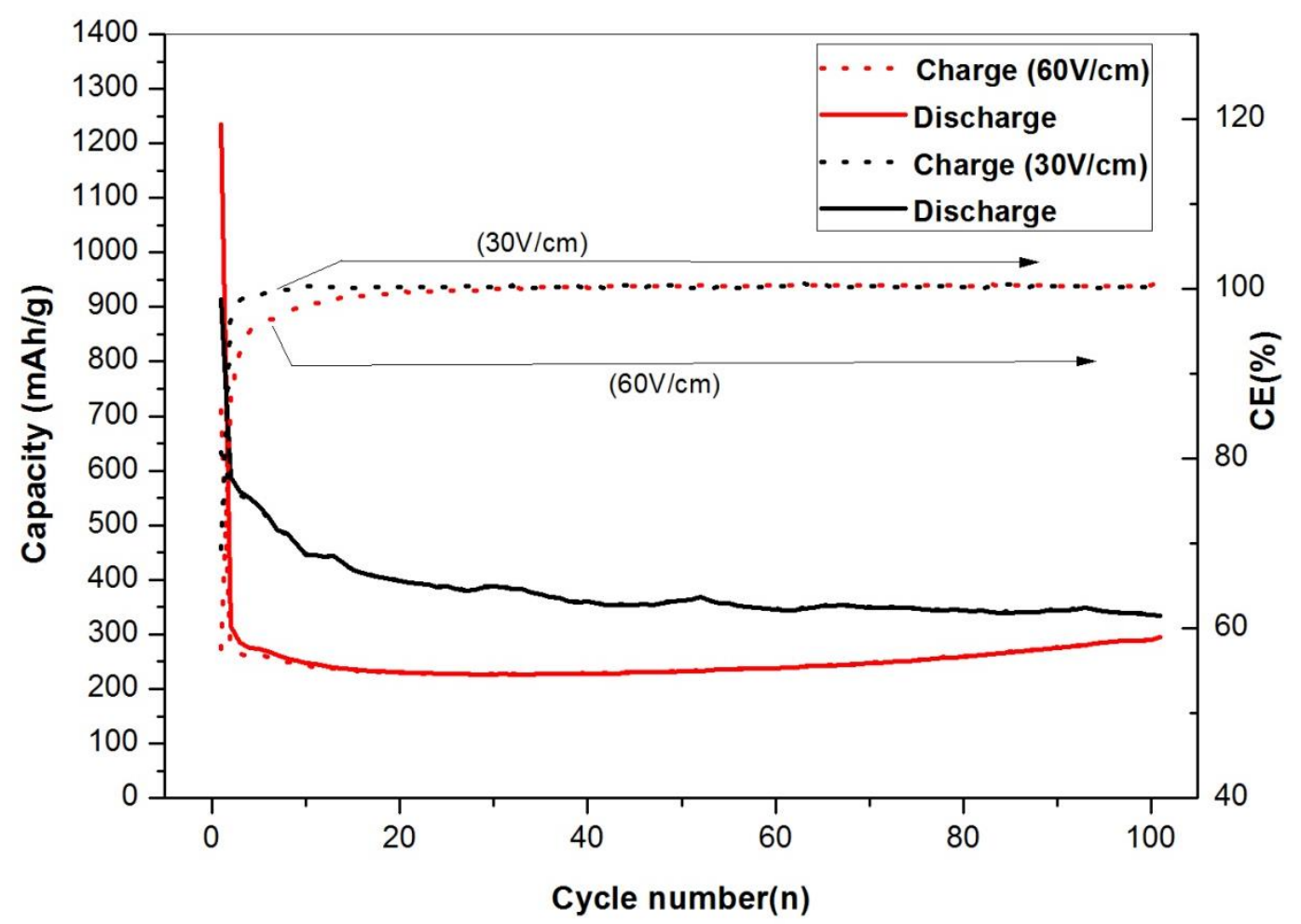

Fig.6.49: Cycling performance of the composite film prepared with different applied voltages. Fig6.50 shows the SEM images of the composite films with different initial ratios of Si to CNFs. Each sample has the similar net structure consisting of CNFs, indicating the amount of Si has little influence on the deposition of CNFs. When the initial ratio is low (1/5), it's hard to find the aggregated $\mathrm{Si}$ at the surface. If the initial ratio is high (4/5), the aggregation of Si among CNFs becomes more serious. 


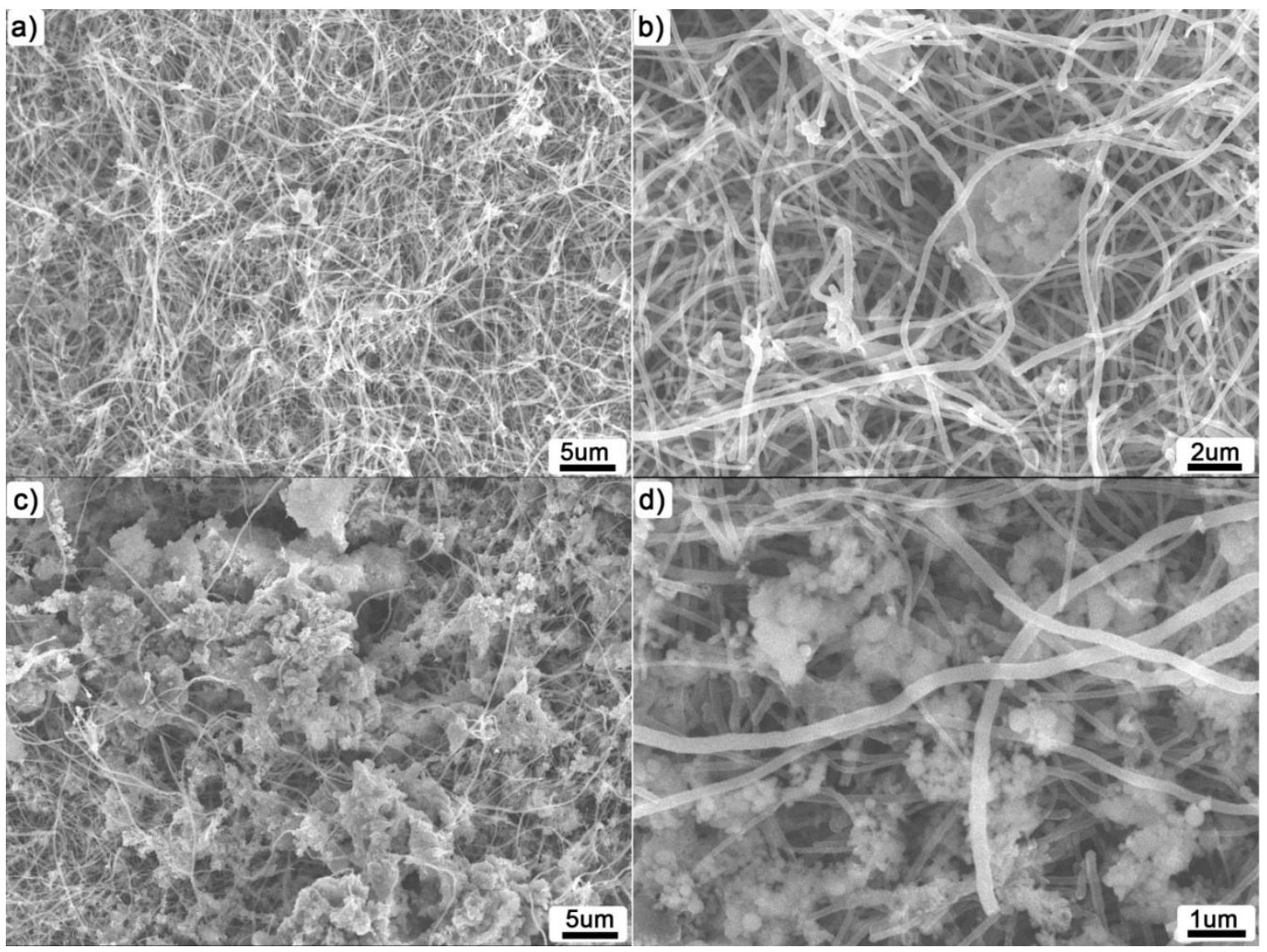

Fig.6.50: SEM images of Si/CNFs films with different initial ratios of Si to CNFs. a, b) 1:5; c, d) 4: 5 .

Fig.6.51 shows the influence of the amount of Si on the cycling performance. If the initial ratio is $1: 5$, the $1^{\text {st }}$ discharge and charge capacity is 450 and $240 \mathrm{mAh} / \mathrm{g}$. In the following 10 cycles, the capacity increases with the cycle number, which is possibly caused by activation of $\mathrm{Si}$ locating at the bottom of the film. Then, the capacity remains stable and $365 \mathrm{mAh} / \mathrm{g}$ can be obtained after 100 cycles. If the initial ratio is $4: 5$, the $1^{\text {st }}$ discharge and charge capacity can be up to 1335 and $681 \mathrm{mAh} / \mathrm{g}$ and the capacity of $600-620 \mathrm{mAh} / \mathrm{g}$ can be maintained in the first 60 cycles. Like the sample with the ratio of 2:5, this composite film also has a decreased capacity after 60 cycles because of the broken conductive net. In the $100^{\text {th }}$ cycle, the capacity is about 433 $\mathrm{mAh} / \mathrm{g}$. As shown in Fig.6.51b, these three samples have the similar ICE values $(53 \%, 54.2 \%$ and $51 \%$ ). After the first several cycles (generally <10), the sample with the ratio of 1:5 or 2:5 has very high CE (>98\%), which almost keeps unchanged during the test. However, the sample with the ratio of 4:5 shows unstable CE curve. It means the SEI layer would be broken and regrow during cycles. Therefore, higher Si content in the film brings higher specific capacity 
after 100 cycles, but more electrolyte and Li atoms are irreversibly consumed, leading to unstable electrochemical properties.
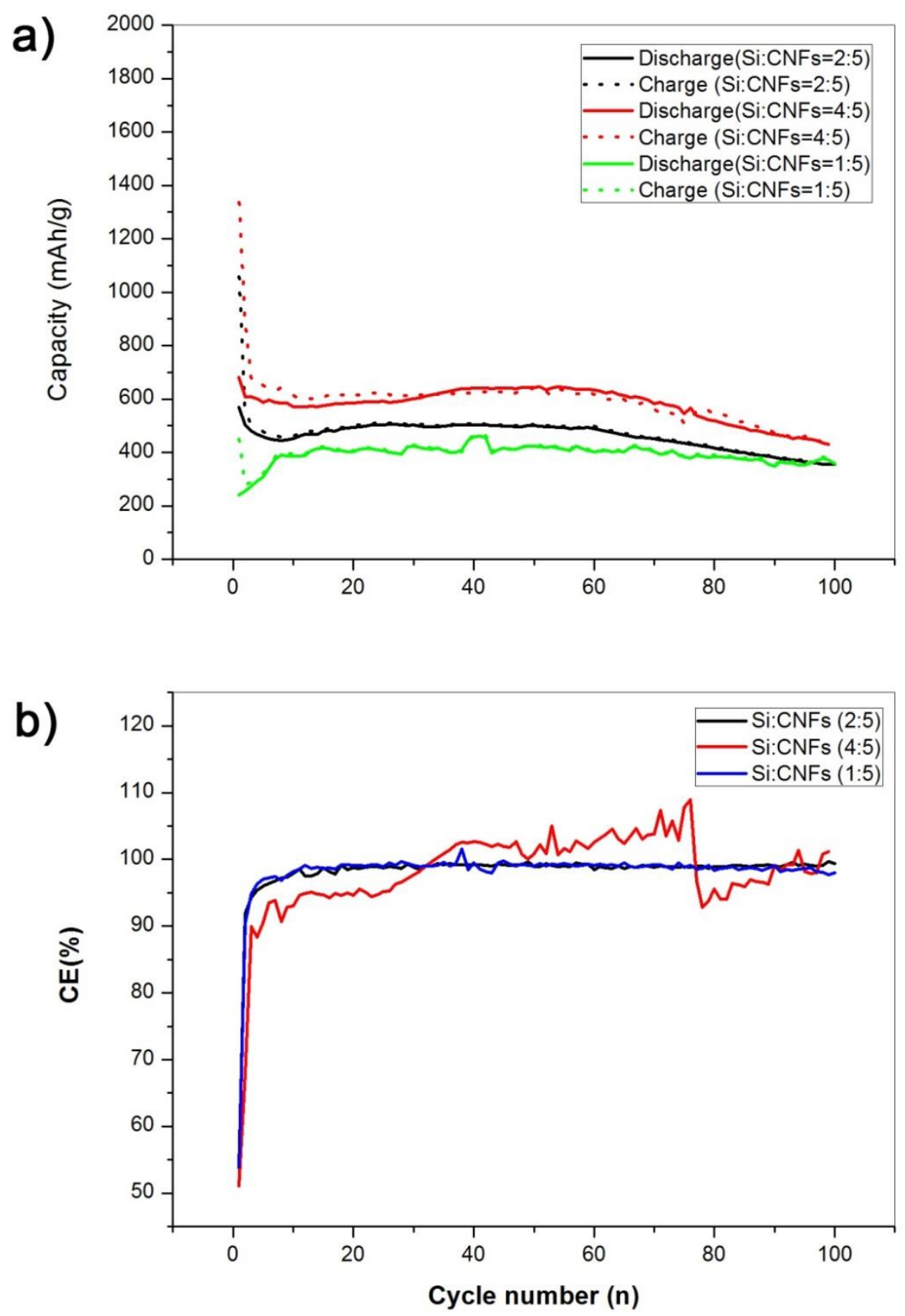

Fig.6.51: a) cycling performance of $\mathrm{Si} / \mathrm{CNFs}$ films with different initial ratios of Si to CNFs; b) profiles of Coulombic efficiency of different Si/CNFs films.

Fig.6.52 shows the influence of salt additives on cycling performance. Although a uniform Si/CNFs composite film (Fig.6.39c) can be prepared with the help of $\mathrm{Li}_{2} \mathrm{CO}_{3}$, the capacity is very low. The $1^{\text {st }}$ discharge and charge capacity is only about 400 and $280 \mathrm{mAh} / \mathrm{g}$. 
After 100 cycles, the capacity is increased to $320 \mathrm{mAh} / \mathrm{g}$, which is still too low to be used. The inactivity of $\mathrm{Li}_{2} \mathrm{CO}_{3}$ to $\mathrm{Li}^{+}$transfer should be the main reason for such bad cycling performance.

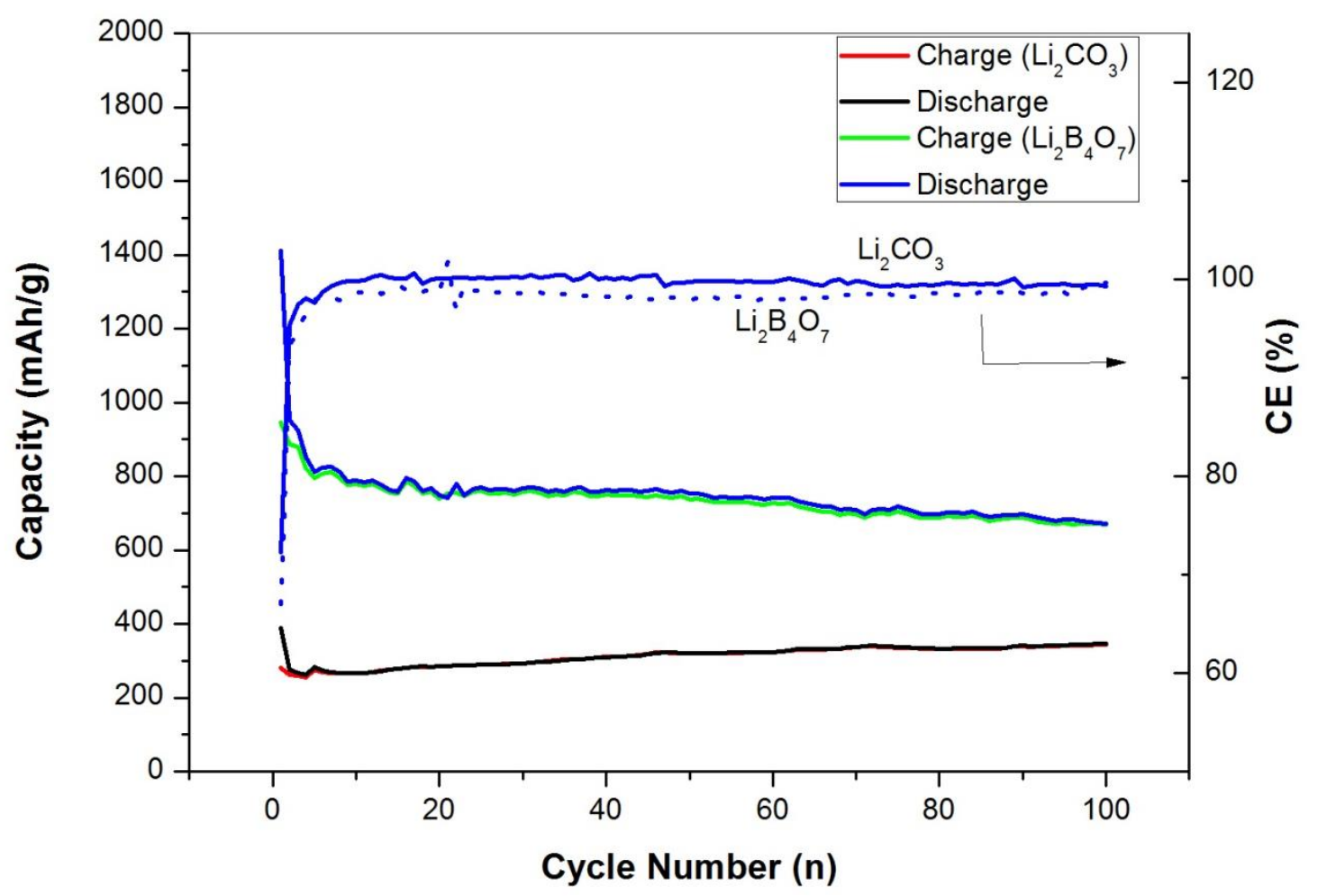

Fig.6.52: Cycle performance of Si/CNFs composite films with different salt additives.

Fig.6.53 shows the influence of surfactant on electrochemical properties of composite films. With the help of TX-100, Si/CNFs film exhibits better cycle life with the capacity of 510 $\mathrm{mAh} / \mathrm{g}$ after 300 cycles. Except the first cycle, the Coulombic efficiency can be kept 100\% during the entire process. However, if using ionic surfactant, as shown in Fig. 6.52b, the electrochemical properties of the composite films become worse, which are mainly caused by the non-uniform microstructure, as shown in Fig.6.44. 

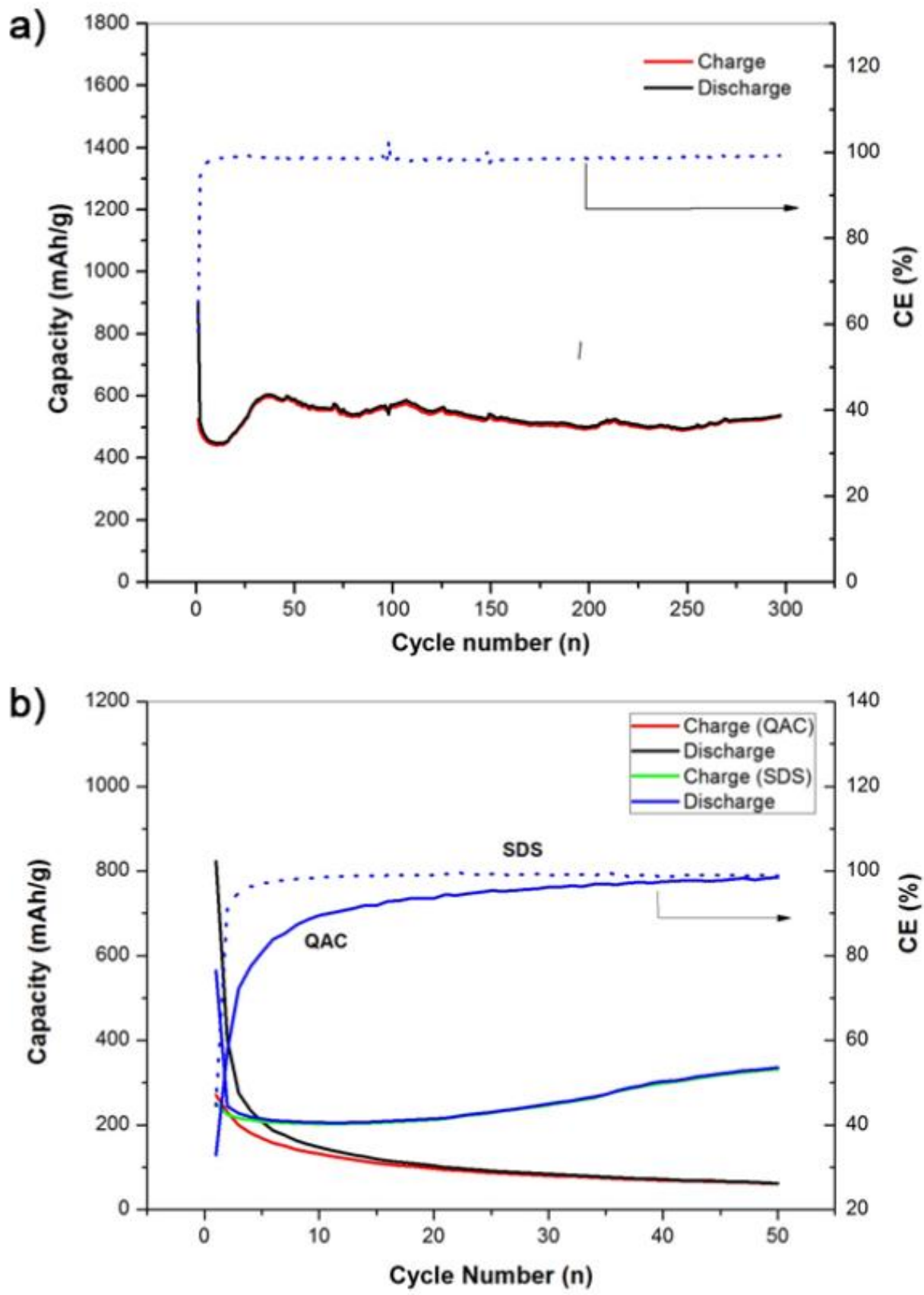

Fig.6.53: Profiles of cycle performance of Si/CNFs film a) with TX-100 additive, b) with ionic additives.

\subsection{Preparation of $\mathrm{Si} / \mathrm{CNFs}$ with necklace structure}

1) Morphology

Fig.6.54a shows the optical photo of the electrophoretically deposited film on the $\mathrm{Cu}$ foil, which presents good integrity and flexibility. The SEM image at a high magnification of the 
surface of the film is shown in Fig6.54b. Most Si clusters with an approximate size range from $200 \mathrm{~nm}$ to $1 \mu \mathrm{m}$ are regularly distributed along the CNFs, which looks like "pearls" on a necklace. The thickness of the film is about $20 \mu \mathrm{m}$ (inset of Fig.1b).

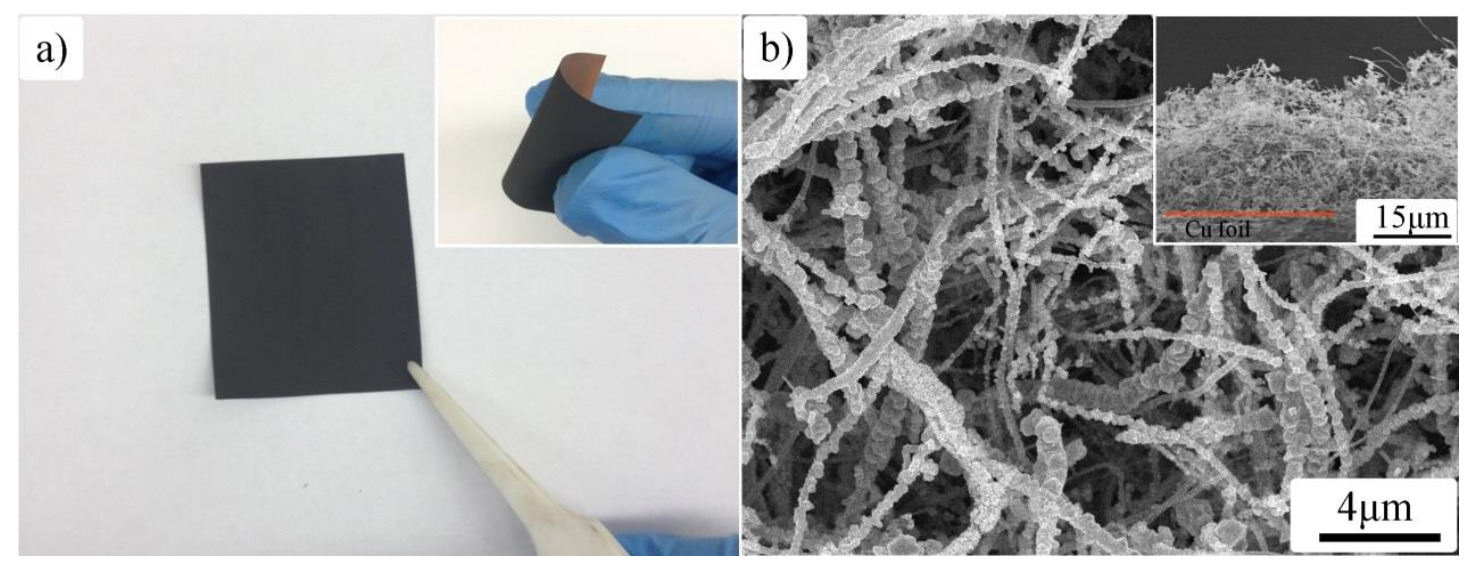

Fig.6.54 a) photograph of Si/CNFs film in ethanol at pH0.5, b) SEM image of Si/CNFs film in ethanol at $\mathrm{pH} 0.5$. The insert of $\mathrm{b}$ is the cross-section SEM.

The formation of such structure can be mainly attributed to the electrostatic interaction among SiNPs and CNFs during the co-deposition. SiNPs and CNFs are functionalized by amino groups $\left(\mathrm{Si}-\mathrm{NH}_{2}\right)$ and carboxylic groups $(\mathrm{CNFs}-\mathrm{COOH})$ via surface pretreatment, respectively. $\mathrm{Si}-\mathrm{NH}_{2}$ has the positive-charged surface owing to ionization in the approximately neutral environment; while CNFs-COOH shows the negative charge. However, in the strong acidic suspension, both $\mathrm{Si}-\mathrm{NH}_{2}$ and $\mathrm{CNFs}-\mathrm{COOH}$ have positive double electric layers $\left(\mathrm{H}^{+}\right.$adsorption, Fig.6.55a), which means all the charged particles will move towards the negative electrode as applying DC electric field (Fig.6.55b: stage 1). According to previous research, the double electric layers are asymmetric in the moving direction with thinner ahead and wider behind. When these particles are close to the electrode, local concentration is increased, which induces the distortion of the double layers and the coagulation process: the thin part of one double layer blend in with another one's extended tail. For the functionalized SiNPs and CNFs, the coagulation is directional, not random. SiNPs are inclined to choose CNFs as "the partner" rather than other SiNPs because of electrostatic attraction between $-\mathrm{NH}_{2}$ and $-\mathrm{COOH}$ (Fig.6.55b: stage 2), so are CNFs. When the particles contact the substrate or formerly deposited layer, the absorbed $\mathrm{H}^{+}$are depleted (obtaining electrons from the negative) and the double layers are gone. Most of SiNPs still keep staying on the surface of CNFs and finally the necklaced-like structure is formed (Fig.6.55b: stage 3). In contrast, the composite film with pure SiNPs and CNFs is 
prepared under the same conditions, which clearly shows "clean" CNFs surface and seriously aggregated SiNPs (Fig.6.56).

a)
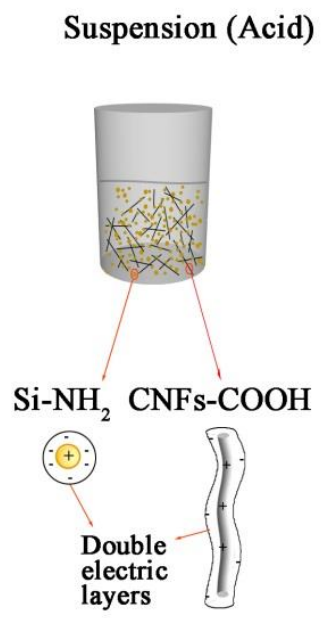

b)

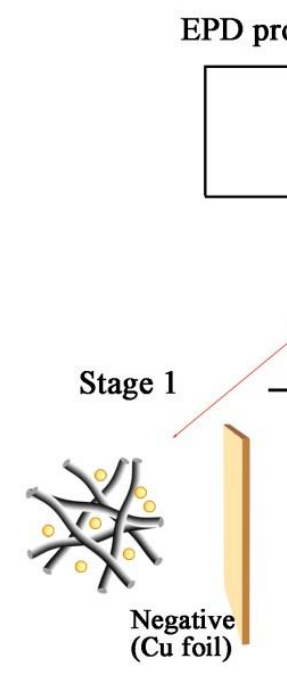

c) Deposited film

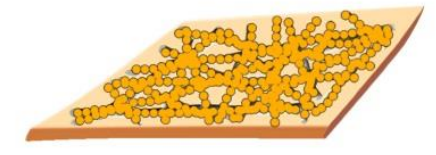

Stage 3:

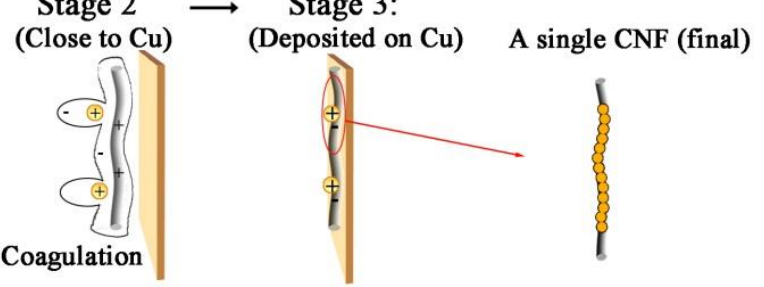

Fig.6.55: Scheme of the deposition process in Si/CNFs suspension.

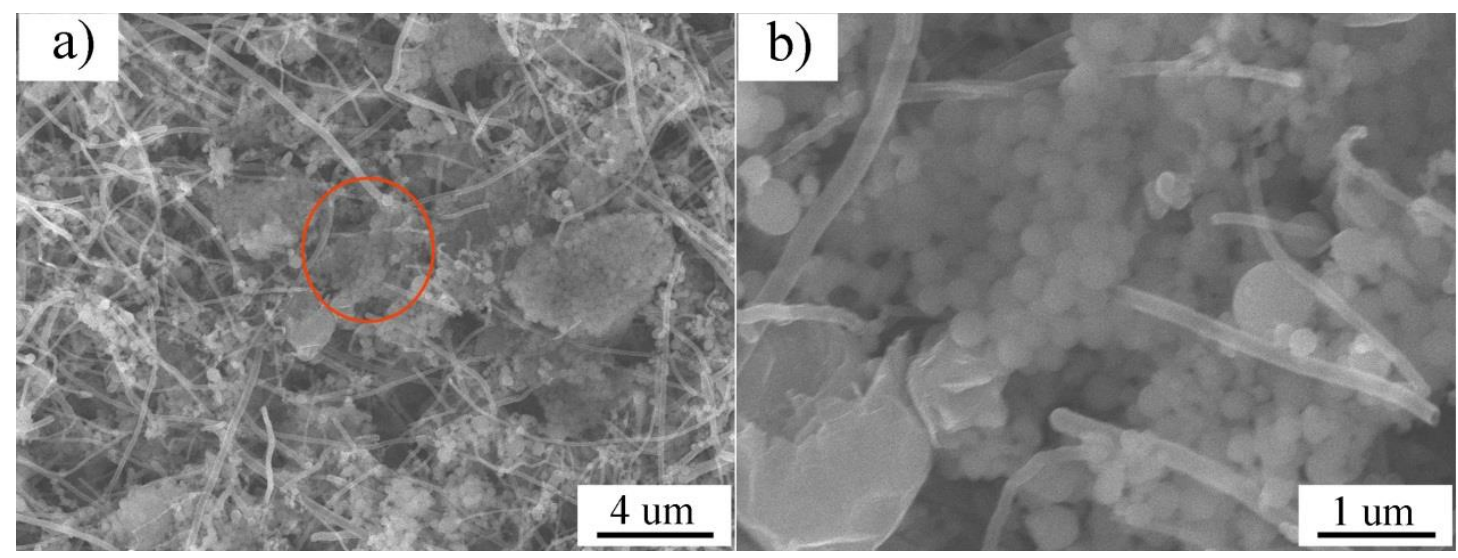

Fig.6.56: SEM images of Si/CNFs composite film without Si surface treatment. a) low magnification, b) high magnification.

Importantly, the improvement of SiNPs distribution is not confined to the film surface.

Fig. 6.57 shows the SEM images of the deposited layers with different EPD time. After 1 min (Fig.6.57a), a film on the Cu foil consisting of "clean" CNFs and necklace-liked Si/CNFs composite is initially formed; while little SiNPs aggregate in the interspace or on the "naked" substrate. The coexistence phenomenon of multi morphologies of CNFs can be attributed to two reasons. 1) CNFs have higher initial concentration than SiNPs; 2) CNFs still have faster mobility rate than SiNPs under the similar condition due to the instability of Si in ethanol. The electrostatic interaction effect doesn't work well during the migration process because both $\mathrm{Si}$ - 
$\mathrm{NH}_{2}$ and $\mathrm{CNF}$ - $\mathrm{COOH}$ have a positive double electric layer in the strong acidic suspension, meaning SiNPs cannot be attached to CNFs beforehand. After 2 min (Fig. 6.57b), the film continues growing and has already covered $100 \%$ substrate. SiNPs are still regularly distributed along CNFs. Moreover, by contrasting Fig6.57a, 6.57b and Fig.6.54b, the proportion of the necklace-like structure is getting higher and higher with the time increasing, which indicates a gradual increase in Si content in the vertical direction to the film.
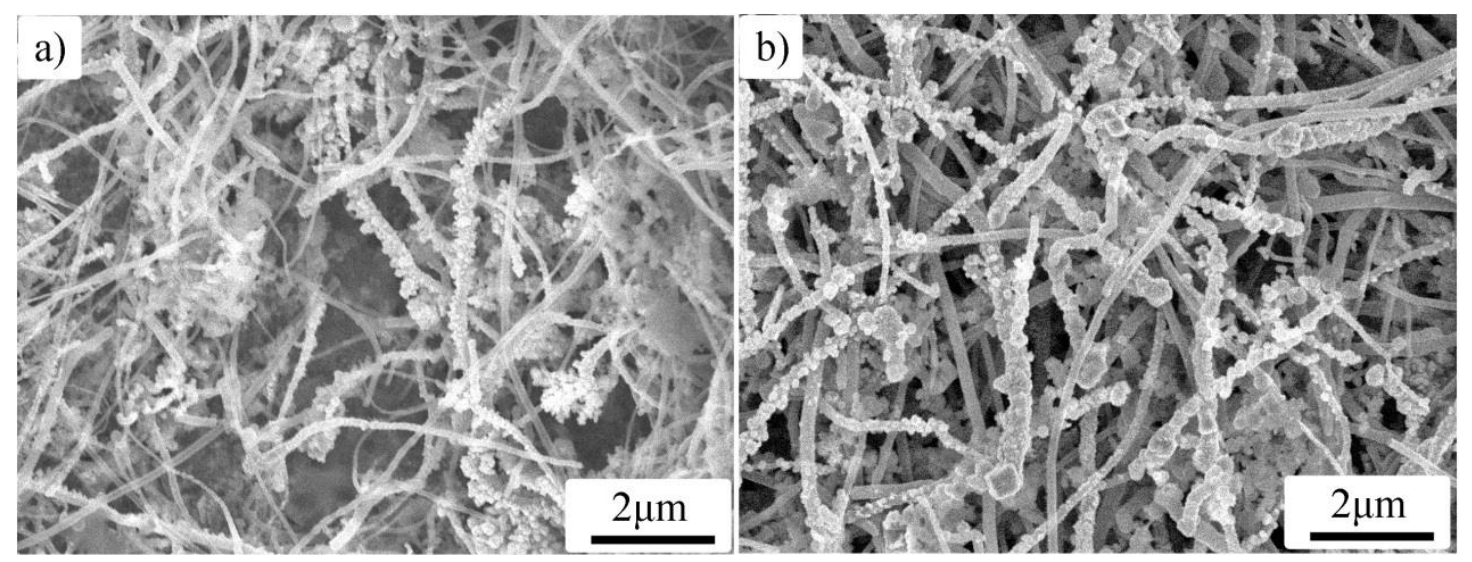

Fg.6.57: SEM images of a) Si/CNFs composite after 1 min EPD, b) Si/CNFs composite after 2 min EPD.

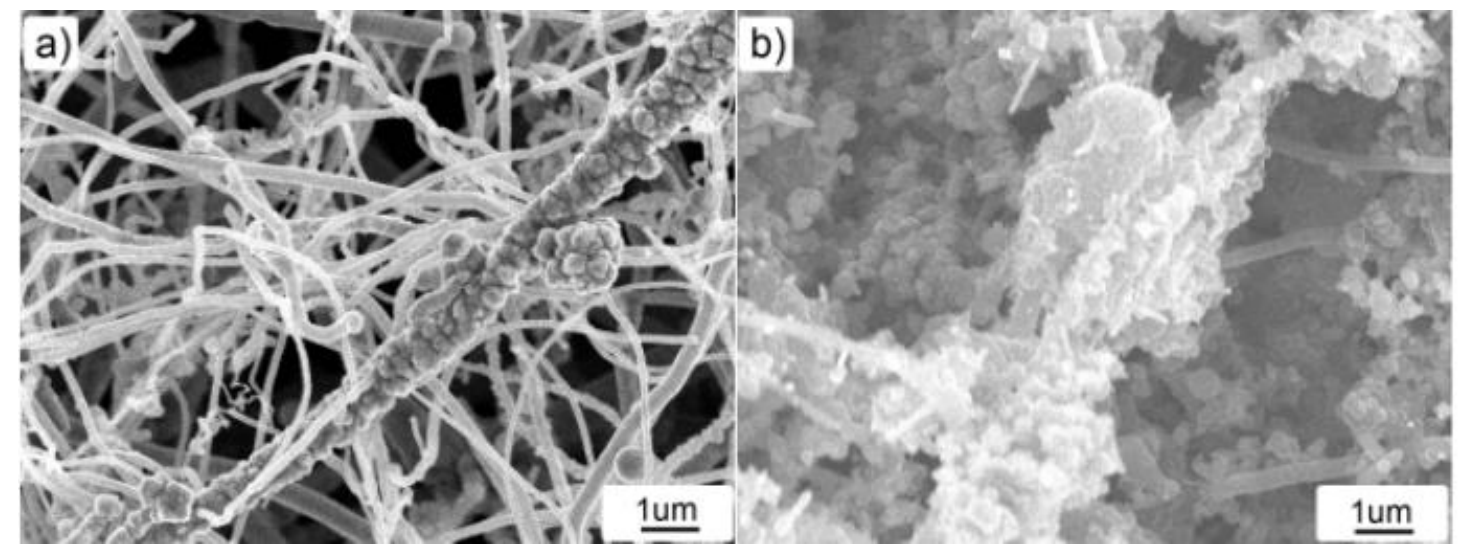

Fig.6.58: SEM images of a) Si/CNFs composite after 10 min EPD. Weight ratio of Si to CNFs: a) 1:5, b) 4:5.

The initial ratio of Si to CNFs has also influenced the microstructure of Si/CNFs film, as shown in Fig.6.58. When the ratio is low (Fig.6.58a), all the SiNPs are distributed along CNFs. No particles among CNFs' space can be observed. As increasing the initial ratio of Si to CNFs to 0.8, bulk SiNPs anchored with CNFs are growing excessively, and part of them falls off, indicating the contact between $\mathrm{Si}$ and CNFs is weak. 
If the magnetic stirring is going on slowly during EPD to make the mixture of Si and CNFs better as they are moving towards the electrode, a dense composite film can be also prepared, as shown in Fig.6.59a. Moreover, the distribution of Si is improved. No serious aggregation of SiNPs is observed even on the surface of CNFs.

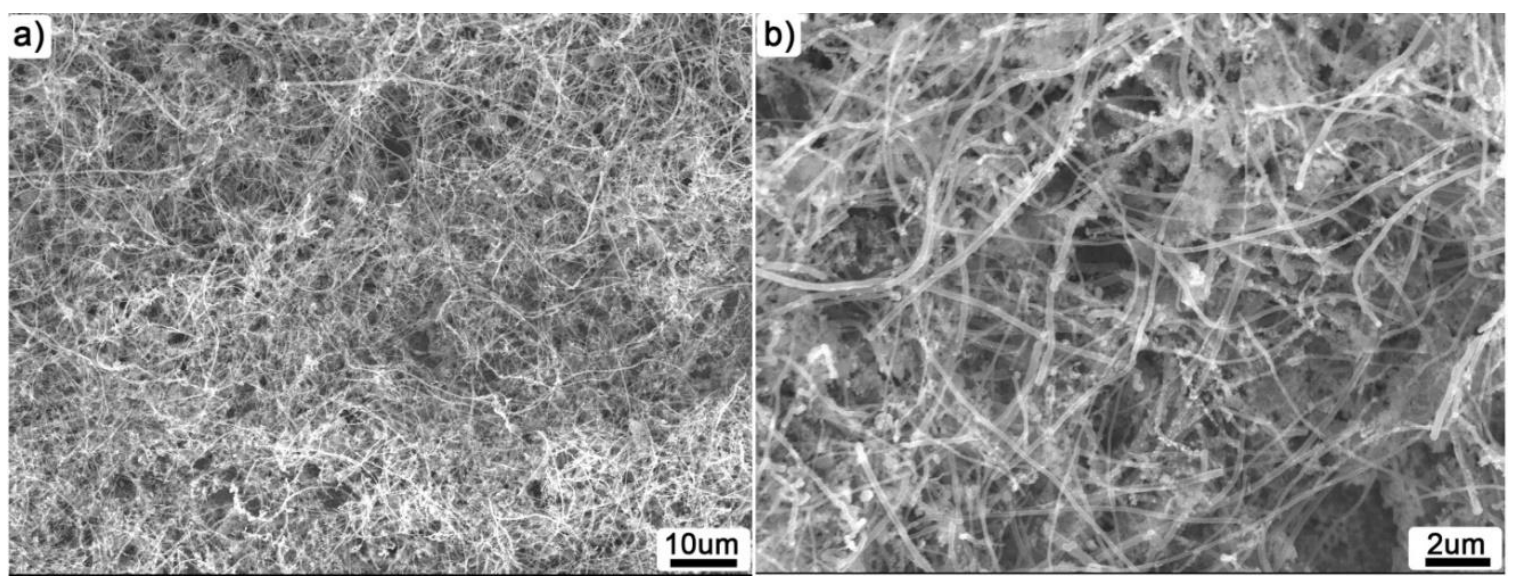

Fig.6.59: SEM images of the $\mathrm{Si} / \mathrm{CNF}$ composite film under the magnetic stirring conditions. a) low magnification; b) high magnification.

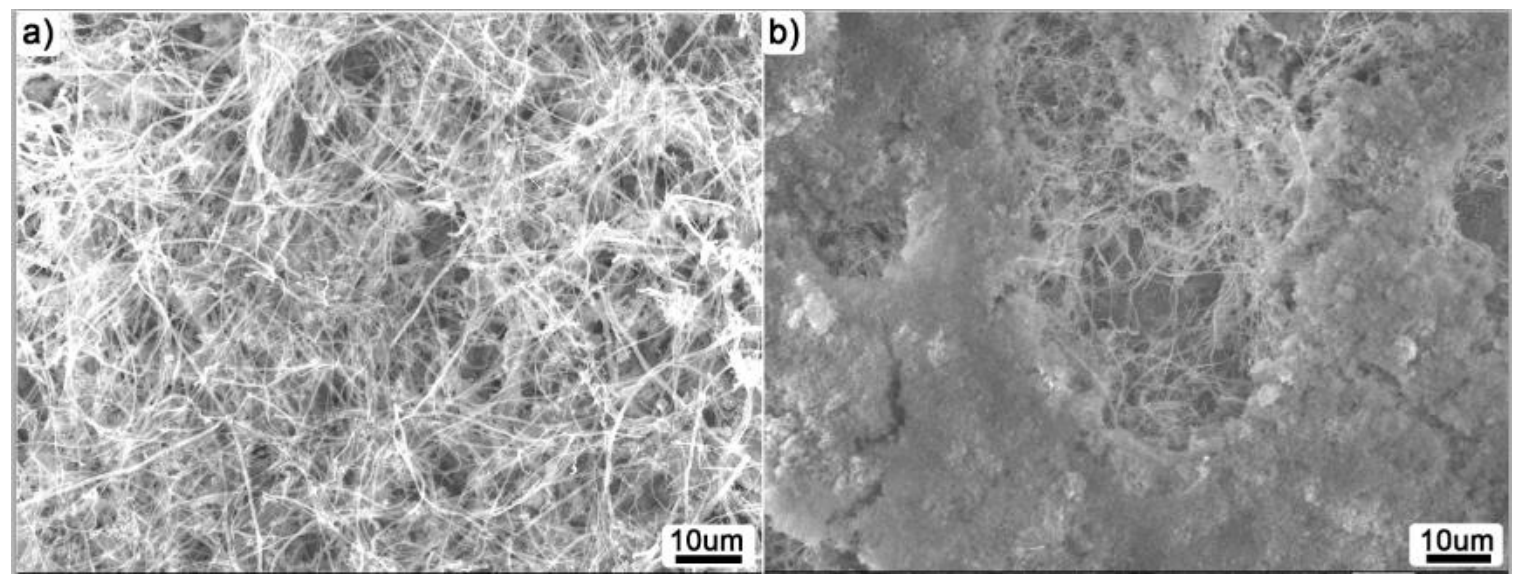

Fig.6.60: SEM images of the film by step-by-step EPD in ethanol at pH0.5. a) CNFs film after 5 min EPD. b) the composite film consisting of 5min-EPD CNFs and 1min-EPD SiNPs.

If depositing CNFs and $\mathrm{Si}-\mathrm{NH}_{2}$ on the $\mathrm{Cu}$ foil by step-by-step EPD, the necklace-liked structure cannot be maintained, as shown in Fig.6.60. After 5 min EPD in CNFs-COOH suspension at pH0.5, a continuous conductive net is formed (Fig.6.60a). In the following deposition process of $\mathrm{Si}-\mathrm{NH}_{2}, \mathrm{CNFs}$ surface is covered by bulk SiNPs, indicating the interaction between $-\mathrm{NH}_{2}$ and $-\mathrm{COOH}$ doesn't work. Therefore, the pre-mixing of SiNPs and CNFs is necessary to obtain the necklace-structural film.

2) Electrochemical properties 

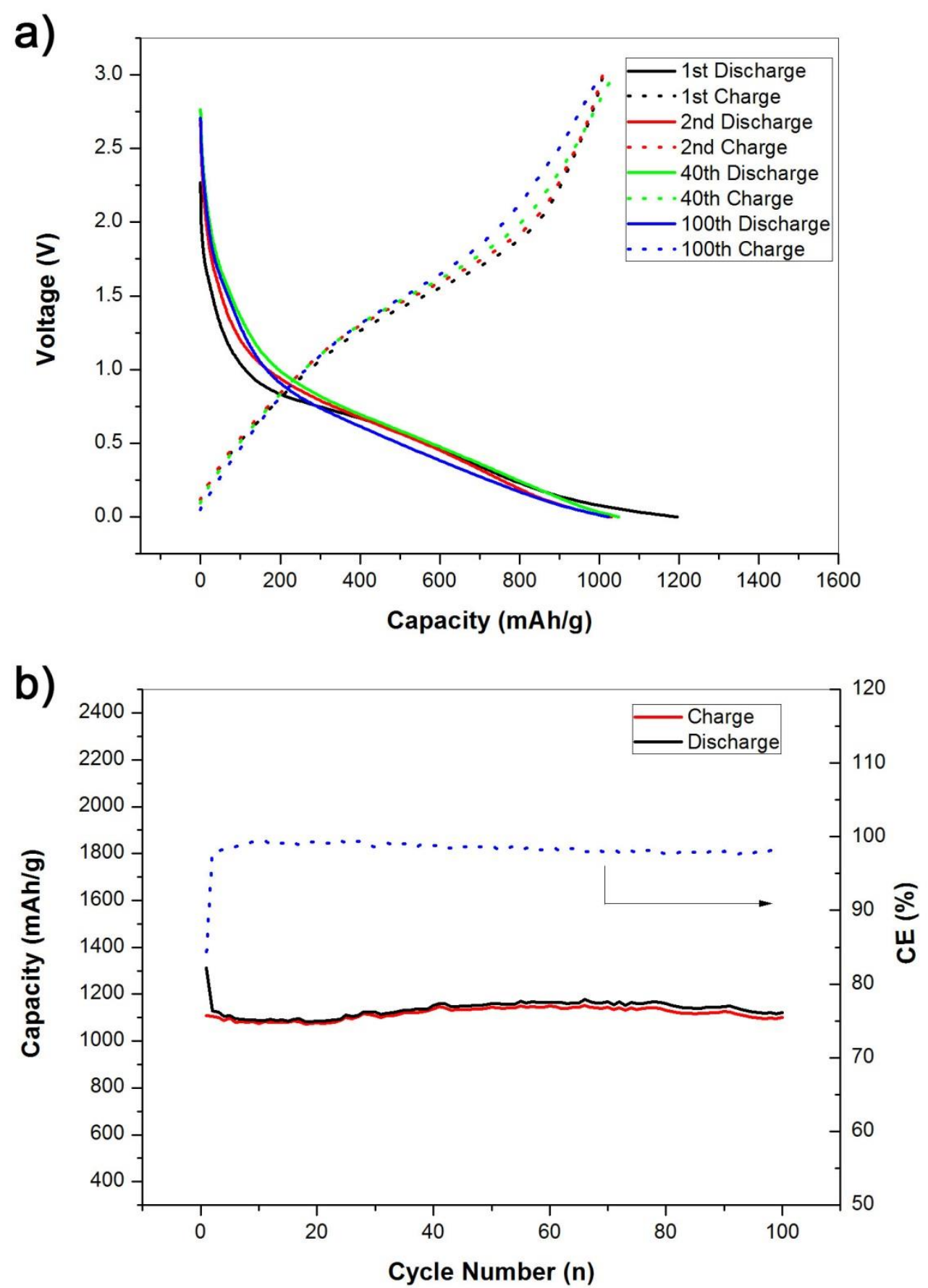

Fig.6.61: a) Galvanostatic discharge-charge curves for the necklaced-like CNFs/Si composite film; b) cycling performance of the Si/CNFs composite film.

The voltage profile of the composite film at the current rate of $400 \mathrm{~mA} / \mathrm{g}$ is shown in Fig.6.61. The film has the $1^{\text {st }}$ discharge capacity of $1192 \mathrm{mAh} / \mathrm{g}$ and the $1^{\text {st }}$ charge capacity is $1070 \mathrm{mAh} / \mathrm{g}$ and the ICE is $84.2 \%$. There is a main platform starting with $0.45 \mathrm{~V}$ on the first discharge curve possibly due to the formation of SEI and $\mathrm{Li}_{\mathrm{x}} \mathrm{Si}$ alloying. In the second cycle, the 
discharge and charge capacity is about $1027 \mathrm{mAh} / \mathrm{g}$ and $1004 \mathrm{mAh} / \mathrm{g}$, and the CE is $97.8 \%$. The sloped platform starting with $1.5 \mathrm{~V}$ indicates the continuous growth of the SEI layer and the activation of $\mathrm{Cu}_{\mathrm{x}} \mathrm{O}$ impurities. As shown in Fig.6.61b, this film exhibits very good cycling performance at $400 \mathrm{~mA} / \mathrm{g}$. After 100 cycles, the discharge and charge capacity can be up to 1020 $\mathrm{mAh} / \mathrm{g}$ and $1000 \mathrm{mAh} / \mathrm{g}$. The coulombic efficiency stays $99 \%$ during the whole test except the first cycle. The excellent electrochemical performance should be attributed to the specific structure. On the one hand, the contact between Si and CNFs via van der Waals force is beneficial to $\mathrm{Li}^{+}$and electrons transfer and suppressing the volume effect during cycles. On another hand, this structure means sufficient contact between Si and electrolyte, leading to the stable SEI formation during the first several cycles. Besides, little free SiNPs in the CNFs net lead to small decrease of the cycle capacity.

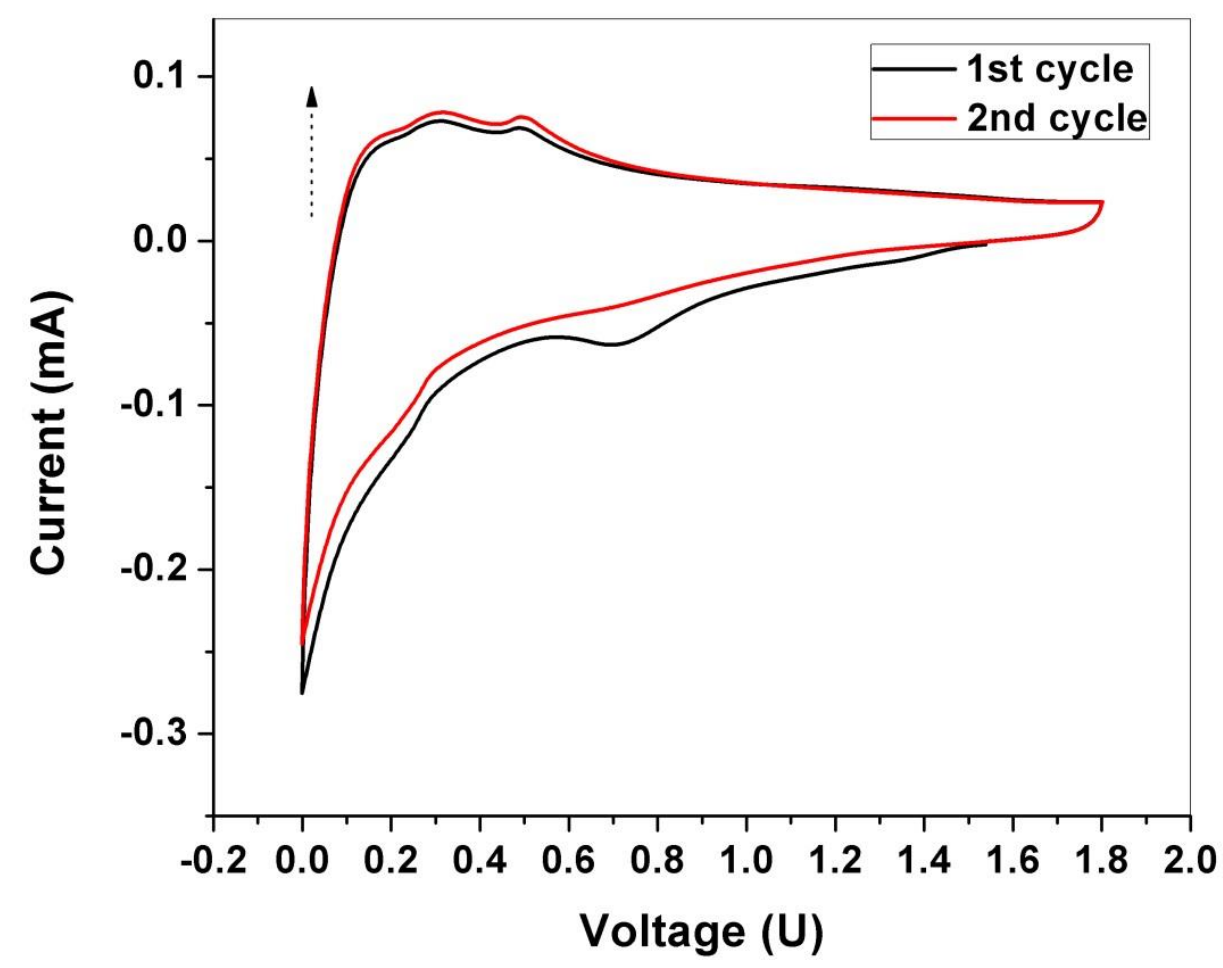

Fig.6.62: Cyclic voltammetry profiles of the necklaced-like Si/CNFs composite film

Fig.6.62 shows the CV profiles in the first two cycles of the composite film. The cathodic peak around $0.7 \mathrm{~V}$ during the $1^{\text {st }}$ discharge is assigned to the formation of a SEI layer, which disappears in the $2^{\text {nd }}$ cycle. It means most SEI layer is formed in the $1^{\text {st }}$ cycle. Two anodic peaks at $0.32 \mathrm{~V}$ and $0.52 \mathrm{~V}$ in the $1^{\text {st }}$ and $2^{\text {nd }}$ charge curves are corresponding to the transformation of $\mathrm{Li}_{\mathrm{x}} \mathrm{Si} / \mathrm{LiC}_{\mathrm{y}}$ to amorphous $\mathrm{Si}$ and CNFs. 
The rate performance of the film is shown in Fig.6.63.

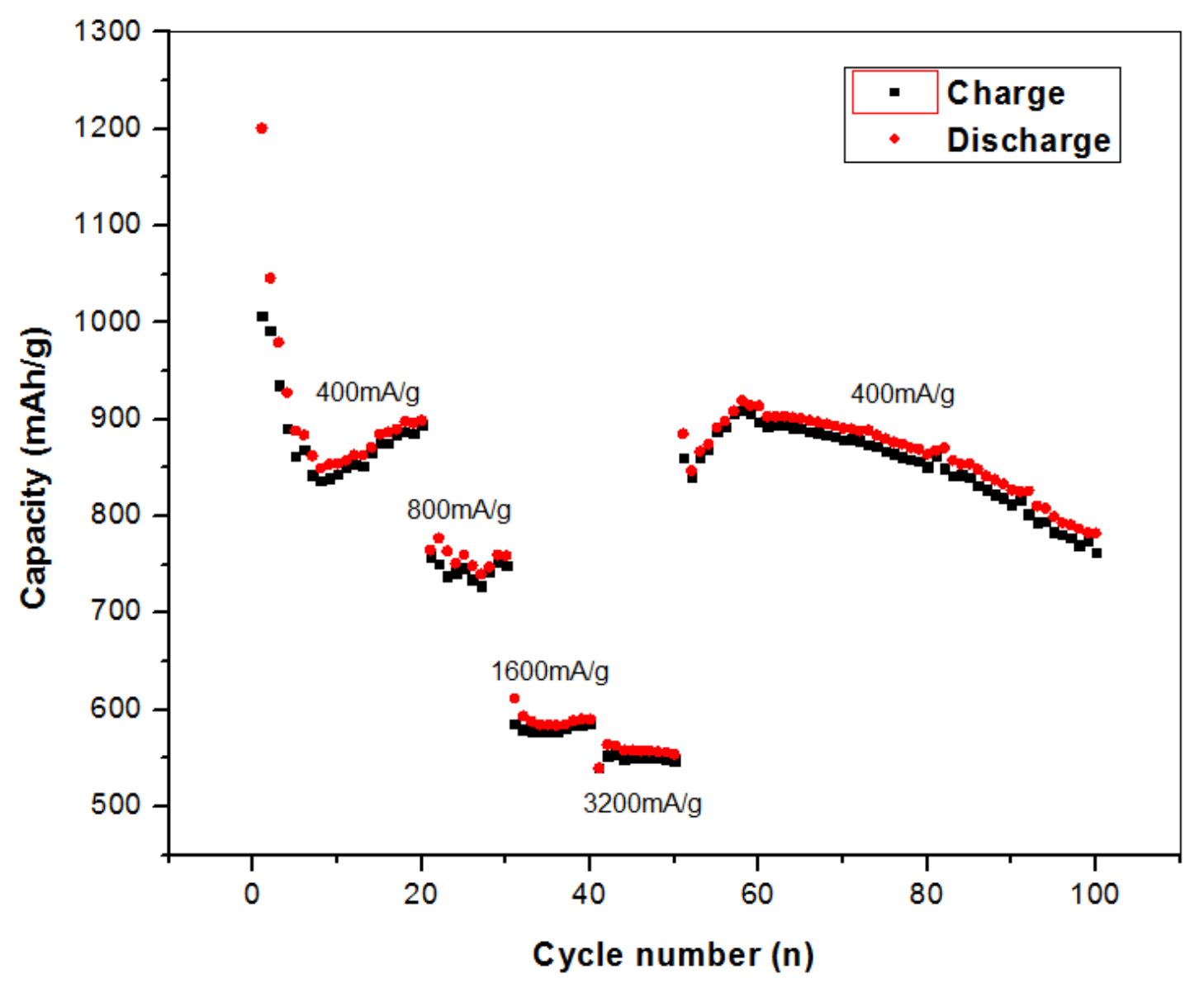

Fig.6.63: Rating performance of the necklaced-like Si/CNFs film.

With the increasing of the current rate from 400 to 800,1600 and $3200 \mathrm{~mA} / \mathrm{g}$, the specific capacity decreases from 900 to 750,580 and $550 \mathrm{mAh} / \mathrm{g}$, respectively. It's noticed that even the "worst" capacity value (at $3200 \mathrm{~mA} / \mathrm{g}$ ) is higher than most commercial anode materials" capacities. When the current rate returns to $400 \mathrm{~mA} / \mathrm{g}$, the capacity can be returned to $774 \mathrm{mAh} / \mathrm{g}$ after 90 cycles. Therefore, the interaction between $\mathrm{Si}$ and CNFs cannot only promote the $\mathrm{Li}^{+} /$electron transport in the active materials, but also maintain the basic framework very well after large current charging/discharging.

The SEM image of the morphology after 100 cycles is shown in Fig.6.64. It clearly shows that the necklace structure is well maintained. Si particles wrapped by membranoid substances (unwashed SEI layer) are still distributed along CNFs. 


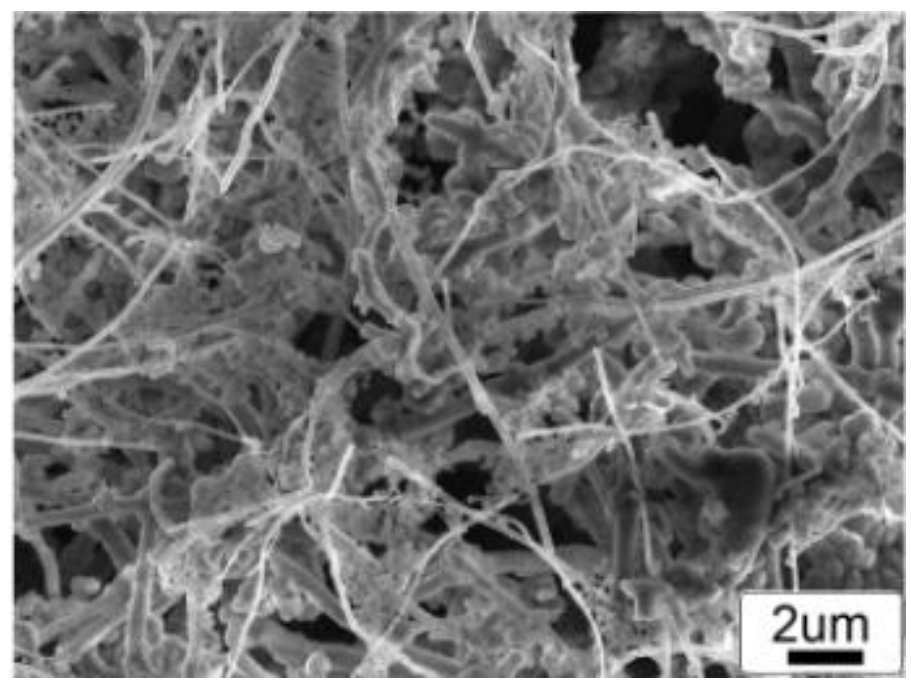

Fig.6.64: SEM images of necklaced-like CNFs/Si composite after 100 cycles.

If increasing the initial $\mathrm{Si}$ ratio of $\mathrm{CNFs}$ from $2 / 5$ to $4 / 5$, the cycle performance of the film is shown in Fig.6.65.

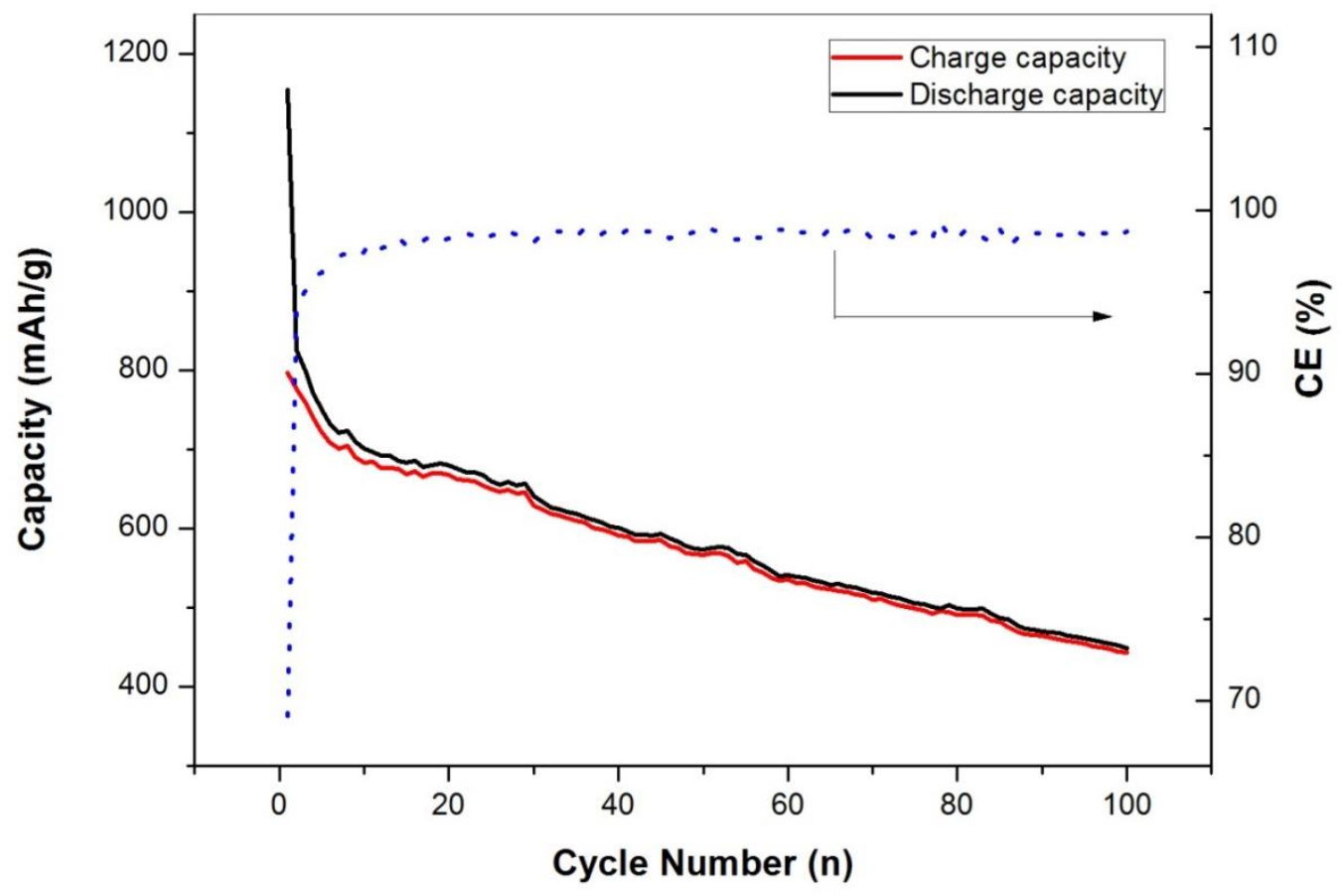

Fig.6.65: Cycle performance of necklaced-like Si/CNFs film with high Si weight ratio.

The first discharge and charge capacity of the film are $1180 \mathrm{mAh} / \mathrm{g}$ and $800 \mathrm{mAh} / \mathrm{g}$. The ICE is about 68\%. Then, both discharge and charge capacities keep going down. After 100 cycles, the discharge capacity is only $460 \mathrm{mAh} / \mathrm{g}$. The reason for capacity decrease can be found in Fig.6.58b. Too many SiNPs locates the same place on the CNFs surface, but only inner SiNPs 
have the interaction with CNFs and the outer SiNPs would fall off during cycles, leading to the continuous decrease of the capacity.

Fig.6.66 shows the influence of magnetic stir on the film's cycle life.

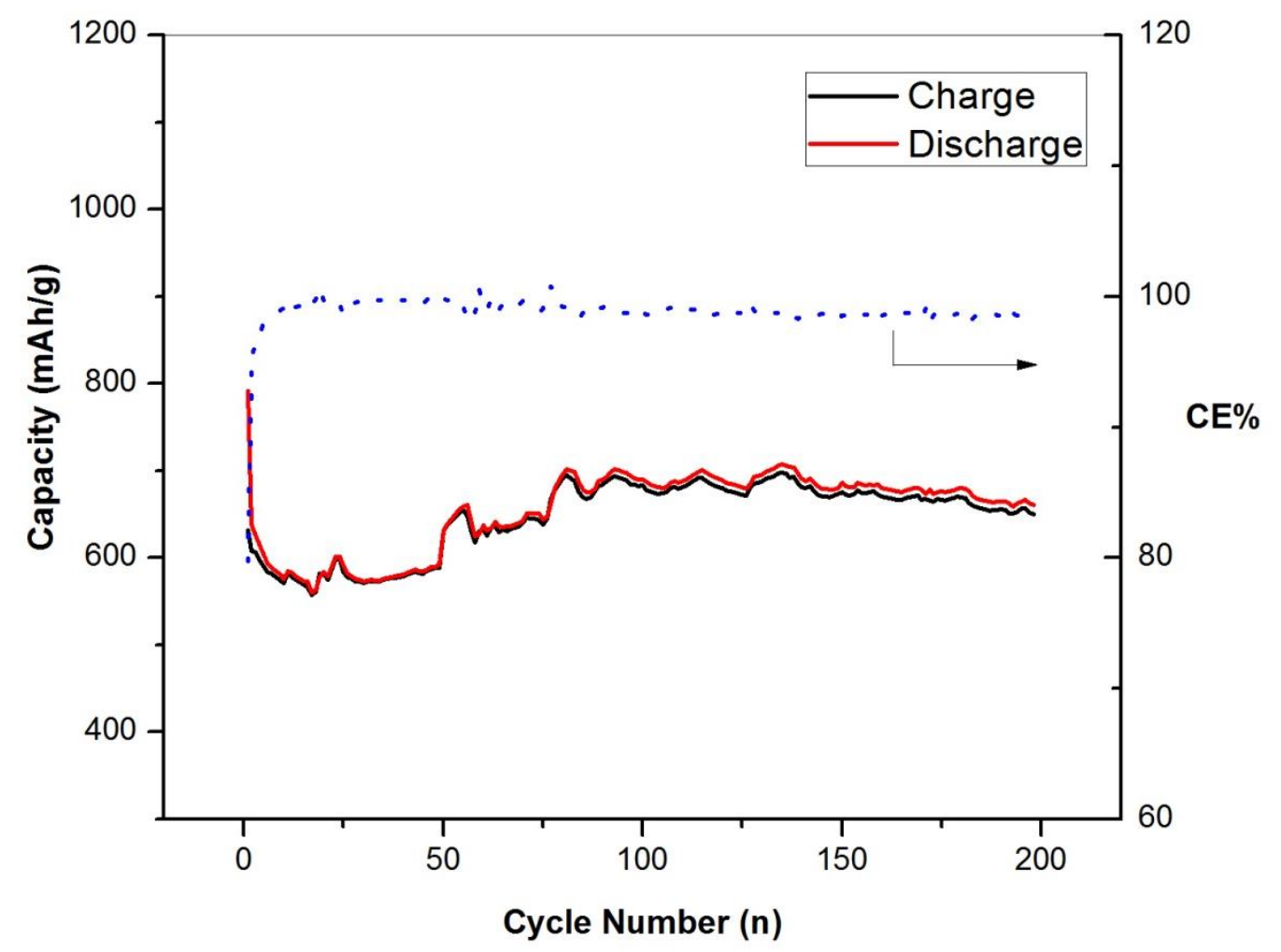

Fig.6.66: cycle performance of necklaced-like Si/CNFs film under stirring condition.

In the first cycle, the discharge and charge capacity are 791 and $631 \mathrm{mAh} / \mathrm{g}$, respectively, and the ICE is about $80 \%$. The coulombic efficiency increases to $99 \%$ after 2 cycles and keep unchanged in the following 200 cycles. After 200 cycles, the discharge capacity can be up to 663 $\mathrm{mAh} / \mathrm{g}$, indicating very good cycle performance for this film. But the uneven cycle curve means the interaction between $\mathrm{Si}$ and CNFs is weaker under the strring condition. SiNPs attached with CNFs are eaily peeled off during cycles because of their volume effect. However, there are large contact area between Si and CNFs with the help of magenetic stirring, it's easy for Si to re-link with CNFs via the interaction between $-\mathrm{NH}_{2}$ and $-\mathrm{COOH}$ groups.

\subsection{Summary}

In this chapter, the stability of modified-Si/CNFs suspension and the corresponding deposition dynamics were investigated. Two kinds of Si/CNFs composite films with improved electrochemical properties were prepared by multi-component EPD. The results show: 


\section{1) EPD of modified-Si}

Two kinds of functional groups, $-\mathrm{OH}$ and $-\mathrm{NH}_{2}$, are introduced onto $\mathrm{Si}$ surface, respectively. The stability of $\mathrm{Si}-\mathrm{OH}$ suspension in ethanol is improved. At pH10, $\mathrm{Si}-\mathrm{OH}$ suspensions with the concentration of $0.2-0.8 \mathrm{mg} / \mathrm{mL}$ are stable in a short time $(<1 \mathrm{~h})$. However, the stability of $\mathrm{Si}-\mathrm{NH}_{2}$ suspension is just improved a little. The deposition rates of both $\mathrm{Si}-\mathrm{OH}$ and $\mathrm{Si}-\mathrm{NH}_{2}$ are influenced by voltage and time. The maximum deposition mass for $\mathrm{Si}-\mathrm{OH}$ suspension at pH10 $\left(0.24 \mathrm{mg} / \mathrm{cm}^{2}\right)$ can be obtained at $60 \mathrm{~V} / \mathrm{cm}$, while that for $\mathrm{Si}-\mathrm{NH}^{2}$ suspension at pH0.5 $\left(0.14 \mathrm{mg} / \mathrm{cm}^{2}\right)$ can be obtained at $45 \mathrm{~V} / \mathrm{cm}$. During the deposition process, the Si film growth can be divided into three parts, and most particles are deposited in the second stage.

2) EPD of modified-Si/CNFs-COOH

If the initial concentration of modified-Si is low $(0.2-0.4 \mathrm{mg} / \mathrm{mL})$, the introduction of $\mathrm{Si}-\mathrm{OH}$ can improve the stability of CNFs-COOH suspension in ethanol at $\mathrm{pH}$ 9 10, while adding $\mathrm{SiNH}_{2}$ can decrease the stability of $\mathrm{CNFs}-\mathrm{COOH}$ suspension. The suitable $\mathrm{pH}$ range for stable modified-Si/CNFs suspensions in ethanol is $9-10$. Besides, $\mathrm{Si}-\mathrm{NH}_{2} / \mathrm{CNFs}$ suspension is metastable at $\mathrm{pH}$ 0.5. In the $\mathrm{Si}-\mathrm{OH} / \mathrm{CNFs}-\mathrm{COOH}$ suspension at $\mathrm{pH} 10$, the deposited mass increases with applied voltage and the maximum value is about $1.22 \mathrm{mg} / \mathrm{cm}^{2}$ at $75 \mathrm{~V} / \mathrm{cm}$. In the $\mathrm{Si}-\mathrm{NH}_{2} / \mathrm{CNF}-\mathrm{COOH}$ suspension at $\mathrm{pH} 0.5$, the maximum deposited mass is about $0.82 \mathrm{mg} / \mathrm{mL}$ at $75 \mathrm{~V} / \mathrm{cm}$. However, high applied voltage damages the uniformity and integrity of composite films, so proper applied voltages for EPD should be lower than $60 \mathrm{~V} / \mathrm{cm}$. The deposited mass also increases with the deposition time. For EPD of $\mathrm{Si}-\mathrm{OH} / \mathrm{CNFs}-\mathrm{COOH}$ suspension at $\mathrm{pH} 10$, the deposited mass of $1.22 \mathrm{mg} / \mathrm{cm}^{2}$ can be obtained by increasing the time from $10 \mathrm{~min}$ to $15 \mathrm{~min}$. Because the suspension of $\mathrm{Si}-\mathrm{NH}_{2} / \mathrm{CNFs}-\mathrm{COOH}$ is metastable at $\mathrm{pH} 0.5$, prolonging time cannot increase the deposited mass too much (the maximum value is only $0.62 \mathrm{mg} / \mathrm{cm}^{2}$ ).

3) Preparation of Si/CNFs film with honeycomb structure and the study of electrochemical properties

A composite film consisting of $\mathrm{Si}-\mathrm{OH}$ and $\mathrm{CNF}-\mathrm{COOH}$ with honeycomb structure can be prepared by homogenous EPD in ethanol at pH10. The film has the intact net structure and Si particles are distributed in it randomly. The film thickness is about $25-35 \mu \mathrm{m}$. The formation of this structure is attributed to adding $\mathrm{Li}_{2} \mathrm{~B}_{4} \mathrm{O}_{7}$ as electrolyte additive. The morphology and structure of the film is greatly influenced by applied voltage, deposition time, salts and surfactant. The film exhibits improved electrochemical properties. After 60 cycles, the capacity can be up to 
$500 \mathrm{mAh} / \mathrm{g}$. The Coulombic efficiency almost keeps $100 \%$ except the 1st cycle. With the help of TX-100, the cycle performance is improved further. The capacity can be up to $510 \mathrm{mAh} / \mathrm{g}$ at 400 $\mathrm{mA} / \mathrm{g}$ after 300 cycles.

4) Preparation of Si/CNFs film with necklace structure and the study of electrochemical properties

A composite film consisting of $\mathrm{Si}-\mathrm{NH}_{2}$ and CNFs-COOH with necklace structure can be prepared by homogenous EPD in ethanol at $\mathrm{pH} 0.5$. All the Si particles are distributed along with CNFs surface. The film thickness is about $15 \mu \mathrm{m}$. The formation of this structure is attributed to the interaction between $-\mathrm{NH}_{2}$ and $-\mathrm{COOH}$ groups. The film exhibits high capacity of 1020 $\mathrm{mAh} / \mathrm{g}$ at $400 \mathrm{~mA} / \mathrm{g}$ after 100 cycles. The rate performance is also good. The capacity can be up to $550 \mathrm{mAh} / \mathrm{g}$ at $3200 \mathrm{~mA} / \mathrm{g}$. With the help of magnetic stirring, less SiNPs are deposited but the distribution of Si along CNFs becomes more uniform, leading to a deceased capacity but longer cycle life. After 200 cycles, the capacity of the composite film is about $663 \mathrm{mAh} / \mathrm{g}$. 


\section{Chapter 7}

\section{CONCLUSIONS}

In this dissertation, different (meta)stable suspensions of Si/CNFs were prepared in ethanol by choosing proper $\mathrm{pH}$ value range and initial concentrations. A stable suspension is the most important precondition for homogeneous EPD of Si/CNFs system. Then, the uniform and integrated Si/CNFs composite films were prepared by using EPD only. The influence of applied voltage, deposition time, additives and other parameters on the film microstructure and the corresponding electrochemical properties are studied. There are at least three kinds of composite films that exhibit improved electrochemical properties. The results are listed as follow.

1) Sing-component EPD for $\mathrm{Si}$ and CNFs are studied, respectively. It's noticed that surface modification is necessary to improve the stability of single-component suspension in ethanol. After introducing - $\mathrm{COOH}$ onto CNFs surface, CNFs suspension can keep stable at $\mathrm{pH} 9$ - 11 and $\mathrm{pH} 0.5$ with the concentration of $0.5-2 \mathrm{mg} / \mathrm{mL}$. Without surface modification, there is no stable suspension for SiNPs in ethanol. After introducing - $\mathrm{OH}$ groups on $\mathrm{Si}$ surface, $\mathrm{Si}$ suspension with the concentration of $0.2-0.8 \mathrm{mg} / \mathrm{mL}$ becomes more stable at $\mathrm{pH} 10$. It's still hard to prepare stable $\mathrm{Si}-\mathrm{NH}_{2}$ suspension, but metastable suspension can be obtained at $\mathrm{pH} 0.5$.

2) A stable CNFs suspension is the fundamental for preparing (meta)stable Si/CNFs suspensions in ethanol no matter what kind of $\mathrm{Si}$ is used. Because the initial concentration of $\mathrm{Si}$ is relatively low and the particle size is small, SiNPs have little influence on CNFs stability. For $\mathrm{Si} / \mathrm{CNF}$ s-COOH, Si-OH/CNFs-COOH and $\mathrm{SiNH} 2 / \mathrm{CNFs}-\mathrm{COOH}$ suspensions, the best $\mathrm{pH}$ values for short-time EPD are 10,10 and 0.5, respectively. The deposited mass of the composite film increases with the applied voltage from $30 \mathrm{~V} / \mathrm{cm}$ to $60 \mathrm{~V} / \mathrm{cm}$. If the voltage is over $60 \mathrm{~V} / \mathrm{cm}$, the uniformity and integrity of the deposition film is damaged. The deposited mass also increases with the deposition time, but the increasing trend slows down. Therefore, the optimal deposition time for film growth is about $10 \sim 15 \mathrm{~min}$.

3) Using different SiNPs in the composite suspension, three kinds of films with different microstructure were prepared by EPD.

Firstly, under the simplest conditions (no Si surface treatment or any other additives), a $\mathrm{Si} / \mathrm{CNFs}-\mathrm{COOH}$ composite film is prepared in ethanol at $\mathrm{pH} 10$. The microstructure of the film 
looks like a simply-mixing type discussed in Chapter 2.3.2. CNFs fabricate a continuous conductive net on $\mathrm{Cu}$ foil, and SiNPs are randomly distributed among the net spaces. There is no strong interaction between SiNPs and CNFs. The deposited mass is about $0.83 \mathrm{mg} / \mathrm{cm}^{2}$. The film exhibits good cycle performance with the capacity of $610 \mathrm{mAh} / \mathrm{g}$ after 100 cycles but relatively low Coulombic efficiency (90\%).

To increase Coulombic efficiency, Si distribution in the composite film must be improved to make SEI layer stable during cycles; therefore, the second sample with honeycomb structure was prepared in ethanol at pH10 with the help of Si surface modification and additives. The composite film consists of Si-OH and CNFs-COOH with the deposited mass of $0.9 \mathrm{mg} / \mathrm{cm}^{2}$. The repulsive force between SiNPs due to $-\mathrm{OH}$ groups at the surface makes SiNPs dispersion better. The introduction of $\mathrm{Li}_{2} \mathrm{~B}_{4} \mathrm{O}_{7}$ makes EDL of CNFs thinner, leading to tight intertwist between CNFs. As a result, the film has the capacity of $500 \mathrm{mAh} / \mathrm{g}$ after 60 cycles with the Coulombic efficiency of nearly $100 \%$ except the 1st cycle. If adding TX-100 as the particle dispersant, no serious aggregation of SiNPs can be observed, and the corresponding film has the capacity of $510 \mathrm{mAh} / \mathrm{g}$ at $400 \mathrm{~mA} / \mathrm{g}$ after 300 cycles.

Although the film with honeycomb structure exhibits high Coulombic efficiency and long cycle life, the capacity is relatively low. It's necessary to make more SiNPs staying Li-active during cycles. An effective way is strengthening the interaction between CNFs and SiNPs on basis of well-distribution of SiNPs along CNFs. With the help of the electrostatic atrraction between $-\mathrm{NH}_{2}$ groups on the $\mathrm{Si}$ surface and $-\mathrm{COOH}$ groups on the CNFs surface, a composite film with necklace structure is prepared by EPD in ethanol at $\mathrm{pH} 0.5$. The acidic suspension is not stable enough; therefore, $2 \mathrm{~h}$ standing time for the suspension is needed before EPD. In this film, SiNPs are regularly distributed along CNFs, which looks like "pearls" on a necklace. The deposited mass is about $0.5 \mathrm{mg} / \mathrm{cm}^{2}$. The film has the capacity of $1020 \mathrm{mAh} / \mathrm{g}$ at $400 \mathrm{~mA} / \mathrm{g}$ after 100 cycles. By introducing magnetic stirring during EPD, the composite film has less deposited SiNPs with better uniform distribution, which exhibits better cycle life with the capacity of 663 $\mathrm{mAh} / \mathrm{g}$ after 200 cycles.

In the future, the experiment can be improved in at least two ways.

1) Strengthening the interaction between SiNPs and CNFs in the alkaline suspension. A film prepared in the alkaline suspension (at pH10) often has higher deposited mass than that in the acidic suspension, but most SiNPs are locating in the interspaces among CNFs rather 
than being along with CNFs surface. Therefore, the interaction between Si and CNFs is weak, leading to short cycle life if Si content is high. There are two possible ways to solve this problem. One is introducing proper ionic surfactant into the suspension, which can tightly wrap SiNPs and CNFs at the same time or serve as an active bridge connecting SiNPs with CNFs via specific functional groups. Another one is introducing pyrolytic carbon coating process after EPD. With the help of the pyrolysis of sucrose, chitosan or conductive polymer under protective environment $\left(\mathrm{Ar}, \mathrm{H}_{2}\right.$, et al), the composite film can be covered with a thin and dense carbon layer, which help maintain the stability of the entire structure.

2) Improving the deposited mass after acidic EPD. The film prepared in the acidic suspension (at pH0.5) has both high capacity and long cycle life, but the deposited mass is relatively low, which cannot be used in the industry. There are still two methods to solve the problem. One is improving the stability of SiNPs in ethanol by introducing other functional groups that can react with $-\mathrm{COOH}$ groups. Higher stability means higher concentration in the homogenous zone and more deposition particles during short-time EPD process. Another one is using porous $\mathrm{Cu}$ foil to increase the contact area between active particles with the substrate. 


\section{REFERENCES}

[1] Acar C., Dincer I. Comparative assessment of hydrogen production methods from renewable and non-renewable sources [J]. International Journal of Hydrogen Energy. 2014, 39: 1 - 12.

[2] Waag W., Fleischer C., Sauer D.U. Critical review of the methods for monitoring of lithiumion batteries in electric and hybrid vehicles [J]. Journal of Power Sources. 2014, 258: 321 339.

[3] Guyomard D., Tarascon J.M. Rocking-chair or lithium-ion rechargeable lithium batteries [J]. Advanced Materials. 1994, 6: 408 - 413.

[4] Fisher R.D., Chilton W.H. Preparation and Magnetic Characteristics of Chemically Deposited Cobalt for High-Density Storage [J]. Journal of the Electronchemical Society, 1962, 109: $485-490$.

[5] Py M.A., Haering R.R. Structural Destabilization Induced by Lithium Intercalation in $\mathrm{MoS}_{2}$ and Related-compounds [J]. Canadian Journal of Physics. 1983, 61: 76 - 84.

[6] Manev V., Ilchev N., Nassalevska A. The Lithium-manganese Dioxide cell I. Oxygen and Water Release During the Thermal Treatment of $\mathrm{MnO}_{2}$ [J]. Journal of Powder Sources. 1989, 25: $167-175$.

[7] Dampier F.W. The Cathodic Behavior of $\mathrm{CuS}, \mathrm{MoO} 3$, and $\mathrm{MnO} 2$ in Lithium Cells [J]. Journal of the Electrochemical Society. 1974, 121: 656 - 660.

[8] Hu Y.X., Zhang T.R., Cheng F.Y., Zhao Q., Han X.P., Chen J. Recycling Application of Li$\mathrm{MnO}_{2}$ Batteries as Rechargeable Lithium - air Batteries [J]. Angewandte Chemie. 2015, 54: $4338-4343$.

[9] Scrosati B. Lithium Rocking Chair Batteries: An old Concept [J]. Journal of the Electrochemical Society. 1992, 139: 2776 - 2781.

[10] Goodenough J.B., Park K.S. The Li-ion Rechargeable Battery: A Perspective [J]. Journal of the American Chemical Society. 2013, 135: 1167 - 1176.

[11] Goriparti S., Miele E., De Angelis F., Di Fabrizio E., Zaccaria R.P., Capiglia C. Review on recent progress of nanostructured anode materials for Li-ion batteries [J]. Journal of Power Sources. 2013, 257: $421-443$. 
[12] Xu W., Wang J.L., Ding F., Chen X.L., Nasybutin E., Zhang Y.H., Zhang J.G. Lithium Metal Anodes for Rechargeable Batteries [J]. 2014, 7: 513 - 537.

[13] Lee H., Yanilmaz M., Toprakci O., Fu K., Zhang X.W. A review of recent developments in membrane separators for rechargeable lithium-ion batteries [J]. Energy\&Environmental Science. 2014, 7: 3857 - 3886.

[14] Xu K. Electrolytes and Interphases in Li-Ion Batteries and Beyond [J]. Chemical Reviews. 2014, 114: 11503 - 11618.

[15] Kasavajjula U., Wang C.S. Appleby A.J. Nano- and bulk-silicon-based insertion anodes for lithium-ion secondary cells [J]. Journal of Power Sources. 2007, 163: 1003 - 1039.

[16] Palacin M.R. Recent advances in rechargeable battery materials: a chemist's perspective [J]. Chemical Society Reviews. 2009, 38: 2565 - 2575.

[17] Wu H., Cui Y. Designing nanostructured Si anodes for high energy lithium ion batteries [J]. Nano Today. 2012, 7: $414-429$.

[18] Obrovac M.N., Christensen L. Structrual Changes in Silicon Anodes during Lithium Insertion/Extraction [J]. Electrochemical and Solid-State Letters. 2004, 7(5): A93 - A96.

[19] Wen C.J., Huggins R.A. Chemical diffusion in intermediate phases in the lithium-silicon system [J]. Journal of Solid State Chemistry. 1981, 37: 271 - 278.

[20] Long B.R., Chan M.K.Y, Greeley J.P., Gewirth A.A. Dopant Modulated Li Insertion in Si for Battery Anodes: Theory and Experiment [J]. The Journal of Physical Chemistry C. 2011, 115: $18916-18921$.

[21] Li J., Dahn J.R. An In Situ X-Ray Diffraction Study of the Reaction of Li with Crystalline Si [J]. Journal of the Electrochemical Society. 2007, 154: A156 - A161.

[22] Key B., Morcrette M., Tarascon J.M, Grey C.P. Pair Distribution Function Analysis and Solid State NMR Studies of Silicon Electrodes for Lithium Ion Batteries: Understanding the (De)lithiation Mechanisms [J]. Journal of the American Chemical Society. 2011, 133: 503 512.

[23] Radvanyi E., De Vito E., Porcher W., Danet J., Desbois P., Colin J.F., Si Larbi S.J. Study of lithiation mechanisms in silicon electrodes by Auger Electron Spectroscopy [J]. Journal of Materials Chemistry A. 2013, 1: 4956 - 4965.

[24] Liu X.H., Wang J.W., Huang S. Fan F.F., Huang X., Liu Y., Krylyuk S., Yoo J.Y., Dayeh S. A., Davydov A.V., Mao S.X., Picraux S.T., Zhang S.L., Li J., Zhu T., Huang J.Y. In situ 
atomic-scale imaging of electrochemical lithiation in silicon [J]. Nature Nanotechnology. 2012, 7: 749-756.

[25] Lee S.W., McDowell M.T., Choi J.W., Cui Y. Anomalous shape changes of silicon nanopillars by electrochemical lithiation [J]. Nano Lett., 2011, 11: 3034 - 3039.

[26] Beaulieu L.Y., Hatcharda T. D., Bonakdarpoura A., Fleischauera M.D., Dahna J. R. Reaction of Li with Alloy Thin Films Studied by In Situ AFM [J]. Journal of the Electrochemical Society. 2003, 150: A1457 - A1464.

[27] Si Q., Hanai K., Imanishi N., Kubo M., Hirano A., Takeda Y., Yamamoto O. Highly reversible carbon-nano-silicon composite anodes for lithium rechargeable batteries [J]. Journal of Power Sources, 2009, 189: 761 - 765.

[28] Kim J.S., Byun D.J., Lee J.K. Electrochemical characteristics of amorphous silicon thin film electrode with fluoroethylene carbonate additive [J]. Current Applied Physics, 2014, 14: 596 -602 .

[29] Farmakis F., Elmasides C., Fanz P., Hagen M., Georgoulas N. High energy density amorphous silicon anodes for lithium ion batteries deposited by DC sputtering [J]. Journal of Power Sources. 2015, 293: $301-305$.

[30] Liang J.W., Li X.N., Zhu Y.C., Guo C., Qian Y.T. Hydrothermal synthesis of nano-silicon from a silica sol and its use in lithium ion batteries [J]. Nano Research. 2015, 8: 1497 - 1504.

[31] Cho J.H., Picraux S.T. Enhanced Lithium Ion Battery Cycling of Silicon Nanowire Anodes by Template Growth to Eliminate Silicon Underlayer Islands [J]. Nano Letters. 2013, 13: $5740-5747$.

[32] Wen Z.H., Lu G.H., Mao S., Kim H., Cui S.M., Yu K.H., Huang X.K., Hurley P.T., Mao O., Chen J.H. Silicon nanotube anode for lithium-ion batteries [J]. Electrochemistry Communications. 2013, 29: $67-70$.

[33] Ge M.Y., Rong J.P., Fang X., Zhang A.Y., Lu Y.H., Zhou C.W. Scalable preparation of porous silicon nanoparticles and their application for lithium-ion battery anodes [J]. Nano Research. 2013, 6: $174-181$.

[34] Demirkan M.T., Trahey L., Karabacak T. Low-density silicon thin films for lithium-ion battery anodes [J]. Thin Solid Films. 2016, 600: 126 - 130. 
[35] Yoshio M., Wang H.Y., Fukud F., Umeno T., Dimov N., Ogumib Z. Carbon-Coated Si as a Lithium-Ion Battery Anode Material [J]. Journal of the Electrochemical Society. 2002, 149: A1598 - A1603.

[36] Lee H.Y., Lee S.M. Carbon-coated nano-Si dispersed oxides/graphite composites as anode material for lithium ion batteries [J]. Electrochemistry Communications. 2004, 6: 465 - 469.

[37] Dimov N., Kugino S., Yoshio M. Mixed silicon-graphite composites as anode material for lithium ion batteries: Influence of preparation conditions on the properties of the material [J]. Journal of Power Sources, 2004, 136: 108 - 114.

[38] Zuo P.J., Wang Z.B., Yin G.P., Jia D.C., Cheng X.Q., Du C.Y., Shi P.F. Electrochemical investigation of silicon/carbon composite as anode material for lithium ion batteries [J]. Journal of Materials Science. 2008, 43: 3149 - 3152.

[39] Zuo P.J., Yin G.P., Hao X.F., Yang Z.L., Ma Y.L., Gao Z.G. Synthesis and electrochemical performance of $\mathrm{Si} / \mathrm{Cu}$ and $\mathrm{Si} / \mathrm{Cu} /$ graphite composite anode [J]. Materials Chemistry and Physics. 2007, 104: 444 - 447.

[40] Zhang Y., Zhang X.G., Zhang H.L., Zhao Z.G., Li F., Liu C., Cheng H.M. Composite anode material of silicon/graphite/carbon nanotubes for Li-ion batteries [J]. Electrochimica Acta. 2006, 51: $4994-5000$.

[41] Wang G.X., Yao J., Liu H.K. Characterization of Nanocrystalline Si-MCMB Composite Anode Materials [J]. Electrochemical and Solid-State Letters. 2004, 7, 8: A250 - A253.

[42] Datta M.K., Kumta P.N. Silicon, graphite and resin based hard carbon nanocomposite anodes for lithium ion batteries [J]. Journal of Power Sources, 2007, 165: 368 - 378.

[43] Ning L.J., Wu Y.P., Wang L.Z., Fang S.B., Holze R. Carbon anode materials from polysiloxanes for lithium ion batteries [J]. Journal of Solid State Electrochemistry. 2005, 9: $520-523$.

[44] Xue J.S., Myrtle K., Dahn J.R. An Epoxy-Silane Approach to Prepare Anode Materials for Rechargeable Lithium Ion Batteries [J]. Journal of the Electrochemical Society. 1995, 142: $2927-2936$.

[45] Wilson A.M., Zank G., Eguchi K., Xing W., Dahn J.R. Pyrolysed silicon-containing polymers as high capacity anodes for lithium-ion batteries [J]. Journal of Power Sources. 1997, 68: $195-200$. 
[46] Wilson A.M., Way B.M., Dahn J.R., Buuren T.V. Nanodispersed silicon in pregraphitic carbons [J]. Journal of Applied Physics. 1995, 77: 2363 - 2369.

[47] Guo L.P., Yoon W.Y., Kim B.K. Fabrication and characterization of a silicon-carbon nanocomposite material by pyrolysis for lithium secondary batteries $[\mathrm{J}]$. Electronic Materials Letters. 2012, 8: $405-409$.

[48] Ng S.H., Wang J.Z., Wexler D., Chew S.Y., Liu H.K. Amorphous Carbon-Coated Silicon Nanocomposites: A Low-Temperature Synthesis via Spray Pyrolysis and Their Application as High-Capacity Anodes for Lithium-Ion Batteries [J]. The Journal of Physical Chemistry C. 2007, 111: $11131-11138$.

[49] Yu J.L, Yang J., Feng X.J., Jia H., Wang J.L., Lu W. Uniform Carbon Coating on Silicon Nanoparticles by Dynamic CVD Process for Electrochemical Lithium Storage [J]. Industrial \& Engineering Chemistry Research. 2014, 53: 12697 - 12704.

[50] Guo Z. P., Milin E., Wang J.Z., Chen J., Liu H.K. Silicon/Disordered Carbon Nanocomposites for Lithium-Ion Battery Anodes [J]. Journal of the Electrochemical Society, 2005, 152: A2211 - A2216.

[51] Wang Z.Y., Fan Li F, Ergang N.S., Stein A. Synthesis of monolithic 3D ordered macroporous carbon/nano-silicon composites by diiodosilane decomposition [J]. Carbon, 2008, 46: $1702-1710$.

[52] Chen Y.J., Nie M.Y., Lucht B.L., Saha A., Guduru P.R., Bose A. High Capacity, Stable Silicon/Carbon Anodes for Lithium-Ion Batteries Prepared Using Emulsion-Templated Directed Assembly [J]. Applied Materials \& Interfaces. 2014, 6: 4678 - 4683.

[53] Du Y.J., Hou M.Y., Zhou D.D., Wang Y.G., Wang C.X., Xia Y.Y. Interconnected sandwich structure carbon/ $/ \mathrm{Si}_{-} \mathrm{SiO}_{2} /$ carbon nanospheres composite as high performance anode material for lithium-ion batteries [J]. Journal of Energy Chemistry, 2014, 23: 315 - 323.

[54] Yi R., Dai F., Gordin M.L., Chen S.R., Wang D.H. Micro-sized Si-C Composite with Interconnected Nanoscale Building Blocks as High-Performance Anodes for Practical Application in Lithium-Ion Batteries [J]. Advanced Energy Materials. 2013, 3: 295 - 300.

[55] Lu Z.D., Liu N., Lee H.W., Zhao J., Li W.Y., Li Y.Z., Cui Y. Nonfilling Carbon Coating of Porous Silicon Micrometer-Sized Particles for High-Performance Lithium Battery Anodes [J]. ACS Nano. 2015, 9: 2540 - 2547. 
[56] Martin C., Alias M., Christien F., Crosnier O., Be'langer D., Brousse T. Graphite-Grafted Silicon Nanocomposite as a Negative Electrode for Lithium-Ion Batteries [J]. Advanced Materials. 2009, 21: 4735 - 4741.

[57] Liu B., Soares P., Checkles C., Zhao Y., Yu G.H. Three-Dimensional Hierarchical Ternary Nanostructures for High-Performance Li-Ion Battery Anodes [J]. Nano Letters. 2013, 13: $3414-3419$.

[58] Luo J.Y., Zhao X., Wu J.S., Jang D.H., Kung H.H., Huang J.X. Crumpled GrapheneEncapsulated Si Nanoparticles for Lithium Ion Battery Anodes [J]. The journal of Physical Chemistry Letters. 2012, 3: $1824-1829$.

[59] Zhao G.Y., Zhang L., Meng Y.F., Zhang N.Q., Sun K.N. Decoration of graphene with silicon nanoparticles by covalent immobilization for use as anodes in high stability lithium ion batteries [J]. Journal of Power Sources. 2013, 240: 212 - 218.

[60] Chen S.R., Gordin M.L., Yi R., Howlett G., Sohn H., Wang D.H. Silicon core-hollow carbon shell nanocomposites with tunable buffer voids for high capacity anodes of lithiumion batteries [J]. Physical Chemistry Chemical Physics. 2012, 14: 12741 - 12745.

[61] Li M., Hou X.H., Sha Y.J., Wang J., Hu S.J., Liu X., Shao Z.P. Facile spraydrying/pyrolysis synthesis of core-shell structure graphite/silicon-porous carbon composite as a superior anode for Li-ion batteries [J]. Journal of Power Sources, 2014, 248: 721 - 728.

[62] Li S., Qin X.Y., Zhang H.R., Wu J.X., He Y.B., Li B.H., Kang F.Y. Silicon/carbon composite microspheres with hierarchical core-shell structure as anode for lithium ion batteries [J]. Electrochemistry Communications, 2014, 49: 98 - 102.

[63] Liu N., Wu H., McDowell M.T., Yao Y., Wang C.M., Cui Y. A Yolk-Shell Design for Stabilized and Scalable Li-Ion Battery Alloy Anodes [J]. Nano Lett., 2012, 12: 3315 - 3321.

[64] Wang W., Kumta P.N. Nanostructured Hybrid Silicon/Carbon Nanotube Heterostructures: Reversible High-Capacity Lithium-Ion Anodes [J]. Acs Nano, 2010, 4: 2233 - 2241.

[65] Martin C., Crosnier O., Retoux R., Bélanger D., Schleich D.M., Brousse T. Chemical Coupling of Carbon Nanotubes and Silicon Nanoparticles for Improved Negative Electrode Performance in Lithium-Ion Batteries [J]. Advanced Functional Materials, 2011, 21: 3524 3530. 
[66] Fan Y., Zhang Q., Xiao Q.Z., Wang X.H., Huang K. High performance lithium ion battery anodes based on carbon nanotube-silicon core-shell nanowires with controlled morphology [J]. Carbon, 2013, 59: $264-269$.

[67] Thakur M., Pernites R.B., Nitta N., Isaacson M., Sinsabaugh S.L., Wong M.S., Biswal S.L. Freestanding Macroporous Silicon and Pyrolyzed Polyacrylonitrile As a Composite Anode for Lithium Ion Batteries [J]. Chemistry of Materials, 2012, 24, 2998 - 3003.

[68] Lu Z.Z., Wong T.L., Ng T.W., Wang C.D. Facile synthesis of carbon decorated silicon nanotube arrays as anode material for high-performance lithium-ion batteries $[\mathrm{J}]$. RSC Advances, 2014, 4: 2440 - 2446.

[69] Geyer N., Huang Z.P., Fuhrmann B., Grimm S., Reiche M., Nguyen-Duc T.K., De Boor J., Leipner H.S., Werner P., Gösele U. Sub-20 nm Si/Ge Superlattice Nanowires by MetalAssisted Etching [J]. Nano Lett. 2009, 9, 3106 - 3110.

[70] Higgins T.M., Park S.H., Paul J.K., Zhang C.F., McEvoy N., Berner N.C., Daly D., Shmeliov A., Khan U., Duesberg G., Nicolosi V., Coleman J.N. A Commercial Conducting Polymer as Both Binder and Conductive Additive for Silicon Nanoparticle-Based LithiumIon Battery Negative Electrodes [J]. ACS Nano, 2016, 10: 3702 - 3713.

[71] Yoo J.K., Kim J., Lee H.J., Choi J., Choi M.J., Sim D.M., Jung Y.S., Kang K. Porous silicon nanowires for lithium rechargeable batteries [J]. Nanotechnology, 2013, 2, 424008 424015 .

[72] Jeong G.J., Kim J.G., Park M.S., Seo M., Hwang S.M., Kim Y.U., Kim Y.J., Kim J.H., Dou S.X. Core-Shell Structured Silicon Nanoparticles@TiO2-x/Carbon Mesoporous Microfiber Composite as a Safe and High-Performance Lithium-Ion Battery Anode [J]. ACS nano, 2014, $8,2977-2985$.

[73] Kim S.O., Shim H.T., Lee J.K. Electrochemical performance of silicon thin film anodes covered by diamond-like carbon with various surface coating morphologies [J]. Journal of Solid State Electrochemistry, 2010, 14: 1247 - 1253.

[74] Wang J., Tong Y.F., Xu Z., Li W.H., Yan P.X., Chung Y.W. Amorphous silicon/carbon multilayer thin films as the anode for high rate rechargeable Li-ion batteries $[\mathrm{J}]$. Materials Letters, 2013, 97: 37-39. 
[75] Arie A.A., Lee J.K. Effect of boron doped fullerene C60 film coating on the electrochemical characteristics of silicon thin film anodes for lithium secondary batteries [J]. Synthetic Metals, 2011, 161: $158-165$.

[76] Li B., Yao F., Bae J.J., Chang J., Zamfir M.R., Le D.T., Pham D.T., Yue H.Y., Lee Y.H. Hollow carbon nanospheres/silicon/alumina core-shell film as an anode for lithium-ion batteries [J]. Scientific Reports, 2015, 5: 7659 - 7668.

[77] Wu J.X., Qin X.Y., Zhang H.R., He Y.B., Li B.H., Ke L., Lv W., Du H.D., Yang Q.H., Kang F.Y. Influence of copper addition for silicon-carbon composite as anode materials for lithium ion batteries [J]. Carbon, 2015, 84: 434 - 443.

[78] Zhang H.G., Braun P.V. Three-Dimensional Metal Scaffold Supported Bicontinuous Silicon Battery Anodes [J]. Nano Letter, 2012, 12: 2778 - 2783.

[79] Choi N.S., Yao Y., Cui Y., Cho J. One dimensional Si/Sn - based nanowires and nanotubes for lithium-ion energy storage materials [J]. Journal of Materials Chemistry, 2011, 21: 9825 -9840 .

[80] Choi J.W., Aurbach D. Promise and reality of post-lithium-ion batteries with high energy densities [J]. Nature Reviews Materials, 2016, 1: $1-16$.

[81] Fukui H., Ohsuka H., Hino T., Kanamura K. A Si-O-C Composite Anode: High Capability and Proposed Mechanism of Lithium Storage Associated with Microstructural Characteristics [J]. ACS Applied Materials \& Interfaces, 2010, 2: 998 - 1008.

[82] Chen T., Wu J., Zhang Q.L., Su X. Recent advancement of $\mathrm{SiO}_{x}$, based anodes for lithiumion batteries [J]. Journal of Power Sources, 2017, 363: 126 - 144.

[83] Yoo H., Lee J.I., Kim H., Lee J.P., Cho J., Park S. Helical Silicon/Silicon Oxide Core-Shell Anodes Grown onto the Surface of Bulk Silicon [J]. Nano Letters, 2011, 11: $4324-4328$.

[84] Hu Y.S., Demir-cakan R., Titirici M.M., Muller J.O., Schlogl R., Antonietti M., Maier J. Superior storage performance of a $\mathrm{Si} @ \mathrm{SiO}_{\mathrm{x}} / \mathrm{C}$ nanocomposite as anode material for lithiumion batteries [J]. Angewandte Chemie - International Edition, 2008, 47: 1645 - 1649.

[85] Van der Biest O.O., Vandeperre L.J. Electrophoretic deposition of materials [J]. Annual Review of Materials Science, 1999, 29: 327 - 354.

[86] Sarkar P., Nicholson P.S. Electrophoretic deposition (EPD): mechanisms, kinetics, and application to ceramics [J]. Journal of the American Ceramic Society, 1996, 79, 8: 1987 2002. 
[87] Boccaccini A.R., Zhitomirsky I. Application of electrophoretic and electrolytic deposition techniques in ceramics processing [J]. Current Opinion in Solid State \& Materials Science, 2002, 6, 3: $251-260$.

[88] Deryaguin B.V., Landau L.D. A theory of the stability of strongly charged lyophobic sols and of the adhesion of strongly charged particles in the solution of electrolytes. Acta Physicochim USSR 1941, 14: 633.

[89] Verwey E.J.W., Overbeek J.Th.G. Theory of the stability of lyophobic colloids. Amsterdam: Elsevier, 1948.

[90] Hiemenz P.C. Principles of colloid and surface chemistry. 2nd ed. New York: Marcel Dekker; 1986.

[91] Besra L., Liu M. A review on fundamentals and applications of electrophoretic deposition (EPD) [J]. Progress in Materials Science, 2007, 52:1- 61.

[92] Hamaker H.C., Verwey E.J.W. The role of the forces between the particles in electrodeposition and other phenomena [J]. Transactions of the Faraday Society, 1940, 36: $180-185$.

[93] Binner J.G.P, $1^{\text {st }}$ editor. Advanced ceramic processing and technology (Materials Science and Process Technology), 1990, vol. 1. 1990. p. $255-83$.

[94] Sarkar P., Datta S., Nicholson P.S. Functionally graded ceramic/ceramic and metal/ceramic composites by electrophoretic deposition [J]. Composites Part B 28B, 1997: 49 - 56.

[95] Koelmans H. Suspensions in non-aqueous media [J]. Phillips Res Rep, 1995, 10: 161 - 193.

[96] Sarkar P., Nicholson P.S. Electrophoretic deposition (EPD): mechanisms, kinetics and application to ceramics [J]. Journal of the American Ceramic Society, 1996, 79: 1987 - 2002.

[97] Cho J., Schaab S., Roether J.A., Boccacini A.R. Nanostructured carbon nanotube/ $\mathrm{TiO}_{2}$ composite coatings using electrophoretic deposition (EPD) [J]. Journal of Nanoparticle Research, 2008, 10: 99 - 105.

[98] Zhu G.Z., Yang W., Lv W.Q., He J.R., Wen K.C., Huo W.R., Hu J., Waqas M., Dickerson J.H., He W.D. Facile electrophoretic deposition of functionalized $\mathrm{Bi}_{2} \mathrm{O}_{3}$ nanoparticles [J]. Materials \& Design, 2017, 116: 359 - 364.

[99] Das D., Bagchi B., Basu R.N. Nanostructured zirconia thin film fabricated by electrophoretic deposition technique [J]. Journal of Alloys and Compounds, 2017, 693: 1220 -1230 . 
[100] Peng Z., Liu M. Preparation of dense platinum-yttria stabilized zirconia and yttria stabilized zirconia films on porous $\mathrm{La}_{0.9} \mathrm{Sr}_{0.1} \mathrm{MnO}_{3}$ (LSM) substrates. Journal of the American Society, 2001, 84: 283 - 288.

[101] Ammam M. Electrophoretic deposition under modulated electric fields: a review [J]. RSC Advances, 2012, 2: 7633 - 7646.

[102] Ferrari B., Moreno R. EPD kinetics: A review [J]. Journal of the European Ceramic Society, 2009, 30: 1069 - 1078.

[103] He C.B., Hu Y.P., Yin L.C., Tang C., Yin C.H. Effects of particle size and surface charge on cellular uptake and biodistribution of polymeric nanoparticles [J]. Biomaterials, 2010, 31, $3657-3666$.

[104] Alves J.A., Baldo J.B. The Behavior of Zeta Potential of Silica Suspensions [J]. New Journal of Glass and Ceramics, 2014, 4: 29 - 37.

[105] Zhang Z.T., Huang Y., Jiang Z.Z. Electrophoretic Deposition Forming of SiC-TZP

Composites in a Nonaqueous Sol Media [J]. Journal of the American Ceramic Society, 1994, $77,1946-1949$.

[106] Zhang D.X., Li X.M. Fabrication and Kinetics Study of Nano-Al/NiO Thermite Film by Electrophoretic Deposition [J]. The Journal of Physical Chemistry A, 2015, 119: 4688 4694.

[107] Taib H., Aziz S.A.B.A. Effect of Voltage and Suspension Medium on Stanum Oxide $\left(\mathrm{SnO}_{2}\right)$ Film Prepared By Electrophoretic Deposition (EPD) [J]. Advanced Materials Research, 2013, 626: 480 - 484.

[108] Tabellion J., Clasen R. Electrophoretic deposition from aqueous suspensions for nearshape manufacturing of advanced ceramics and glasses - applications [J]. Journal of Materials Science, 2004, 39: 803 - 811.

[109] Kurnosov D.A., Baturin A.S., Bugaev A.S., Nikolski K.N., Tchesov R.G., Sheshin E.P. Influence of the interelectrode distance in electrophoretic cold cathode fabrication on the emission uniformity [J]. Applied Surface Science, 2003, 215: 232 - 236.

[110] Boccaccini A.R., Cho J., Roether J.A., Thomas B.J.C., Minay E.J., Shaffer M.S.P. Electrophoretic deposition of carbon nanotubes [J]. Carbon, 2006, 44: 3149 - 3160. [111] Boccaccini A.R., Keim S., Ma R., Li Y., Zhitomirsky I. Electrophoretic deposition of biomaterials [J]. Journal of the Royal Society Interface, 2010, 7: S581 - S613. 
[112] Xiong C.Y., Li T.H., Zhu Y.C., Zhao T.K., Dang A., Li H., Ji X.L., Shang Y.D., Khan M. Two-step approach of fabrication of interconnected nanoporous 3D reduced graphene oxidecarbon nanotube-polyaniline hybrid as a binder-free supercapacitor electrode [J]. Journal of Alloys and Compounds, 2017, 695: 1248 - 1259.

[113] Castro Y., Ferrari B., Moreno R., Duran A. Coatings produced by electrophoretic deposition from nano-particulate silica sol-gel suspensions [J]. Surface \& Coatings Technology, 2004, 182: 199 - 203.

[114] Ogihara H., Katayama T., Saji T. One-step electrophoretic deposition for the preparation of superhydrophobic silica particle/trimethylsiloxysilicate composite coatings [J]. Journal of Colloid and Interface Science, 2011, 362: 560 - 566.

[115] Al-Saleh M.H., Sundararaj U. A review of vapor grown carbon nanofiber/polymer conductive composites [J]. Carbon, 2009, 47: 2-22.

[116] Zhang B., Kang F.Y., Tarascon J.M. Recent advances in electrospun carbon nanofibers and their application in electrochemical energy storage [J]. Progress in Materials Science, 2016, 76: $319-380$.

[117] Ye Y., Cai S.J., Yan M., Chen T.Y., Guo T.L. Concentration detection of carbon nanotubes in electrophoretic suspension with UV-vis spectrophotometry for application in field emission devices [J]. Applied Surface Science, 2013, 284: 107 - 112.

[118] Shin S., Jang J., Yoon S.H., Mochida I. A study on the effect of heat treatment on functional groups of pitch based activated carbon fiber using FTIR [J]. Carbon, 1997, 35 : $1739-1743$.

[119] Yoon C.M., Long D.H., Jang S.M., Qiao W.M., Ling L.C., Miyawaki J., Rhee C.K., Mochida I., Yoon S.H. Electrochemical surface oxidation of carbon nanofibers [J]. Carbon, 2011, 49: 96 - 105.

[120] Masliyah J.H, Bhattacharjee S. Electrokinetic and Colloid Transport Phenomena. A John Wiley \& Sons, INC., Chapter 5, p113-115.

[121] Masliyah J.H, Bhattacharjee S. Electrokinetic and Colloid Transport Phenomena. A John Wiley \& Sons, INC., Chapter 5, p131, 170.

[122] Falk G., Nold A., Wiegand B. Experimental and numerical analysis of electrophoretic deposition on charge selective surfaces in external electric fields [J]. Advances in Applied Ceramics, 2014, 113: 55 - 64 . 
[123] Giera B., Zepeda-Ruiz L.A., Pascall A.J., Kuntz J.D., Spadaccini C.M., Weisgraber T.H. Mesoscale particle-based model of electrophoresis [J]. Journal of the Electrochemical Society, 2015, 162: D3030 - D3035.

[124] Masliyah J.H, Bhattacharjee S. Electrokinetic and Colloid Transport Phenomena. A John Wiley \& Sons, INC., Chapter 5, p318.

[125] Bagwe R.P., Hilliard L.R., Tan W.H. Surface modification of silica nanoparticles to reduce aggregation and nonspecific binding [J]. Langmuir, 2006, 22: 4357 - 4362.

[126] Li G.Y., He B.H., Zhou M.J., Wang G.X., Zhou N.B., Xu W.Y., Jing M.J., Hou Z.H. In situ growth of ultrashort rice-like $\mathrm{CuO}$ nanorods supported on reduced graphene oxide nanosheets and their lithium storage performance [J]. Ionics, 2017, 23: $607-616$.

[127] Wang J.T., Wang Y., Huang B., Yang J.Y., Tan A., Lu S.G. Silicon Supported on Stable Si-O-C Skeleton in High-Performance Lithium-Ion Battery Anode Materials [J]. Acta Phys. - Chim. Sin., 2014, 30: 305 - 310.

[128] Wu P, Wang H., Tang Y.W., Zhou Y.M., Lu T.H. Three-Dimensional Interconnected Network of Graphene-Wrapped Porous Silicon Spheres: In Situ Magnesiothermic-Reduction Synthesis and Enhanced Lithium-Storage Capabilities [J]. Applied Materials \& Interfaces, $2014,6,3546-3552$.

[129] Zhuravlev L.T. Concentration of Hydroxyl-groups on the Surface of Amorphous Silicas [J]. Langmuir, 1987, 3: $316-318$.

[130] Wang G., Yan F., Teng Z.G., Yang W.S., Li T.J. The surface Modification of Silica with APTS [J]. Progress in Chemistry, 2006, 18: 239 - 245.

[131] Rostami M., Mohseni M. Investigating the effect of pH on the surface chemistry of an amino silane treated nano silica [J]. Pigment \& Resin Technology, 2011, 40: 363 - 373. 